\title{
Geotechnics, energy and climate change: the 56th Rankine Lecture
}

\author{
RICHARD J. JARDINE*
}

\begin{abstract}
Geotechnical engineering has matured sufficiently to contribute to resolving some of society's grand challenges. The 56th Rankine Lecture considered one of the most pressing global problems: maintaining vital energy supplies while also recognising, mitigating and reducing the climate consequences of fossil fuel consumption. This written version reports geotechnical research relating to these wide-ranging issues, considering paired topics within its three main parts and illustrating these with specific practical examples. Part 1 focuses on supporting offshore hydrocarbon production, considering advances in understanding and designing the driven piles that support most continental shelf platforms, before moving to the large underwater landslides that can affect deeper water developments. Part 2 describes investigations into the geotechnical impact of climate change in a permafrost region and a peatland study that contributes to alleviating flood risks exacerbated by climate change. Part 3 outlines research that is improving the economics of renewable offshore wind energy for multi-pile and monopile supported turbines. Integrating geology and rigorous analysis with advanced laboratory and field experiments is shown to be essential to resolving the complex geotechnical problems considered, as is careful full-scale checking and monitoring. Close cooperation with co-workers from industry and academia was central to the studies described and the contributions of many collaborators are emphasised. The concluding section identifies examples of significant questions from each of the six topic areas that remain to be resolved fully.
\end{abstract}

KEYWORDS: footings/foundations; landslides; piles \& piling

\section{GEOTECHNICS AND ENERGY}

Geotechnics has developed over the last century into a discipline that engages thousands of professional specialists worldwide. The first two conferences of the International Society for Soil Mechanics and Foundation Engineering, held in 1936 and 1948, mark perhaps the two most significant events in the practical assimilation of the seminal contributions of Coulomb (1776), Rankine (1857), Prandtl (1920), Terzaghi (1925), Hvorslev (1937) and other early pioneers. Tremendous advances have followed since, many of which have been recorded in the 55 Rankine Lectures delivered before this contribution, ranging from critical laboratory experiments to rigorous theoretical investigations and from computer coding triumphs through to large-scale field studies. Research motives have ranged from pure curiosity through to a wish to address urgent industrial or societal questions; these researchers' combined efforts have created extensive bodies of new knowledge.

As geotechnics matures, ever greater resources appear necessary to achieve significant advances. Research teams are often encouraged to focus their efforts on the 'grand challenges' that are most critical to human societies and quality of life, as well as sustaining or improving the quality of our natural and built environments. Among the most pressing questions to resolve over the next decades are those related to energy production. Choosing this main theme reflects the seminal contributions in thermodynamics of

Manuscript received 19 April 2018; manuscript accepted 6 June 2019. Published online ahead of print 16 July 2019.

Discussion on this paper closes on 1 June 2020, for further details see p. ii.

Published with permission by the ICE under the CC-BY 4.0 license. (http://creativecommons.org/licenses/by/4.0/)

$*$ Department of Civil and Environmental Engineering, Imperial College London, London, UK.
Rankine (1850) that led, with his later publications, to lasting international recognition. For example, the process employed in steam-operated electricity generators is known widely as the 'Rankine cycle'.

Pasten \& Santamarina (2012) present convincing evidence of the social benefits of increasing energy provision per capita, especially in the developing world. Collating data from the world's 22 most populous nations, they show that positive outcomes, including greater average life expectancy, longer schooling years and higher incomes correlate directly with the 5 to $10 \mathrm{~kW} /$ capita consumption range enjoyed by economically leading nations. Negative measures such as infant mortality rates fall greatly as energy consumption levels rise. Conservation measures and other factors are leading to energy use per capita reducing in some advanced nations (see e.g. World Bank, 2018). However, global demand is currently growing by $20 \%$ per decade as the world's less prosperous populations gradually achieve better living standards.

More than $85 \%$ of global energy production is derived currently from fossil fuels that produce large masses of carbon dioxide $\left(\mathrm{CO}_{2}\right)$ by-product according to Natural Resources Canada (NRCan, 2017). Maintaining or increasing production cannot be reconciled with the internationally acknowledged environmental need to cut greenhouse gas emissions drastically in the decades ahead. Each $\mathrm{kWh}$ of electricity generated from coal produces approximately $1 \mathrm{~kg}$ of carbon dioxide, depending on coal grade, while oil and natural gas fuel produce less, around 0.75 and $0.5 \mathrm{~kg} / \mathrm{kWh}$, respectively. Meeting the internationally agreed greenhouse gas targets calls for a rebalancing of energy production away from coal and towards gas and renewable sources. There remains intense international debate on how to achieve such changes without disrupting energy supplies, blocking economic growth or holding back developing nations.

Engineers from all disciplines are contributing to the world's 'grand challenge'. Geotechnical researchers are active in areas ranging from ground energy storage and production schemes 
through to assessing the impact of climate change on foundations, earthworks and slopes. This paper covers only areas where the author, working in conjunction with several colleagues, has made contributions. Its three main parts consider paired topics relating to the following.

1. Maintaining safe and efficient offshore oil and gas supplies.

2. Assessing and mitigating the environmental impact of climate warming.

3. Improving the efficiency and safety of renewable energy production.

The parts' relative weights reflect the balance of the author's work and the first is considerably longer than the others.

Four overarching themes apply throughout.

(a) The vital need to integrate geology, experiments, analysis and field observations when approaching new large-scale field geotechnical problems.

(b) How collaboration is essential to achieving effective advances in broad areas. There are great advantages in recognising and sharing skills with industrial and academic colleagues.

(c) That tools developed for design and analysis need to be 'as simple as possible' to encourage application, but 'no simpler than is necessary' to represent field behaviour.

(d) The value of interchanging experience and research developments between the offshore and mainstream civil geotechnical sectors.

Highly significant advances are being made internationally across the topics raised in this paper and in a far broader range of related areas. While it is not possible within the space available to offer general reviews of these developments, the Rankine Lectures by Brandl (2006), Gens (2010) and Houlsby (2016) provide valuable and relevant perspectives on related issues.

\section{PART 1 - MAINTAINING OFFSHORE OIL AND GAS SUPPLIES}

The first part of the paper concerns research conducted to help enable the safe and economic supply of offshore oil and gas, which has helped to balance the international energy market over the past 50 years. Production platform water depths increased gradually and reached around $200 \mathrm{~m}$ by 1980 . Maximising the hydrocarbon recovery from continental shelf fields now involves extending production from existing, sometimes relatively old, infrastructure as well as developing new, often smaller, fields as economically as possible. Large reserves have been discovered in far deeper waters, where traditional fixed production platforms are not viable. Implementing the development concepts summarised in Fig. 1 led to a step change between 1997 and 2005 in hydrocarbon production water depths, from the low hundreds of metres to more than $2 \cdot 1 \mathrm{~km}$. However, the pace of development slowed after severe difficulties were encountered and tragic accidents occurred. The $3400 \mathrm{~m}$ water depth Raya-1 well (offshore Uruguay) appears to be the deepest drilled to date; see OET (2016).

The paper's first topic concerns advancing the understanding and design of the driven piles which underpin most continental shelf oil and gas production platforms. The focus is on improving economy while ensuring the foundations' ability to withstand storm loading and operating conditions. The second, specifically deep-water, topic is the analysis of geohazards posed by very large landslides, which are encountered frequently on the slopes that run down from the continental shelf to the oceanic abyssal plains.

\section{TOPIC 1.1: IMPROVING THE UNDERSTANDING AND DESIGN OF DRIVEN PILES \\ Background}

Driven steel tubular piles provide the most common foundation system for fixed continental-shelf oil and gas production platforms. They are also employed in some

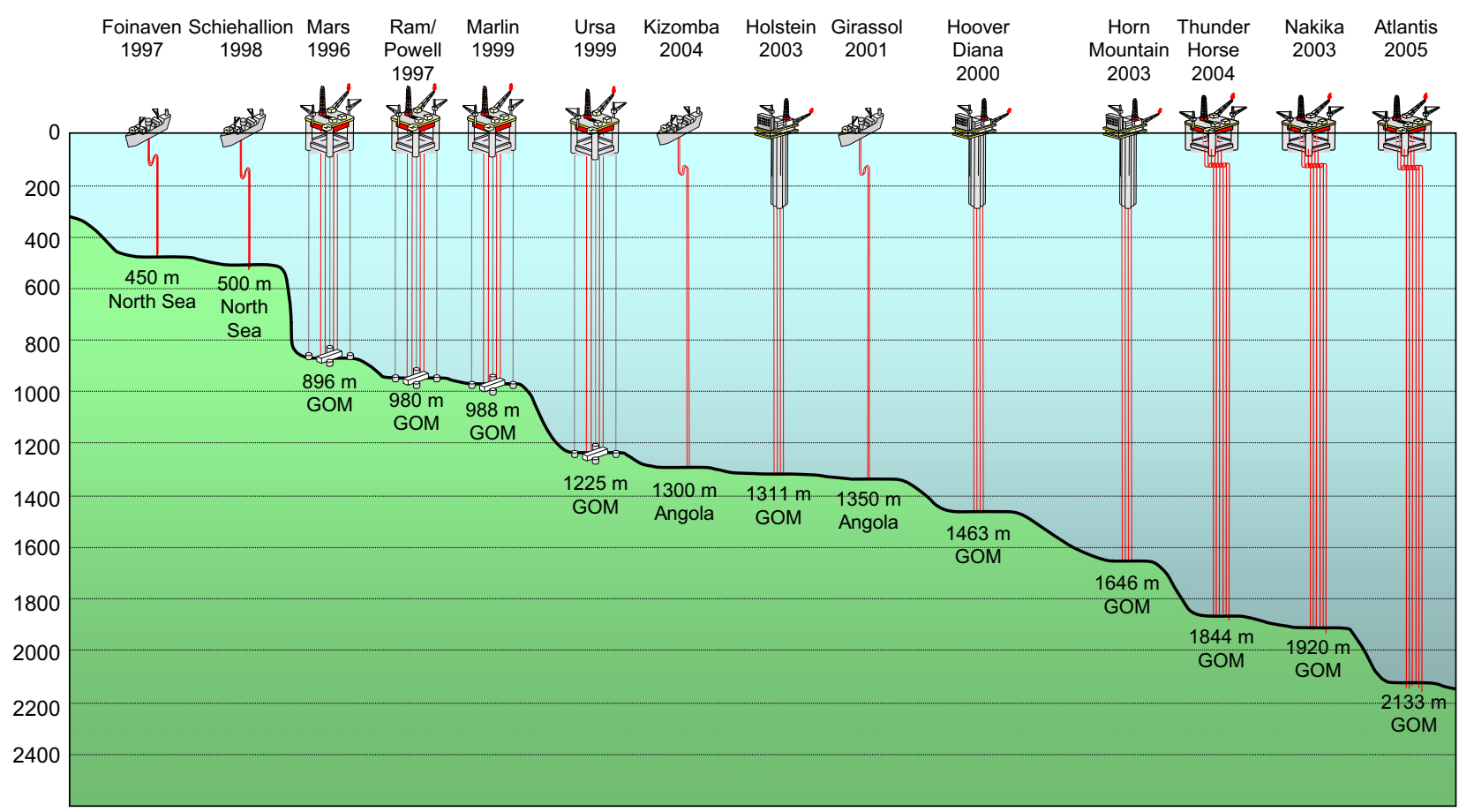

Fig. 1. Sequence of deep-water production projects holding water depth records, 1997 to 2005; after Evans (personal communication, 2006). GOM signifies Gulf of Mexico 
deep-water applications, including tension leg platforms (TLPs) and subsea facilities, as well as in major port and bridge projects. Their design involves making choices for diameters, wall thicknesses and embedded lengths so that the piles can be driven without damage or undue fatigue and fulfil suitable serviceability and ultimate limit state criteria. The piles' axial, lateral and moment load-displacement responses need to be assessed in platform pile design, but driveability and axial capacity tend to be the most critical factors. As discussed later in Part 3, lateral and moment loading are of greater concern with monopile wind-turbine structures. In most international settings, platform designers follow the recommendations and procedures set out in the broadly parallel American Petroleum Institute (API, 2014) and International Organization for Standardization (ISO, 2007) documents.

\section{Importance of regional geology}

Understanding geology is crucial to successful foundation design. The API and ISO documents have evolved slowly from approaches developed initially for Gulf of Mexico projects, where considerable thicknesses of low overconsolidation ratio (OCR) Quaternary marine clays and sands are encountered. Davies et al. (2011) summarise conditions in the UK North Sea sector, where the current author was first occupied with offshore geotechnics. Quaternary soils dominate, but the 15 main units mapped in Fig. 2(a) comprise multiple glacial tills combined with marine sand and clay sediments overlying Tertiary, Cretaceous, Jurassic and older bedrocks. The latter are encountered closer to the seabed in the south and older sediments are encountered on the eastern coastline north of Teesside. The northern Quaternary sediments become thicker with distance away from the UK's eastern coastline (see Fig. 2(b)) and reach their maximum (around $800 \mathrm{~m}$ ) in the central North Sea. Davies et al. (2011) demonstrate that repeated glaciation took place in the North Sea Basin during the Middle and Late Pleistocene through ice sheets originating in northern Scotland. Sea levels fluctuated greatly between glacial and inter-glacial stages and the submerged glacial geomorphology is highly variable with frequent buried channels, moraines, boulder beds and other pro-glacial features. The sediments vary from very hard clay tills and extremely dense sands through to low OCR, very soft clay buried valley infills. Fig. 3 provides, as an example, a schematic representation of the features identified for the Clair Ridge development west of Shetland by Hampson et al. (2017), which will be discussed again later in Part 1, before moving on to consider deep-water landslides.

Field monitoring of driven pile foundations in the North Sea

Concern that the Gulf of Mexico approaches to site investigation and foundation design might not apply to North Sea conditions prompted a series of industry-led research and
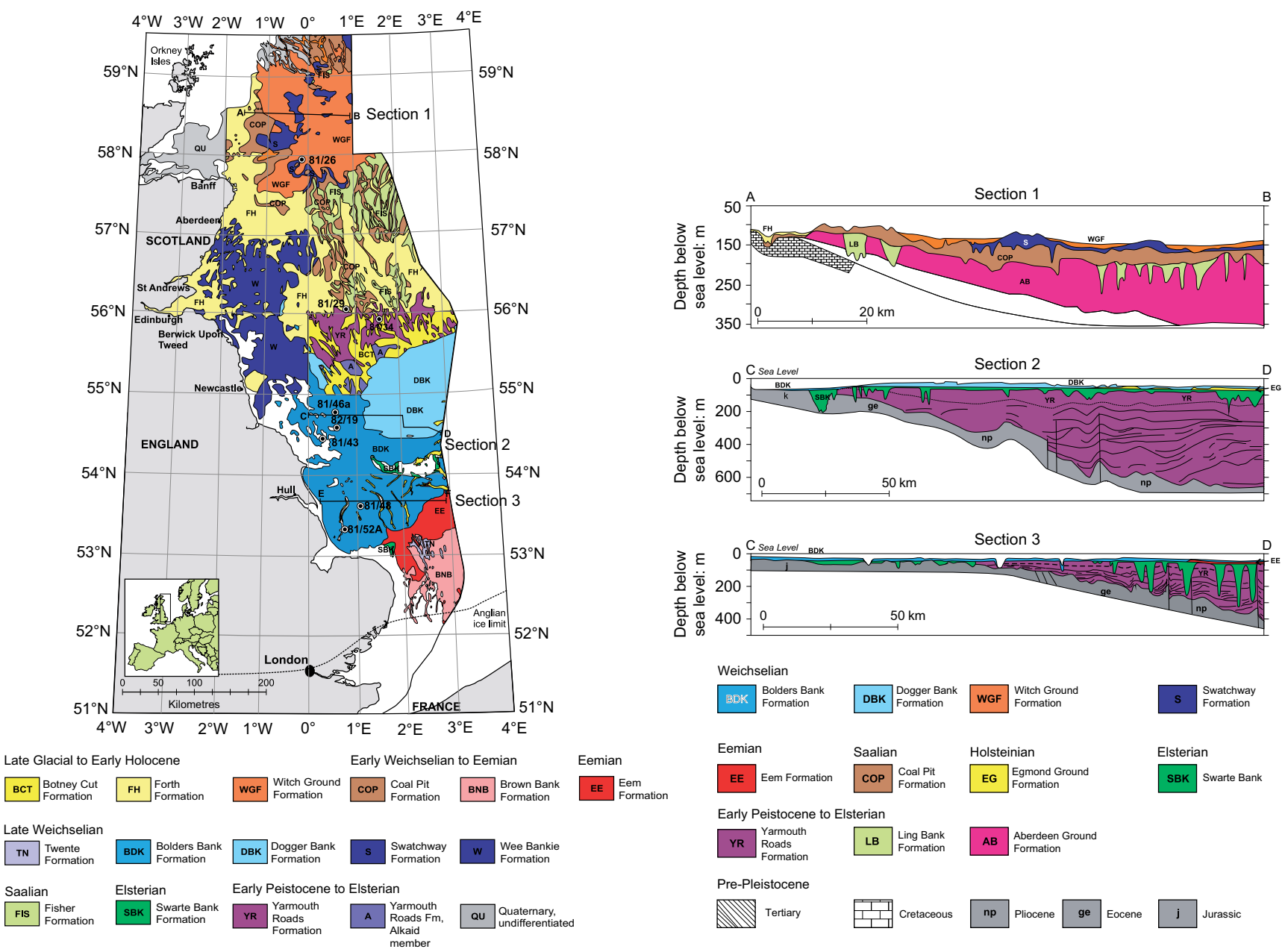

(a)

(b)

Fig. 2. Summary of geology for UK North Sea sector: (a) map and (b) section showing 15 main Quaternary units, from Bolders Bank to Yarmouth Roads; after Davies et al. (2011) 


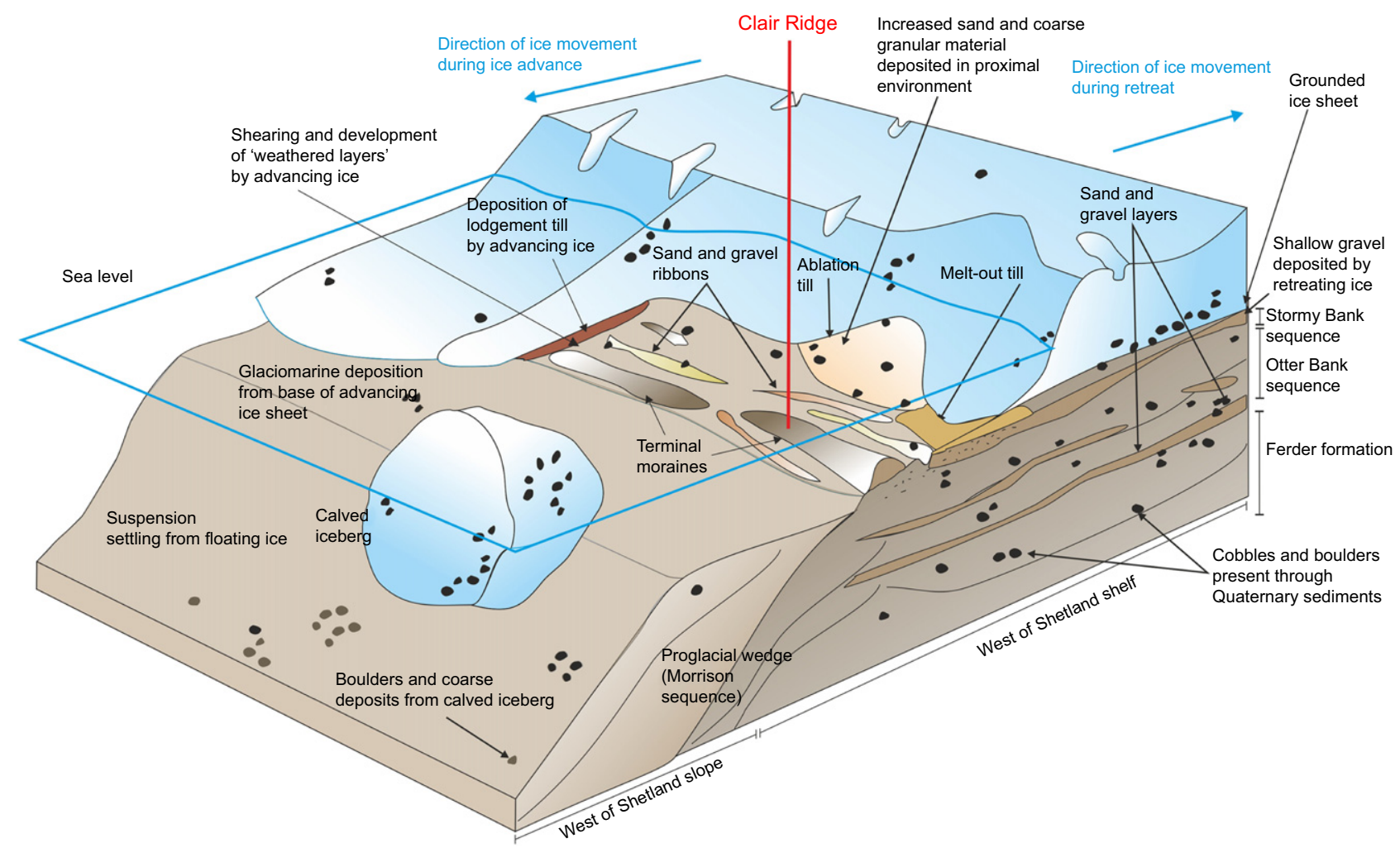

Fig. 3. Glacial geomorphology and sedimentary ground model for west of Shetland continental shelf edge near BP's Clair Ridge platform; after Hampson et al. (2017)

development projects from the 1980s onwards. Jardine (1985) describes site characterisation and instrument design studies, field monitoring and analysis of pile-group load-displacement behaviour undertaken for BP's Magnus steel jacket, then the largest worldwide, and also the first TLP (Conoco's Hutton TLP), whose northern North Sea sites are identified in Fig. 4. Four circular groups of nine, $2 \cdot 13 \mathrm{~m}$ dia., piles were driven in $186 \mathrm{~m}$ water depth to $82 \mathrm{~m}$ penetration through mainly hard to very stiff lean glacial tills at Magnus, while four similar groups of eight, $1.83 \mathrm{~m}$ dia., piles were driven in $148 \mathrm{~m}$ of water to $58 \mathrm{~m}$ penetration through hard tills and dense to very dense sands for the Hutton TLP. The Magnus piles carried large compressive loads and sustained wave and wind moment loading through 'push-pull' pile action. The Hutton TLP applied entirely tensile loads, as shown in Fig. 5. Successful deployment at Hutton led to multiple TLPs being installed for subsequent deep-water projects, including the examples shown in Fig. 1.

Most platform designers assess foundation loaddisplacement behaviour through the API (2014) approaches, which treat single piles by a Winkler beam-column approach; axial and horizontal loading are considered onedimensionally without any interactive coupling. Non-linear axial shaft $(t-z)$, lateral $(p-y)$ and axial pile tip $(Q-z)$ 'springs' are specified that depend principally on the local axial or lateral capacities found from simple empirical, generic approaches. As discussed further later, in Part 3, little use is made of site-specific soil stiffness information. Pile group action is addressed by assuming the interactions are elastic and selecting 'operational' profiles of linear shear stiffness with depth.

Kenley \& Sharp (1993) describe the dynamic measurements of axial and lateral load-deflection behaviour made with accelerometers and strain gauges at Magnus under storm conditions, while Jardine et al. (1988) describe the high-precision static load-displacement measurements made

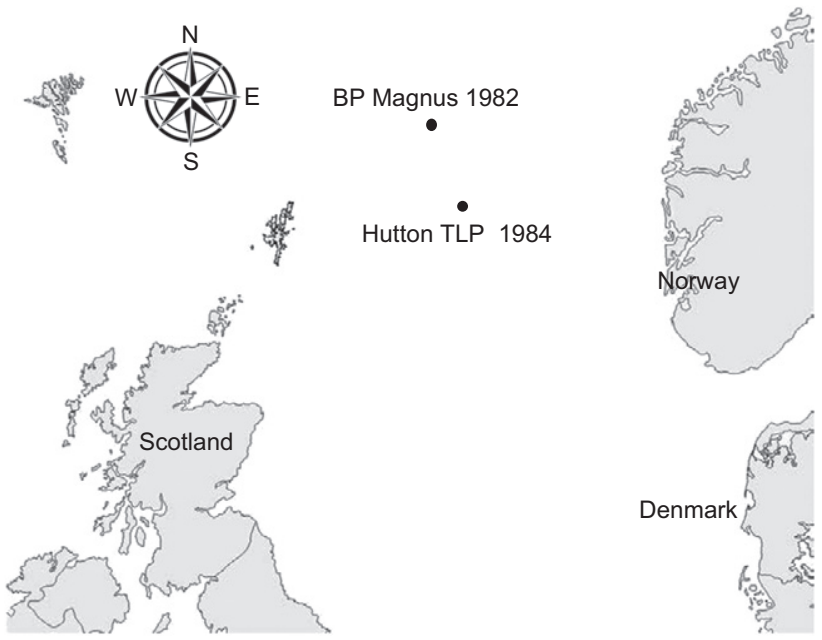

Fig. 4. Locations of BP's Magnus and Conoco's Hutton TLP developments in northern North Sea

at Hutton, with purpose-designed remote sensors, of the pile groups' axial and moment rotation stiffness. The data gathered at both sites showed unequivocally that the API approaches, as applied by experienced practitioners, underpredicted the pile groups' stiffnesses by factors of around 2 to 4 , depending on the loading mode.

Parallel work at Imperial College allowed predictions to be made by modelling the highly non-linear stiffness behaviour seen from very small strains through to failure in locally instrumented laboratory stress path tests on Magnus till and other soils; see Jardine et al. (1984). Finite-element (FE) calculations employing the Imperial College finiteelement program (ICFEP, see Potts \& Zdravkovic, 1999, 2001) adopted modified Cam Clay and Mohr-Coulomb 


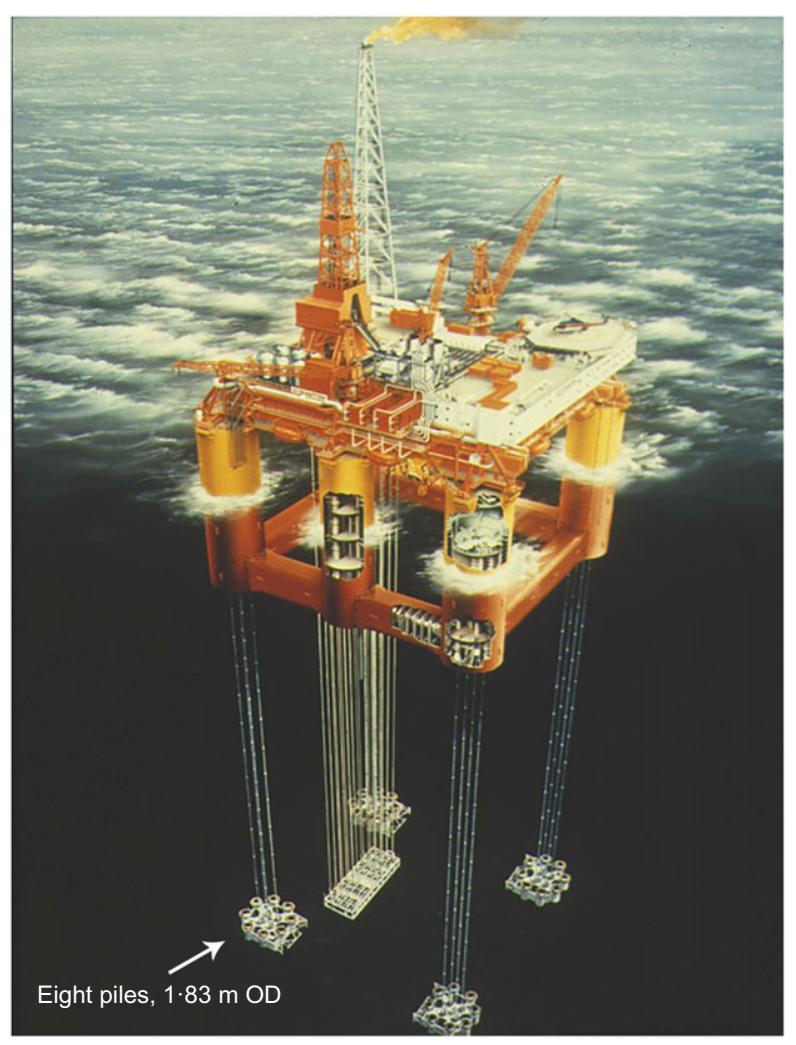

(a)

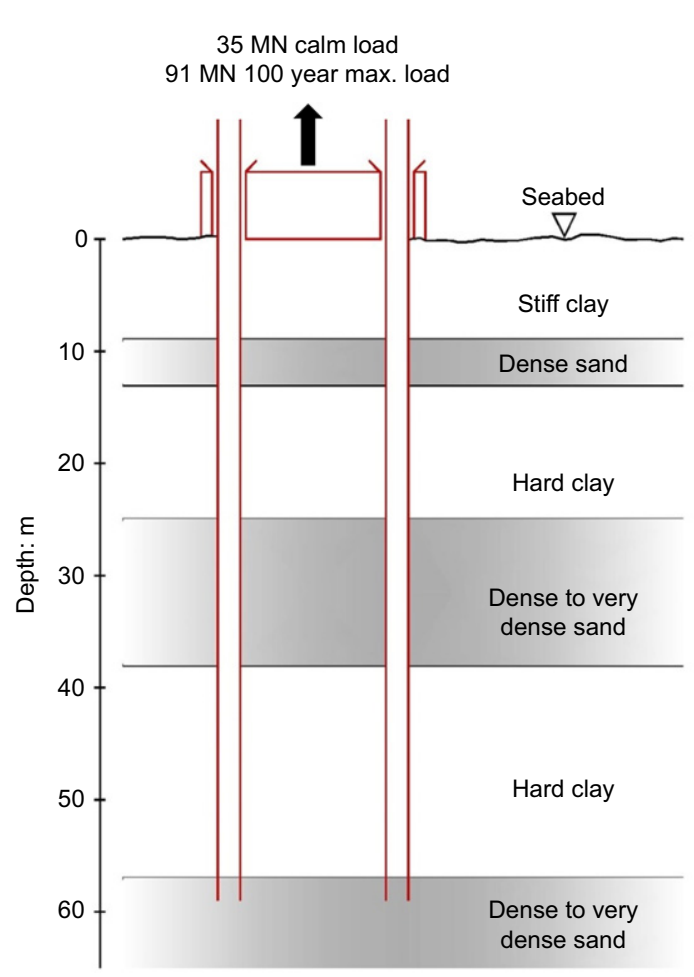

(b)

Fig. 5. (a) Schematic representation of Hutton TLP. (b) Nominal cross-section through one of the Hutton TLP's four (eight pile) deep foundation pile groups, showing maximum design storm loading. High-resolution sensors, attached to each pile group by divers, sensed pile movements, while load cells in hull compartments measured the applied tension forces. After Jardine et al. (1988)

models for the clay tills and sands, respectively, combined with an effective stress 'non-linear small-strain' stiffness formulation, similar to that set out by Jardine et al. (1986). Shaft-soil slip was captured with interface failure criteria from ring shear interface tests. Allowance was also made for the effects of pile installation on the initial stresses, based on a review of all available evidence. Pile group interaction was addressed through a non-linear procedure developed from the pile FE analyses.

Jardine \& Potts $(1988,1993)$ showed that their alternative approach led to 'Class-A' predictions (Lambe, 1973) that matched the field axial and rotational responses far more closely than the designers' conventional API analyses. An example of the predictions and measurements made for the Hutton TLP pile groups' axial stiffness response is presented in Fig. 6. Ganendra (1994) extended the ICFEP modelling to cover lateral loading, finding good agreement with the lateral load-deflection measurements gathered at Magnus under storm loading conditions, without changing the non-linear models, input parameters, or specified soil effective stress conditions.

The conventional (API) methods' marked overestimation of field pile-group movements in stiff to hard North Sea clay tills and dense sands has significant implications for the fatigue lives of structural members and for foundation performance monitoring. Nevertheless, the offshore industry has retained the standard API approaches for most new design work, assuming perhaps that the outcomes would at least lead to conservative structural designs. However, it is now appreciated that this is not always true and that the load distributions assessed from overly soft foundation models may lead to the sections of some members being under-sized while others are often unnecessarily heavy (Jeanjean et al., 2015). A particular concern arose when assessing fatigue lives

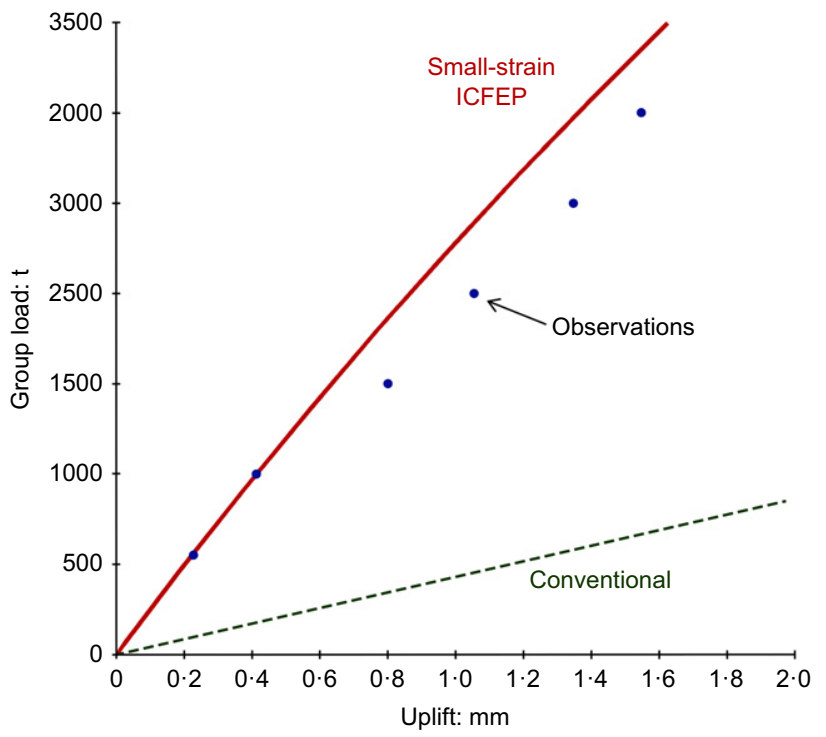

Fig. 6. Comparison between field measurements and predictions for axial pile group load-deflection behaviour during TLP installation; after Jardine \& Potts (1988)

for well conductors, where the simplified 'conservative' standard API $p-y$ treatment indicated uneconomically short service lives for deep-water soft clay sites when large, modern blow-out preventers are deployed to ensure safety. Improvement has become an urgent industrial priority, especially for very high-value deep-water wells. Jeanjean et al. (2017) propose improvements for $p-y$ analyses in clays that employ site-specific simple shear laboratory testing. 
As noted in Part 3, advances have also been made recently in the 'small-strain' triaxial stress path laboratory and FE approach that have been applied in recent analyses of monopiles under lateral and moment loading.

The 'small-strain' FE approach is generic and has been applied to many boundary value problems since the 1980s, including slope stability (reported in Part 2) and hundreds of urban projects where ground movements and soil-structure interaction can govern design for foundations, retaining walls, tunnels and deep excavations. Generally good matches have been demonstrated between predictions and field measurements in multiple case histories reported with colleagues at Imperial College and the Geotechnical Consulting Group (GCG, London); see, for example, Jardine et al. (1991, 2005b) and Higgins \& Jardine (1998).

Investigations into the static axial capacities of piles driven in sands and clays

Predicting the axial capacity of piles driven in clays and sands is central to assessing foundation safety and is usually a more pressing design concern than improving loaddisplacement analysis. Database studies by Briaud \& Tucker (1988), Tang et al. (1990) and others raised concerns that the main text API approaches are subject to wide scatter and possible bias when assessed against load tests, particularly in sands. The methods' relatively poor predictive performances might indicate potentially inadequate reliability in service when applied in combination with the factors recommended in the API's working stress design (WSD) or load and resistance factor design (LRFD) approaches. The lack of pile load tests that represent North Sea geotechnical conditions led two joint industry groups to initiate research with instrumented $762 \mathrm{~mm}$ outside diameter (OD) piles (Clarke, 1993). The large-diameter pile 'LDP' group ran tests onshore in the UK in stiff high OCR Jurassic Oxford clay covered by glacial till at Tilbrook Grange and in a deep profile of low OCR glacio-lacustrine clay-silt at Pentre. Neither site fully matched the most common North Sea conditions, but offshore tests were considered prohibitively costly. Kolk et al. (2005a) report the parallel EURIPIDES tests run in a representative dense North Sea sand at Eemshaven in the Netherlands.

Parallel research at Imperial College by the author's group included developing instruments (with Cambridge Insitu) that could measure accurately the local axial loads, porewater pressures, radial and shear stresses acting on model Imperial College pile (ICP) closed-ended displacement piles. The $102 \mathrm{~mm}$ dia., up to $20 \mathrm{~m}$ long, piles illustrated in Fig. 7 (described in detail by Bond et al. (1991)) were used to study installation, equalisation and load testing in field campaigns by Bond (1989), Lehane (1992) and Chow (1997) with multiple ICP installations at the six site locations indicated in Fig. 8, which were identified with help from colleagues at the Building Research Establishment (BRE), the French Laboratoire Central des Ponts et Chaussées (LCPC, now IFSTTAR) and Institut Français du Pétrole (IFP).

The four UK clay sites at Canons Park, Cowden, Bothkennar and Pentre offered a spread of marine, glacial, shallow marine-estuarine and glacio-lacustrine deposits, respectively, and presented a wide range of undrained shear strength, sensitivity and yield stress ratio (YSR) profiles. Additional ICP test and site characterisation campaigns were run in France at the Labenne loose dune sand site and in dense (primarily marine) sand at Dunkirk. Details of the wide range of soils' mechanical characteristics were established through comprehensive in situ and laboratory testing campaigns.

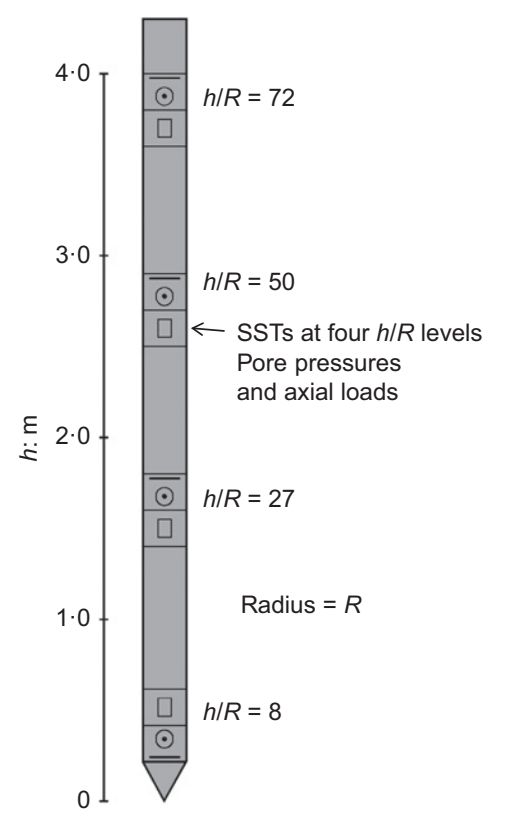

Fig. 7. Schematic diagram of ICP instrumented displacement pile

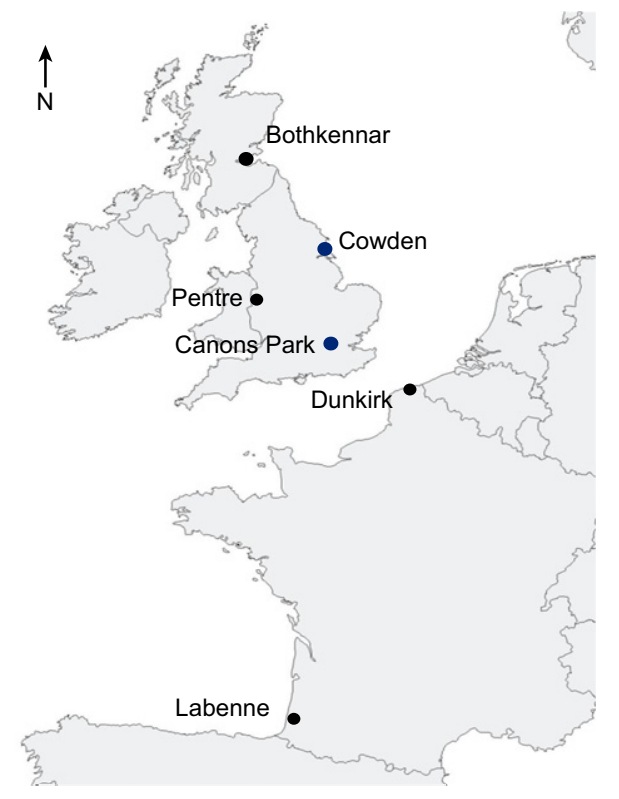

Fig. 8. Locations of ICP test sites: 1984 to 1995

The ICP experiments reported by Bond \& Jardine (1991, 1995), Lehane et al. (1993), Lehane \& Jardine (1994a, 1994b) and Chow (1997) provided the basis for the physically based design procedures proposed by Jardine \& Chow (1996) and extended by Jardine et al. (2005a). Close geometrical similarity allowed base failure to be related directly to local cone penetration test $(\mathrm{CPT})$ cone resistance, $q_{\mathrm{c}}$, while the maximum local shaft shear stresses that can be sustained on the shaft under axial loading $\tau_{\mathrm{rz}}$ were shown to be governed by an effective stress Coulomb expression

$$
\tau_{\mathrm{rzf}}=\sigma_{\mathrm{rf}}^{\prime} \tan \delta^{\prime}
$$

where $\delta^{\prime}$ is the friction angle applying at the soil-steel interface as measured in laboratory ring shear interface tests run to specific procedures (see Ramsey et al., 1998; Ho et al., 2011) and $\sigma_{\mathrm{rf}}^{\prime}$ is the radial effective stress at failure. Low ultimate $\delta^{\prime}$ angles (sometimes less than $10^{\circ}$ ) can develop in clays that form 
orientated, polished shear planes close to the pile shafts (as with many stiff, high-plasticity UK clays), while higher values apply to lean sandy glacial tills and still higher angles (exceeding $30^{\circ}$ ) have been found in diatomaceous, highplasticity-index clays which form in marine and lake deposits worldwide. Correlations with plasticity index cannot capture these variations; site-specific interface shear tests are essential.

In clays $\sigma_{\mathrm{rf}}^{\prime}$ may be taken as 0.8 times the local radial effective stress $\sigma_{\mathrm{rc}}^{\prime}$ acting after all pore pressure dissipation is complete and ground stresses have equalised. The ICP tests showed that $\sigma_{\mathrm{rc}}^{\prime}$ can be expressed as a multiple $K_{\mathrm{c}}$ of $\sigma_{\mathrm{v} 0}^{\prime}$, where $K_{\mathrm{c}}$ is a specified function of the clay's YSR (or apparent overconsolidation ratio (OCR), which is defined as $\sigma_{\mathrm{vy}}^{\prime} / \sigma_{\mathrm{v} 0}^{\prime}$ where $\sigma_{\mathrm{vy}}^{\prime}$ is the vertical yield stress under $K_{0}$ loading) and sensitivity, $S_{\mathrm{t}}$, at any depth below ground level as well as the relative pile tip depth $h / R^{*}$, where $h$ is the depth of the tip below the point in question and $R^{*}$ is an effective radius defined for tubular piles as

$$
\begin{aligned}
& R^{*}=\left(R_{\text {outer }}^{2}-R_{\text {inner }}^{2}\right)^{0.5} \\
& K_{\mathrm{c}}=\left(2 \cdot 2+0 \cdot 016 \mathrm{YSR}-0 \cdot 870 \Delta I_{\mathrm{vy}}\right) \mathrm{YSR}^{0.42}\left(h / R^{*}\right)^{-0.20}
\end{aligned}
$$

$$
\Delta I_{\mathrm{vy}}=\log _{10} S_{\mathrm{t}}
$$

where $h / R^{*}$ is limited to a minimum of 8 . The radial effective stresses that can be developed on the shaft at any given depth below ground level decay as $h / R^{*}$ increases, through a combination of the phenomena outlined by Jardine \& Chow (2007) that were termed loosely as 'friction fatigue' for clays by Heerema (1980).

In sands $\sigma_{\mathrm{rf}}^{\prime}$ may be taken as $\sigma_{\mathrm{rc}}^{\prime}+\Delta \sigma_{\mathrm{rd}}^{\prime}$ at failure in compression, where the component $\Delta \sigma_{\text {rd }}^{\prime}$ reflects constrained dilation at the interface that may be estimated as

$$
\Delta \sigma_{\mathrm{rd}}^{\prime}=d \mathrm{r} 2 G / R
$$

where $d \mathrm{r}$ is the pile shaft's average peak to trough roughness, $G$ is the sand's shear stiffness (which can be estimated from cone resistance, $q_{\mathrm{c}}$ ) and $R$ is the pile's outside radius. Lower radial shear stresses (and shaft resistances) apply with sands at failure in tension, for which $\sigma_{\mathrm{rf}}^{\prime}=0.9\left(0 \cdot 8 \sigma_{\mathrm{rc}}^{\prime}+\Delta \sigma_{\mathrm{r}}^{\prime}\right)$ with tubular piles.

The ICP tests in sands showed that $\sigma_{\mathrm{rc}}^{\prime}$ depends directly on local CPT resistance $q_{\mathrm{c}}$ and $h / R^{*}$, which has a still stronger influence in sands than with clays. The local vertical effective stress (normalised by atmospheric pressure, $P_{\mathrm{a}}$ ) is also mildly influential, giving

$$
\sigma_{\mathrm{rc}}^{\prime}=0.029 q_{\mathrm{c}}\left(\sigma_{\mathrm{v} 0}^{\prime} / P_{\mathrm{a}}\right)^{0.13}\left(h / R^{*}\right)^{-0.38}
$$

again, $h / R^{*}$ is limited to a minimum of 8 . Tests on open-ended tubular piles driven at Canons Park, Cowden, Pentre and Dunkirk showed that equations (3) and (6) are equally applicable to both closed and open-ended piles, provided their equivalent radii $R^{*}$ are employed as defined in equation (2).

Jardine et al. (2005a) also show how the expressions may be applied to the steel $\mathrm{H}$ section and solid square section concrete piles that are often driven for smaller scale onshore civil engineering projects.

\section{Field verification studies and alternative approaches}

The ICP design procedures were evaluated further by Chow (1997), who assembled a database of tests from suitably characterised sites identified in the literature as well as unpublished research and industrial reports. Jardine et al. (2005a) extended the set to comprise 68 cases in clays and 81 in sands, including the LDP and EURIPIDES joint industry experiments. Statistical comparisons between calculated $Q_{\mathrm{c}}$ and measured $Q_{\mathrm{m}}$ axial capacities demonstrated far better predictive reliability than the conventional API main text approach, especially for sands.

Several alternative approaches have been proposed for piles driven in sand that address some of the physical phenomena observed in the ICP tests. The UWA-05 variant (Lehane et al., 2005) of the ICP sand method employs, in place of equation (3), a formulation involving the incremental filling ratio (IFR) of the internal pile plug for open-ended tubular piles that defines an 'effective' pile area, which affects both shaft and base capacity. Kolk et al. (2005b) and Clausen et al. (2005) introduced the related Fugro-05 and NGI-05 methods, which took other routes to capture the effect of pile tip position and geometry.

Lehane et al. (2005) assessed the alternative 'sand' methods' predictive performance against an extended database of tests, concluding that the UWA-05 and ICP-05 methods give the least bias and scatter. They report broadly comparable reliability statistics to Jardine et al. (2005a) and the CPT methods offered improvements over the API main text approach. All four are now included as viable alternative approaches in the Commentary section of API (2014).

Recent joint studies involving significantly larger pile test datasets and stricter quality criteria include a study by Zhejiang University (ZJU) and Imperial College (ICL), reported by Yang et al. $(2015,2017)$ and a joint industry project led by the Norwegian Geotechnical Institute (NGI) and reported by Lehane et al. (2017). These two independent studies led to broadly similar overall conclusions for sands.

It is important to recognise that most database tests were conducted relatively soon after installation and, as shown later, age after driving has a marked impact on shaft capacity in both clays and sands. Table 1 summarises the $Q_{\mathrm{c}} / Q_{\mathrm{m}}$ statistics found from the 80 'age filtered' tests in the ZJUICL sand database, in which only piles tested at ages of between 10 and 100 days after driving are considered. Also shown is the Yang et al. (2017) re-evaluation of the 'LCPC' CPT method employed in France, as outlined by Bustamante \& Gianeselli (1982). The individual $Q_{\mathrm{c}} / Q_{\mathrm{m}}$ ratios found for the restricted set of 80 tests varied by up to $\pm 0 \cdot 1$ from those applying to the full group of 117 cases. This degree of sensitivity to the specific entries is typical of pile databases involving around 100 tests. The statistics become more sensitive to individual cases being included or omitted, and probably less meaningful, as the database populations reduce.

Table 1 indicates a slightly more favourable outcome for the API main text method than earlier studies. The Yang et al. (2017) analysis also highlighted the significantly poorer statistical outcomes when the 'offshore variants' of the ICP-05 and UWA-05 approaches specified in the API

Table 1. Joint ZJU-ICL database test assessment of approaches for axial capacity prediction in sands; means and coefficients of variation $(\mathrm{CoV})$ for $Q_{\mathrm{c}} Q_{\mathrm{m}}$ ratios; summarised from Yang et al. (2017)

\begin{tabular}{l|c|c}
\hline Method & Mean & CoV \\
\hline API, main text & $0 \cdot 88$ & $0 \cdot 55$ \\
Fugro-05; Kolk et al. (2005a) & $1 \cdot 20$ & $0 \cdot 47$ \\
ICP-05 (full); Jardine et al. (2005a) & $0 \cdot 94$ & $0 \cdot 30$ \\
NGI-05; Clausen et al. (2005) & $1 \cdot 23$ & $0 \cdot 48$ \\
UWA-05 (full); Lehane et al. (2005) & $1 \cdot 05$ & $0 \cdot 35$ \\
LCPC-82; Bustamante \& Gianeselli (1982) & $1 \cdot 25$ & $0 \cdot 40$ \\
\hline
\end{tabular}


(2014) Commentary sections are considered. Yang et al. (2017) emphasise that it is better to retain the full ICP-05 procedure in practical design.

Parallel evaluations by Lehane et al. $(2013,2017)$ have shown that site characterisation approaches have a more critical impact with clays than appreciated previously and the statistical outcomes are highly sensitive to which cases are ruled in, or out. There are surprisingly few high-quality pile load tests at sites where sufficient sampling, laboratory and in situ testing has been undertaken to allow objective comparisons between a representative spread of methods. For example, reliable interface shear testing and YSR profiles are crucial to the ICP-05 approach, while CPT methods cannot be assessed without high-quality profiles from soundings close to the test piles.

Despite efforts made over the last 30 years, it appears that emphasis needs to be placed again on assessing predictive capabilities for large piles driven in clay. Only two load tests (both at Cowden in Humberside) are present in the Lehane et al. (2017) dataset that represent the extensive North Sea glacial tills mapped in Fig. 2. Although till was present over the upper part of the profile at one other site (Tilbrook Grange) it contributed only $30 \%$ of the 'LDP' test pile's shaft capacity.

The 'ICP' clay and sand axial capacity procedures have been applied in offshore foundation design since 1995. Overy (2007) describes their use in nine Shell (UK) projects and presents pile driving monitoring data that demonstrate their advantages over the conventional API capacity methods. His set includes the central North Sea Shearwater A jacket platform, which stands in $142 \mathrm{~m}$ of water and has the layout shown in Fig. 9. Overy (2007) describes the hard clay and dense sand site profile and notes that adopting the ICP design method allowed the $2 \cdot 13 \mathrm{~m}$ dia. piles' lengths to be reduced significantly to give $51 \mathrm{~m}$ final design penetrations. Conventional API (2014) axial $(t-z)$, lateral $(p-y)$ and axial pile tip $(Q-z)$ non-linear spring approaches were retained to predict the overall load-displacement response of the structure and its foundations under storm loads. Hunt (1999) reports how the jacket performed in late December 1998 under conditions that matched approximately the 20 year return period storm. An axial push-pull mechanism supplied the main reaction to the over-turning moments imposed by waves and wind. It is reassuring that, as shown in Fig. 10, the horizontal sways recorded by deck-level accelerometers indicated a far stiffer than expected field foundation performance. As at Magnus and Hutton, the movements were several times smaller than predicted by the API procedures.

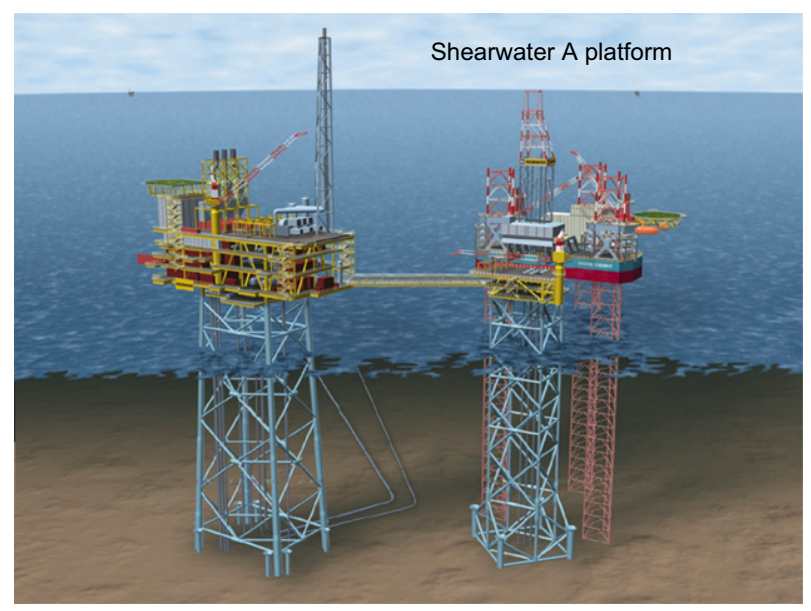

Fig. 9. Schematic representation of Shell's Shearwater A platform in central North Sea; courtesy Shell UK

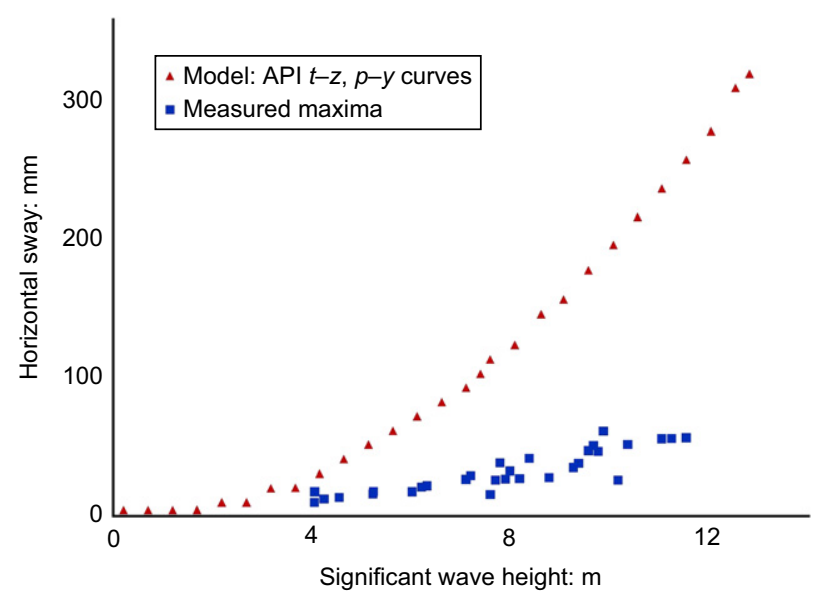

Fig. 10. Predictions and measurements for horizontal deck sways against significant wave height measured during near 20 year storm event at Shell's Shearwater A platform, 28 December 1998; re-drawn after Hunt (1999)

It is reassuring that the reduced length Shearwater A piles indicated no sign of being under-designed.

\section{Outstanding research questions}

While the research described above yielded encouraging results, it was recognised that conventional field monitoring and static pile testing provide only limited information. Tests to failure are usually conducted within a few days or weeks of installation. Checks on the degree of driving excess pore pressure dissipation are rarely made before testing. Noting that the critical design cases are likely to apply well after driving is complete, designers must gauge, or assume, how set-up and ageing in service affect pile response. This question becomes most pressing when assessing ageing foundations. Their original design, potentially undertaken many years earlier, may not provide capacities that meet current criteria. Equally, foundation loading requirements may have become more onerous due to topside plant or production risers being added, or the effects of structural damage, corrosion, seabed scour, marine growth or the impact of climate change on storm loading levels.

The critical pile loading cases at Hutton, Magnus and Shearwater all involved repeated, cyclic, storm loading, begging the question as to how the cyclic field responses may compare with those seen under slow, monotonic pile testing. If the impact of cyclic loading is significant, how can it be addressed and incorporated into practical design?

To address these two questions, it was necessary to consider a third: how to characterise the effective stress regime set up in the ground around piles during driving and over their service lives? The extreme strains, dynamic conditions and wide range of pressures and stress paths involved in pile driving make the installation process impossible to model accurately with routine numerical or analytical methods.

Four strands of collaborative research have been undertaken with co-workers from several groups to investigate these and other outstanding questions through four means

(a) macro-scale field tests to establish how industrial driven piles respond to ageing and cyclic loading

(b) laboratory model experiments with highly instrumented displacement piles to isolate the local stresses developed on pile surfaces and within the soil mass under conditions that match the macro-scale field tests 
(c) stress-path element and interface shear experiments that represent the monotonic and cyclic conditions in the field

(d) numerical analysis of the installation process through emerging FE and discrete-element method (DEM) techniques.

The following nine sub-sections review the progress made, considering first ageing and then cyclic loading. Space limitations have led to attention being focused primarily hereafter on piles driven in sand. Database studies show that axial design is statistically less certain in sands, whose constitutive behaviour is intrinsically harder to model. Problems encountered at sand sites range from severely insufficient capacity in some cases to refusal and buckling on driving at others. However, parallel work has been conducted with clays; see, for example, Karlsrud \& Haugen (1985) and Karlsrud et al. (1992, 2014), Jardine et al. (2012) and Puech (2013). Part 3 restores a degree of balance by placing greater emphasis on behaviour in clays and other geomaterials.

Field tests in dense Dunkirk sand with industrial-scale piles

The first research stream involved returning to the dense sand test site at Port Ouest, Dunkirk, northern France identified in Fig. 8. Seven $457 \mathrm{~mm}$ OD, steel tubular piles were driven in association with the GOPAL (grouted offshore piles for alternating loading) joint industry project, see Parker et al. (1999). Additional CPTu tests were carried out, adding to earlier intensive stress path laboratory testing at Imperial College along with in situ profiling, as described by Chow (1997), Kuwano (1999) and Jardine (2013). Staged first-time tension load tests to failure on three $\approx 19 \mathrm{~m}$ long piles provided the clear evidence in Fig. 11 of strong growth in shaft resistance over 235 days, without any change in initial axial stiffness (Jardine et al., 2006). Re-tests on individual piles led to more confused and staggered trends that failed to demonstrate the same impressive capacity gains. Adding data from a longer term test by Chow (1997) on a $324 \mathrm{~mm}$ OD, $21 \mathrm{~m}$ long, tubular steel pile driven earlier nearby by the CLAROM (Conseil de Liaison des Associations de Recherche sur les Ouvrages en Mer) group led Jardine et al. (2006) to conclude the following.

(a) End of driving shaft resistances fall $\approx 30 \%$ below the ICP estimates.

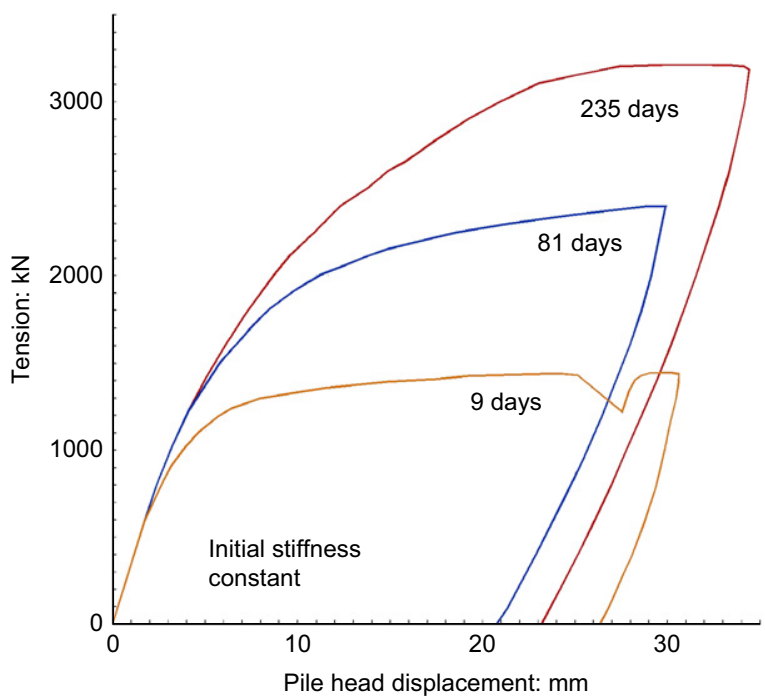

Fig. 11. Results of first-time tension load tests to failure carried out 9 to 235 days after driving on three identical $c .19 \mathrm{~m}$ long $457 \mathrm{~mm}$ OD piles driven at Dunkirk test site; after Jardine et al. (2006) (b) Tension capacities grow to match the ICP estimates some days or weeks after driving.

(c) Shaft capacities stabilised around 1 year after driving at values around $2 \cdot 4$ times the ICP estimates.

(d) Static testing to failure disrupts and sets back the beneficial ageing processes. As noted later, cyclic loading can either degrade or enhance capacity growth, depending on the levels applied.

Comparable, but fully independent, 'first-time tension test' programmes were run with tubular piles of similar sizes in dense sand driven above the water table at Blessington, Ireland (Gavin et al., 2013) and in loose, submerged sand at Larvik, Norway (Karlsrud et al., 2014). Their trends were brought together by Rimoy et al. (2015) and Gavin et al. (2015) in Fig. 12, where ICP-05 sand shaft capacity predictions are employed to normalise for each site's specific ground profile and identify a common overall ageing trend. The beneficial ageing trends may help to explain why offshore foundation failure is rare in service, despite the unsatisfactory predictive reliability statistics shown in Table 1. However, before relying on ageing in potentially hazardous offshore projects, it is important to know more about the processes that control capacity growth and any conditions that might be necessary for the benefits suggested by Fig. 12 to apply. Jardine et al. (2006) outlined three potential mechanisms that might contribute to the pile ageing processes: $(a)$ physio-chemical and corrosion reactions involving the pile shaft, sand and groundwater leading to higher stationary radial stresses than given by equation (6), or higher interface shearing resistance angles than are seen in tests employing fresh sands and interfaces; $(b)$ enhanced dilation at the interface boosting the contribution defined by equation (5) through either additional radial dilation $d_{\mathrm{r}}$ or increased sand stiffness $G$; $(c)$ shaft radial stresses rising above those expected from equation (6) due to stress redistribution linked to creep within the surrounding sand mass.

Chow (1997), Axelsson (2000), Rimoy (2013) and others reported evidence that concrete and steel piles set up at similar rates after driving in the field, so it appeared unlikely that the ageing trends of industrial piles could be related purely to chemical reactions involving their shaft surfaces. In the same way the pile loading tests shown in Fig. 11 indicated that sand stiffness changes were unlikely to be the main driving factor. Research was therefore concentrated on experiments to investigate purely mechanically related aspects of the second and third mechanisms.

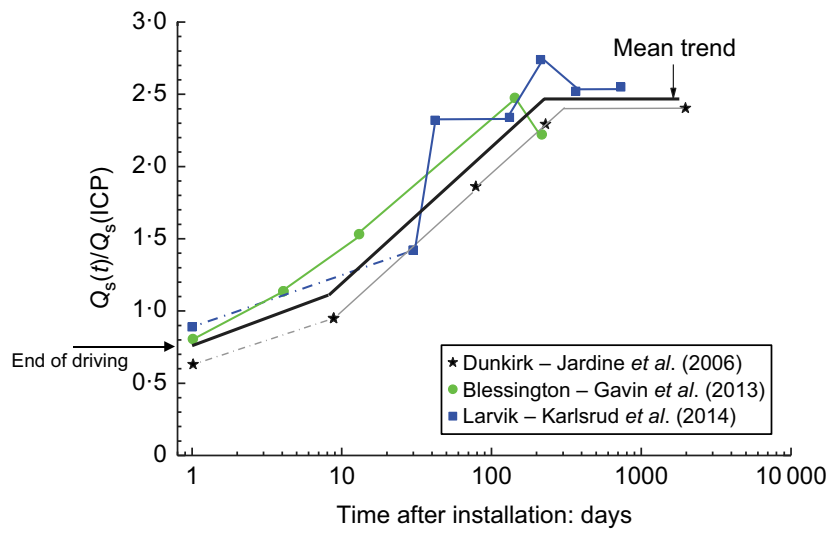

Fig. 12. Trends for growth in first-time shaft capacity with time at three sites, tension capacities normalised by pile specific ICP-05 predictions; after Rimoy et al. (2015) 
Calibration chamber instrumented model pile experiments at Grenoble

The need to know more about the stress conditions around displacement piles in sand led to a collaborative investigation with the late Professor Pierre Foray's group at the Université Grenoble Alpes' 3S-R laboratory. Their large calibration chamber was reconfigured to allow long-term, highly instrumented, model pile experiments under closely controlled conditions. Jardine et al. (2009, 2013a, 2013b), Zhu et al. (2009) and Rimoy et al. (2015) describe multiple experiments with a $36 \mathrm{~mm}$ dia., $1 \mathrm{~m}$ long, stainless steel mini-ICP pile that could measure shaft shear and normal stresses at three levels. The mini-pile was jacked into the sand through a cyclic procedure in which the pile head load was reduced to zero after each stroke. The standard stroke length adopted was $50 \mathrm{~mm}$, although the effects of shorter and longer strokes were also investigated. Choosing stainless steel for the pile material eliminated any chemical reactions involving the pile shaft. As indicated in Fig. 13, dozens of soil stress sensors were also deployed within the masses of NE34 and GA39 grade silica Fontainebleau sand that were air-pluviated into the chamber at an average void ratio, $e_{0}=0.62$ (corresponding to relative density $D_{\mathrm{r}}=72 \%$, see Yang et al. (2010)). A $150 \mathrm{kPa}$ vertical stress was then applied for an extended period to match the average sand state (void ratio and pressure) applying to the Dunkirk field tests. NE34 has a similar grading and comparable grain shapes to Dunkirk sand; parallel laboratory studies were undertaken at Imperial College, including interface shear and high-pressure tests that matched the radial stress conditions indicated after installation by the pile and calibration chamber stress embedded stress-cell measurements; see Yang et al. (2010), Altuhafi \& Jardine (2011), Liu et al. (2017), Altuhafi et al. (2018) and Liu (2018).

A fresh $4 \cdot 2 \mathrm{t}$ sand mass was prepared for each test and the piles were left to age, under pressure, for several months between installation and load testing. Additional tests were undertaken with CPT devices and plain driven piles made of both mild and stainless steel, and with different pile

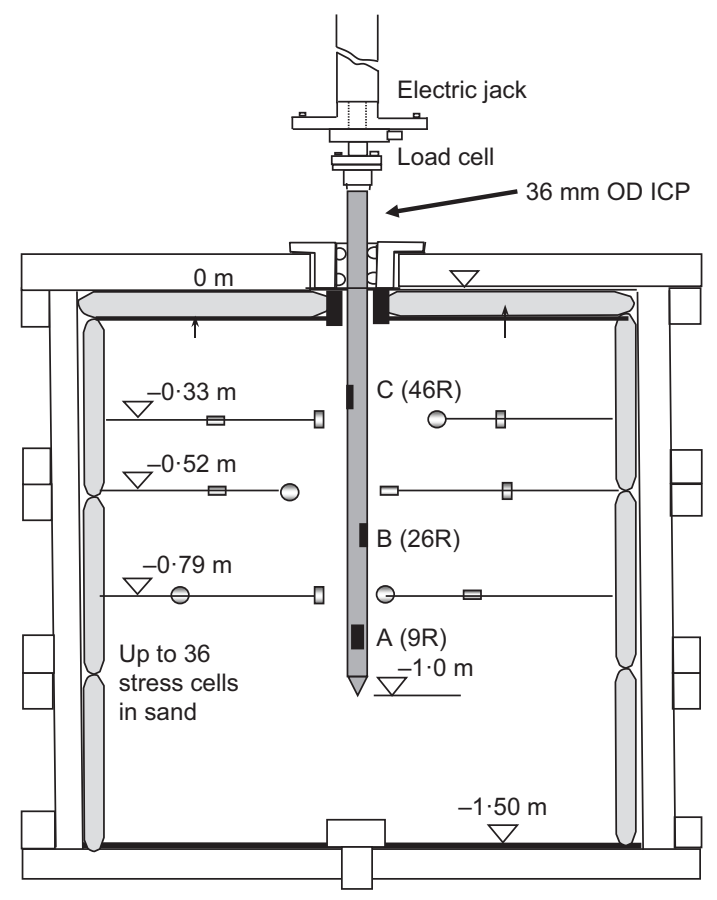

Fig. 13. Schematic diagram of mini-ICP instrumented model pile tests conducted in Grenoble 3S-R calibration chamber with dense, air-pluviated, NE34 sand, after Jardine et al. (2013a) diameters, chamber boundary conditions and (wet and dry) sand states. The experiments provided new insights into the stress conditions developed around displacement piles in sands and static and cyclic pile loading tests also provided highly valuable data. However, the stainless steel model piles failed to manifest the ageing shaft capacity gains seen in the field; only the mild steel piles showed significant set-up, and this was far less impressive than the gains indicated in Figs 11 and 12. The model piles showed no increase over time in either the stationary shaft radial effective stresses or the dilative radial stress changes invoked by loading to failure.

Seeking to explain the paradox between the field and model piles' ageing trends, Rimoy et al. (2015) suggested that absolute pile diameter may affect the ageing mechanism. The thicknesses of the crusts of crushed sand are found adhering to the mini-pile shafts in the Yang et al. (2010) laboratory tests and in field-driven piles at Dunkirk by Chow (1997), at Blessington (Gavin et al., 2013) and at Eemshaven (where cemented iron hydroxides were identified by Kolk et al. (2005a) around the EURIPIDES piles) grew with grain size and relative penetration depth, $h$, but did not scale up in proportion to pile diameter. Yang et al. (2010), Rimoy (2013) and Silva (2014) noted the annular thickness of the crushed sand zones represents a far greater proportion of the mini-piles' outside pile diameters than with larger industrial piles. Yang et al. (2010) showed that large compressive volume strains occur within the annular crushed sand zone whose impact on any stress re-distribution mechanism would therefore be far more significant with small-diameter piles. The grain crushing and soil-pile stress redistribution processes are also likely to be affected by the open- or closed-ended, conical or flat, pile tip geometry.

\section{Further field studies of potential effects on ageing set-up of pile diameter}

A vital question was whether large offshore piles gain shaft capacity over time in sands. Jardine et al. (2015a) reported data from dynamic stress-wave matching of accelerometer and strain gauge signals recorded during pile driving in very dense marine sands for the Borkum Riffgrund offshore jacket in the German North Sea. Signal matching was undertaken for the project with the CAPWAP (case pile wave analysis program) code that incorporates expanded versions of the conventional Smith (1960) one-dimensional pile driving modelling assumptions. The soil resistance profiles may be varied until a good match is achieved between the predicted and measured strain and acceleration traces. The structure, which stands in $24 \mathrm{~m}$ of water, is illustrated in Fig. 14. It is reassuring that the platform's eight $(2.13 \mathrm{~m} \mathrm{OD}, 38.5 \mathrm{~m}$ penetration) piles indicated mean end-of-driving shaft resistances that fell only $7 \%$ below site-specific ICP predictions. Records from a restrike test conducted 6 days after driving indicated $45 \%$ shaft capacity growth. As demonstrated later in Part 3, planned long-term restrikes on 'virgin' piles can give highly cost-effective information, especially when clusters of offshore structures are to be installed in similar ground conditions.

A further observation from the Borkum Riffgrund driving analysis was that the dynamically measured base resistances fell well below those expected by the ICP-05, or any other common predictive approach. Byrne et al. (2012) report similar findings; it appears that the displacements developed during dynamic hammer blows fall far below those required to mobilise full bearing failure under the annular tip area.

Further ageing research involving driven micro-piles has been completed recently in joint work with the NGI, 


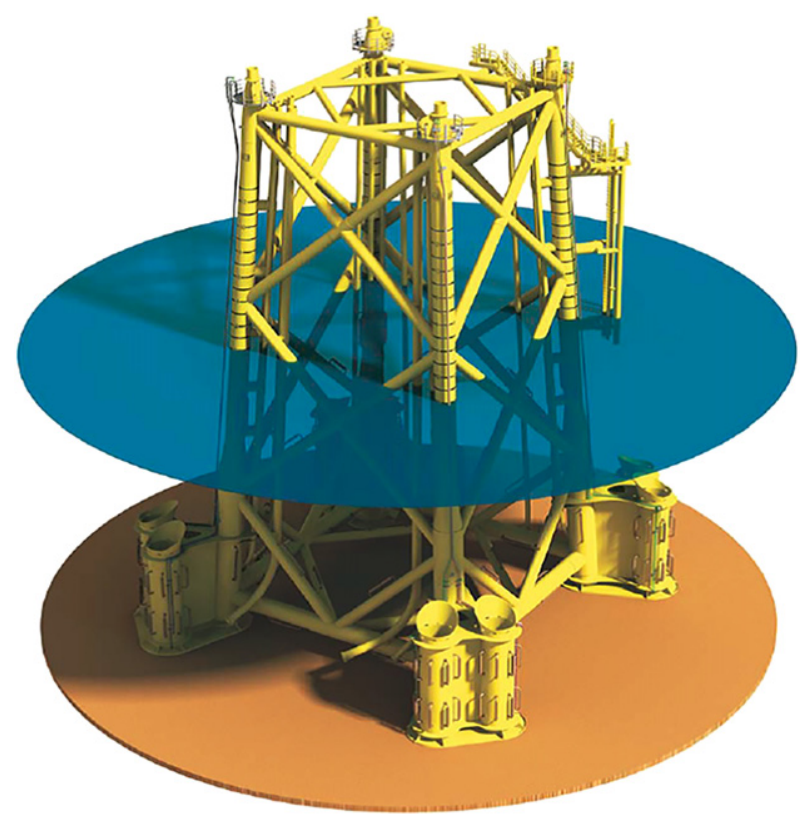

Fig. 14. Orsted's Borkum Riffgrund offshore jacket platform installed at very dense sand in German North Sea; after Jardine et al. (2015a)

University College Dublin and Grenoble $3 \mathrm{~S}-\mathrm{R}$ at the three sites where larger piles were driven and for which the results were plotted in Fig. 12. Dozens of (50 to $60 \mathrm{~mm}$ OD, approximately $2 \mathrm{~m}$ long) mild steel and stainless/galvanised steel micro-piles were tested in tension up to 2 years after driving. Carroll et al. (2019) report that the micro-piles could only develop significant set-up through corrosion reactions that both roughened the shafts and pushed the eventual shaft failure mechanism out into the sand mass. As with the larger piles in Fig. 12, the micro-piles' set-up reached stable upper limits within a year. However, even the corrodible mild steel micro-piles showed less marked set-up, at the same sites, than the larger piles. Carroll et al. (2019) conclude: (a) that physio-chemical reactions contribute significantly to steel pile set-up in sand, while also noting $(b)$ that other processes must be at play and that the ageing behaviour of piles driven in sand is diameter dependent as $(c)$ industrial scale steel and concrete driven piles show similar rates of set-up in the field. Further evidence that other mechanical processes are influential is given by the Borkum Riffgrund offshore piles' rapid $45 \%$ shaft capacity gains. It appears unlikely that corrosion reactions could have made such an impact within 1 week under the anoxic conditions applying tens of metres below the North Sea floor.

\section{Stress regime developed around displacement piles in sand}

While the Grenoble calibration chamber model pile tests could not recover the impressive field ageing gains seen with larger piles in Fig. 12, they gave new insights into the stress conditions developed during penetration in sands and provided indications that support the hypothesis that radial stress redistribution may provide a purely mechanical mechanism that contributes to the marked pile ageing behaviours of large, open-ended piles driven in sands. Multiple model pile installations in the chamber generated thousands of normal stress and shaft surface stress measurements. Jardine et al. (2013a, 2013b) present contour plots for the stresses recorded at points initially located at $2<r / R<20$ radial positions from the pile axis in the sand mass during pile 'penetrating' and 'load-off' pauses between jack strokes.
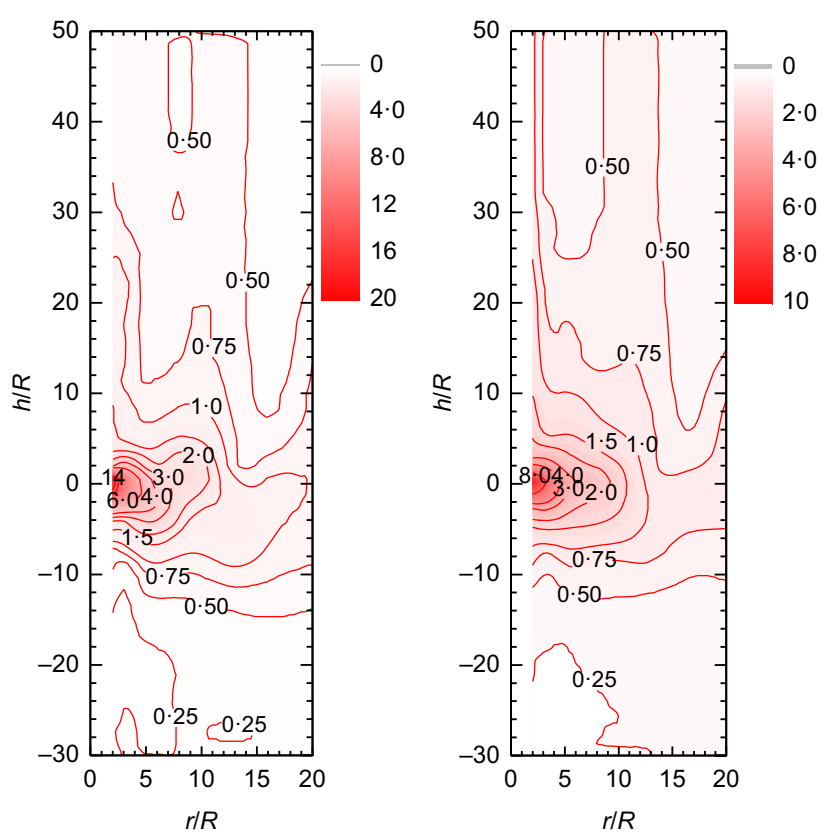

Fig. 15. Contoured distributions of radial effective stresses, normalised by local CPT $q_{\mathrm{c}}$ values (and expressed in per cent) as measured in dense NE34 sand during mini-ICP installation under $150 \mathrm{kPa}$ vertical boundary stress: (a) as pile penetrates and (b) during load pauses between jack strokes; after Jardine et al. (2013b)

Measurements could not be made closer to the pile axis at $r / R<2$. The radial effective stress $\sigma_{\mathrm{r}}^{\prime}$, trends are summarised in Fig. 15, normalised by the local CPT $q_{\mathrm{c}}$ values (typically $20 \mathrm{MPa}$ ) developed in the sand mass and shown in per cent. The radial stresses vary systematically with the relative radius from the pile axis (over the $2<r / R<20$ range) and relative vertical distance $(-30<h / R<50)$ above and below the piles' $60^{\circ}$ conical tips.

Intense stress concentration occurs at the $r / R=h / R=0$ (tip point) origin, where the average vertical effective stresses $\sigma_{z}^{\prime} \approx q_{\mathrm{c}}$, as the mini-ICP pile tip has the same geometry and size as a CPT tip. Yang et al. (2010) argue that the sand experiences high-pressure, large-strain, triaxial compression failure beneath the tip with the radial and circumferential stresses achieving maxima of $\sigma_{z}^{\prime} K_{\mathrm{A}}$, where $K_{\mathrm{A}}=\tan ^{2}\left(45+\phi_{\mathrm{cs}}^{\prime} / 2\right)$. Critical state $\phi_{\mathrm{cs}}^{\prime} \approx 30^{\circ}$ for NE34 under the conditions imposed (Altuhafi \& Jardine, 2011), giving $\sigma_{\mathrm{r}}^{\prime}=\sigma_{\theta}^{\prime} \approx q_{\mathrm{c}} / 3$ on the $r / R=0$ axis and stresses that exceed those measured by the nearest sand mass radial stress sensors, which were positioned at $r / R=2$ prior to pile installation. The stresses decay away sharply with distance from the tip. The radial stresses measured higher on the shaft are only a small fraction of the maxima developed when the tip first arrived at the same depth, leaving the sand heavily pre-loaded and pre-sheared as the pile advances through each horizon. Each jack stroke (or driving blow) also imposes a full cycle of normal stress changes (as shown by the different stress distributions applying to penetrating and pause stages) and shaft shear failure, from downward slip to upward rebound.

Adding the on-pile surface stress measurements allowed the radial stresses to be monitored at $r / R=1$ for fixed $h / R$ values. The circumferential stress components cannot be sensed at the shaft and are harder to measure in the sand mass. Cylindrical equilibrium was invoked to develop the radial distributions of $\sigma_{\mathrm{r}}^{\prime}$ and $\sigma_{\theta}^{\prime}$ plotted in Figs 16(a) and $16(\mathrm{~b})$. The profiles, which cover the stress conditions applying after the end of installation, are normalised by CPT 
$q_{\mathrm{c}}$ and plotted against $r / R$ for four positive values of $h / R$. The interpretation made by Jardine et al. (2013b) assumed that vertical shear stresses $\tau_{\mathrm{r} z}$ were negligibly small on the shaft and in the soil mass after the end of jacking, when no pile head load was applied, to help derive consistent stress

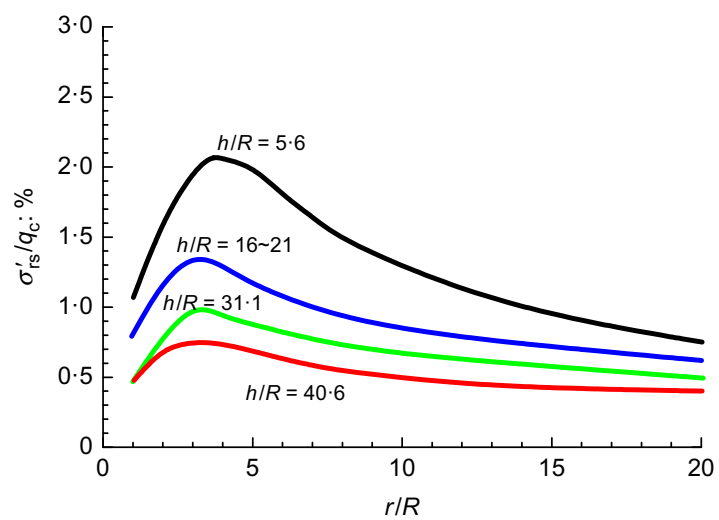

(a)

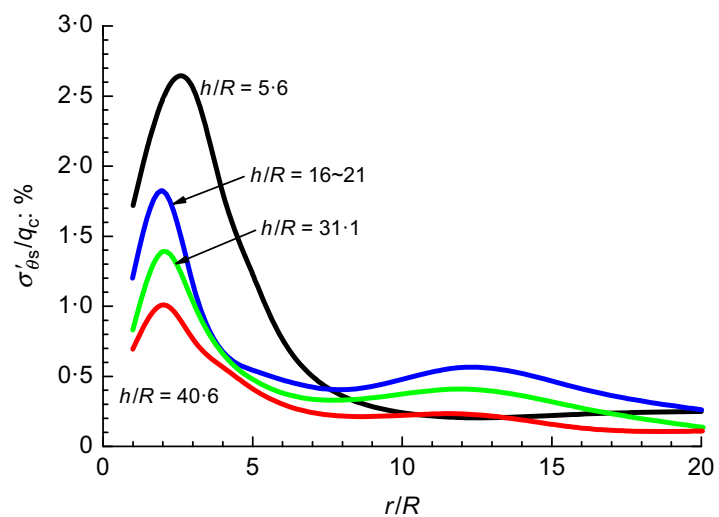

(b)

Fig. 16. Effective stresses measured in NE34 sand mass at end of mini-ICP installation in calibration chamber, normalised by local CPT $q_{\mathrm{c}}$ values and plotted against radius $r$, normalised by pile radius, $R$ : (a) radial stresses; (b) circumferential stresses; after Jardine et al. (2013b) distributions for the axially symmetric system. However, it is acknowledged that small, residual, locked-in pile tip loads were noted experimentally that would have provoked balancing shaft shear stresses.

The radial stresses measured in the sand mass after the end of all jacking exceeded those measured on the pile shaft with the mini-pile surface stress transducers (SSTs). As shown in Fig. 16, the $\sigma_{\mathrm{r}}^{\prime}$ and $\sigma_{\theta}^{\prime}$ distributions show distinct maxima at 2 to 4 relative radii $(r / R)$ from the pile axis. This indicates that the pile shaft is shielded by circumferential arching in the sand mass. Any weakening of the arching action over time due to creep in the sand (following the extreme stress changes imposed by driving) or by moderate load cycling could lead to stress redistribution and radial shaft stress (and capacity) increases at the interface. As argued earlier, the degree of stress redistribution that could take place in the calibration chamber experiments may have been reduced by the relatively high thickness of the crushed sand zone compared to the pile diameter; the redistribution mechanism could prove far more important with larger industrial-scale piles. The sand stress distributions are also likely to be affected by details of the pile tip geometries as well as particle-scale processes, such as grain crushing, local densification and shaft abrasion (Yang et al., 2010).

The Grenoble experiments provide benchmarks against which analyses may be tested. Professor Einav's group at the University of Sydney was the first to attempt predictions. Zhang et al. (2013) applied an arbitrary LagrangianEulerian (ALE) FE analysis to model monotonic pile penetration within the Grenoble calibration chamber shown in Fig. 13, incorporating a grain crushing model calibrated to the NE34 sand laboratory tests reported by Altuhafi \& Jardine (2011). Fig. 17 presents their matches for (a) the pile tip base resistances, $q_{\mathrm{b}}$ (which equal $q_{\mathrm{c}}$ for the conically tipped mini-ICP), as a function of penetration depth $S$ into the chamber, $(b)$ the distributions of particle breakage, as represented by their parameter $B$. The analyses predict encouraging matches with the experimental measurements. Fig. 18 adds the $\sigma_{\mathrm{r}}^{\prime}$ and $\sigma_{\theta}^{\prime}$ distributions predicted around the piles in further collaborative analyses made with the same authors, models and geometry, as reported by Zhang et al. (2014). The soil stress predictions share many features with the experiments in Fig. 16, including the

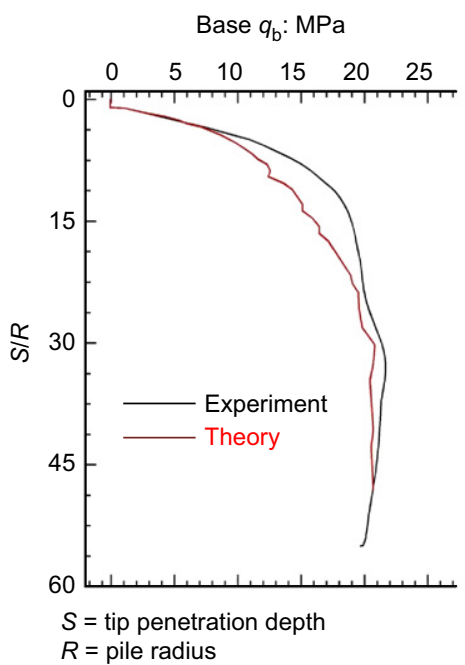

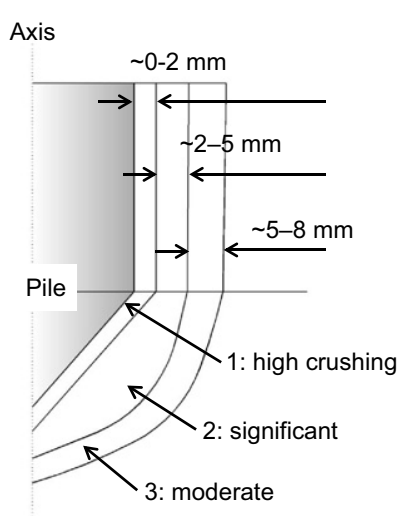

(b)

Grain breakage

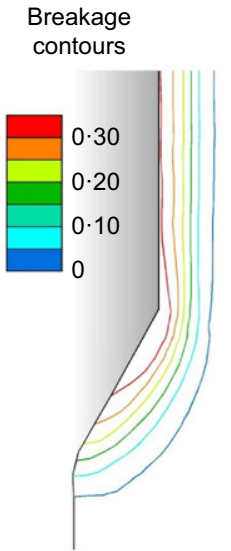

(c) None $B=0$, full $B=1$

(a)

Fig. 17. Pile tip failure for mini-ICP during penetration in NE34 sand in calibration chamber. (a) Tip stresses $q_{\mathrm{b}}$ measured by Yang et al. (2010) plotted against penetration depth $S$, compared with predictions from ALE FE modelling with crushable grain model by Zhang et al. (2013). (b) Failure system and particle breakage zoning observed by Yang et al. (2010). (c) Particle breakage pattern predicted around tip by Zhang et al. (2013) 


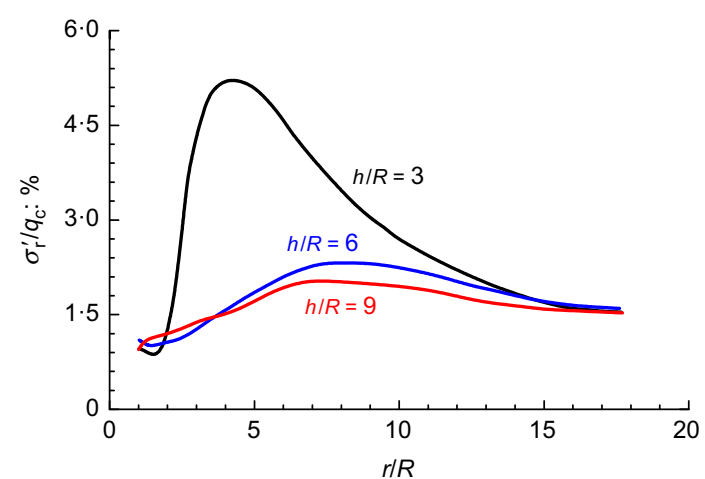

(a)

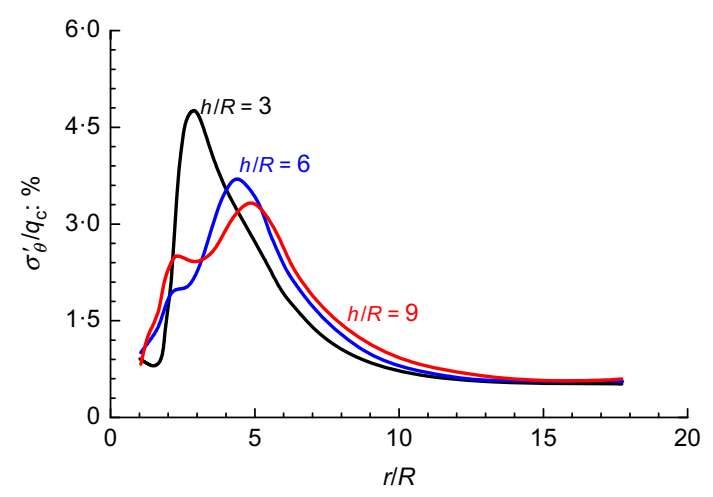

(b)

Fig. 18. Effective stresses predicted by ALE FE modelling with crushable grain model for sand mass of calibration chamber during mini-ICP installation, normalised by $q_{\mathrm{c}}$ values and plotted against radius $r / R$ : (a) radial stresses; (b) circumferential stresses; after Zhang et al. (2014)

arching mechanism, the maxima developing at modest $(3<r / R<7)$ radial distances from the shaft and the approximate order of the maximum stress values (2 to $6 \%$ of $q_{\mathrm{c}}$ ). Refinement appears necessary to improve the predictions of how stresses vary with $h / R$. Zhang et al. (2014) propose that incorporating cyclic loading action and shaft abrasion could help to bring the analysis closer to the experimental observations.

Discrete-element analyses have also been made of the experiments by Ciantia (personal communication, 2016), whose simulations employed $5 \times 10^{5}$ crushable, oversized $\left(8.5 \mathrm{~mm} D_{50}\right)$ particles, configured to replicate the laboratory behaviour of NE34 sand, which has $D_{50} \approx 0.2 \mathrm{~mm}$. He also had to restrict the diameter and height of his 'virtual calibration chamber' to smaller dimensions (with radius 12 times pile radius $R$ and total depth of $50 R$ ) than those employed in the Grenoble experiments to allow his DEM analyses runs, which were conducted with a powerful work station, to complete within around 1 month each. Ciantia (personal communication, 2016) applied stiffness-controlled boundary conditions to reduce the effects of his virtual chamber's reduced scale. His relatively large DEM particles inevitably led to scatter that called for careful numerical smoothing. However, Ciantia was able to achieve good matches for the experimentally observed base resistancepenetration profile, patterns of grain breakage and stress regime around the pile shaft. Fig. 19 presents his stress distributions, adopting the same axes as Figs 16 and 18.

It is reassuring that similar results are emerging from such different numerical analyses. Work is now progressing to consider a wider range of cases and pile tip geometries, including open-ended tubular piles. Promising preliminary results are emerging from FE analyses conducted with ALE

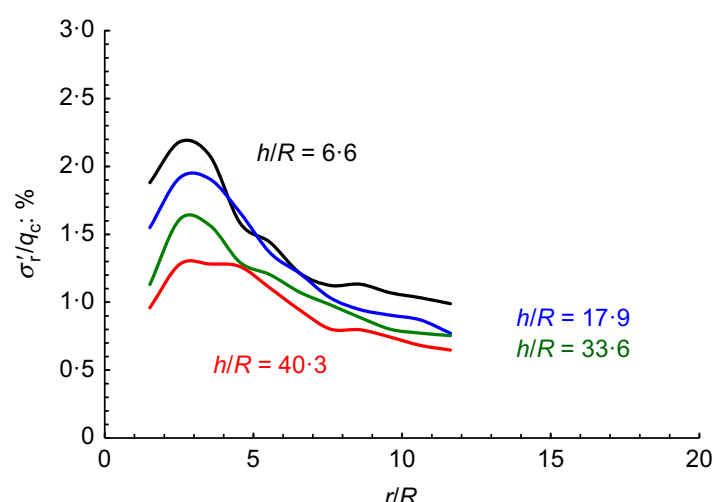

(a)

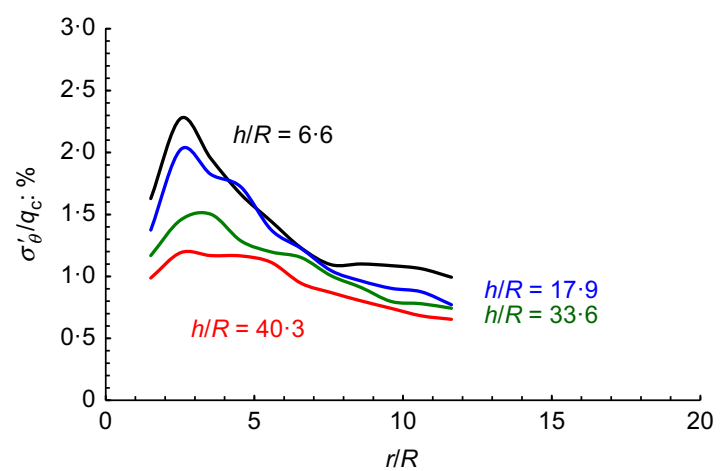

(b)

Fig. 19. Effective stresses predicted by DEM modelling with crushable grain model for sand mass of calibration chamber during mini-ICP installation, normalised by $q_{\mathrm{c}}$ values and plotted against radius rIR: (a) radial stresses; (b) circumferential stresses; after Ciantia (personal communication, 2016)

and coupled Eulerian-Lagrangian (CEL) approaches in studies of pipe pile penetration in sands, as reported by Guo (2017). However, it appears that particle-scale phenomena will have to be modelled to capture any dependency on pile diameter of the stresses around driven piles. Time-dependent particulate behaviour or interface resistance laws will have to be introduced to capture these aspects of field ageing behaviour.

\section{Field research into the impact of cyclic loading}

The seven, industrial-scale, $457 \mathrm{~mm}$ OD, plain steel piles driven at Dunkirk were employed to investigate the macroscale impact of axial cyclic loading. Jardine \& Standing (2012) report 12 (one-way) tests that involved only tension loading and a pair of two-way experiments that spanned from compression to tension loading. All applied regular load-controlled cycles with periods around $60 \mathrm{~s}$. Cyclic failure - defined as when either axial movements gradually approached $10 \%$ of pile diameter, or when the cyclic deflections grew so sharply with each additional cycle that the tests could not be controlled - was reached in 11 cases; two other tests were halted without failure after around 200 cycles and one other after 1000 cycles. Static tests were conducted, in addition to those in Fig. 11, to track the variations of tension capacities $\left(Q_{\mathrm{T}}\right)$ due to time and load cycling.

The impact of each batch of cycles depended critically on $N$, the number of cycles imposed and the loading variables, defined in Fig. 20 as the mean cyclic head load $Q_{\text {mean }}$ and (half peak-to-trough) cyclic amplitude $Q_{\text {cyclic }}$. These loads are normalised by the tension capacity, $Q_{\mathrm{T}}$, that was assessed from parallel tests as applying just before load cycling 


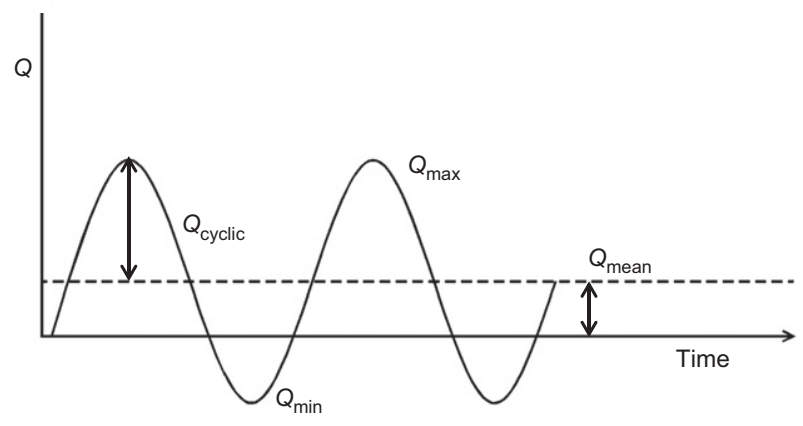

Fig. 20. Definitions of cyclic loading variables

commenced. Static tension tests to failure were conducted after each cyclic experiment. Summary three-dimensional (3D) diagrams presented by Rimoy et al. (2013) showed how cyclic stiffness and permanent displacements varied systematically with $N$ and the normalised cyclic loading parameters. Jardine \& Standing (2012) presented the overall summary cyclic interaction diagram given in Fig. 21, which records the loading parameters and number of cycles $N$ value associated with each experiment, and identified three broad styles of response, as follows.

(a) Stable and benign, with no significant change in stiffness or permanent displacement drift.

Tension capacity grew slightly rather than degraded.

(b) Unstable, with failure ensuing within 100 cycles and tensile capacity losses that were confirmed by the post-cyclic failure static tests. Shaft capacity was halved within tens of cycles under the most severe two-way loading cases, which involve high $Q_{\text {cyclic }}$ and $Q_{\text {mean }}=0$. Jardine et al. (2012) recommend that designers avoid loading piles within this region by applying load or resistance factors that become progressively more onerous as $Q_{\text {cyclic }} / Q_{\text {mean }}$ rises.

(c) Metastable, where failure is reached within hundreds of cycles, but capacities and stiffness degrade, and permanent displacements accumulate, at low initial rates. Modest numbers of such cycles may be sustained without significant degradation.

An example of a metastable, almost unstable, test is shown in Fig. 22. Significant displacement accumulation was delayed under one-way cycling with $Q_{\max }=Q_{\text {mean }}+Q_{\text {cyclic }}=0.84 Q_{\mathrm{T}}$ until $N$ exceeded 50, after which movements grew. The last few cycles imposed at $N>200$ led to a pull-out failure and a post-cyclic failure static test confirmed a 16\% loss of shaft capacity.

Jardine (1991) reviewed the near shaft soil boundary conditions illustrated in Fig. 23 and noted that under purely axial loading: (a) the circumferential strains must be zero close to the relatively rigid shaft due to axial symmetry; (b) vertical strains would be very small with the stiff steel piles until local slip occurs; and (c) any radial straining is resisted by the shear stiffness of the surrounding soil mass (as indicated by equation (5)). He also noted from limited sets of ICP tests undertaken by Lehane (1992) in loose Labenne sand that cycling impacts negatively on shaft capacity through the local $\sigma_{\mathrm{r}}^{\prime}$ stresses unloading and the local $\tau_{\mathrm{r} z}-\sigma_{\mathrm{r}}^{\prime}$ effective stress paths drifting towards interface failure and slip. The Labenne tests involved fully drained conditions, so the effective stress changes that led to the losses of shaft capacity must reflect total radial stress reductions developing around the pile shafts. Jardine et al. (2012) note that the highly kinematically constrained near shaft boundary conditions outlined above give rise to effective stress paths which

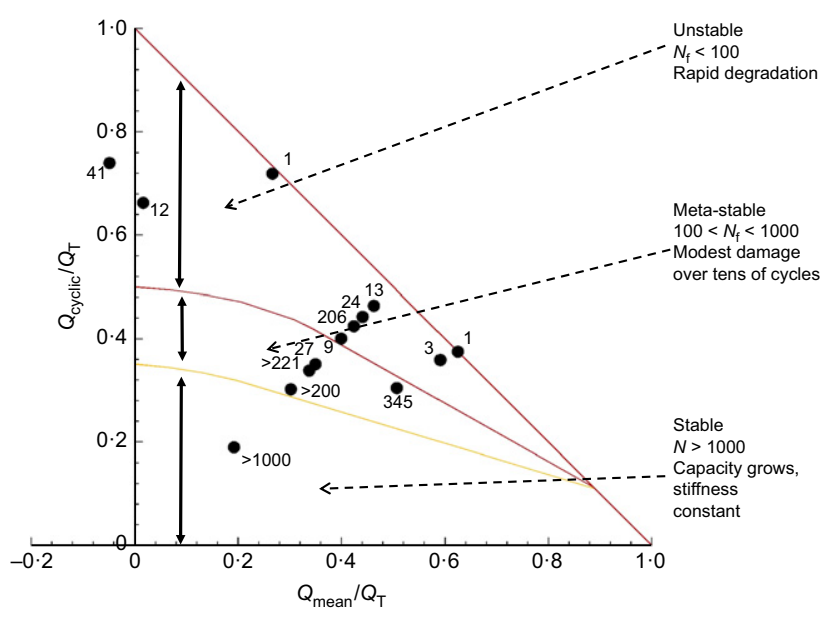

Fig. 21. Global cyclic interaction diagram for $457 \mathrm{~mm}$ OD steel tubular piles tested under axial cycling at Dunkirk test site; after Jardine \& Standing (2012), showing zones of stable, metastable and unstable cyclic responses

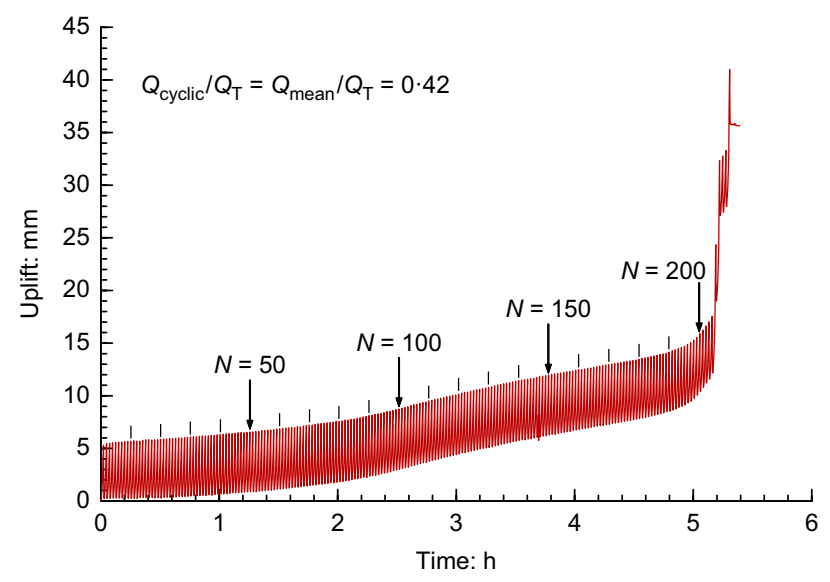

Fig. 22. Example of metastable outcome from cyclic test on $457 \mathrm{~mm}$ OD steel tubular pile at Dunkirk test site; after Jardine \& Standing (2012)

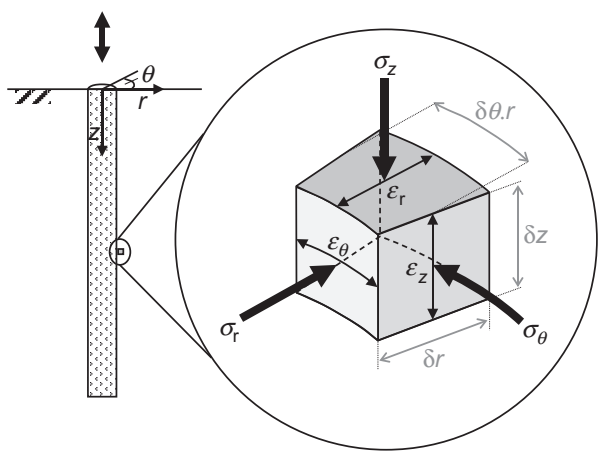

Fig. 23. Stress system close to displacement pile shaft, with vertical and circumferential strains limited to very low values and radial straining constrained by stiffness of surrounding soil mass; after Jardine (1991)

resemble those seen in constant volume or constant normal stiffness shear tests.

The French national SOLCYP (comportement des pieux soumis à des sollicitations cycliques) programme of research into pile cyclic loading response incorporated new cyclic loading tests in similar Flandrain sand at Loon Plage, about 
$5 \mathrm{~km}$ south of the ICP Dunkirk site, employing a range of different pile technologies, as reported by Puech (2013). The bored piles tested by SOLCYP responded to cyclic loading in a far less satisfactory manner than that proven in either the Imperial College driven pile tests summarised in Figs 21 and 22 , or a limited programme of cyclic tests by the SOLCYP team on piles driven at Loon Plage. Installation method clearly affects the shaft effective stress paths that develop under cyclic (and static) shaft loading. The pre-stressing and pre-cycling imposed by displacement piling leads to a more robust response to cyclic loading in service. Driving also appears to trigger one or more beneficial ageing processes; bored concrete piles do not show the set-up exhibited by driven concrete piles.

\section{Model pile tests to establish local stress conditions under cyclic loading}

It is very difficult to measure in situ effective stresses reliably on (or around) piles driven dynamically in the field. However, Tsuha et al. (2012) and Jardine et al. (2013a) report on the effective stresses developed on the mini-ICP surface and in the surrounding sand mass during cyclic and static loading tests in the Grenoble calibration chamber, relating these to the kinematic yielding behaviour seen in static triaxial stress path tests. Examples of the shaft effective stress paths followed with the mini-ICP's SSTs are plotted, in $\tau_{\mathrm{r} z}-\sigma_{\mathrm{r}}^{\prime}$ coordinates, in Fig. 24. Fig. 24(a) displays the paths followed at three instrument positions in a stable load-controlled cyclic test, where steeply inclined and closed effective stress loops developed that were practically stationary over $1000 \mathrm{~s}$ of cycles, with no permanent displacement developing and modest capacity increases ensuing after cycling. The stable local effective stress paths lie well within the sand-steel $\delta^{\prime}$ failure envelope, as defined from interface ring shear tests. In contrast, Fig. 24(b) displays the paths from a fully unstable displacement-controlled test in which the pile was moved sufficiently for the local $\tau_{\mathrm{r} z}-\sigma_{\mathrm{r}}^{\prime}$ effective stress paths to engage the interface Coulomb failure envelope during the first cycle, and on the upward and downward portions of each subsequent test stroke. The effective stresses are constrained by the $\delta^{\prime}$ failure envelopes and form broad hysteretic 'butterfly wing' shaped paths that migrate sharply to the left. Shaft resistance falls and displacements grow markedly with each cycle.

Multiple metastable tests were also undertaken. The kinematically constrained near-shaft boundary conditions discussed above led to slow effective stress path drifts to the left, which resemble those seen in constant volume or constant normal stiffness shear tests. While one experiment was undertaken with wet sand, the others were conducted dry and all were fully drained. The experiments reported by Tsuha et al. (2012), Rimoy (2013) and Silva (2014) were integrated to develop cyclic interaction diagrams (equivalent to that for Dunkirk in Fig. 21) that covered jacked and driven piles, as well as the finer GA39 grade of Fontainebleau sand. Summary 3D plots described how the cyclic and permanent displacements varied with the cyclic loading variables.

\section{Approaching cyclic design for driven piles}

There is no internationally recognised approach for cyclic pile design. However, the SOLCYP project developed a workflow scheme, reproduced in Fig. 25, which recognises global, local and full numerical design routes. The process starts with screening checks made with interaction diagrams of the type given in Fig. 21; designers need to consider more detailed site-specific analyses when screening suggests significant potential cyclic degradation. Jardine et al. (2005a)

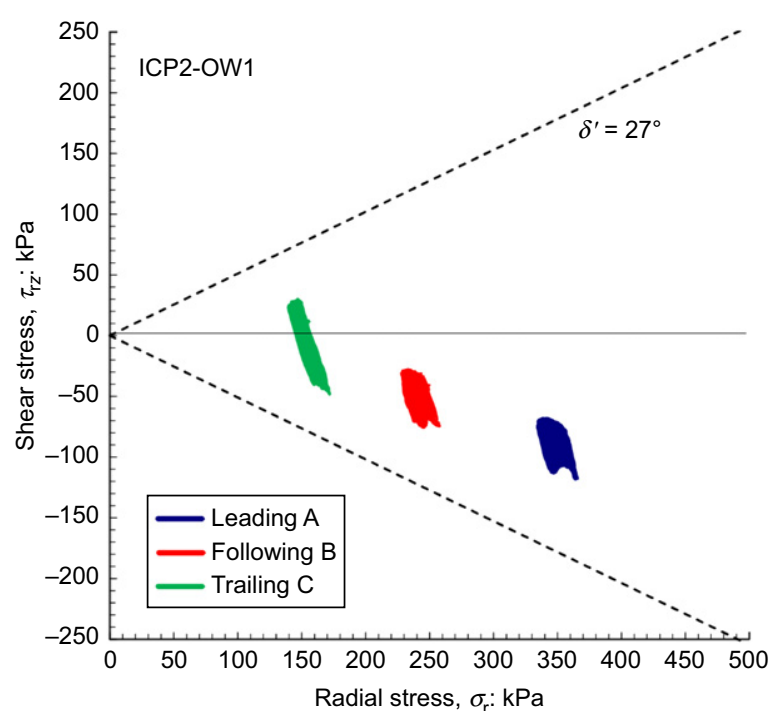

(a)

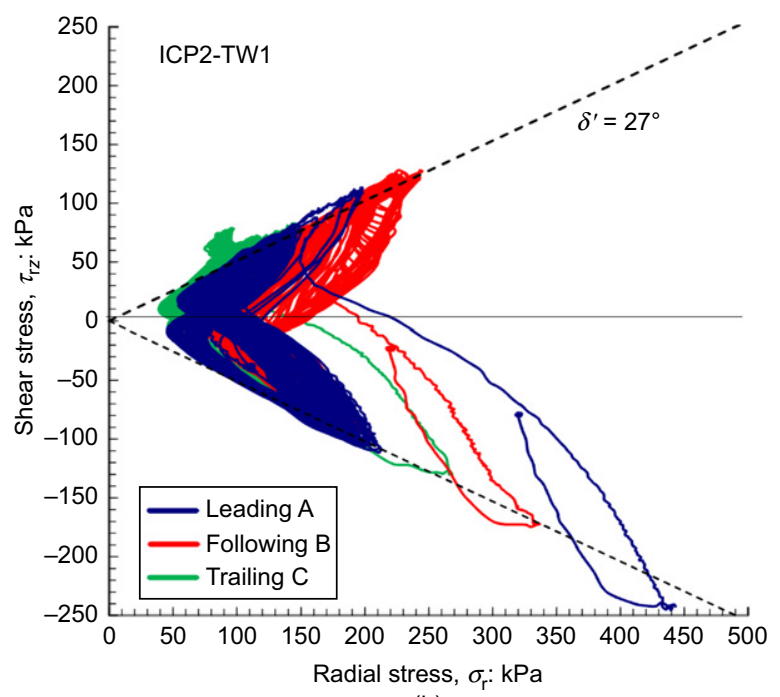

(b)

Fig. 24. Local shaft shear-to-radial effective stress paths measured at three levels on mini-ICP during cyclic testing. (a) Stable test taken to thousands of cycles under load control. (b) Unstable test undergoing cyclic failure under displacement control; $150 \mathrm{kPa}$ vertical boundary stress; after Tsuha et al. (2012)

proposed expressions, including the simple ' $A, B, C$ ' approach given in equation (7) to characterise the local rates of $\sigma_{\mathrm{r}}^{\prime} \mathrm{drift}$ from field, model or laboratory tests. Combining this with equations (1)-(6) offers a way to predict the number of cycles required to reach shaft failure under constant regular cycling.

$$
\Delta \sigma_{\mathrm{r}}^{\prime} / \sigma_{\mathrm{r} 0}^{\prime}=A\left[B+\tau_{\text {cyclic }} / \tau_{\text {max static }}\right] N^{C}
$$

In equation (7), $\sigma_{\mathrm{r} 0}^{\prime}$ is the initial radial effective stress acting on the shaft; $\tau_{\text {cyclic }}$ is the amplitude of the cyclic shaft shear stresses $\left(\tau_{\mathrm{r} z}\right)$; and $\tau_{\max }$ static is the initial static shaft capacity applying before cycling starts. The expression was built into cyclic $t-z$ analyses of full piles in joint analyses of the Dunkirk cyclic tests undertaken by Atkins (2000). Here the $\sigma_{\mathrm{r}}^{\prime}$ drift rates were assumed independent of the mean shear stress imposed, which Aghakouchak (2015) and Rattley et al. (2017) found reasonable for metastable conditions but less applicable to unstable cycling.

Jardine \& Standing (2012) showed how the equivalent global capacity expression, equation (8), can be manipulated 


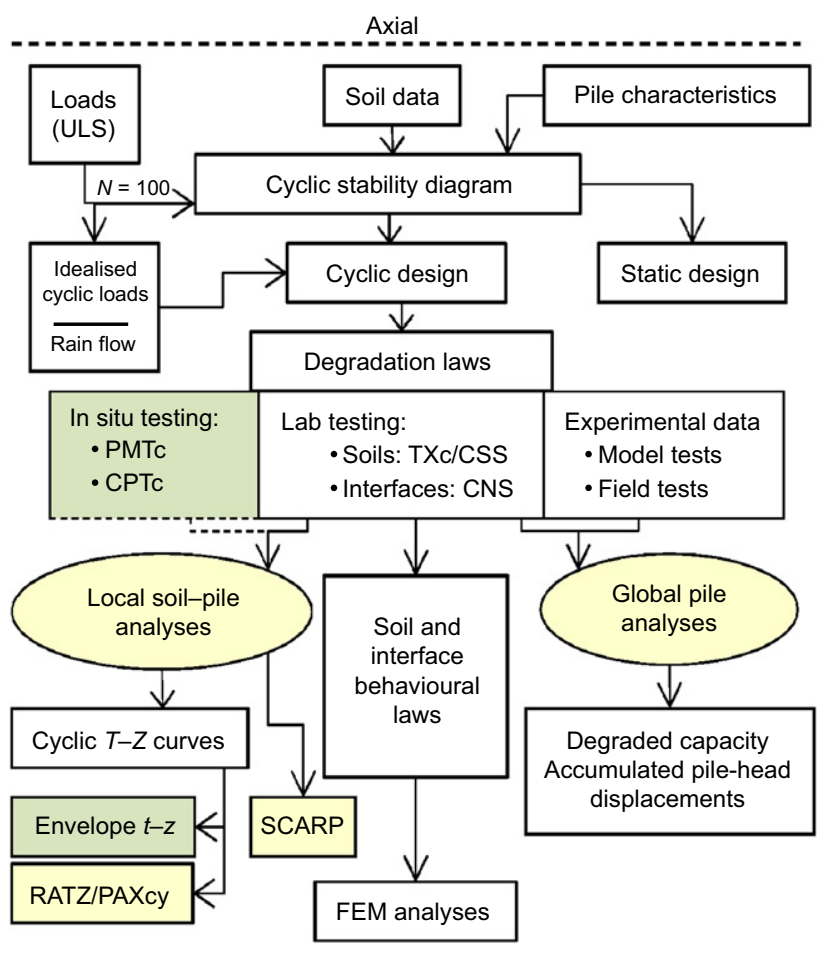

Fig. 25. SOLCYP workflow process for use in design of piles to carry axial cyclic loading; after Jardine et al. (2012)

to project boundaries for interaction diagrams such as Fig. 21. Such charts can only apply to relatively uniform ground profiles and may be pile-scale dependent. Local $(t-z$ or other) cyclic analyses, or field tests at different scales, are required to confirm whether piles driven to greater penetration depths experience more progressive cyclic 'unzipping'.

$$
\Delta Q / Q_{0}=A\left[B+Q_{\text {cyclic }} / Q_{\mathrm{T}}\right] N^{C}
$$

Offshore storms apply irregular cycling. 'Rainflow' and 'equivalent number of cycles' methods are often applied in analyses of gravity base (GBS) and other structures to transform real storms into batches of regular cycles whose impact is considered additively, assuming that Miner's rule holds; see Andersen (2015). While approximate and simplified, this approach provides a tractable and probably conservative way of assessing cyclic effects, which have otherwise been ignored in practical pile design. A key question, however, is how to find a reliable means of estimating the parameters required to apply equations (7) and (8) or any other cyclic assessment procedure.

\section{Stress-path laboratory tests to model driven pile shaft} responses to cyclic loading

Field and model tests can be run for onshore civil engineering applications to develop global cyclic model parameters. However, site-specific programmes are rarely feasible offshore and reliance has to be placed on laboratory tests. Puech's (2013) observations on the markedly different cyclic behaviours of bored and driven piles underscore the importance of capturing the piles' installation stress histories when designing laboratory tests to model cyclic shaft loading.

Aghakouchak et al. (2015) and Aghakouchak (2015) consider how such conditioning could be achieved in triaxial and hollow cylinder apparatus (HCA) tests. Multiple trials led to practical procedures. Saturated water-pluviated specimens were adopted to match the sands' in situ state and fabric. These were subjected to the effective stress paths illustrated in Fig. 26, which involved consolidating (under $K_{0}$ conditions for simplicity) to the maximum stresses that could be imposed practically, representing conditions as the pile tip approaches any given layer from above. An unloading stage follows to model the pile tip advancing to greater depth. Aghakouchak et al. (2015) report that reducing the mean effective stress fourfold was sufficient. Drained pre-cycling was also applied (at point $\mathrm{C}$ in Fig. 26) to match the displacement pile paths, along with $48 \mathrm{~h}$ pauses at points $\mathrm{B}$ and $\mathrm{D}$, over which drained residual creep strain rates diminished to very low values.

The overall impact of the conditioning steps is illustrated in Fig. 27 by undrained cyclic triaxial tests on identically formed Dunkirk sand samples that each imposed 100 cycles

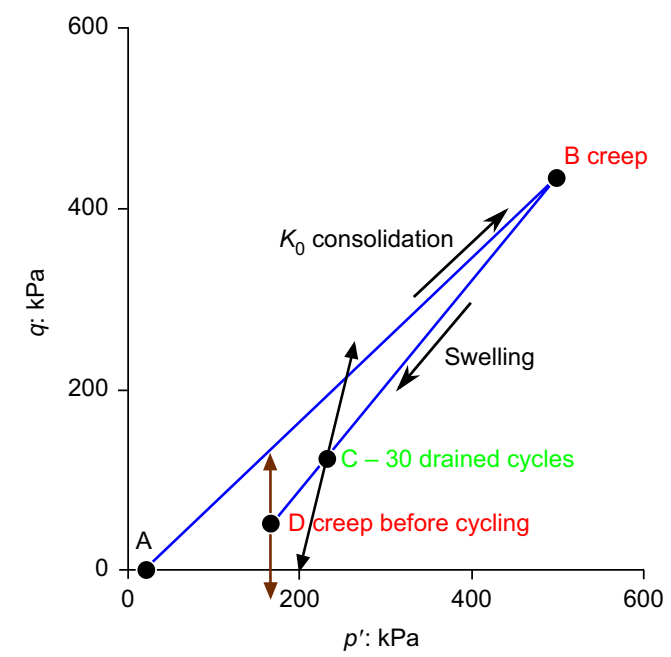

Fig. 26. Effective stress path followed in triaxial tests designed to simulate installation and shaft loading processes observed in Dunkirk and calibration chamber pile experiments; after Aghakouchak et al. (2015)

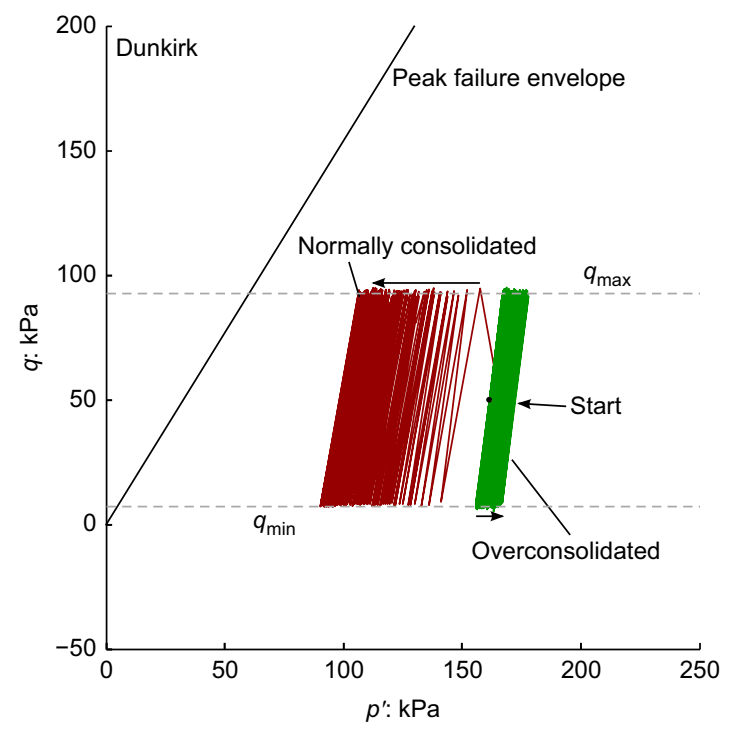

Fig. 27. Impact of applying effective stress path outlined in Fig. 26 on effective stress path response of dense Dunkirk sand under undrained triaxial cycling at $\mathrm{CSR}=\mathbf{0 \cdot 2 5}$. Note contrasting outcomes of 'overconsolidated' sample conditioned to represent driven pile case, with 'normally consolidated bored' pile test; after Aghakouchak et al. (2015) 
with a cyclic stress ratio $(\mathrm{CSR})=q_{\text {cyclid }} / p_{0}^{\prime}=0 \cdot 25$, where $p_{0}^{\prime}$ is the initial mean effective stress. The 'driven pile' sample, which had experienced all the above conditioning steps, responded entirely stably under this level of cyclic loading, with $p^{\prime}$ increasing marginally rather than falling. However, the sample that followed the 'bored pile' stress path by cycling at $\mathrm{OCR}=1$, employing the same stress levels, responded by reducing $p^{\prime}$ by $40 \%$. Bored piles show greater degradation because they have not experienced pre-stressing or precycling. Furthermore, they are not constrained by interface shearing $\delta^{\prime}$ angles that fall below the soils' $\phi^{\prime}$ values and so truncate, as demonstrated in Fig. 24, the loading effective paths that would otherwise lead to larger plastic strains in the surrounding soil.

Randolph \& Wroth (1981) argued that undrained simple shear tests that 'rotated' the near shaft pile stress regime shown in Fig. 23 through $90^{\circ}$ provided a good model for assessing the loading response when dealing with low-OCR clays. Jardine et al. (2012) concluded that the near shaft kinematic conditions outlined earlier allow the pile shaft stresses that develop in response to cyclic loading to be represented and tracked in a similar manner through simple shear tests conducted in HCA. The HCA experiments suffer from less stress non-uniformity than conventional simple shear tests, due to their annular shapes. In addition to sensing the average shear and normal effective stresses as in standard simple shear tests, the HCA experiments also measure all three principal stresses, the pore water pressures and variations over each cycle of $\alpha$, the angle that the $\sigma_{1}$ axis subtended to the vertical. The 'normal-stiffness' relationship between the HCA tests' vertical displacements and stresses should represent the radial movement-stress 'normalstiffness' relationship imposed by the sand surrounding the pile shaft. However, as specified in equation (5), the normal stiffness relationship involves pile radius $R$ and sand shear stiffness $G$. Because $G$ is pressure and strain level dependent and may be anisotropic, it is difficult to select single values for any point on the shaft, or a representative average for the whole pile. Constant volume conditions, which imply infinite normal stiffness, were chosen to provide safe estimates for the local soil response. The HCA tests were therefore conducted undrained. Routine constant volume cyclic simple shear tests can achieve similar results, although with less precision and without the same insight into the test specimens' stress states. Cyclic triaxial tests may serve a similar purpose, provided their interpretation recognises their different shearing conditions.

Aghakouchak (2015) applied the above conditioning steps in multiple HCA and triaxial tests on Dunkirk and Fontainebleau NE34 sands before imposing batches of up to 5000 regular, undrained shear loading cycles. His samples' initial relative densities (around 75\%) and stress states matched the Dunkirk field and Grenoble calibration chamber conditions. His triaxial tests involved modified Bishop and Wesley stress path cells equipped with highresolution strain sensors, while his HCA experiments were conducted in the equipment depicted in Fig. 28 and the steps described by Nishimura (2006) and Anh-Minh et al. (2011) were applied to maintain simple shear conditions through a combination of mechanical and servo-controls.

Applying the laboratory tests to predict cyclic pile response

Examples of 'driven pile' cyclic triaxial element tests are presented in Fig. 29, which shows the proportional $\Delta p^{\prime} / p_{0}^{\prime}$ drifts developed over regular 4500 cycles by seven identical specimens of Dunkirk sand and a parallel set for NE34 sand under fixed CSRs ranging from $0.05 \leq q_{\text {cyclid }} / p_{0}^{\prime} \leq 0 \cdot 6$. Cycling at CSR $<0.25$ led to fully stable responses and

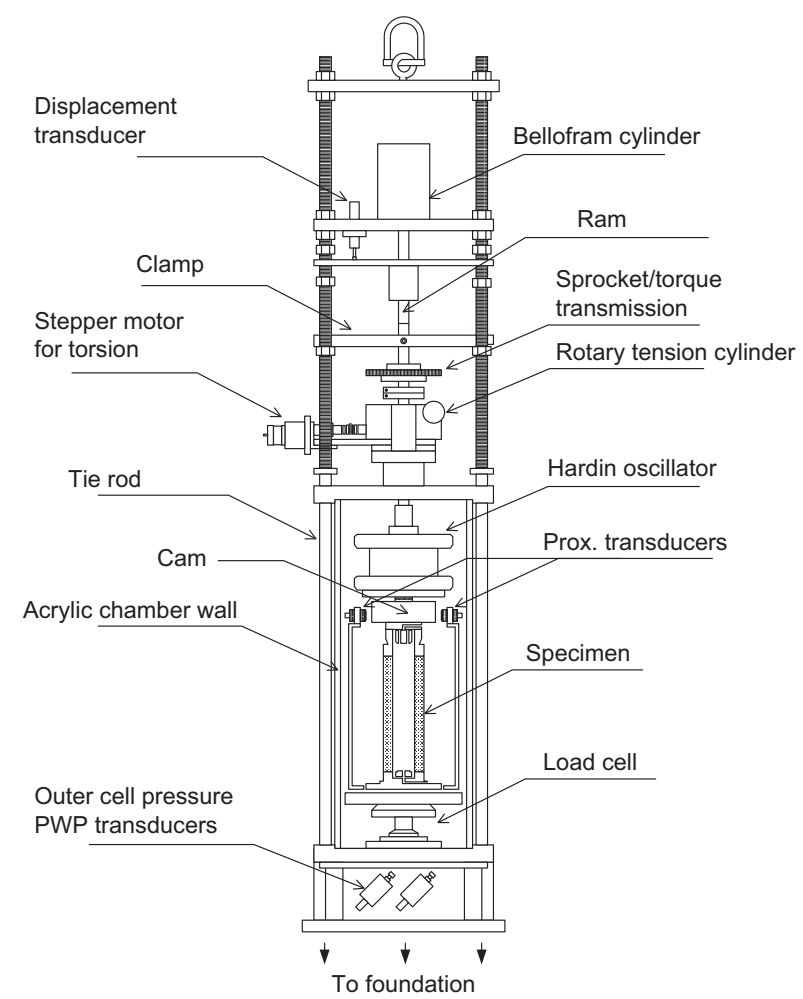

Fig. 28. Hollow cylinder apparatus employed for 'driven pile' cyclic test simulations, after Nishimura (2006). Prox., proximity; PWP, pore water pressure

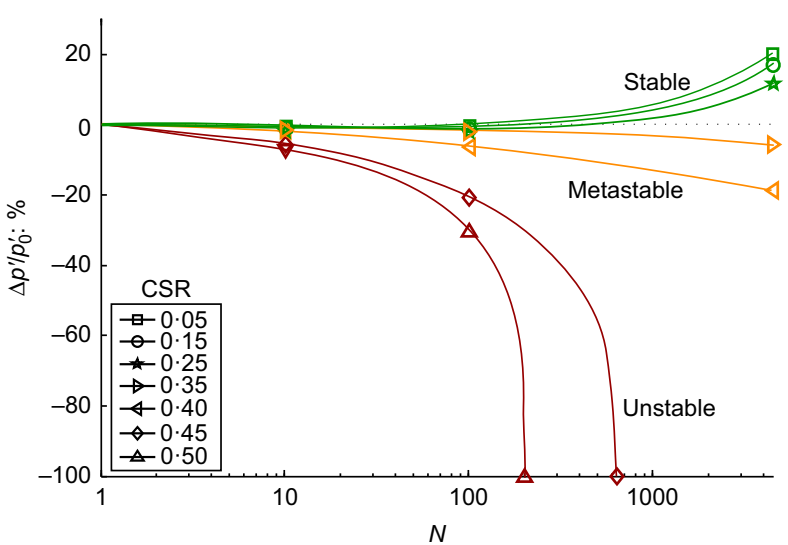

(a)

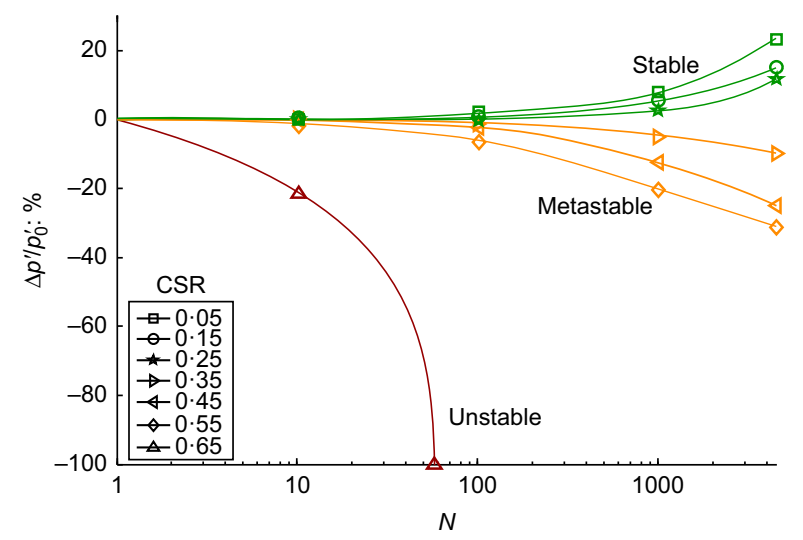

(b)

Fig. 29. Mean effective drift responses of dense sands under undrained triaxial cycling at seven CSRs: (a) Dunkirk sand; (b) NE34 sand, all preconditioned to simulate driven piles, as shown in Fig. 26; after Aghakouchak et al. (2015) 
positive $p^{\prime}$ changes with both sands. As shown by Aghakouchak et al. (2015), the high-resolution local gauges indicated similarly stable strain and stiffness trends. Two of the Dunkirk samples and one NE34 specimen responded to high-level cycling by developing marked losses (20 to 40\%) of $p^{\prime}$ over their first 100 cycles and progressed to full cyclic failure. Tests at intermediate CSRs developed metastable responses where significant $p^{\prime}$ reductions took place over hundreds and thousands of cycles, accompanied by permanent strains and stiffness reductions. Dunkirk sand proved marginally more susceptible to cycling than Fontainebleau NE34 sand.

The equivalent families of HCA test curves are presented in Fig. 30. Although the results can be plotted with the same axes as the triaxial tests, they are presented here as $\Delta \sigma_{z}^{\prime} / \sigma_{z 0}^{\prime}$ drifts against $N$. In the 'rotated' HCA tests $\sigma_{z}^{\prime}$ is equivalent to the radial effective stress acting against the pile shaft. Five CSRs were applied ranging from $0 \cdot 05 \leq \tau_{\text {cyclid }} p_{0}^{\prime} \leq 0 \cdot 45$. CSRs below $0 \cdot 20$ led to a fully stable response with both sands, while cycling at CSR above 0.30 led to unstable outcomes and a metastable response was seen between these limits. As with the triaxial tests, the strain and stiffness trends were fully consistent, and Dunkirk sand appeared marginally more susceptible to cycling than NE34 sand.

Aghakouchak (2015) showed how the ratio of the mean to (normal) vertical effective stress $\left(p_{0}^{\prime} / \sigma_{z}^{\prime}\right)$ varies gradually during undrained simple shear cycling. This allowed him to examine his HCA and triaxial experiments' ability to predict

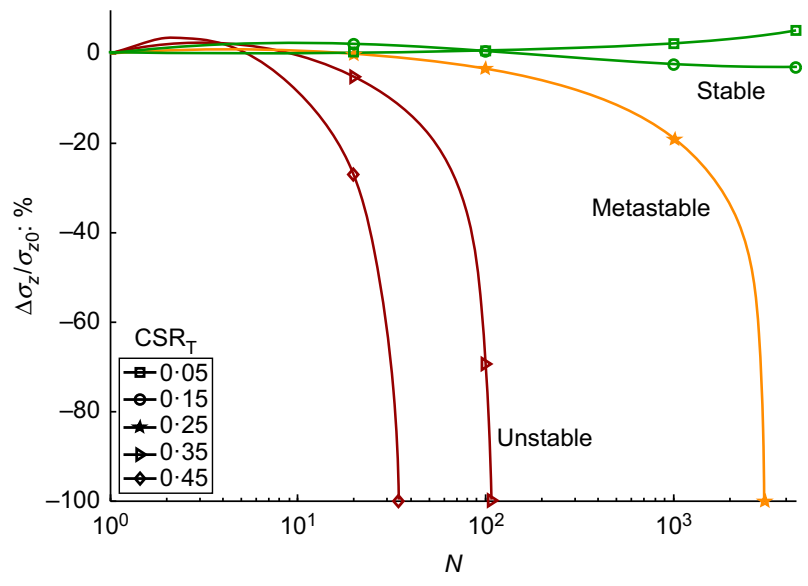

(a)

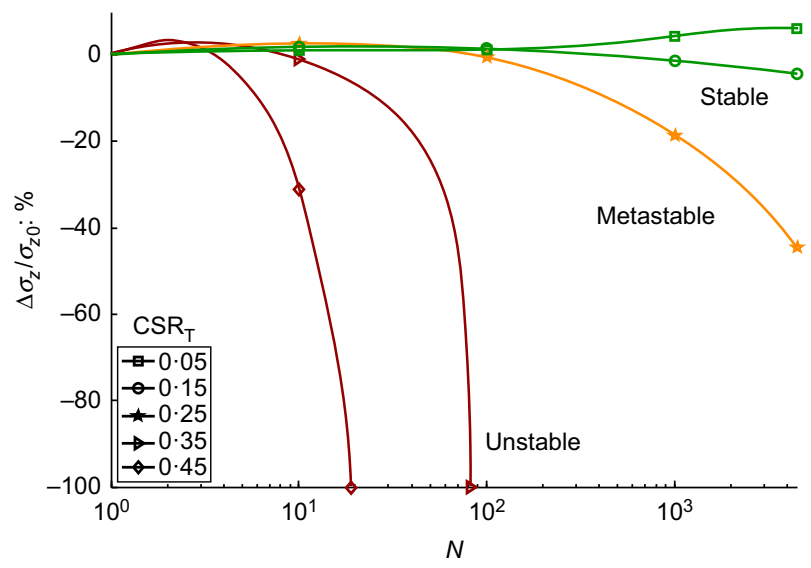

(b)

Fig. 30. Normal effective drift responses of dense sands under undrained HCA simple shear cycling at five CSRs: (a) Dunkirk sand; (b) NE34 sand, all preconditioned to simulate driven piles, as shown in Fig. 25; after Aghakouchak (2015) the outcomes of the Dunkirk and Grenoble cyclic pile tests. He tackled the question as simply as possible, assuming the element tests could represent the global pile response. He found, for each imposed CSR, the mean cyclic loads that would, through normal effective stress drift under cycling, bring the shaft stresses to meet the failure $\delta^{\prime}$ envelopes at the top of $(a)$ the 100th cycle in one set of calculations and then (b) the 1000th imposed cycle in a further set. The results predicted the upper and lower boundaries to the metastable zone in global cyclic interaction diagrams, which could be compared directly with the boundaries interpreted from the cyclic pile experiments. Two examples are presented in Fig. 31. Fig. 31(a) compares predictions based on the triaxial tests presented in Fig. 29 with the Dunkirk field tests presented in Fig. 21. Fig. 31(b) makes a similar comparison for the calibration chamber cyclic model pile experiments in NE34 sand, taking in this case predictions from the HCA tests and comparing these with the Rimoy (2015) model pile interaction diagram. The agreement is reassuringly close, given the complex factors and approximations involved.

The above laboratory-based approach has been applied to gauge the impact of axial cycling on piles driven in sands and clays for oil and gas offshore platforms. Argiolas \& Jardine (2017) report on the UK North Sea development project

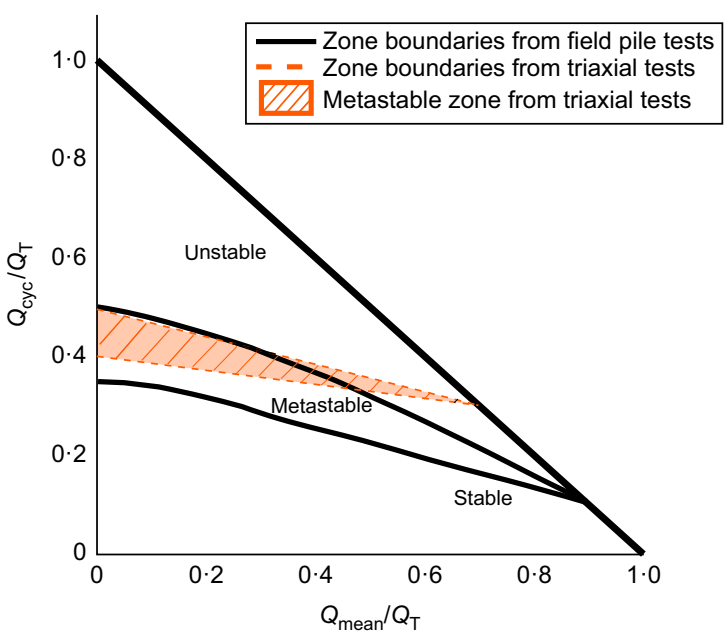

(a)

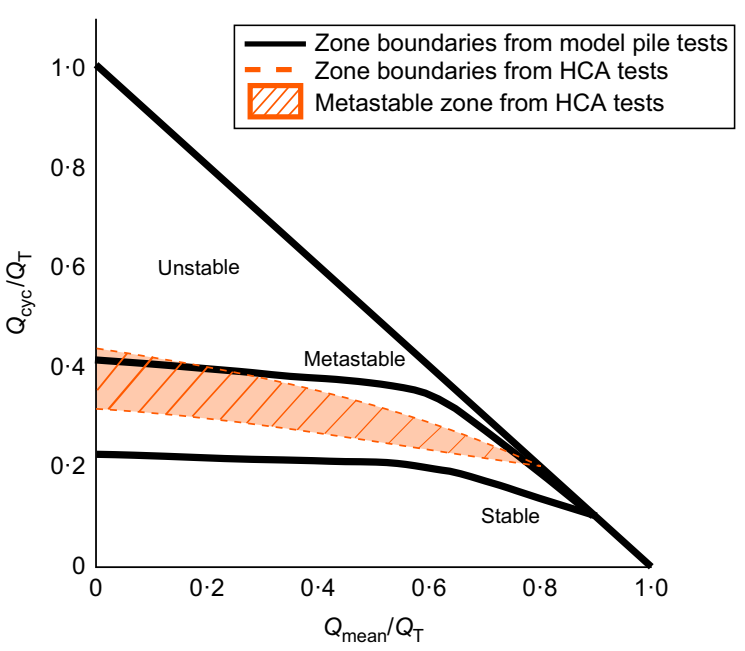

(b)

Fig. 31. Global cyclic interaction diagrams from cyclic tests on piles compared with predictions made from effective drift responses seen in 'conditioned' laboratory tests: (a) Dunkirk sand, compares field response and triaxial predictions; (b) compares mini-ICP test outcomes with HCA test predictions; modified from Aghakouchak (2015) 
illustrated in Fig. 32, which comprises new structures and the reconfiguring of platforms installed in the 1990s. The existing structures' pile driving data were examined to check and update initial assumptions regarding the very dense sand layers that provided the main part of the piles' axial capacity, as well as the low- and high-OCR clays that lie above the sands. A subsequent 'ground-truthing' site investigation added new boreholes, high-capacity CPT profiling and extra laboratory testing to define the ICP-05 sand and clay method input parameters reliably. The new investigations confirmed the interpretation and informed the final foundation assurance, which recognised the effects of both axial and lateral cyclic loading conditions during design storms. The design storm $Q_{\text {cyclic }} / Q_{\text {mean }}$ ratios indicated that direct axial cyclic loading effects were likely to be minor. However, lateral pile cycling could have a more significant impact on capacity and Argiolas \& Jardine (2017) describe how both potential sources of axial degradation were accounted for within the ICP-05 framework.

Other recent case histories include the accounts by Evans et al. (2010), Jardine et al. (2011) and Hampson et al. (2017) of foundation assurance for BP's trio of lightweight Clair and Clair Ridge jacket structures. These west-of-Shetland platforms, one of which is shown in Fig. 33, experience

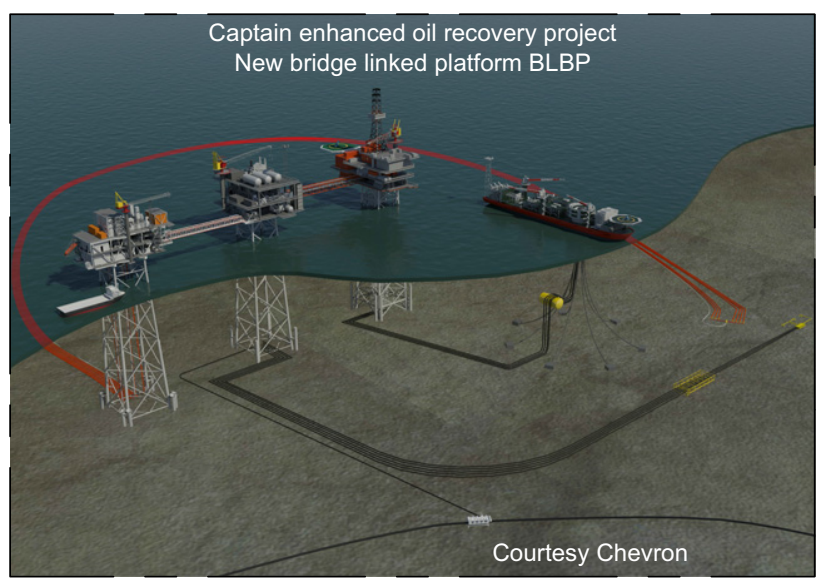

Fig. 32. Schematic representation of current UK North Sea production enhancement project, involving ICP static and cyclic procedures for new structures' and upgraded facilities' piles driven in very dense sands overlain by clays; modified from Argiolas \& Jardine (2017). Image courtesy Chevron

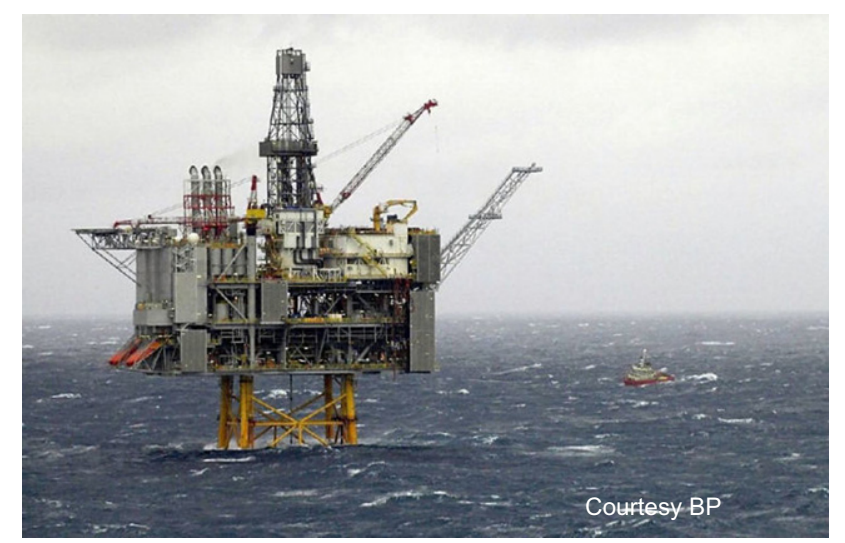

Fig. 33. Photograph of BP's Clair platform in service, west of Shetland. ICP static and cyclic procedures applied at Clair and subsequent Clair Ridge for jacket piles driven in exceptionally hard glacial tills in geotechnical conditions outlined in Fig. 2. Photograph courtesy BP exceptionally high levels of met-ocean environmental loading. The complex glacial depositional conditions of the strata encountered, shown in Fig. 3, include extremely hard, lean glacial tills containing potentially large, hard rockboulder erratics, as well as deeper layers with lower YSRs and very dense sands. Screening checks indicated a need for site-specific assessments. Cyclic analyses made within the ICP-05 framework were calibrated against suites of cyclic simple shear tests on the glacial tills that comprise much of the Clair profile. Modest shaft capacity reductions were predicted from analyses that addressed the critical design storm conditions. These were accounted for fully in the foundation assurance exercise, as was the assessed impact of lateral cycling on axial capacity. Hampson et al. (2017) also report how dynamic pile driving and restrike monitoring helped to confirm the baseline static capacities assessed for the Clair Ridge piles.

\section{Overall summary for first lecture topic}

This first section of the paper, which is considerably larger than all that follow, has described improvements in understanding and designing driven piles. The importance of regional geology was emphasised before reporting long-term laboratory, field, database and theoretical studies into: constitutive behaviour; pile load-displacement response; group action; installation effects; and axial capacity, in situ ageing trends and cyclic loading. Much of the research involved collaboration with industry and academic colleagues. The practical implications, as illustrated by example projects, are also relevant to onshore civil engineering. The 'small-strain' load-displacement approach developed for the Magnus and Hutton TLP foundations has been employed in hundreds of (often urban) projects. Similarly, the ICP-05 axial capacity procedures have aided international bridge, port and industrial developments, starting with the cases reported by Tomlinson (1996) and Williams et al. (1997). Hydraulic hammers have been used under $2 \mathrm{~km}$ of water and driving appears feasible at $3 \mathrm{~km}$ depths (Menck, 2018), so the design methods can also be applied to conductors, anchors and template piles driven for deeper-water energy projects.

\section{TOPIC 1.2: THE ANALYSIS OF VERY LARGE DEEP-WATER LANDSLIDES}

The second topic concerning sustaining offshore oil and gas supplies relates to specifically deep-water settings. Large underwater landslides are identified frequently on slopes leading from the continental shelf down to the abyssal ocean plains. The five following sub-sections describe how a team assembled from Houston in the USA, Imperial College and GCG developed a first principles approach to assessing the hazards such landslides may pose. The first step was to understand the regional geology and geomorphology. Field and laboratory investigations followed, to characterise the stratigraphy, soil properties and ground profiles and enable representative numerical analyses. Finally, the predictions were checked against field evidence.

\section{Background}

The numerical approach which enabled fully coupled numerical analysis of progressive failure in brittle strata was advanced by Potts et al. $(1990,1997)$ to study earth dams and rail and highway cuts that were usually less than $50 \mathrm{~m}$ high. Opportunities arose from the late 1990s for a group including the present author to apply the progressive failure research in deep-water offshore projects where underwater slopes were 


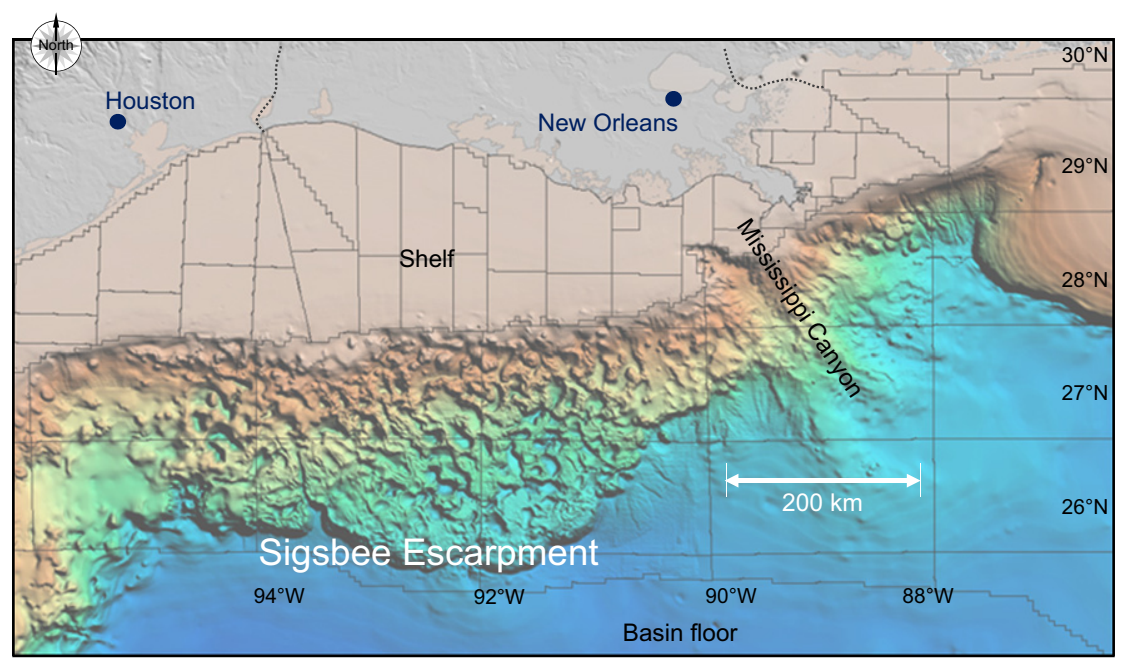

Fig. 34. Location, geomorphology and bathymetry of Sigsbee Escarpment, deep-water offshore Gulf of Mexico; modified from image given in Offshore (2001), courtesy of Schlumberger

encountered with heights approaching $1 \mathrm{~km}$. The Ormen Lange development, offshore Norway (Kvalstad et al., 2005), sited in the slide scar of the historical Storegga slide, was the first. This analysis, and others undertaken for projects offshore Africa and the USA, required elaboration to cope with far higher, deeply submerged, slopes that had experienced more complex and active geological histories. A Gulf of Mexico example reported by Kovacevic et al. (2012) is outlined below to illustrate the approach adopted.

\section{Regional geology and geomorphology}

The study concerned the Sigsbee Escarpment, located several hundred kilometres south of the US Gulf coastline and continental shelf sea area, as shown in Fig. 34, which marks a break in water depth from around $1.5 \mathrm{~km}$ to more than $2 \mathrm{~km}$. Nowacki et al. (2003), Orange et al. (2003) and Young et al. (2003), among others, describe the regional interplay between geology, tectonics and large underwater slope failures. The escarpment slope angles can exceed $20^{\circ}$, while the areas above and below have gentle inclinations. Large oil and gas reserves have been discovered and a variety of production facilities and tie-back pipelines have been installed in the area over the past 20 years. Multiple scars from large previous landslides are found along the escarpment whose geomorphology has been mapped by sonar imaging. As illustrated in Fig. 35, the slide scars can be several kilometres wide and long. Physically based risk analyses that recognise the landslide mechanisms and capture the recurrence intervals of landslides are vital to the design and assurance of oil and gas developments on or near the slope.

Intensive studies have been made of the area's active geology. Fig. 36 presents a reflective geophysical section through a $700 \mathrm{~m}$ high escarpment location that was surveyed close to the study area. The geophysics, together with deep exploration boreholes and geotechnical boreholes sampled to depths around $400 \mathrm{~m}$ below the seabed, show a deep succession of Quaternary, low-OCR sediments upslope (north) and downslope (south) of the escarpment face. The layers are draped over active salt diapirs that have constrained, uplifted and distorted the overlying Quaternary sediments. The Jurassic salt lies below Miocene shales and has been squeezed south and upwards by the overlying Quaternary sediments, which are more than $1 \mathrm{~km}$ thick north of the escarpment face.

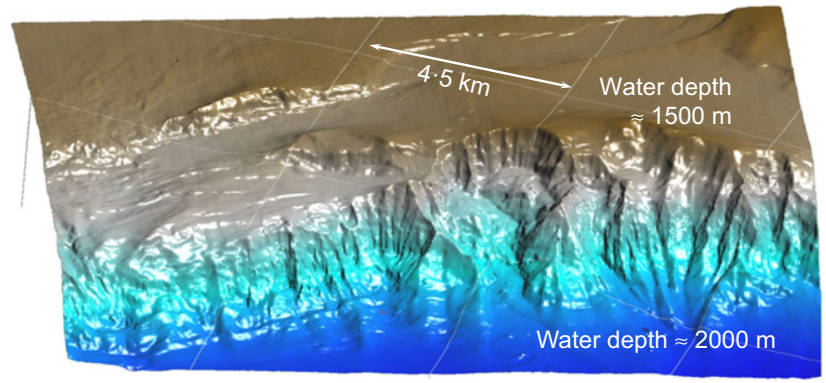

Fig. 35. Example of bathymetry from sidescan sonar imaging of Sigsbee Escarpment slope face; modified from Spikula (personal communication, 2016)

Geophysical slope image, anchored back to deep boreholes $\approx 4 \mathrm{~km}$

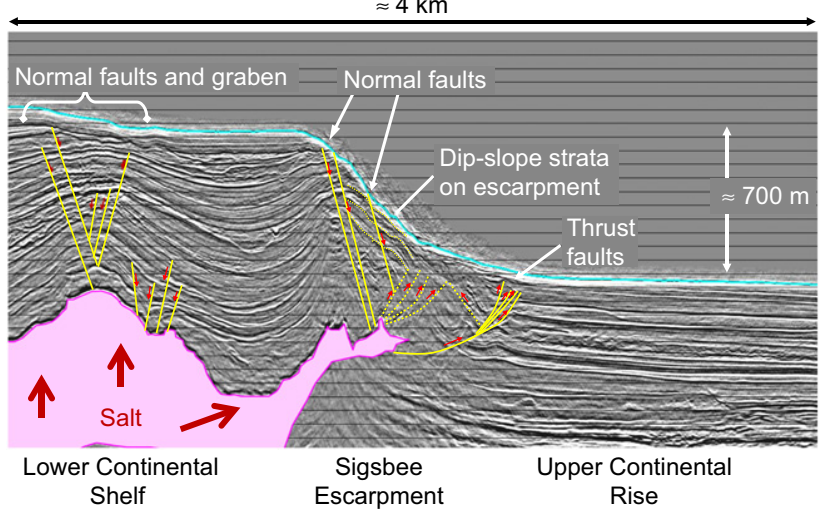

Uplifting and spreading Jurassic salt constrains and distorts Quaternary sediments

Fig. 36. Reflective geophysical survey of Sigsbee Escarpment stratigraphy; modified from Kovacevic et al. (2012)

The uplifting and spreading diapirs have generated families of normal and thrust faults in the overlying sediments during the last million years, as well as graben features; see Fig. 36. The landslides illustrated in Fig. 35 have eaten back into the slope periodically and run out into the continental rise area below, leaving the denuded slope areas in an unloaded and eventually 'overconsolidated' state. The unloading process generates large pore pressure reductions. Long periods elapse before hydrostatic equilibrium is restored after each landslide. 
Ground and slope modelling

Seven Quaternary geophysical marker horizons (H0 to H6) were identified through the slope section that could be traced back to deep regional stratigraphic and geotechnical boreholes. The reflective marker horizons, which do not necessarily correlate with significant changes in the sediments' mass properties, mark out the sedimentary architecture, which was converted by the team into the spatial ground model illustrated in Fig. 37 for the main study section. Quantitative analysis shows how Quaternary sedimentation has been affected by the uplifting shale and salt, with much thinner layers developing over the diapir crown, and how the layers have been distorted and faulted. Geotechnical boreholes could not be advanced to cover the $1 \mathrm{~km}$ plus thickness of Quaternary strata. Discontinuous sampling to $400 \mathrm{~m}$ identified alternating medium- and high-plasticity clays that reflected global temperature variations during the Quaternary. It was assumed that these variations applied at a similar rate through the whole sediment stack. One or more sand layers may also have been present.

Pre-formed slickensided shear surfaces were noted in the plastic clay samples, which are indicative of brittle behaviour in shear and low ultimate $\phi_{\text {res }}^{\prime}$ angles of shearing resistance. Such polished shear surfaces are encountered in the UK's high-plasticity overconsolidated stiff clays and have been understood since Skempton (1964) to play a key role in slope stability. While routine limit equilibrium analysis can be used to analyse the stability of known pre-existing landslides in such clays, it cannot provide accurate forward predictions for first-time slides in clays that fail progressively. Potts et al. (1997) show that more advanced coupled numerical procedures are required to answer

(a) whether a progressive slope failure could develop at any given section

(b) if so, what would be its style and scale

(c) and how long would the progressive failure take to develop?

Potts et al. (1997) analyses with ICFEP showed how brittle clays' geological histories, pre-failure stiffness, peak-to-residual shear strength brittleness and permeability characteristics affect the eventual stability, or delayed failure, of slopes following perturbations such as slope cutting or natural toe erosion. The style and timing of any eventual instabilities depend critically on the $K_{0}$ profile applying prior to excavation.

Recognising that the in situ effective stress conditions imposed by the Sigsbee Escarpment's active geology could affect the analytical predictions, it was decided to model the study slope's genesis from the Quaternary sediments' initial deposition onwards before considering the potential for

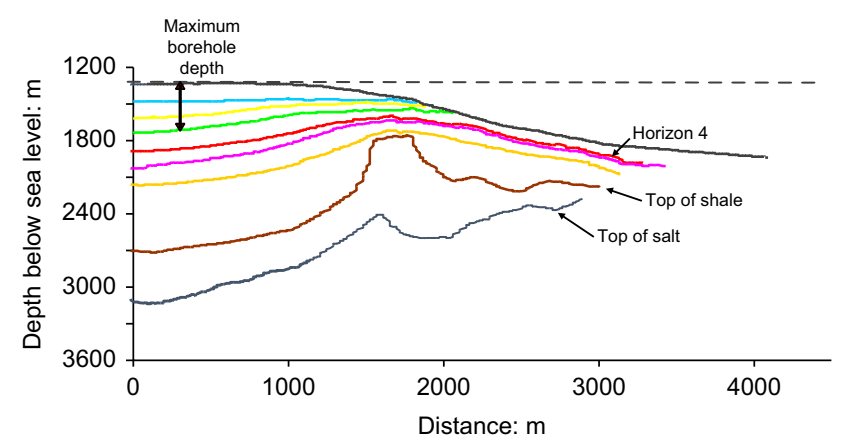

Fig. 37. Ground modelling from geophysical survey data shown in Fig. 36; modified from Kovacevic et al. (2012) future progressive failure. A degree of simplification was essential to make the problem tractable. Figs 38-40, which employ an exaggerated vertical scale, show three stages in the large-strain FE modelling of the study slope's submarine genesis. Kovacevic et al. (2012) give further details of the FE meshes, boundary conditions and numerical techniques applied. Extensive code development was required to cope with the extreme mesh distortions experienced and water pressure variations caused by the ground movements, which involved very high ambient pressures due to the great water depths. The main steps are listed below.

(a) Advancing the numerical analysis from horizon 4 (around $600000 \mathrm{bp}$ ) onwards, starting with the assumption of initially flat ground.

(b) Modelling gradual normally consolidated sedimentation on a gentle $1^{\circ}$ slope upslope of the initial escarpment face, which was assumed to have a $10^{\circ}$ angle.

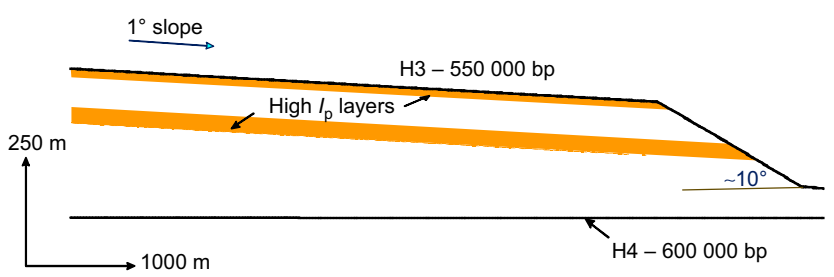

Fig. 38. Reconstruction of Sigsbee Escarpment slope formation; horizons $\mathrm{H4}$ to H3; modified from Kovacevic et al. (2012), note exaggerated vertical scale

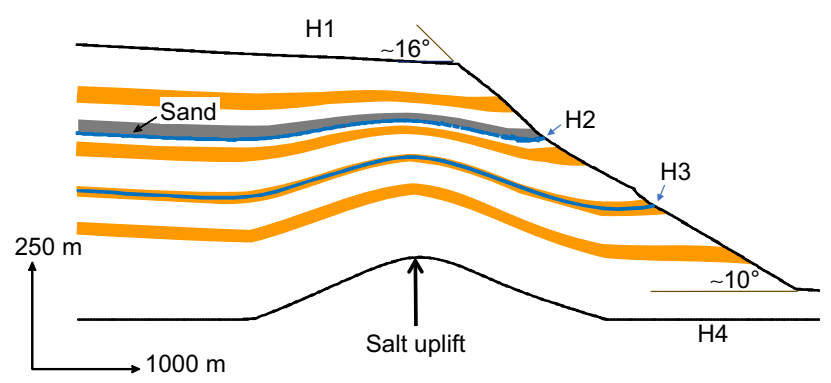

Fig. 39. Reconstruction of Sigsbee Escarpment slope formation; horizons $\mathrm{H} 4$ to $\mathrm{H1}$, with basal salt diapir uplift from $\mathrm{H3}$ onwards; modified from Kovacevic et al. (2012), note exaggerated vertical scale

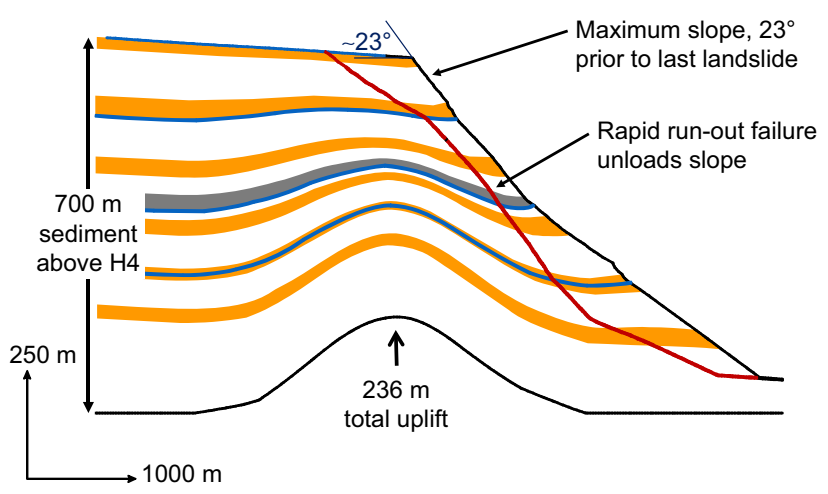

Fig. 40. Reconstruction of Sigsbee Escarpment slope formation; horizons $\mathrm{H} 4$ to $\mathrm{HO}$, with total of $236 \mathrm{~m}$ of basal salt diapir uplift and $700 \mathrm{~m}$ of sediment accumulation upslope prior to indicated last landslide event 5000 to $8000 \mathrm{bp}$; modified from Kovacevic et al. (2012), note exaggerated vertical scale 
(c) Placing alternating medium- and high-plasticity normally consolidated layers as shown in Fig. 38. The strata were represented by a modified Cam Clay variant with the parameters for both clay types defined from high-quality triaxial and oedometer tests on good quality samples. The permeabilities within each stratum were modelled as varying with void ratio, based on the laboratory tests. The layers' relative thicknesses were based on an analysis of the deep boreholes which showed thicker medium-plasticity layers.

(d) Progressive basal uplift applied from the deposition of horizon $\mathrm{H} 3$ onwards, around $550000 \mathrm{bp}$. As shown in Figs 39 and 40, the combination of continuing sedimentation on a $1^{\circ}$ slope and the imposition of basal uplift, adopting a parabolic vertical profile, led to the sediments progressively thinning and distorting above the uplifting salt diapir. These features were well developed by the 290000 bp stage of the analysis, when horizon $\mathrm{H} 1$ was deposited. An automatic outcome was the progressive steepening of the escarpment face. One thin sand layer was incorporated around the $\mathrm{H} 2$ horizon so that its potential influence on slope stability could be assessed. The imposed pattern of salt uplift and spreading matched the detailed reconstruction of the site's geological history.

(e) Sedimentation and uplift were applied concurrently until the onset of the Holocene at horizon 0. As illustrated in Fig. 40, $700 \mathrm{~m}$ of sediment had built up above horizon $\mathrm{H} 4$ by this stage and a total of 236 m of salt uplift which had produced, automatically, a steep escarpment with a maximum slope angle of around $23^{\circ}$.

(f) The predicted maximum past slope shown on Fig. 40, which is compatible with the steepest regional geomorphology, is not fully stable. Sample dating shows that a rapid run-out failure took place 5000 to $8000 \mathrm{bp}$ that denuded the slope to its present profile, shown in Figs 36 and 37. The best geometrical representation that could be achieved of the post-slide slope with the distorted mesh geometry is shown in Fig. 40.

(g) The slide mass indicated in Fig. 40 was removed rapidly to simulate the last landslide, leaving pore pressures well below hydrostatic levels beneath the former slide mass. The post-slide stress conditions defined the initial conditions for the long-term process of pore pressure equalisation that could potentially lead to a further progressive failure through effective stress and shear strength reductions.

Analysing the future stability of the study slope section

The analytical steps set out in Figs 38-40 established the conditions applying several thousand years ago. Diapir uplift and spreading, combined with rapid sedimentation over 600000 years, affected the slope's stress regime. Further analysis was undertaken to model the subsequent gradual swelling, overconsolidation and potential progressive failure of the denuded, post-run-out, slope.

The modelling employed a fully coupled, strain-softening Mohr-Coulomb model for the brittle clay layers. Based on high-quality undrained triaxial stress path tests with pore pressure measurements, the plastic clay layers were assessed to have peak $\phi_{\text {peak }}^{\prime}=18^{\circ}$. Modest peak effective cohesion was applied, with $c^{\prime}=10 \mathrm{kPa}$, that had little effect on the overall (700 m high) slope but avoided numerical problems when excavating individual, potentially steep-sided, finite elements. Kovacevic et al. (2012) report that the final outcomes are particularly sensitive to the exact value of $\phi_{\text {res }}^{\prime}$ and discuss how ranges found in ring shear tests at Imperial College and elsewhere led to the selection of $\phi_{\text {res }}^{\prime}=12^{\circ}$ and $c^{\prime}=0$. The transition between peak and residual conditions was scaled to correspond to a specified range of plastic shear strain invariant, which was chosen to produce the relative shear displacements indicated by the triaxial and ring shear tests, taking account of the thicknesses of the relevant finite elements. Triaxial and ring shear tests on the mediumplasticity clays showed broadly ductile behaviour and an average critical state $\phi_{\text {crit }}^{\prime} \approx 25^{\circ}$. No samples existed of the putative sand layer incorporated into the FE analysis, so a moderate $\phi^{\prime}=30^{\circ}$ value was adopted for the band that might be present at one or more depths. The pre-failure bulk and shear stiffnesses were modelled by the same approach as for the Magnus and Hutton TLP FE analyses (Jardine \& Potts, 1988, 1993) based on laboratory triaxial tests. The clays' variable permeability characteristics were also simulated through non-linear expressions derived from oedometer tests on representative samples.

The primary ICFEP analysis was intended to assess the timing and detailed mechanism of any potential slope failure by adopting the 'best-estimate' soil parameters outlined above. Additional simulations assessed the impact of varying the plastic clay layers' $\phi_{\text {res }}^{\prime}$ angles and dilation angles. The key prediction, identified in Fig. 41, was that a large delayed progressive failure can be expected at the study section. As marked in red, residual shear strength development was predicted to progress from the slope face upwards in all the plastic clay layers. The most likely mechanism exploited the second deepest plastic clay layer over most of its $1.3 \mathrm{~km}$ length, although alternative mechanisms could develop if any of the predicted slide was impeded by any unanticipated local factor. The numerical analysis indicated failure around 4500 years after the earlier slide, as shown in Fig. 42 by the horizontal displacement-time trend of a mid-slope point. Movements of several metres are predicted over the first few thousand years that slow until suddenly picking up, just before the abrupt failure develops.

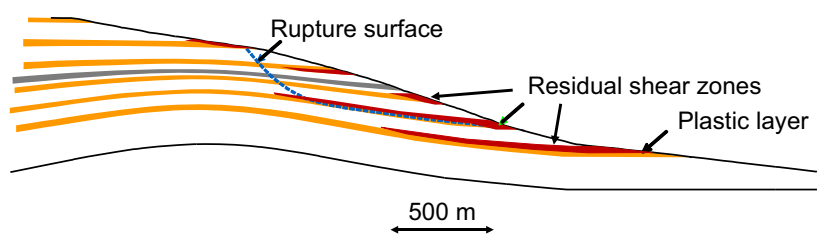

Fig. 41. Forward prediction of future instability of escarpment face by large-scale progressive delayed failure following last landside; modified from Kovacevic et al. (2012)

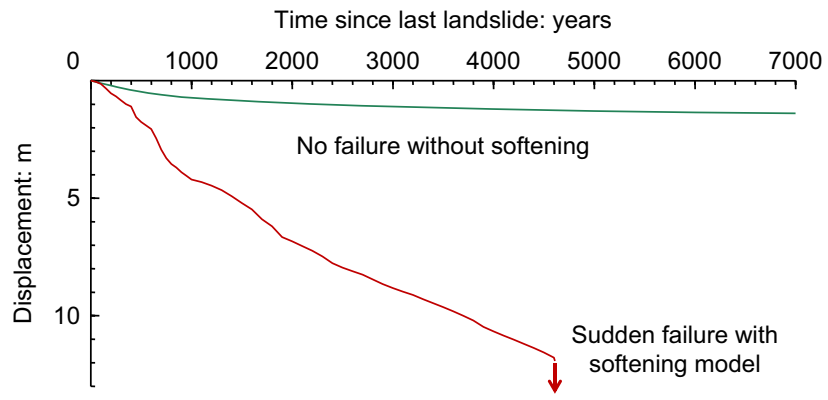

Fig. 42. Forward prediction for mid-slope horizonal movements associated with both future large-scale failure when progressive softening to residual strength is modelled and stable slope equalisation if plastic clay layers exhibit ductile, non-softening response; modified from Kovacevic et al. (2012) 
The analysis did not include any soil strain rate dependency that may have generated more marked creep displacements as failure approached and might also moderate movement rates during the final failure.

Also shown in Fig. 42 is the outcome expected if the plastic clays were ductile rather than brittle. In this case, the ground beneath the slope was predicted to swell slowly and reach a stable equilibrium around 10000 years after the last slide, with far smaller horizontal movements. The sensitivity analyses showed that raising $\phi_{\text {res }}^{\prime}$ by just $1^{\circ}$ was sufficient to impart marginal long-term slope stability; changing the dilatancy angles had far less impact. Activating the sand layer had little effect on the pattern of eventual instability.

\section{Key outcomes and scope for field verification}

The Sigsbee Escarpment study developed and demonstrated a practical process for making forward predictions of slope stability. It applied first-principles modelling and made best use of the available geological, geophysical and geotechnical data. Information on the mechanisms and timescales of possible future slope failures is clearly valuable to planners making project development decisions in such geologically active settings. However, it was important to recognise that imperfect information and implicit modelling simplifications can impact the predictions made for such complex geotechnical processes. Field verification was sought and secured by demonstrating a good match between the predicted slide geometry and the local geomorphology. Core dating of adjacent slides confirmed that landslides have occurred nearby in the last several thousand years.

While there was no expectation that a future failure date could be predicted precisely, the analyses confirmed the order of the time intervals necessary for large landslides to recur and gave an understanding of the geotechnical factors that control landslide styles and recurrence times. The study informed risk assessment analyses regarding oil and gas operations in this active deep-water province.

\section{PART 2 - ASSESSING AND MITIGATING THE ENVIRONMENTAL IMPACTS OF CLIMATE WARMING Introduction}

Part 1 of this paper set out research intended to help maintain the world's supplies of offshore oil and gas safely and efficiently. Geology, experiments and analysis were all vital to developing practical geotechnical analyses and design rules, as was verification through field observations. The importance of collaborating with industrial and academic colleagues was underscored, as were the benefits of interchanging research findings between the offshore and onshore sectors. Now attention is returned to the broader perspective outlined in the introduction, where the societal benefits of increasing the world's energy supplies were set out, along with the negative climate consequences of current fossil fuel consumption levels. Part 2 of the paper concentrates on this second aspect of the energy conundrum and starts by assessing the potential magnitude of climate change, before moving to two related geotechnical research topics.

Rising fossil fuel consumption led to global atmospheric annual carbon dioxide concentration growth rates doubling between 1960 and 2000; see United States Environmental Protection Agency (US EPA, 2015). Carbon dioxide concentration growth rates continue to climb and methane $\left(\mathrm{CH}_{4}\right)$ concentrations have also started to grow sharply again after reducing over the past decade; United States National
Oceanic and Atmospheric Administration (US NOAA, 2017). Without concerted international action, carbon dioxide emissions appear set to grow from around $35 \mathrm{Gt} /$ year emissions in 2015 up to perhaps $50 \mathrm{Gt} /$ year by 2050 . The probable impacts of future emission levels are considered regularly by the United Nations' Intergovernmental Panel for Climate Change (IPCC).

The IPCC collates data and predictions from leading international teams who simulate the global climate with complex atmospheric and ocean general circulation models (AOGCMs). The accumulation of meteorological data and the refinement of AOGCMs in recent years have improved confidence in the IPCC's assessment of future global air temperature trends. The IPCC have been able to conclude that continuing the world's energy production on a 'business as usual' basis will lead to a mean global temperature rise of $3-5 \cdot 5^{\circ} \mathrm{C}$ by 2100 (IPCC, 2015). Far greater than average temperature rises are expected in cold northern regions. Decreases in Arctic sea ice, snow cover and shallow permafrost areas are very likely. In the same way, more frequent intense northern European precipitation events are probable, which will raise the risks of flooding from rivers. There is also medium-level confidence that Atlantic storm tracks and the routes of westerly weather patterns will shift, causing increases in the North Atlantic oscillation, which could give rise to further river and marine flooding hazards, as well as changing the met-ocean conditions that have an impact on offshore and coastal structures; see IPCC (2015).

The United Nations' Conference of the Parties (COP21) held in Paris in late 2015 led to international agreement on how climate change could be slowed and secured commitments from almost all world governments; United Nations (UN, 2018). It is a matter of conjecture how the programme will develop and affect global climate trends in future years. However, air temperatures are undoubtedly set to rise well above the $1^{\circ} \mathrm{C}$ average global increase measured since 1750 , the notional start of the industrial revolution. It is also clear that the rises will be non-uniform, with cold northern regions being affected far more markedly than the global mean trend. For example, Lyle et al. (2014) report current warming rates around 0.5 to $1^{\circ}$ per decade in the Yukon (Canada); higher rates have been reported for Alaska and can be expected in northern Siberia, see AMAP (2017).

The two geotechnical research studies outlined here in Part 2 were designed to help assess and mitigate the environmental impact of climate warming. The first addresses modelling the ground's response in the cold regions that are likely to be the most significantly affected globally. The fate of widespread areas of permafrost terrain is considered through a study of a Siberian area, setting out a new approach that integrated: $(a)$ a regional geographical information systems (GIS) tool with $(b)$ high-level geological and geotechnical characterisation and $(c)$ detailed onedimensional geothermal analyses conducted for multiple spot locations. As with the offshore piling and landslide studies, field observations were employed to 'ground truth' the analytical predictions.

After considering the extreme impact of climate change in cold regions, the role that geotechnical research can play in helping to mitigate the human consequences of global warming is illustrated by considering a more familiar geotechnical problem. An account is given of how full-scale field testing, combined with laboratory, in situ testing and geotechnical analysis has helped flood defence strengthening on difficult peat ground in the Netherlands. As with the permafrost research, investigating the second topic involved close collaboration with industry and other researchers. The main findings were carefully verified through field observations. 
TOPIC 2.1: GEOTECHNICAL IMPACT OF CLIMATE CHANGE IN PERMAFROST REGIONS

In 2007 BP commissioned Imperial College to perform a multi-disciplinary study of how climate change might impact their infrastructure. The group (which included the author) identified cold regions as being particularly vulnerable to climate warming and advanced a broad physically and analytically based framework for considering such areas, as described by Clarke et al. (2008). Greatest attention was given to the fate of northern permafrost terrains, recognising from Delisle (2007) that most AOGCMs cannot consider sub-surface ground conditions and geothermal processes.

The approach started with Professor Toumi's group (in Imperial College's physics department) interrogating AOGCM predictions to consider future trends under a range of global emission scenarios, working with the full ensemble of IPCC models to improve their overall predictive reliability. Recognising that the AOGCMs' geographical resolution was too coarse to specify how the climate may change in specific study areas, local adjustments were made based on regional meteorological observations.

Defining the probable future variations in local climate for cold regions allowed geothermal and geotechnical analyses of their likely impact on ground conditions in permafrost areas. The first aim was to provide high-level assessments of the potential vulnerability of the relevant areas and facilities. Regional geothermal analyses were conducted, employing GIS and thermal FE tools developed for the study as described by Nishimura et al. (2009a). Geotechnical design aids ranging from existing simple geocryological methods through to a new, fully coupled, thermal hydro-mechanical (THM) FE modelling approach could then be applied to guide resilient new designs, or remedial retro-fitting, for specific infrastructure assets. Nishimura et al. (2009b) describe the critical-state based THM model developed with Professors Gens and Olivella at Universitat Politècnica de Catalunya (UPC) to support detailed design in permafrost soils. Gens (2010) described the mechanics of the fully coupled numerical method approach in an earlier Rankine Lecture, so attention is focused below on the parallel regional assessment approach.

The defining feature of permafrost ground is a temperature-depth profile such as that shown in Fig. 43. Some thickness of ground must exist beneath any seasonally thawing active layer where the temperature is always below $0^{\circ} \mathrm{C}$. The permafrost extends down to the point where thermal flux from the earth's core raises the temperature above freezing point, with gradients that vary with ground type and the local deep geology. The permanently frozen layer between these limits can be characterised by its thickness and either its mean top temperature (TTOP) or its zero annual amplitude temperature (TZAA), which applies at the depth where seasonal thermal variations become insignificant and the 'trumpet curves' defined by the maximum and minimum seasonal temperatures converge. The air above the ground has a known lapse rate under ordinary conditions (when no thermoclines act) and cools by around $6.5^{\circ} \mathrm{C} / \mathrm{km}$ of altitude, leading to permafrost being colder and thicker on higher ground.

The greatest thicknesses of permafrost present in the northern hemisphere are found in northern Alaska, Canada and Siberia. Continuous masses with maximum depths exceeding $1 \mathrm{~km}$ have been identified in northern Siberia that have very low TTOP and TZAA values. The permafrost layers gradually thin and warm to the south, becoming first spatially discontinuous and finally only sporadic on local high ground peaks before eventually disappearing. Climate change has the greatest potential for immediate impact in the marginally discontinuous areas

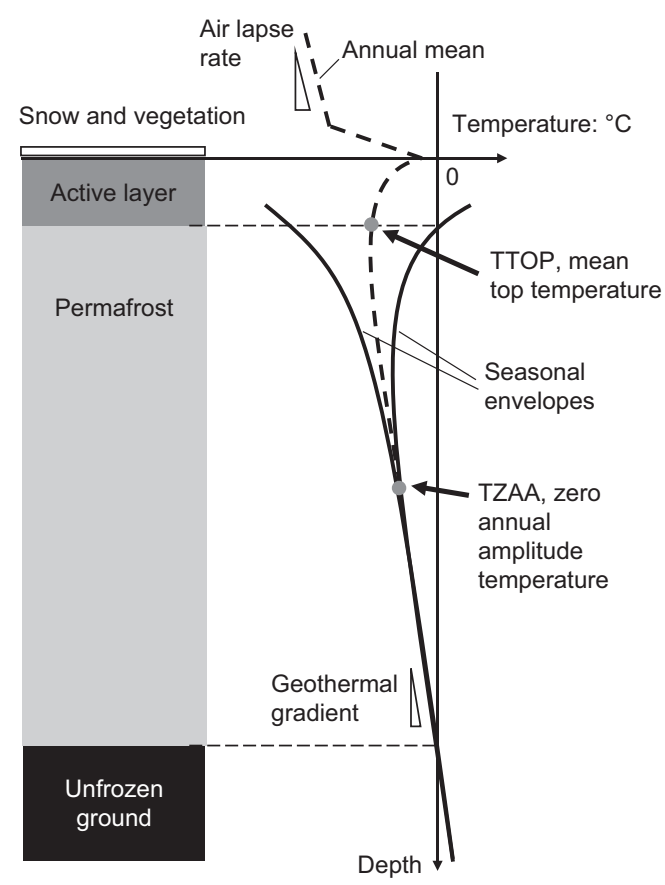

Fig. 43. Thermal profile and definitions for permafrost ground

where warming will first eliminate the historical permafrost. Thawing ground loses shear strength dramatically and promotes slumps, and foundation, pavement and pipeline failures as well as landslides on slopes. The rates of change depend on geotechnical and geothermal processes that are not captured by the AOGCMs. However, evidence of warming is now being witnessed widely. Lyle et al. (2014) report the thermal creeping, $350 \mathrm{~m}$ wide, Little Salmon Lake YT landslide example shown in Fig. 44, which developed in glaciofluvial soils in a discontinuous permafrost area in Yukon, Canada. Similarly, Canada's North West Territories Geological Survey (NWTGS, 2015) report multiple thermokarst thaw-slump features developing in flatter regions which can be up to $25 \mathrm{~m}$ deep and 30 ha in area.

\section{Tools developed for regional analysis}

Regional permafrost analysis tools were developed at Imperial College to predict transient thermal ground

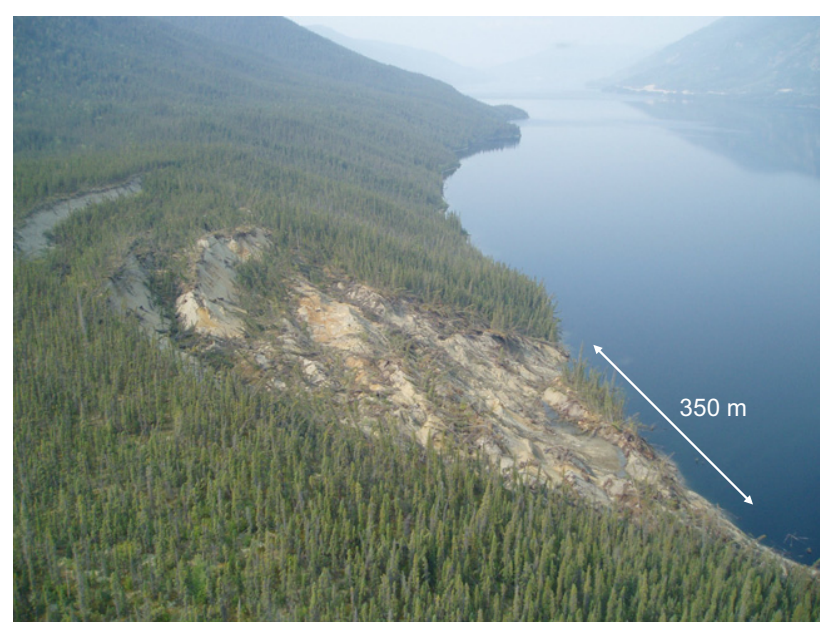

Fig. 44. Photograph of thermal creeping landslide in sporadic permafrost; Little Salmon Lake, Yukon, Canada: courtesy Lyle (personal communication, 2016) 
responses to climate change over wide areas. The aim was to generate mapped geocryological predictions for future permafrost table depth, TTOP and TZAAvalues and ground temperature at any desired depth. These data are not provided by current AOGCMs. The approach integrated IPCC climate model predictions, local meteorological adjustments (after Simmons \& Gibson (2000)), regional geological assessments, non-linear thermal FE analysis and terrain digital elevation models (DEMs) derived from remote sensing data. The predictions were tested by assessing their ability to predict, from first principles, the current conditions as recorded in local geocryological survey maps. The GIS code was extended to provide simple, high-level, geohazard guidance maps for any chosen study area.

The regional geothermal analyses relied on a onedimensional FE code developed by Nishimura et al. (2009a) that modelled non-linear heat conduction and energy storage for ground with temperature-dependent thermal properties. Similar analyses have been performed by Kane et al. (1991) and Delisle (2007), among others. A one-dimensional system was developed that could be applied efficiently in hundreds or thousands of specific cases. The main features were: (a) thermal conductivity and heat capacity that varied with the soils' contents of unfrozen water, which in turn depend on temperature; $(b)$ incorporating latent heat capture or release on freezing and thawing; $(c)$ material properties that could vary with depth; $(d)$ seasonal variations of insulating snow cover that were modelled explicitly; and (e) air-ground surface energy transfer that was modelled through the empirical $n_{\mathrm{t}}$ air-to-ground temperature factor approach of Lunardini (1978). The governing heat equation is

$$
\frac{\partial u(T)}{\partial t}-\frac{\partial}{\partial x}\left[\lambda(T) \frac{\partial T}{\partial x}\right]-q=0
$$

where $u$ is the specific internal energy, $T$ is the absolute temperature, $q$ is the heat production/sink, $\lambda$ is the thermal conductivity, $t$ is the time and $x$ is the depth. The internal energy and mass thermal conductivity are both non-linear functions of temperature, due to water phase changes. The internal energy term is expressed as

$$
\begin{aligned}
\frac{\partial u(T)}{\partial t}= & \frac{\partial}{\partial t}\left(\left\{c_{\mathrm{s}} \rho_{\mathrm{s}}(1-\phi)+c_{\mathrm{l}} \rho_{\mathrm{l}} S_{\mathrm{l}}(T) \phi\right.\right. \\
& \left.\left.+c_{\mathrm{i}} \rho_{\mathrm{i}}\left[1-S_{\mathrm{l}}(T)\right] \phi\right\} T+l \rho_{\mathrm{l}} S_{\mathrm{l}}(T) \phi\right)
\end{aligned}
$$

where $c, \rho, l$ and $\phi$ are the specific heat capacity, the mass density, the specific latent heat of fusion and porosity, respectively. Subscripts 'l', 'i' and 's' indicate liquid water, ice and soil particles, respectively. $S_{1}(T)$ is the degree of liquid saturation as a function of $T$, defined by volume as

$$
S_{1}=V_{1} /\left(V_{\mathrm{i}}+V_{1}\right)=V_{1} /\left(V-V_{\mathrm{s}}\right)
$$

Following Anderson \& Morgenstern (1973) and Andersland \& Ladanyi (2004) and others, the function adopted to describe the degree of liquid-ice saturation $S_{1}$, of the permafrost pore space was

$$
S_{\mathrm{l}}=\alpha \frac{\rho_{\mathrm{s}}(1-\phi)}{\rho_{\mathrm{l}} \phi}|T|^{-\beta}
$$

for $T<0^{\circ} \mathrm{C}$, otherwise $S_{1}$ is taken as 1

where $\alpha$ and $\beta$ are material constants. The mass thermal conductivity, $\lambda$, of the soil containing solid, liquid and ice phases varied also with $S_{1}$ and was expressed as the geometric mean

$$
\lambda\left(S_{1}\right)=\lambda_{\mathrm{s}}^{1-\phi} \lambda_{1}^{S_{1} \phi} \lambda_{\mathrm{i}}^{\left(1-S_{1}\right) \phi}
$$

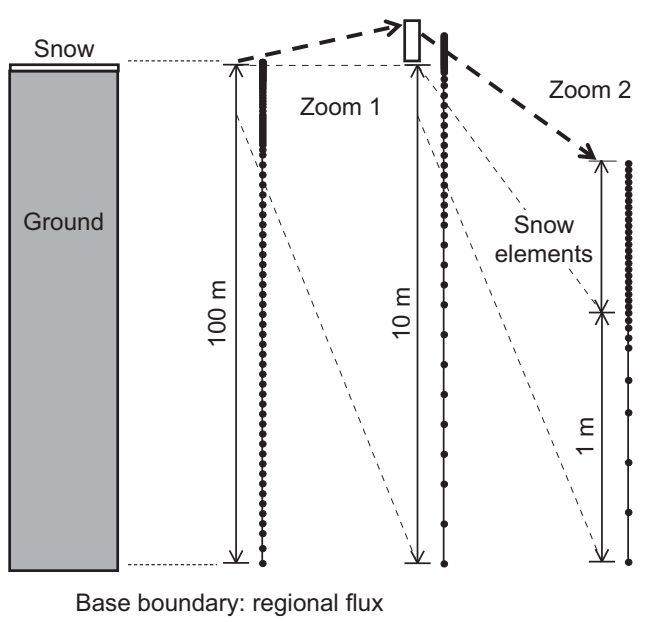

Fig. 45. General scheme of the one-dimensional FE ground model; after Nishimura et al. (2009b)

The one-dimensional FE ground model is illustrated in Fig. 45. The top boundary condition comprised specified ground temperatures, which are controlled by air temperatures and other factors including insolation (solar energy input per unit area), slope aspect, snow cover, vegetation and presence of block fields (boulders shading the ground surface), infrastructure, surface water and peat layers. The base FE boundary condition was defined by the regional geothermal flux, applying published regional data. The purpose-written code allowed automatic continuous processing of multiple cases.

\section{Study area}

The cold region study concerned the example region of south-eastern Siberia shown in Fig. 46, which surrounds Lake Baikal and covers almost 2 million $\mathrm{km}^{2}$. Atlases and local geocryological maps (see for example Yershov (1991)) indicate permafrost that is continuous and deep in the higher altitude and latitude areas, through to absent in the lower southerly areas. Where the permafrost is discontinuous it is generally concentrated over the higher ground because of the $6.5^{\circ} \mathrm{C} / \mathrm{km}$ air lapse rate. The study examined how ground temperatures would respond to climate change over the whole region. A regional desk study of the geology, geomorphology and geocryology was undertaken. Digital elevation models were then derived for areas of interest from space-shuttle radar tomography mission (SRTM) data published by the United States Geological Survey (USGS, 2017). Site reconnaissance visits were undertaken by team members, and other remote sensing data were acquired to characterise the nature of the ground surfaces over the seasons. An engineering geology interpretation was made with colleagues at Imperial College that divided the whole study area, as shown in Fig. 47, into mountains; foothills; rolling hills; fluvial plains and loess plains provinces, where broadly similar conditions applied. Martin (2008) developed generic ground models for each of these settings that identified the key geomorphological features and ground risks associated with each. The most important material properties required to progress the geothermal analysis (outlined by equations (9)-(13)) were the conductivity and freezing functions. The latter depended principally on the profiles of soil porosity and grain size distributions.

Nishimura et al. (2009b) illustrated the application of the integrated analytical approach by considering one 60 by $80 \mathrm{~km}$ area whose general features are illustrated in Fig. 48, 


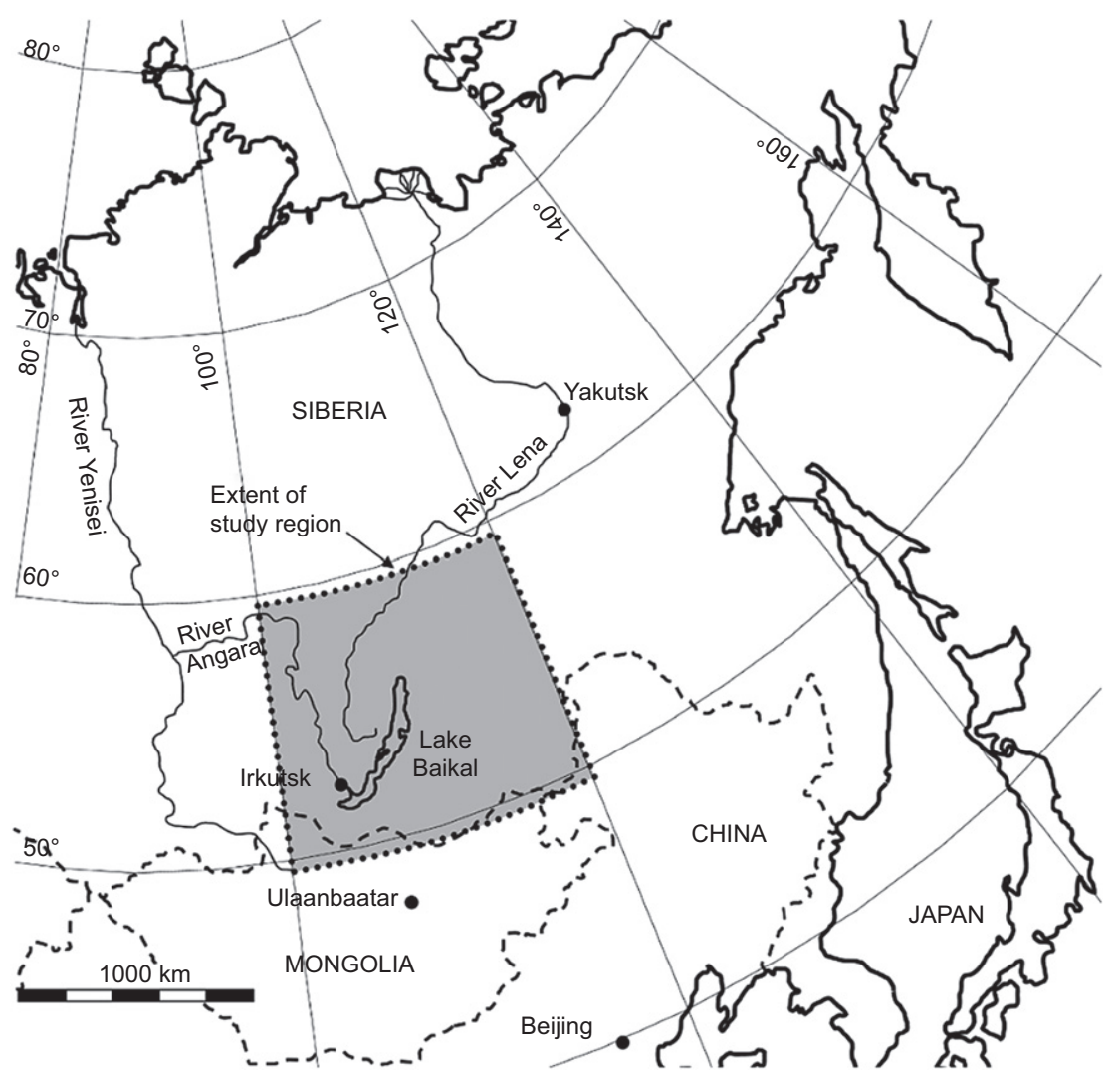

Fig. 46. Map showing Siberian permafrost study region; after Nishimura et al. (2009b)

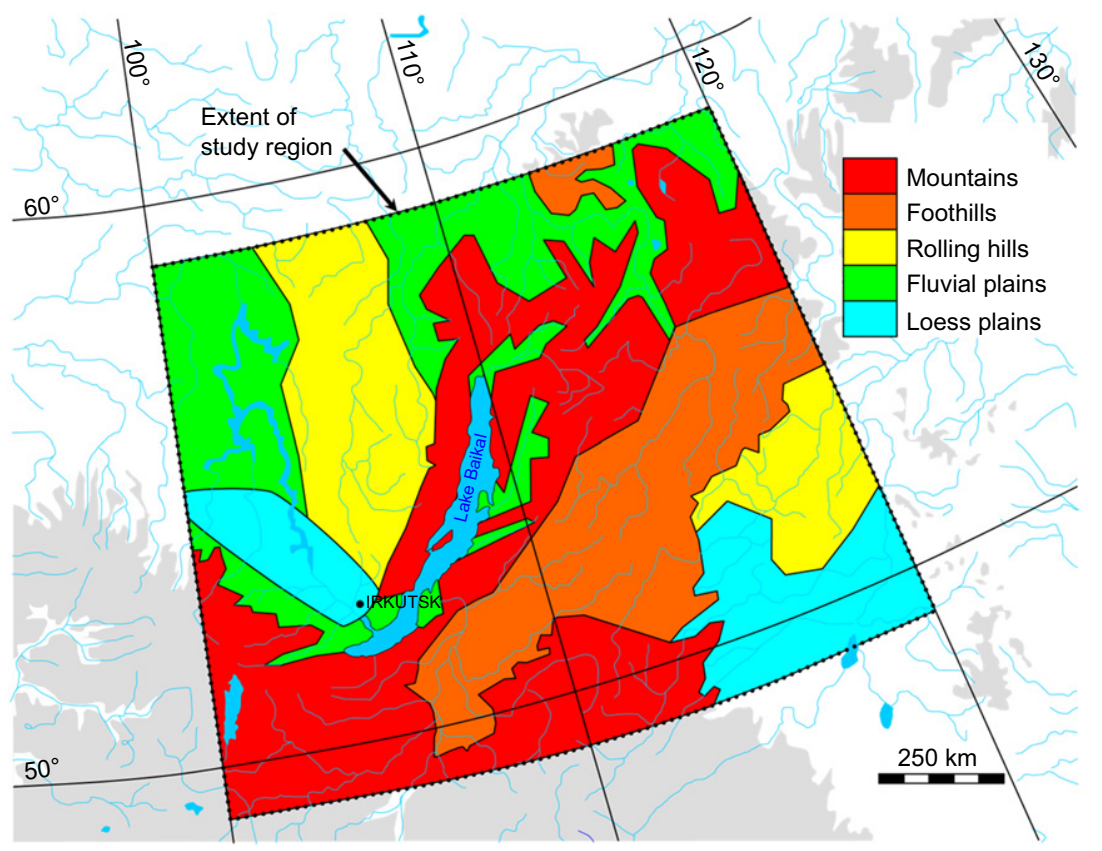

Fig. 47. Division of Siberian study region into five geomorphological stereotypes

where currently discontinuous and relatively dry permafrost is found within the 'rolling hills' terrain stereotype. A relatively thin snow cover is present in winter and the permafrost was expected to be less than $100 \mathrm{~m}$ thick at all points in the study area. The 'rolling hills' geomorphology was further subdivided into flat 'alluvial valley' (profile A) areas, which were cut by rivers into the 'bare rock' (profile B) flat-topped hills composed of Cambrian and Ordovician sedimentary rocks, with 'colluvium slope' (profile C) areas between the hill tops and valleys. Taiga forest vegetation covers the lower ground levels. The team drew on the literature and their field experience to develop generic average porosity profiles associated with the A, B, C profile landforms illustrated in Fig. 49, based on the local rock types and geomorphological conditions. It was recognised that the profiling should be refined for any more detailed analysis by applying local borehole and laboratory testing data. 


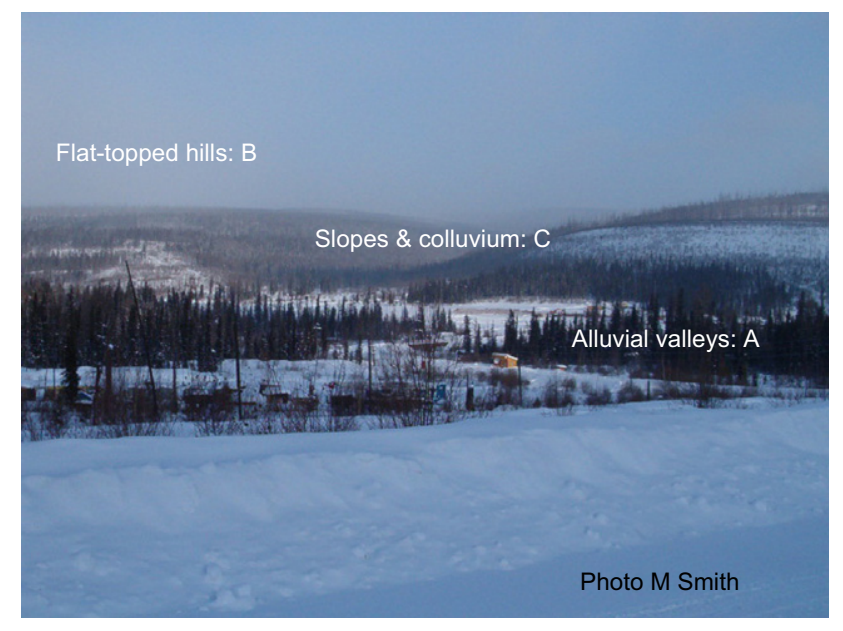

Fig. 48. Photograph taken by M. Smith of 'rolling hills' terrain of Siberian study area in winter

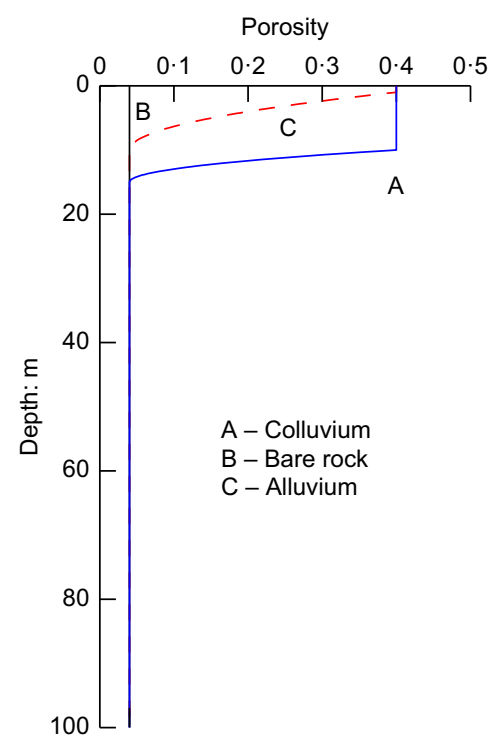

Fig. 49. Generic porosity profiles associated with the A, B, C landforms shown in Fig. 48 for 'rolling hills' terrain of Siberian study area; modified from Nishimura et al. (2009b)

\section{Integrated analysis of permafrost fate in 60 by $80 \mathrm{~km}$ example area}

Nishimura et al. (2009b) applied their integrated GIS-FE method (FEM) modelling approach to consider how the historical and expected future climate would affect geocryological conditions in the study area from 1940 to 2059. The physics group (Reifen and Toumi) defined the progressively changing seasonal climate conditions. Fig. 50 shows the annual variations in snow cover and air temperature expected for points with a $640 \mathrm{~m}$ elevation above sea level in the study area, which were assessed applying the IPCC's 'SRES A2' scenario (Nakicenovic et al., 2000), which assumes fully plausible future global greenhouse gas emission trends. The shifts in temperature indicate around $0.35^{\circ} \mathrm{C}$ of warming per decade, which falls below the rates currently being measured in the Yukon and Alaska; see Lyle et al. (2014).

Parametric analyses run with the purpose-built geothermal FEM code demonstrated that ground surface elevation, ground shape, vegetation and local geological variations all affect the permafrost predictions. A database of hundreds of one-dimensional thermal FE analyses was then compiled that covered the full extent of the range of surface elevations,

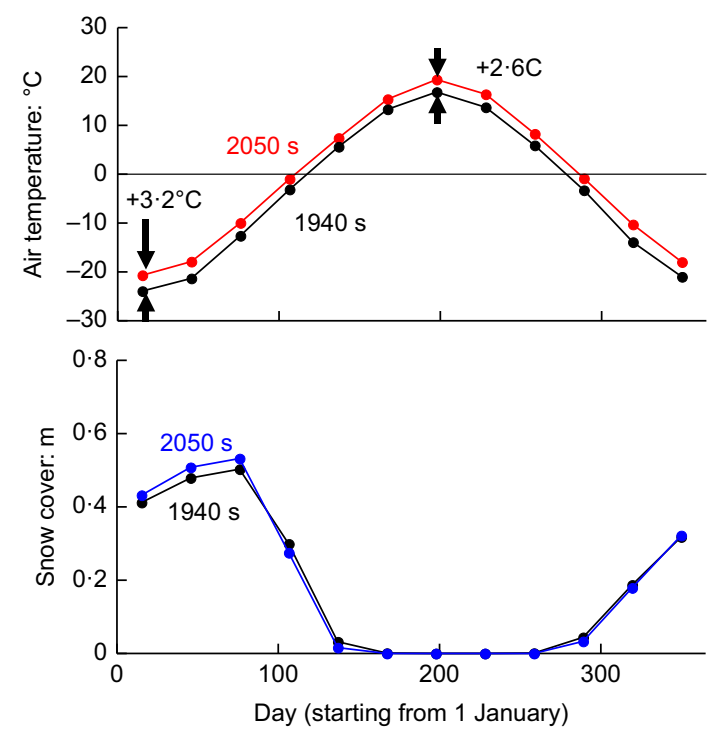

Fig. 50. Annual variations in snow cover and air temperature expected for points with a $640 \mathrm{~m}$ elevation above sea level in the study area, contrasting 1940 s data with prediction for 2050 s made applying the IPCC's 'SRES A2' emissions scenario; after Nishimura et al. (2009b)

ground profiles (A, B, C), slope aspects, summer ground surface character and base fluxes in combination with the locally adjusted time series of temperature and winter snow cover steps, which were adjusted from the AOGCM datasets on the basis of regional meteorological observations by the physics department team.

The aim was to generate useful geocryological maps for the study area that predicted the TTOP temperature, the permafrost table depth and ground temperatures at any desired depth. The initial geocryological conditions were found for each case by applying the 1940 climate as having been constant for the preceding 1000 years. This conditioning was sufficient to establish an initial equilibrium in the study area that was subsequently perturbed by imposing the gradually changing climate variations summarised in Fig. 50, applying the slow shifts in the daily and seasonal cycles predicted by the AOGCM models. Assessing the impact of climate change over the study area called for input data to be provided for each point in the wide study area, which included the following components.

(a) Topography: information was extracted from digital elevation models developed from the SRTM dataset, applying GIS tools to find the elevation of any point above sea level, its slope angle and aspect.

(b) Ground nature: satellite remote sensing data were interrogated to establish the likely ground surface type and its degree of cover in summer, based on image colour matches, which defined the appropriate local Lunardini (1978) $n_{\mathrm{t}}$ air-to-ground temperature transfer coefficients. The $n_{\mathrm{t}}$ values changed sharply once winter snow cover was established.

(c) Geological ground profile: local profiles were inferred by applying to the digital elevation model outputs rules set from the regional engineering geology interpretation that established which of the three (A, B or C) porosity-depth and grading curve-depth profiles applied to any individual point, depending on the local ground slope.

(d) Local geothermal base flux, expressed in $\mathrm{W} / \mathrm{m}^{2}$ based on published regional datasets.

(e) Local time series for temperature and snow cover; the latter were assessed from the elevation, AOGCMs and local meteorological observations. 
A purpose-built automated GIS based system applied the workflow scheme illustrated in Fig. 51 to bring these streams of data together and define the geocryological parameters applying to any given point on the map. A formal queryand-return database process identified for each point the best possible match among hundreds of one-dimensional thermal FE analyses that covered the full range of expected parameters. The selected FE analysis was then interrogated to provide geothermal predictions for the point in question. Repeating the process automatically for thousands of points over the study area provided automatically generated maps that captured the desired predictions for permafrost temperature and thickness.

\section{Verification of the analytical process and predictions for future permafrost state}

The analytical procedures outlined above involved assumptions and simplifications that could lead to significant predictive errors. The essential field checking was achieved by comparing predictions made for the 1940 to 2000 period with the latest field ground temperature surveys, as published by Yershov (1991). Fig. 52 presents maps of ground zero amplitude TZAA temperature generated for the year 2000 through the analytical steps described above. Also shown are the most recent survey data. The permafrost is predicted to be discontinuous: it is coldest over the tops of the hills and absent in the main valleys. Apart from a currently unexplained thin feature on the eastern edge of the study

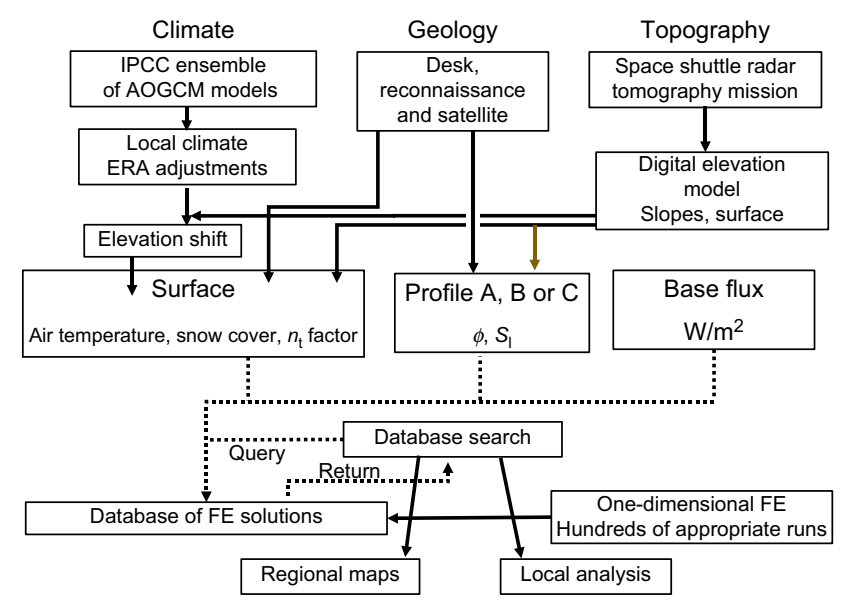

Fig. 51. Workflow for GIS based system for regional analysis of permafrost fate; after Nishimura et al. (2009b) area, which may represent an atypical area of peat, the predictions match the survey data encouragingly closely. The 'first principles' geothermal regional modelling approach appears capable of predicting the TZAA temperature trends to within $1^{\circ} \mathrm{C}$, or closer, over the $60 \times 80 \mathrm{~km}$ 'rolling hills' area. The tools therefore appear suitable for making regional first-order assessments that can be followed up by ground reconnaissance, survey and sitespecific local investigations.

The future trends will depend on political, social and economic decisions, as well as physics. Fig. 53 outlines how the ground temperatures can be expected to react if society opts for the reasonably probable IPCC's 'SRES A2' greenhouse gas emissions scenario outlined by Nakicenovic et al. (2000) and if future warming rates fall well below those currently applying in the Yukon. Maps are presented across the 60 by $80 \mathrm{~km}$ area showing the TTOP permafrost temperatures predicted for 1940, 2000 and 2059, which show comparatively little change in the second half of the twentieth century. However, significantly faster warming is predicted over the first half of the twenty-first century. Even the coldest permafrost found at the tops of the hills is predicted to warm to near melting by 2059 . The landscape can be expected to release methane stored in the frozen ground, which will add to greenhouse gases. The ground will lose shear strength and become far more compressible. Slope failures and slumps can be expected that will affect the regional hydrology and cause distress to roads, railways, power transmission lines, the foundations of any buildings and the operation of any pipelines.

The cold region study also involved reviewing and developing tools that could be applied to help cope with the impact of permafrost warming. Nishimura et al. (2009b) added routines to their GIS based software that identified and flagged potential geohazards automatically in maps. Routine geocryological tools could then be employed to consider any potentially serious consequences for the environment, inhabitants, facilities or infrastructure. Advanced THM analysis tools may be required to help design adaptive works to protect existing, or new, high-value facilities. A 'critical-state based, three-phase' THM model was developed and implemented into the UPC FE program Code Bright, as described by Nishimura et al. (2009a), who also report the code's validation against field data. Predictions run for gas pipeline freezing and thawing experiments conducted in Calgary, Canada by Slusarchuk et al. (1978) showed how the THM model captured faithfully the pipeline uplift on ground thawing that most concerns pipeline engineers working in permafrost regions. Gens (2010) describes other slope stability applications
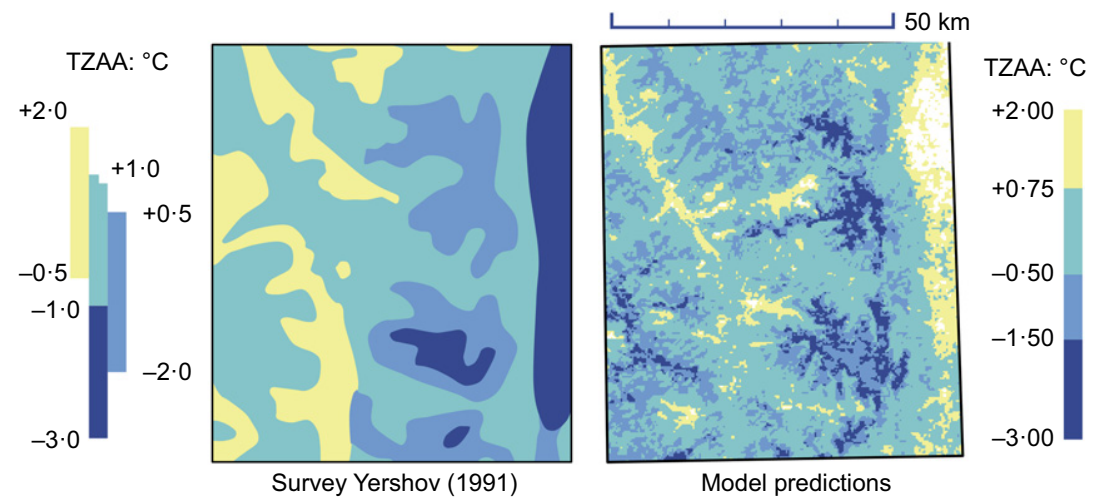

Fig. 52. Maps of ground zero amplitude TZAA temperature generated for $60 \times 80 \mathrm{~km}$ area of 'rolling hills' terrain, considering predictions for 2000 and most recent survey data by Yershov (1991); after Nishimura et al. (2009b) 


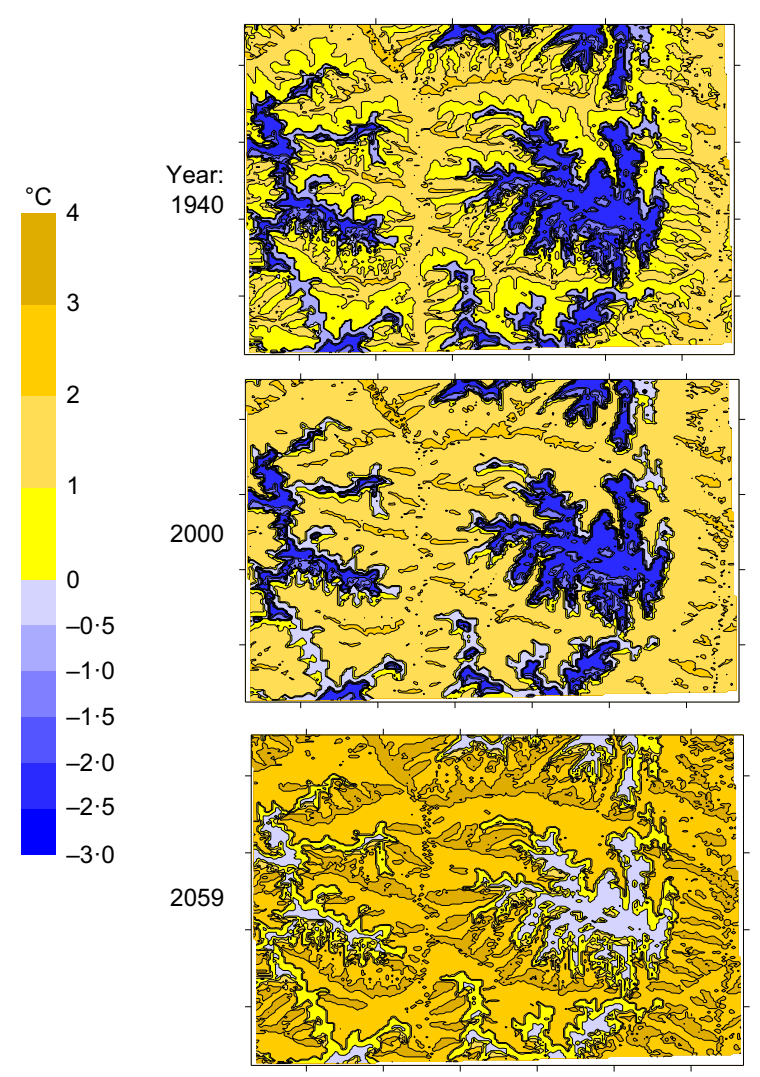

Fig. 53. Maps of TTOP permafrost temperatures predicted for 1940, 2000 and 2059 years for $60 \times 80 \mathrm{~km}$ area of 'rolling hills' terrain; after Nishimura et al. (2009b)

for the THM model in permafrost terrain, while Viggiani \& Casini (2015) report on applying the code to help analyse ground freezing operations employed in metro tunnelling works in Naples, Italy.

Recognising that relatively few geotechnical engineers work on permafrost problems, the second Part 2 topic calls attention to a more familiar northern European problem to demonstrate the practical 'nuts and bolts' of how geotechnical engineering can help to mitigate the hazards posed by future climate change.

\section{TOPIC 2.2: MITIGATING FLOODING HAZARDS POSED BY CLIMATE CHANGE IN NORTHERN EUROPE}

Climate warming is currently most marked in cold regions such as Alaska, Siberia and the Yukon. However, only 0.5 to 3 people inhabit each square kilometre in these regions. The human and economic impact of climate change is likely to be greater in more densely populated areas, even if their warming rates are lower. The highest population densities in Europe are in the Netherlands and the UK, with 488 and 395 inhabitants $/ \mathrm{km}^{2}$, respectively. IPCC modelling predicts significant impacts in these countries that are likely to exacerbate river and sea flooding risks. The UK currently seeks to cope with 1000 year return period flood events for London's tidal flood defences, while Holland, which is particularly vulnerable to flooding, seeks to ensure that its $22000 \mathrm{~km}$ of flood defence dykes can withstand 10000 year return period events. The following six sub-sections set out research directed to the strengthening of flood defence dykes on difficult peat ground in the Netherlands.

\section{Background}

Landva (2006) and others have made invaluable contributions to the geotechnical characterisation of organic soils. However, definitive guidance based on modern soil mechanics appears to be lacking for site investigations and earthworks raised on peat and organic soils. Peats are generally considered particularly poor foundation soils and are often removed by excavation before attempting construction. Low penetration resistances, potential rate effects, possible anisotropy and fibrous inclusions hinder in situ shear strength test measurements; see Boylan et al. (2011). Laboratory oedometer tests and field observations show very high compressibility coupled with high secondary compression coefficients. High pore pressure ratios $(\Delta u / \Delta q)$ are also often observed in undrained laboratory tests, as well as remarkably low stiffness. However, Yamaguchi et al. (1985), Den Haan \& Kruse (2006) and Zwanenburg et al. (2012) report the paradox that triaxial tests on peats often indicate exceptionally high $\phi^{\prime}$ values without clear peaks in $q$ or failure planes developing.

\section{Flood defence study setting and aims}

Zwanenburg \& Jardine (2015) describe how 'as simple as possible' design tools were developed in research conducted with Deltares (Delft) for the national Rijkswaterstaat and local Hoogheemraadschap Hollands Noorderkwartier (HHNK) water authorities to support engineering remedial work design for a $30 \mathrm{~km}$ length of ancient flood defence. The dyke was raised gradually on peat from medieval times up to its last filling in 1916. It currently stands around $4.6 \mathrm{~m}$ above the 'polder' reclaimed land level running north of Amsterdam along Markermeer lake, passing the small town of Uitdam at the location shown in Fig. 54. The dyke shown in Fig. 55 defines the margin to the waterside polder areas where residents and many visitors enjoy access to the outstanding natural beauty and spectacular avian wildlife. Effective flood defence is essential as large areas of land behind the dyke fall more than $1 \mathrm{~m}$ below the lake's average water level and the mean sea level (Normaal Amsterdams Peil (NAP)). However, the existing dyke comprises largely un-engineered fill placed on very soft and highly compressible peat, whose thickness has reduced beneath the dyke centre-line by $80 \%$ through consolidation and long-term creep. The dyke fails stability checks performed to the Netherlands' current standards, which indicate that the foundations have no reserve of capacity to withstand further

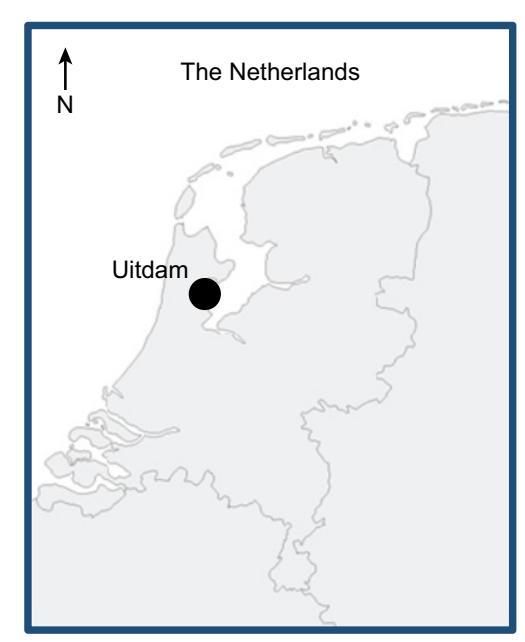

Fig. 54. Map showing Markermeer lake and location of Uitdam in the Netherlands 


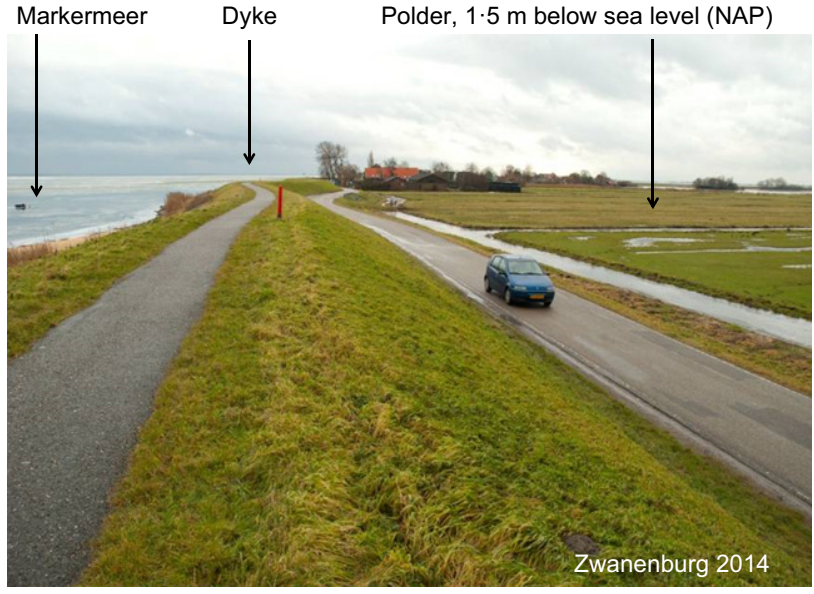

Fig. 55. Photograph by C. Zwanenburg of Markermeer flood dyke near Uitdam field test location

dyke raising to mitigate the potential effects of climate change.

The engineering goal was to enable design for strengthening works and provide a more robust flood defence, while minimising environmental impact and economic costs. Designers must satisfy minimum stability analysis targets covering both construction and in-service cases. Analyses of possible strengthening work schemes call for information concerning: (a) probable field consolidation rates; $(b)$ whether critical field failures would be drained or undrained events; $(c)$ how the governing operational shear strengths should be characterised; $(d)$ how to cater for the spatial shear strength variations that can be expected between the previously unloaded 'polder' areas and those that have been loaded for long periods; and $(e)$ information on ground movements. The Uitdam study progressed by considering first geology, then site characterisation through laboratory and in situ tests and finally comprehensive full-scale loading trials to check and calibrate the main conclusions from the research.

Ground conditions and peat properties at the Uitdam test site

A 1.6 ha area of agricultural polder land was acquired behind the existing dyke near Uitdam and six instrumented foundations, most combined with excavations, were set up and taken to controlled failures. Site characterisation involved comprehensive in situ testing with piezocones $(\mathrm{CPTu})$, field vanes (FVT) and ball penetrometer soundings, as well as 18 boreholes, sampled by the Begemann system, combined with careful geological logging. The geological profile was uniform across the test site, with $4.5 \mathrm{~m}$ of peats, classed as H2-H3 on the Von Post scale (Landva, 2006), which comprise Phragmites (with sedge and sphagnum inclusions) with minor vegetal decomposition. Water can be squeezed from the peat by hand, indicating relatively high permeability under low effective stresses. In situ falling head piezometer tests indicate 'free-field' permeabilities from $8.5 \times 10^{-7}$ to $2 \cdot 3 \times 10^{-6} \mathrm{~m} / \mathrm{s}$, far above those interpreted from oedometer tests; as noted also for Japanese peats by Hayashi et al. (2012). Organic and inorganic clays extend below the peat to approximately $8.8 \mathrm{~m}$ below ground level, beneath which a thin basal peat layer and thick Pleistocene aeolian sand are present.

The peat is $85 \%$ organic and has the density profile shown in Fig. 56. Although peat samples appear relatively dry, fibrous and crumbly, their natural water contents range from

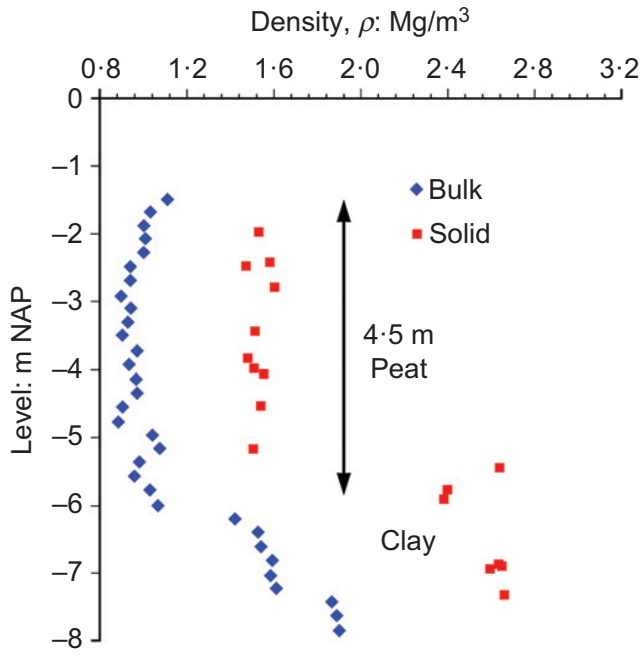

Fig. 56. Density profile for peat at Uitdam test site; after Zwanenburg \& Jardine (2015)

750 to $1200 \%$ and unit weights are close to that of water; the solid particles' specific gravities $G_{\mathrm{s}}$ are around 1.6. Free blocks of peat can float in ditches once all total stresses are released and some gas comes out of solution. Vertical effective stress levels are therefore very low in situ $(5 \mathrm{kPa}$ or less) and depend principally on the very minor degree of groundwater depression afforded by the ditches seen in Fig. 55. Historical periods of relative drought led to a thin surface 'crust' developing near ground level, which is evident in the water content, in situ penetration and laboratory oedometer yield stress $\sigma_{\mathrm{vy}}^{\prime}$ profiles. Oedometer tests on crust samples give $20<\sigma_{\mathrm{vy}}^{\prime}<30 \mathrm{kPa}$, with yield stresses dropping sharply to $\approx 14 \mathrm{kPa}$ below this and declining to around $8 \mathrm{kPa}$ at the peat's base; see Fig. 57. Higher values apply in the underlying lightly overconsolidated, soft clay. The peats' normally consolidated oedometer $C_{\mathrm{c}}$ values range from $2 \cdot 5$ to $4 \cdot 0$. Secondary compression coefficients are also high, with $C_{\alpha \mathrm{e}} / C_{\mathrm{c}} \approx 0.08$ and the welling stages of oedometer tests indicated coefficients $C_{\mathrm{s}}$ that were on average $0 \cdot 14$ of the respective $C_{\mathrm{c}}$ values.

Hayashi et al. (2012) report numerical analyses of field loading tests on peats and note that the outcomes proved highly sensitive to the assumed initial horizontal stress

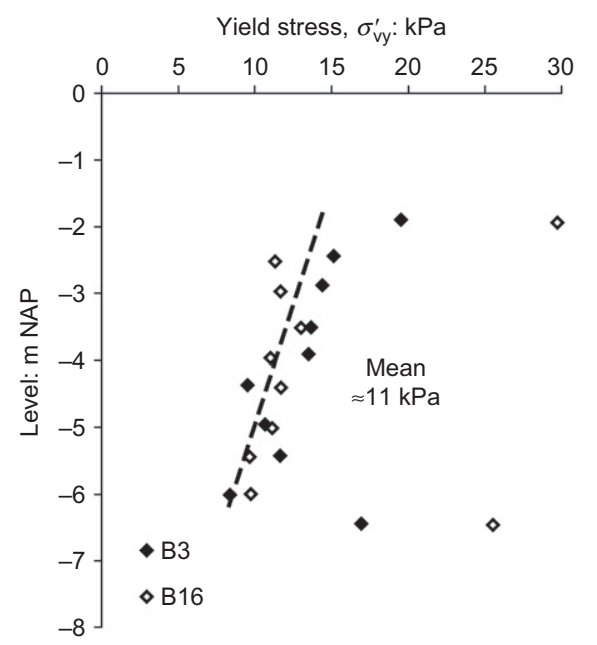

Fig. 57. Oedometer vertical yield stress profile for peat at Uitdam test site; after Zwanenburg \& Jardine (2015) 
profiles. The same authors report field and laboratory studies of the $K_{0}$ values applying at sites, showing these to be both sensitive to OCR and surprisingly low under normally consolidated conditions. Studies at four peat sites on Hokkaido led to the empirical expression given below as equation (14), which relates $K_{0}$ under normally consolidated conditions to the peats' percentage mass loss on ignition $L_{\mathrm{i}}$ (in \%) and predicts $K_{0}^{\mathrm{NC}} \approx 0 \cdot 26$ for the Uitdam peats, which corresponds closely to $K_{0}^{\mathrm{NC}}$ values determined from several constant strain rate tests run on Uitdam peat samples in oedometer cells instrumented to measure radial stresses.

$$
K_{0}^{\mathrm{NC}}=0.472-0.0025 L_{\mathrm{i}}
$$

The same authors show that, when overconsolidated, their peats' $K_{0}$ values could be expressed as $K_{0}^{\mathrm{OC}}=K_{0}^{\mathrm{NC}} \mathrm{OCR}^{n}$ where $n$ could be estimated from $L_{\mathrm{i}}$ through equation (15), which indicates $n \approx 0.88$ for Uitdam. The yield stress profile in Fig. 57 , in combination with the peats' $\approx 5 \mathrm{kPa}$ initial vertical effective stresses, indicates OCRs that fall from around 6 in the surface 'crust' to $\approx 1.8$ at the base of the peat, indicating in situ $K_{0}^{\mathrm{OC}}$ may approach or exceed unity near the surface and fall gradually to around $0 \cdot 43$ just above the clay.

$$
n=0.45+0 \cdot 005 L_{\mathrm{i}}
$$

Figure 58 presents stress-strain and effective stress path data from undrained tests conducted on Uitdam peat samples after isotropic consolidation to $10 \mathrm{kPa}<p^{\prime}<80 \mathrm{kPa}$. Most tests started from normally consolidated states and few showed clear deviator stress peaks, although all were taken to large strains. The isotropically consolidated undrained compression (CIU) tests' effective stress paths all tended towards the upper, zero radial effective stress tension limit, which cannot be crossed in routine triaxial tests and corresponds to the maximum possible $\phi^{\prime}=90^{\circ}$. Some tests appeared to turn and run up the no-tension line; the samples' fibrous nature may have allowed tensile circumferential effective stresses to develop. Fig. 58 also shows how undrained shear strengths were extrapolated for each test by Deltares, which indicated undrained shear strengths $\left(S_{\mathrm{u}}\right)$ in the $5-10 \mathrm{kPa}$ range under the polder areas' in situ stress conditions.

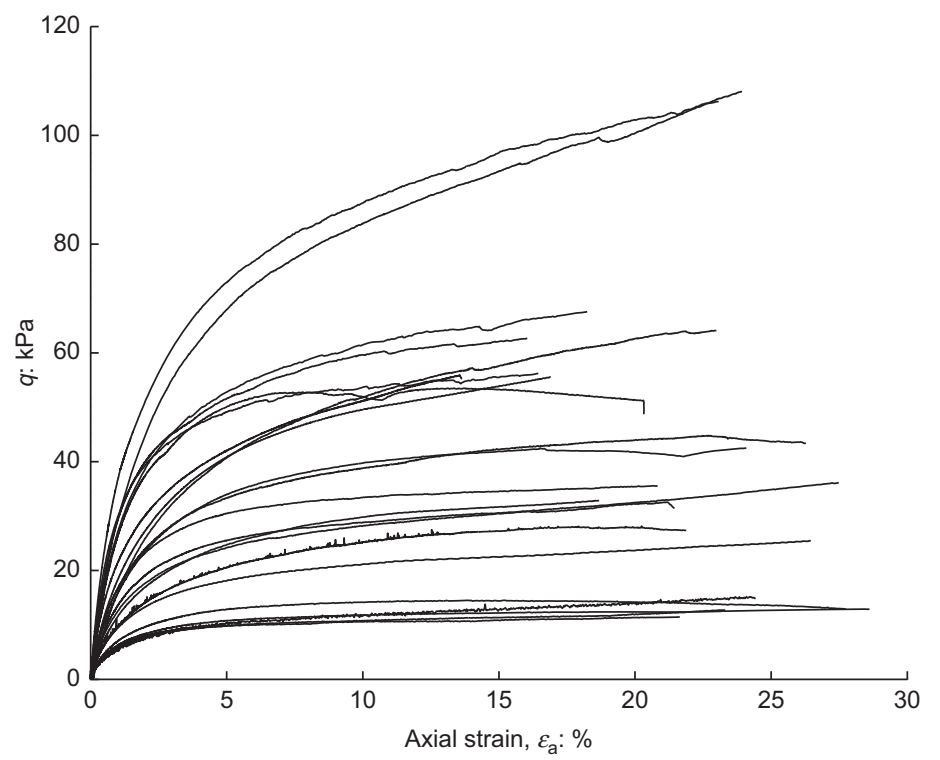

(a)
Similar, although slightly lower, $S_{\mathrm{u}}$ values were interpreted from simple shear tests which were consolidated to the estimated $5 \mathrm{kPa}$ vertical effective stresses. Although the absolute shear strengths were low, the average ratios of $S_{\mathrm{u}}$ to vertical consolidation stress $\sigma_{\mathrm{vy}}^{\prime}$ from normally consolidated samples were surprisingly high, $\approx 0.59$ for the CIU triaxial tests. A lower ratio $(0 \cdot 48)$ was inferred from direct simple shear tests when, as is conventional, $S_{\mathrm{u}}$ was assumed equal to the maximum horizontal stress. These ratios fall within the ranges reported for peats by Den Haan \& Kruse (2006), Mesri \& Ajlouni (2007) and Zwanenburg et al. (2012), but are around double those expected for most soft clays at OCR $=1$; Jardine (2002). Menkiti (1995) and Jardine \& Menkiti (1999) show that conventional simple shear strength interpretation underestimates true shear strength. Tests conducted on contractant specimens after $K_{0}$ normal consolidation fail with their $\sigma_{1}$ axes inclined at angles $\alpha$ (with respect to the vertical) well below the $45^{\circ}$ orientation expected conventionally.

\section{Design of the field trials}

Many studies have been made of soft organic clay behaviour under embankment loading, including those reported from the Thames estuary $(\approx 200 \mathrm{~km}$ southwest of Uitdam) by Marsland \& Powell (1977), Nicholson \& Jardine (1981) and Pugh (1978, 1985). However, the slope areas and minimum crest widths of trial embankments call for large surface footprint areas and unsustainable masses of lost fill. Back-analyses of failure can also be unduly sensitive to assumptions made regarding fill pore water pressures, soil parameters and tension cracks.

Jardine et al. (1995) and Lehane \& Jardine (2003) preferred to load rigid concrete pads with re-usable kentledge in single and multi-stage foundation tests at the Bothkennar site, whose location was shown in Fig. 8. The Uitdam field tests involved similar, although considerably larger and more refined systems of reusable, weighed, $2 \mathrm{~m}$ by $2 \mathrm{~m}$ and $140 \mathrm{~mm}$ thick concrete slabs, combined with controlled water tanks. Loading was applied over areas up to $28 \mathrm{~m}$ long and $7 \mathrm{~m}$ wide in a safe and effective

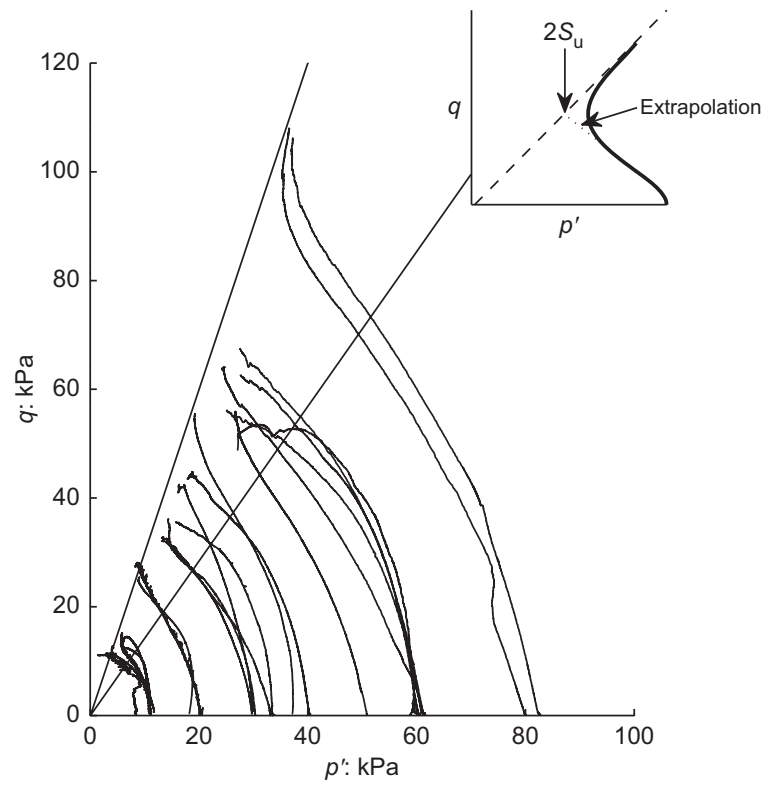

(b)

Fig. 58. Undrained tests on isotropically consolidated Uitdam samples: (a) stress-strain curves and (b) effective stress paths; after Zwanenburg \& Jardine (2015) 


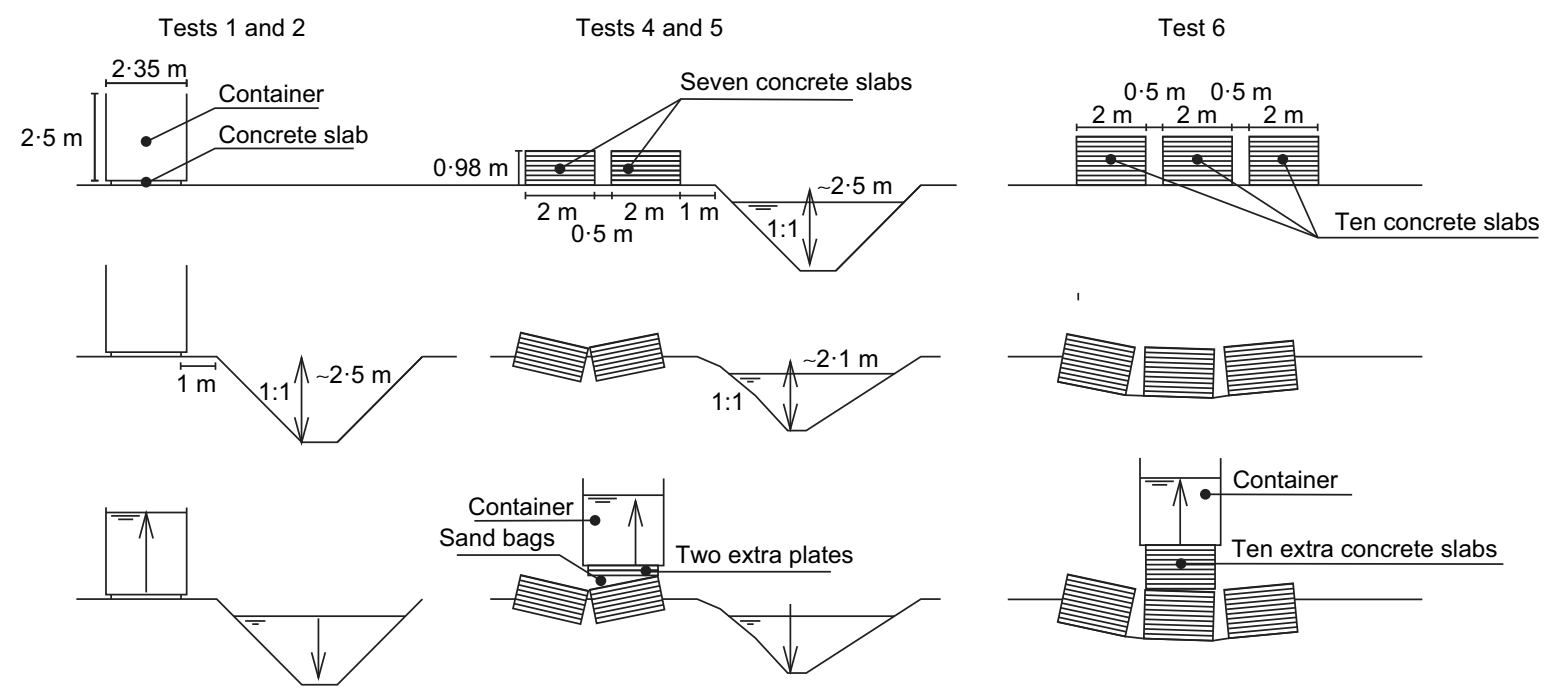

(a)

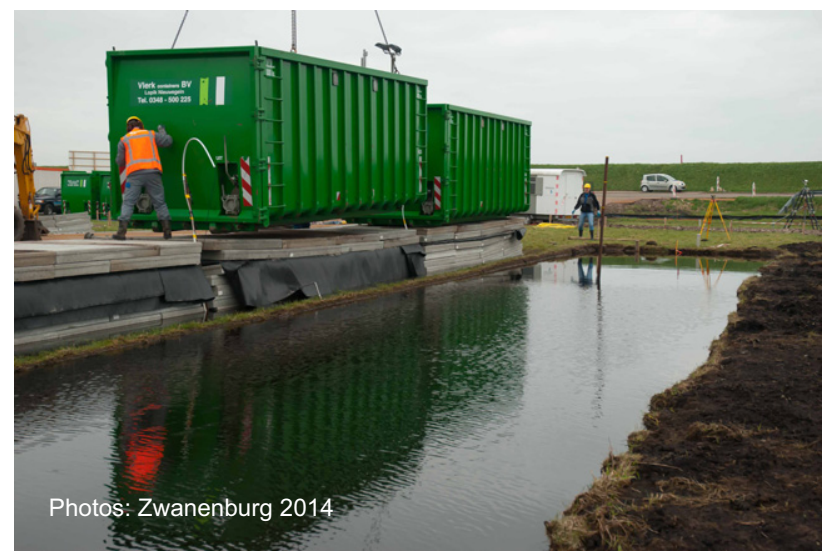

(b)

Fig. 59. (a) Cross-sections illustrating loading arrangements for Uitdam tests $1,2,4,5$ and 6 involving combinations of reusable concrete slabs, controlled water tank loading and (in four cases) ditches with $1: 1$ slopes whose water levels could be controlled by pumping. (b) Photograph by C. Zwanenburg of instrumented Uitdam field test, showing case with water-filled excavated ditch

manner. Multiple vibrating wire piezometers, along with settlement gauges and inclinometers, were installed beneath and around the concrete slabs. The experiments included excavating ditches with 1:1 slopes alongside the loaded areas to match the dyke's sloping geometry in four cases, as shown in Fig. 59(a), including the example shown in the photograph in Fig. 59(b). Failures were induced by adding concrete slabs in stages and gradually filling the remotely controlled water tanks. Water was also pumped out from the parallel ditches provided in four of the tests, which had filled shortly after being excavated. All ponded water levels were recorded; video records were made of each failure. Prolonged pre-loading stages were imposed in three tests to assess consolidation under load. Test 6 , which was conducted without any parallel excavation, applied the highest preload $(33.6 \mathrm{kPa})$ in four continuously monitored consolidation stages that extended for 215 days and led to $\approx 1.5 \mathrm{~m}$ settlement (and an average vertical strain of $35 \%$ ) in the peat before starting the controlled loading to failure; see Fig. 60. Zwanenburg and Jardine (2015) give full details of the loading sequences applied.

\section{Test outcomes}

The first findings from the Uitdam tests concerned the field consolidation rates. Pore pressures dissipated fully within 10 days under low load levels, but consolidation

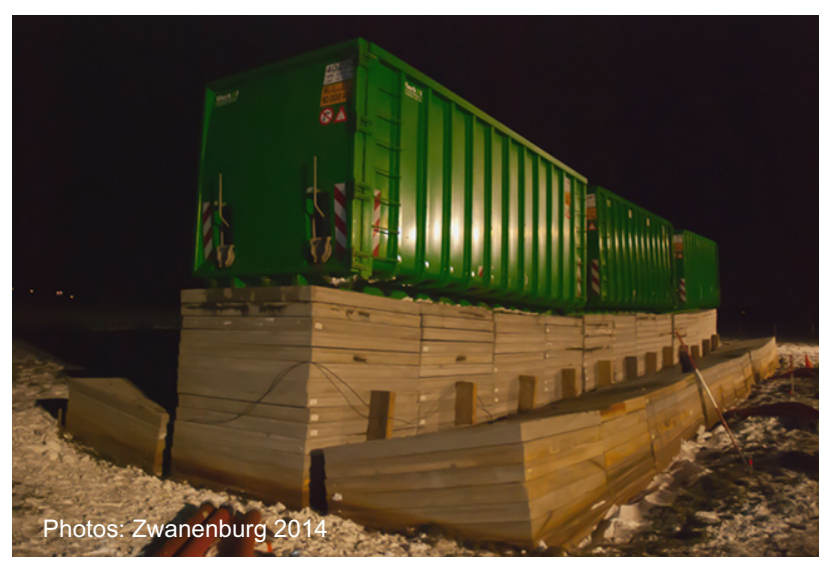

Fig. 60. Photograph by C. Zwanenburg of most heavily pre-loaded instrumented Uitdam field test 6 , note $1.5 \mathrm{~m}$ settlement developed under pre-loading

times extended to over 50 days in test 6 as bearing pressures were raised in steps to $33.6 \mathrm{kPa}$. Coupled FE consolidation analyses that applied permeability and compressibility data from oedometer tests greatly over-predicted field consolidation times. In situ permeability tests combined with laboratory compressibilities offered more representative estimates, 
although account had to be taken of permeability reducing as void ratios fell, as seen with organic Thames estuary clays by Nicholson \& Jardine (1981).

The next research aim was to assess whether field failures developed in a primarily drained or undrained manner. The responses seen on loading to failure are summarised in Figs 61(a) and 61(b). Generally, significant initial settlements of up to $500 \mathrm{~mm}$ developed with relatively small lateral movements over loading periods of 30 to $60 \mathrm{~h}$ before vertical movements accelerated suddenly, accompanied by rapid lateral movements of similar or greater magnitudes. It is interesting that test 6 , which was the most heavily pre-loaded case and had no associated ditch excavation, developed the smallest pre-failure settlements and lateral movements. It also manifested the most abrupt failure, as well as offering the highest overall bearing capacity. Jardine (2002) noted that patterns of ground movements developed by soft clays prior to single-stage loading failures are heavily influenced by partial consolidation, with water expulsion and volume changes contributing more than shear deformations over the early stages; he also argued that multi-stage failures are likely to be more abrupt than those seen under single-stage loading. Zwanenburg \& Jardine (2015) show that markedly non-hydrostatic pore pressures developed during the sudden failures, which the trials therefore proved to be primarily undrained events. Post-failure trial trenching confirmed the foundation failure mechanisms and identified clear tension ruptures.
The next pair of questions concerned: (a) how the governing operational shear strengths should be characterised and $(b)$ how to cater for the spatial shear strengths varying both with depth and laterally across the foreshore, under the dyke and beneath the 'polder'. Ideally, the back-analysis would be based on critical state models, as in the piling and permafrost studies. However, as demonstrated later, the peat's remarkable undrained shear strength characteristics cannot be matched with classical models such as modified Cam Clay. Before attempting to apply potentially complex 'peat-specific' constitutive formulations, the analysis started with a 'simple-as-possible' Tresca interpretation of the single-stage failures engendered in field tests 1 and 2, neither of which had experienced any significant pre-loading. Elastic, perfectly plastic, Plaxis FE analyses were undertaken for each case that captured, as shown in Fig. 62, the ground geometry shortly before failure, the weight and stiffness of the concrete slabs, the water tank loads and water levels in the ditches at failure (and in any depressed areas formed by ground settlement), as well as the presence and properties of the basal clay layer. The initial horizontal stresses were specified to be as compatible as possible with the assessed pre-loading $K_{0}$ and groundwater conditions. The operational Young's modulus was assessed as $500 \mathrm{kPa}$ in the 'polder' peat. Operational 'single-stage' $S_{\mathrm{u}}$ profiles having the same shape as the in situ test profiles reported in Fig. 63 were specified and varied systematically in multiple analyses of each case until a good match was achieved for the overall

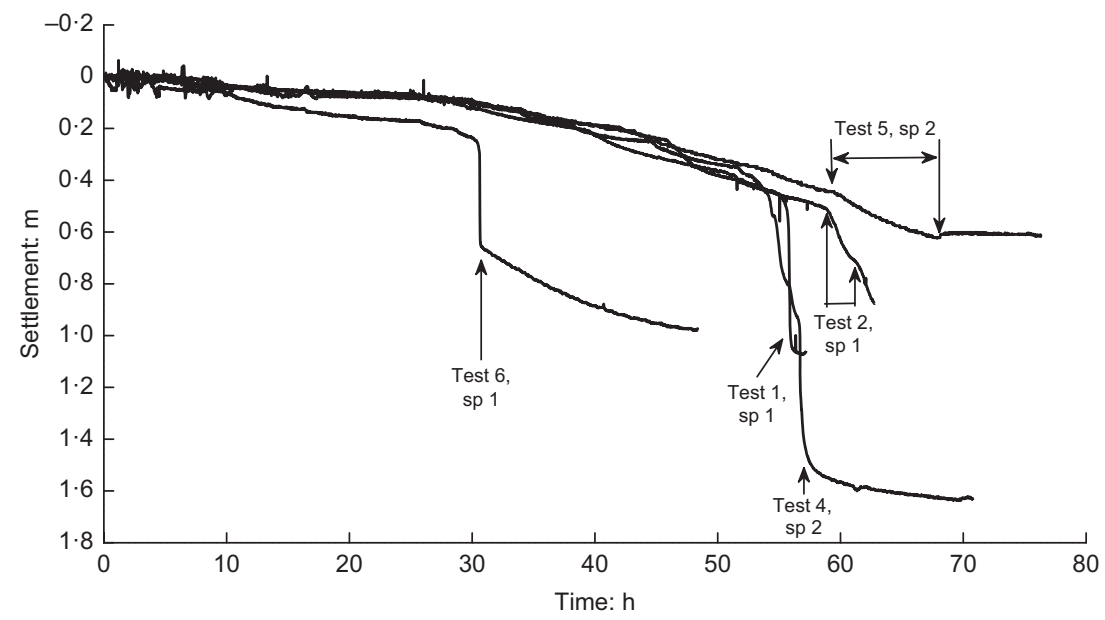

(a)

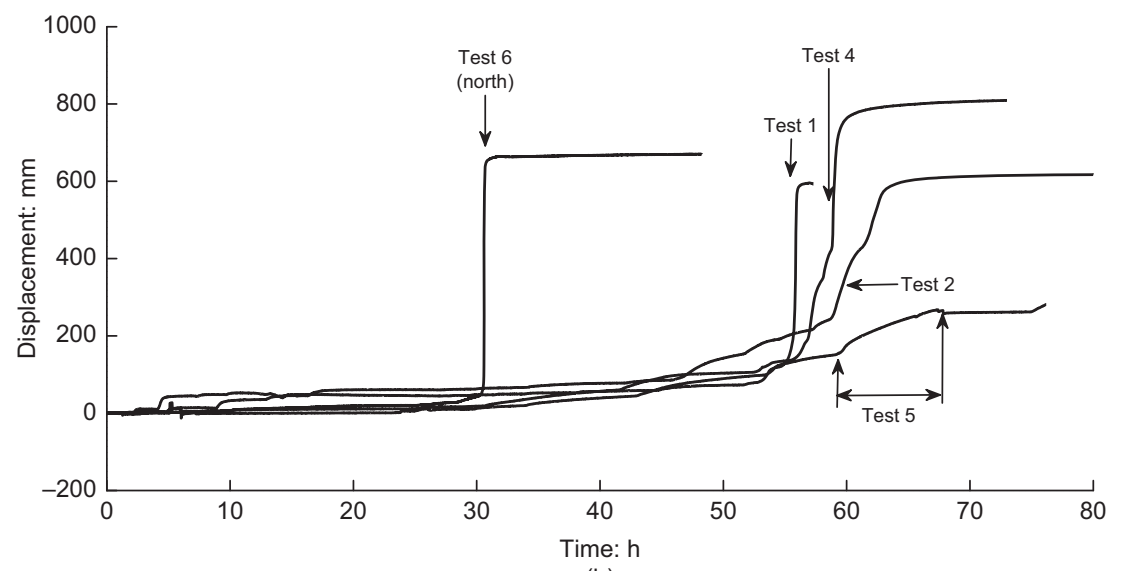

(b)

Fig. 61. (a) Concrete slab settlement-time responses seen on loading to failure of five Uitdam tests; modified from Zwanenburg \& Jardine (2015). (b) Maximum lateral ground movement-time responses seen on loading to failure of five Uitdam tests; modified from Zwanenburg \& Jardine (2015) 
collapse load and mechanism. Checks against solutions for bearing failures close to sloping ground by Georgiadis (2010) confirmed the accuracy of the FE results.

Back-analysis led to robust estimates for operational average 'polder' shear resistance as $7.3 \mathrm{kPa}$, well above the $\approx 1.7 \mathrm{kPa}$ assessed by the current Dutch effective stress based characterisation approach. This average correlated with the average oedometer vertical yield stress $\sigma_{\mathrm{vy}}^{\prime} \approx 11 \mathrm{kPa}$. Both $S_{\mathrm{u}}$ and $\sigma_{\mathrm{vy}}^{\prime}$ can be expected to vary with depth as shown in Figs 57 and 63, reflecting prior drought events, the peat's very low submerged unit weights and prior creep compaction. The operational single-stage field shear strengths, which fell in the same range as the triaxial and direct simple shear strengths for the undisturbed polder areas, were employed to calibrate factors $N_{\mathrm{kt}}=15 \cdot 3$, $N_{\text {ball }}=16.5$ and $\mu=0.5$ for three types of in situ tests, as specified in equations (16)-(18).

From CPTu

$S_{\mathrm{u}}=\left(q_{\mathrm{t}}-\sigma_{\mathrm{v} 0}\right) / N_{\mathrm{kt}}$

From ball penetrometer

$S_{\mathrm{u}}=q_{\text {ball }} / N_{\text {ball }}$

For FVT

$S_{\mathrm{u}}=\mu S_{\mathrm{u}}^{\mathrm{FVT}}$
Zwanenburg \& Jardine (2015) describe how the single-stage failure analysis outcomes were carried forward in iterative FE analyses of the three pre-loaded 'multi-stage' loading cases. Figure 63 shows the $S_{\mathrm{u}}$ values found from applying the calibrated $N_{\mathrm{kt}}, N_{\text {ball }}$ and $\mu$ factors to soundings conducted in the test 6 area prior to any loading. Note that the $\mathrm{CPTu}$ and ball cone profiles show far lower degrees of scatter than the FVT, finer resolution and greater reliability. These profiles, which indicate marginally weaker initial conditions for tests 1 and 2, defined the shear strengths assumed for back-analysis of test 6 in areas that had not experienced consolidation before being failed. The higher average shear strength and stiffness required in the 'consolidated' region to match the observed collapse conditions were then determined, taking account of in situ CPT and other test soundings that tracked the strength gains within the 'consolidated' area. Iterations led to FE solutions that were as compatible as possible with the in situ tests and stress conditions indicated by the FE analysis.

Back-analyses of the three multi-stage cases were combined with the single-stage outcomes to develop the correlation presented in Fig. 64 between the average operational $S_{\mathrm{u}}$ and vertical effective stress $\sigma_{\mathrm{v} 0}^{\prime}$ applying in the test areas just before each final loading to failure took place. An interpreted field $S_{\mathrm{u}}-\sigma_{\mathrm{v} 0}^{\prime}$ relationship is shown that is linear and passes through the origin for normally consolidated
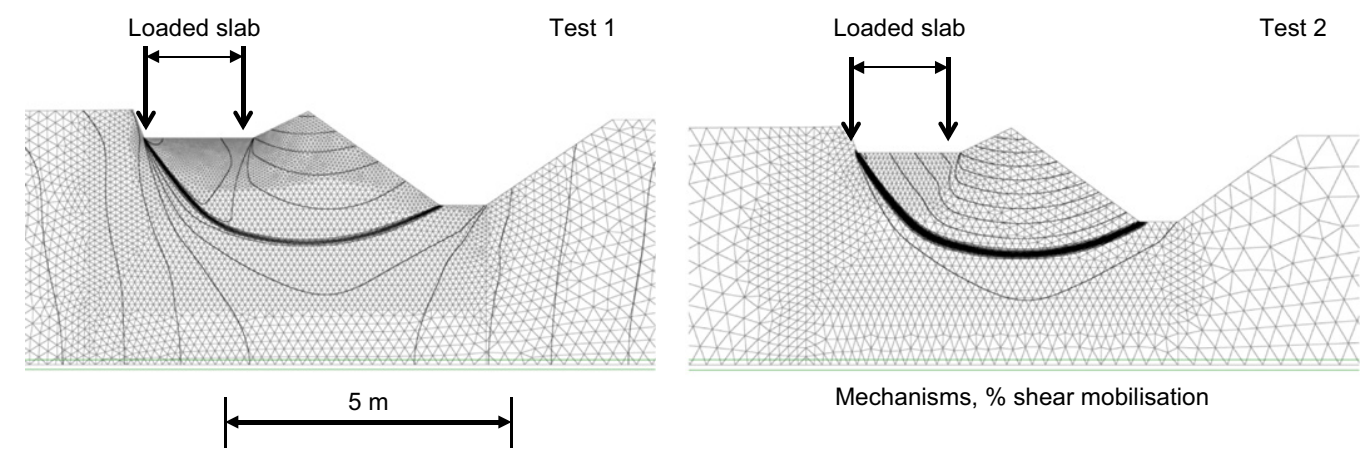

Fig. 62. Finite-element analyses of tests 1 and 2, accounting for ground geometry shortly before failure, concrete slab properties, water tank loads, water levels in ditches and the basal clay layer
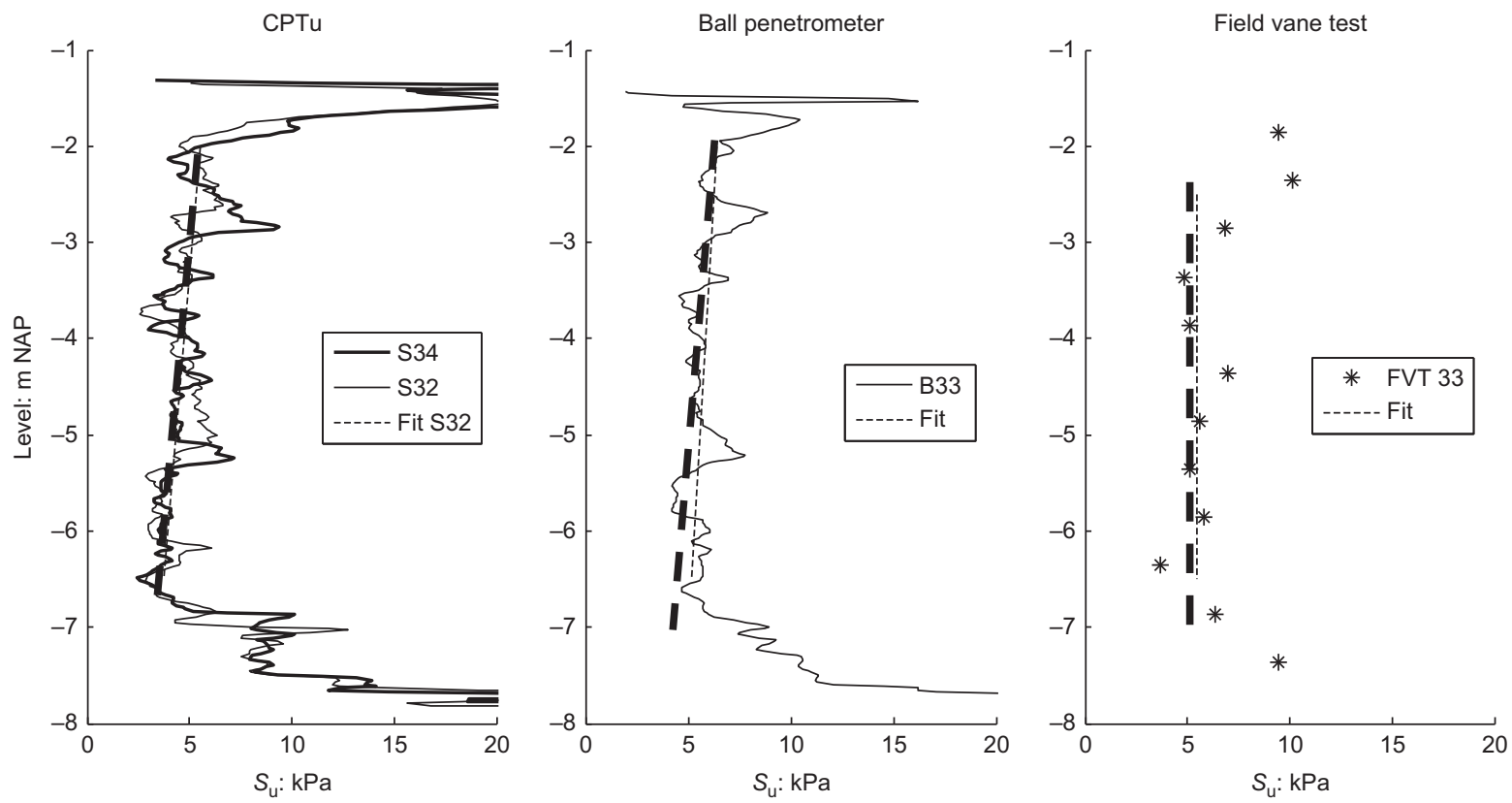

Fig. 63. Profiles for operational $S_{\mathrm{u}}$ in test 6 area prior to any loading, applying the calibrated $N_{\mathrm{kt}}, N_{\mathrm{ball}}$ and $\mu$ factors to piezocone, ball penetrometer and field vane soundings 


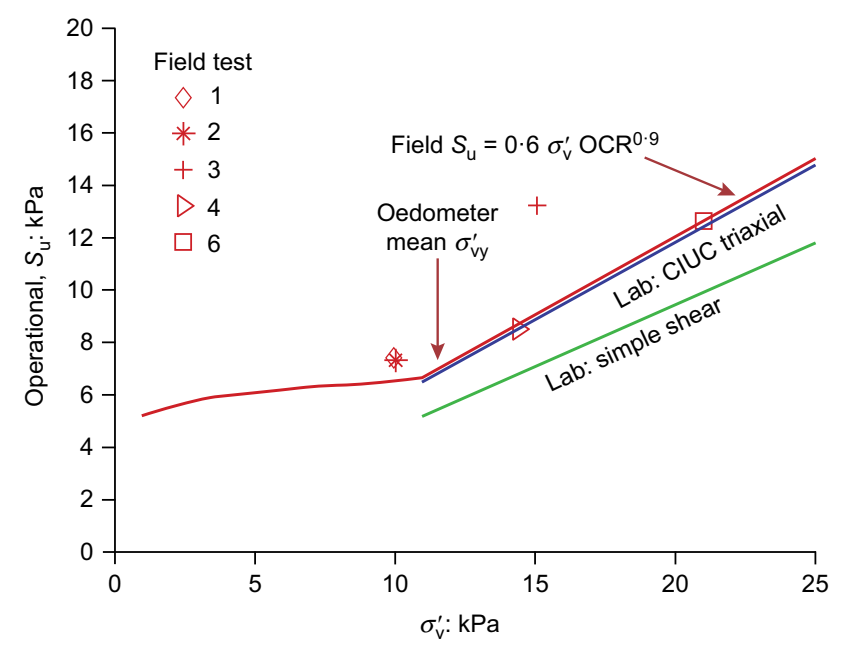

Fig. 64. Undrained shear strength data back-analysed from field tests at Uitdam. Mean operational values at failure plotted against vertical effective stresses to which ground had been consolidated prior to loading to failure, covering both single-stage and multi-stage loading cases

states, where $\sigma_{\mathrm{v} 0}^{\prime}$ exceeds the mean oedometer vertical yield stress of $11 \mathrm{kPa}$ (see Fig. 57) and gives a relatively flat curve $S_{\mathrm{u}}-\sigma_{\mathrm{v} 0}^{\prime}$ for lightly overconsolidated states in which $\sigma_{\mathrm{v} 0}^{\prime}<11 \mathrm{kPa}$. The proposed relationship provides a lower bound to the back-analysis results and follows the Shansep form proposed by Ladd \& Foot (1974), given in equation (17), which is also compatible with that expected within classical critical state soil mechanics.

$$
S_{\mathrm{u}}=\sigma_{\mathrm{v} 0}^{\prime}\left(S_{\mathrm{u}} / \sigma_{\mathrm{v} 0}^{\prime}\right)^{\mathrm{NC}} \mathrm{OCR}^{m}
$$

The best-fitting $\left(S_{\mathrm{u}} / \sigma_{\mathrm{v} 0}^{\prime}\right)^{\mathrm{NC}}=0.6$ is remarkably high, although close to the average $(0.59)$ interpreted from CIU triaxial tests and $25 \%$ above that gauged from the conventional interpretation of the direct simple shear tests, which underestimate true simple shear strength. The exponent $m=0.9$ is compatible with a $C_{\mathrm{s}} / C_{\mathrm{c}}$ ratio $\approx 0 \cdot 1$, which is broadly consistent with the $0 \cdot 14$ ratio given by oedometer tests on Uitdam samples. The normalised field test results can be used in consolidated undrained analyses of dyke stability, provided the profiles of OCR and vertical in situ stresses can be estimated reliably across any given cross-section.

The peat has very low stiffness, so potentially large ground movements can be expected under loading that may be assessed through classical methods calibrated to the laboratory and field observations. Long-term vertical strains are likely to be exceptionally large and amount to $80 \%$ under the existing dyke centre-line. It is therefore vital to make allowance for geometry changes as well as strain rate dependency and creep when making such assessments. Scope clearly exists for analytical refinement. Large-strain analyses would represent the long-term field test conditions more faithfully, as would a 3D treatment that accounted for the test footings' limited lengths. Coupled consolidation treatments that captured permeability and compressibility varying with void ratio, as well as the spatially varying operational undrained shear strengths and shear deformations, within a critical state effective stress-based framework, would be very valuable. As noted earlier, such analyses would need to start from realistic $K_{0}$ initial stress profiles to be successful.

However, the surprisingly high $S_{\mathrm{u}} / \sigma_{\mathrm{v} 0}^{\prime}$ ratios found for the peat by field and laboratory tests cannot be recovered with classical critical state models. Potts \& Zdravkovic (1999) provide equations (20) and (21) for modified Cam Clay, in which

(a) the ratio $\kappa / \lambda$ is defined by the isotropic swelling and virgin compression (VCL) $v-\ln p^{\prime}$ slopes

(b) the $g(\theta)$ yield function gradient $J / p^{\prime}$ varies with the Lode angle $\theta$ in the deviatoric plane, where $\theta=0$ under plane strain and $-30^{\circ}$ under triaxial compression conditions.

(c) the results are highly sensitive to $K_{0}^{\mathrm{NC}}$.

$$
\begin{aligned}
& S_{\mathrm{u}}=\sigma_{\mathrm{vo}}^{\prime} g(\theta) \cos \theta\left(\frac{1+2 K_{0}^{\mathrm{NC}}}{3}\right)\left[\frac{1+B^{2}}{2}\right]^{1-(\kappa / \lambda)} \\
& B=\frac{\sqrt{3}\left(1-K_{0}^{\mathrm{NC}}\right)}{g\left(-30^{\circ}\right)\left(1+2 K_{0}^{\mathrm{NC}}\right)}
\end{aligned}
$$

The Uitdam laboratory tests confirm that the peats' highly compressible behaviour can be described, on average, as following $v=9.9-1.43 \ln p^{\prime}$ on the isotropic VCL while swelling tests indicate $\kappa / \lambda \approx 0 \cdot 1$. If this ratio is adopted, the above equations can predict the maximum plane-strain undrained shear strength ratio once a $g(\theta)$ yield function is chosen. If one assumes for simplicity a circle in the deviatoric plane, and substitutes $\phi_{\mathrm{cs}}^{\prime}$ values into $g(\theta)=\sin \phi_{\mathrm{cs}}^{\prime}$ and assumes $K_{0}^{\mathrm{NC}}=0 \cdot 26$ (from both equation (14) and the instrumented Uitdam oedometer tests), equations (20) and (21) lead to a range for plane strain $S_{\mathrm{u}} / \sigma_{\mathrm{v} 0}^{\prime}$ at OCR $=1$ that is relatively insensitive to $\phi^{\prime}$ at high angles and increases only marginally from 0.43 to 0.44 as $\phi^{\prime}$ rises from 45 to $90^{\circ}$. The maximum plane-strain $\left(S_{\mathrm{u}} / \sigma_{\mathrm{v} 0}^{\prime}\right)^{\mathrm{NC}}$ achievable with modified Cam Clay falls almost $40 \%$ below the $\approx 0.6$ ratio found in the laboratory and field experiments. The mismatch results from the tensile resistance of the peat fibres, which may allow negative minor principal effective stresses at ultimate failure. While the peat could be modelled conservatively by adopting modified Cam Clay (taking an arbitrary $\phi^{\prime}$ well below $90^{\circ}$ ) in combination with suitable initial $K_{0}^{\text {nc }}$ values, such an approach could not reproduce the field foundation failures accurately in any back-analysis.

The simpler uncoupled approach interpreted from the Uitdam trials offers a practical interim means of characterising shear strength from laboratory and in situ tests to aid flood dyke strengthening works and counter the increased flooding risks that are expected to result from climate change. Further laboratory research and modelling developments are required to characterise the peat fibres' contribution to mechanical behaviour, as well as consider its strain rate dependency and potential mechanical anisotropy within an appropriate, critical-state, framework.

\section{Applicability to other settings}

The findings from Uitdam have implications for other peatlands, which make up around 3\% of the earth's surface. While approximately $11 \%$ of the European land mass is covered by peat, the largest areas are found in Russia, Canada, USA and Indonesia; extensive peat deposits are found as well in tropical Africa, Latin America and the Caribbean; World Energy Resources (WER, 2013).

Peats are also present offshore. Some peatlands that formed inland during the ice ages, when sea levels were up to $120 \mathrm{~m}$ lower, are now submerged below sea level on shallow sections of the continental shelf. Such deposits formed in wetland areas between south-east England and 
northern Europe that were both partially eroded and covered by marine sediments as sea levels rose in the Holocene. Organic matter and peat is often found in geotechnical boreholes drilled in the shallower parts of the southern North Sea. For example, a large-diameter tree trunk was found 'sampled' at a depth well below sea level when one of the open EURIPIDES steel pipe piles was extracted at the coastal Eemshaven site in Holland (Kolk et al., 2005b). Similar observations can apply to the permafrost areas considered in the first Part 2 topic. Large areas of thick permafrost that formed at low onshore altitudes in polar coastal regions during the glacial maxima are now encountered beneath the seafloor by offshore geotechnical surveys. While the paired Part 2 topics primarily concerned onshore geotechnical engineering, they also have implications in some offshore settings.

\section{PART 3 - GEOTECHNICAL CONTRIBUTIONS TOWARDS IMPROVING RENEWABLE ENERGY EFFICIENCY AND SAFETY The energy conundrum}

Part 2 of this paper outlined collaborative and integrated research into modelling the ground's response to climate change and improving flood defences in response to climate hazards. New tools employing a range of complexities were described that can address the design of climate-change-resistant infrastructure in both cold and temperate regions. Careful checks confirmed that the tools are sufficiently representative of field behaviour to be fit for practical use. Several research areas were identified which appear ripe for further research and elaboration.

However, the 2015 Paris international COP21 conference concluded that decisive and immediate action is required to tackle the root causes of future climate change. Applying AOGCMs in conjunction with the currently agreed intended nationally determined contributions indicates that, even if all national commitments are honoured, the climate is likely to warm globally by $2 \cdot 7$ to $3 \cdot 2^{\circ} \mathrm{C}$ by 2100 . To avoid this outcome requires greenhouse gas emissions to peak by 2025 and reduce to minimal levels by 2100 . Tools such as those available on INDCs (2016) indicate that around 1400 coal burning power stations will need to close over coming decades and oil consumption fall sharply. New technologies will be required for carbon capture and storage, transport, heating and electrical power supplies.

The UK's currently stated aim is to achieve an $80 \%$ reduction in carbon emissions by 2050 . Coal electricity generation is scheduled to end by 2025 and greater reliance is to be placed on gas, nuclear and offshore wind resources. Part 3 of this paper outlines geotechnical research to improve the economics of offshore wind electricity generation by reducing the costs of foundations, which account for around $25 \%$ of total offshore wind farm capital expenditure.

\section{Geotechnics and offshore wind energy development}

Offshore oil and gas production commenced with shallow water oil and gas installations founded on soft Quaternary Gulf of Mexico deposits, before spreading to a range of international geological settings and extending to water depths greater than $3 \mathrm{~km}$. In a similar way, offshore wind developers concentrated initially in shallow northern European waters. In 2017 two-thirds of the world's operating capacity was installed offshore the UK $(36 \%)$ and Germany $(29 \%)$. However, sites with greater water depths are being developed in North Europe and the Asian-Pacific and US markets are growing rapidly; China now has the third largest installed capacity; Global Wind Energy Council (GWEC, 2017).

To date most wind farms have involved water depths of less than $30 \mathrm{~m}$ and relied on monopile foundations. However, multi-pile jacket and tripod structures are becoming more common at deeper water sites and have been employed in depths up to $60 \mathrm{~m}$. Statoil's Hywind floating design is now operating offshore Peterhead, Scotland, in $129 \mathrm{~m}$ of water and could be deployed in up to $800 \mathrm{~m}$ water depths (Statoil, 2017). Other foundation solutions exist, including gravity bases and suction caissons, but these have yet to be used as widely. One significant difference with oil and gas installations is that greater attention must be given to foundation stiffness. Turbine operation is sensitive to the support structures' resonant frequencies - which depend on foundation response, as do the structures' fatigue lives. Permanent movements related to operating and storm loading conditions must also be limited. The current industry standard DNV-GL (2016) design recommendations call for fixed wind turbines' vertical axes to tilt by less than $1.5^{\circ}$ over their (typically 20 year) design lifetimes.

As ever, it is vital to consider geology. Developers working with the sands and clays found under much of the UK North Sea (see Fig. 2) have been able to optimise their axial pile designs by applying the oil and gas piling research described in Part 1. However, it may be recalled from Fig. 2 that the Quaternary deposits thin towards the UK's eastern coastline, where many wind farms are sited, and are absent from large sections of its coast. New projects are encountering older strata more frequently at foundation depth, ranging from Tertiary London Clay in the UK's largest operating London array wind farm through to Chalk on both sides of the English Channel and on Baltic coastlines. Older and stronger rocks are met on the UK's west coast and north of Flamborough Head on the east, as is the case in France to the south of Le Havre, where igneous and metamorphic rocks are found. Conventional pile driving may not be suitable or even feasible in these strata and far less guidance is available to aid foundation design.

Developments in the Asian-Pacific and other growth regions are also posing new challenges, which include potentially greater seismic hazards and typhoon storm loading. Design rules that work well for silica sands are not applicable to carbonate or mica sands, silts or very silty sands; some very silty clay types also exist for which clay methods give very poor predictions (Jardine et al., 2005a; Lehane et al., 2017). New research and site-specific testing is required to achieve reliable, cost-effective design for the thousands of wind turbines that will be installed worldwide in the next decade. Part 3 of the paper covers two areas of research designed to improve offshore wind economics and safety. First, improving pile design for jacket, tripod or floating wind turbine support structures is considered, and finally, recent research that advances monopile foundation design.

\section{TOPIC 3.1: IMPROVING THE DESIGN OF OFFSHORE WIND TURBINES SUPPORTED BY MULTIPLE \\ DRIVEN PILES}

Part 1 of the paper described research to improve predictions for the load-displacement and axial capacity of offshore driven piles and its application in oil and gas projects. The driven piles employed for jacket or tripod supported wind turbines work in a similar way to oil and gas jackets: they carry wind and wave moment loads through an axial push-pull loading system, although cyclic loading may be a more significant issue due to the relatively low self-weights of the wind turbine structures. Below, the focus is placed on axial behaviour, starting with two projects where 
the ICP-05 static and cyclic analysis design approaches were employed at North Sea Quaternary sand and clay sites before moving to less familiar geomaterials. The piles' loaddisplacement response to combined lateral and moment loading is the principal focus of the second, monopile, Part 3 topic.

\section{Application of modern design tools at North Sea sand and clay sites}

Trianel's Borkum West II wind farm has been operating since 2015 at the location shown in Fig. 65. Forty large tripod units were positioned, as shown in Fig. 66, in up to $33 \mathrm{~m}$ of water over 120 submerged, pre-driven, open-ended $2.48 \mathrm{~m}$ outer diameter (OD) steel piles to provide support structures for $5 \mathrm{MW}$ turbines. The project's collaborative design approach is described by Merritt et al. (2012) and Jardine et al. (2015b). Fig. 67 illustrates the range of Quaternary clay and sand deposits encountered, contrasting one turbine location's mixed sand-and-clay CPT $q_{\mathrm{c}}$ profile (A) with another (B) from a location where very dense sand was present from $14 \mathrm{~m}$ depth. Fig. 68 presents the axial capacity-depth curves derived from the ICP-05 and main text API (2014) procedures for the two locations. Adding a

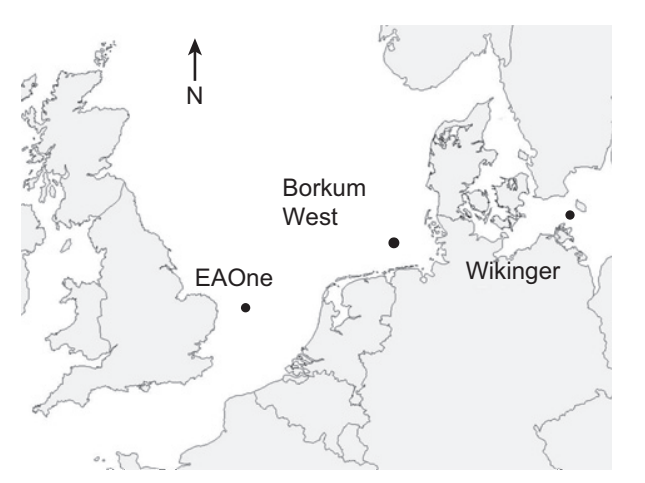

Fig. 65. Site locations for Borkum West II, EAOne and Wikinger offshore windfarms in German and UK waters

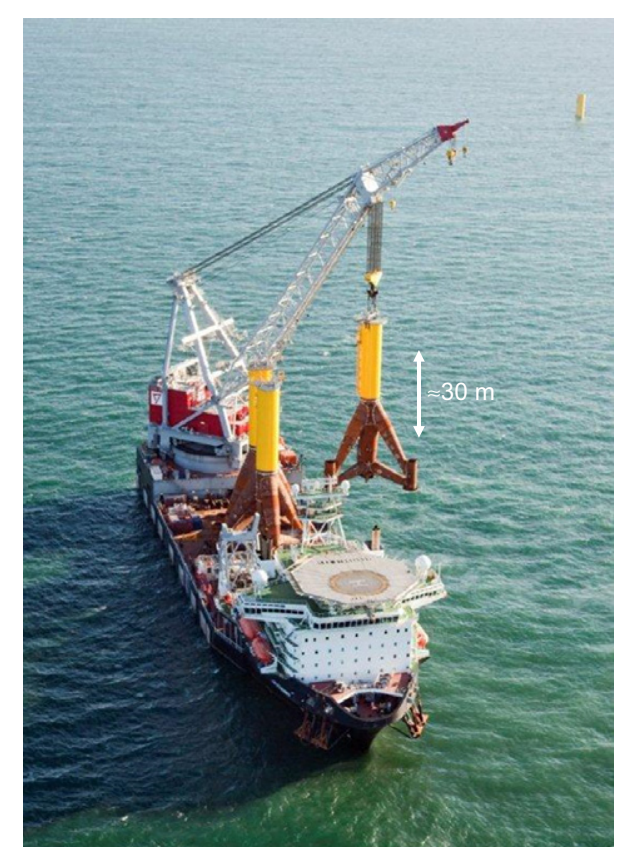

Fig. 66. Photograph of Borkum West II tripod foundation structures being positioned over pre-driven piles; courtesy Trianel nominal $40 \mathrm{MN}$ compression capacity target helps indicate how significant economies could be made in steel and installation costs by applying the ICP-05 at profile A, while far greater benefits could be taken at profile B. The final design made explicit allowance for the potential effects on capacity of the axial and lateral cyclic loading imposed by the 50 year design storm through the ICP-05 framework. All piles were driven without difficulty and were left to age in situ before the tripods and turbine superstructures were installed.

The EAOne wind farm is currently under construction for Scottish Power Renewables as part of the East Anglia offshore array, at the location shown in Fig. 65. Development is currently in hand for three substantial further phases. Rattley et al. (2017) describe the approach taken to design foundations for the 102 three-legged jackets that will support $7 \mathrm{MW}$ turbines with $154 \mathrm{~m}$ dia. rotors in up to $53 \mathrm{~m}$ of water. Great care was given to characterising the mainly Quaternary clays and silica sands encountered through geophysics, drilling and sampling combined with in situ testing. The ICP-05 static and cyclic pile design procedures were applied from the site investigation stage onwards, initially as live tools to help optimise drilling, sampling and in situ testing. The laboratory testing included extensive programmes of cyclic triaxial and simple shear tests, which applied the principles set out by Aghakouchak et al. (2015) as described in Part 1. Very significant economies were made by adopting ICP-05 rather than the API (2014) main text approaches. Further benefits remain to be harvested in future projects by applying the small-strain laboratory and FE approach described in Part 1 to model load-displacement behaviour.

Research to aid piling in less well-characterised geomaterials While procedures exist to optimise pile design at Quaternary clay and sand sites, greater uncertainty arises for piles bearing into the older geomaterials encountered around north-west European coastlines. Drilled rock socket or drill-drive solutions are being adopted for harder rocks where driving cannot be considered, sometimes supported by trials and tests at onshore analogue sites. However, even when driving is feasible, it is often difficult to predict pile capacities and load-displacement characteristics accurately. One of the most commonly encountered older strata is the Chalk and consideration is given below to research into designing foundations in this high-porosity, calcareous, very soft rock.

\section{Driven pile behaviour in chalk}

Chalk-like deposits are found worldwide, including areas of the Middle East and North America. It is also present under the north-west European area shown in Fig. 69, where it occurs as a white, low-density, structured, fine-grained, porous, weak, carbonate rock containing dark grey, diagenetically converted, silica flint nodules and layers. Chalk was deposited by prodigious marine biological production of foraminifera shells and coccolith muds. The low-to-medium north-west European Chalks have unconfined compressive strengths (UCS) from $<3$ to $5 \mathrm{MPa}$ (Bowden et al., 2002) and cone tip resistance, $q_{\mathrm{c}}$, from 4 to $50 \mathrm{MPa}$ (Power, 1982).

Current driven pile design practice in Chalk involves adopting the CIRIA C574 recommendations (Lord et al., 2002), taking ultimate shaft resistances of $120 \mathrm{kPa}$ for high-density chalk and $20 \mathrm{kPa}$ in all other densities and grades, values that appear very low in comparison with the Chalk's UCS and $q_{\mathrm{c}}$ ranges. The CIRIA guidelines, which were based on a small database of uncoordinated tests, offer designers a stark choice which can impact very significantly on wind farm economics. Lord et al. (2002) suggest 

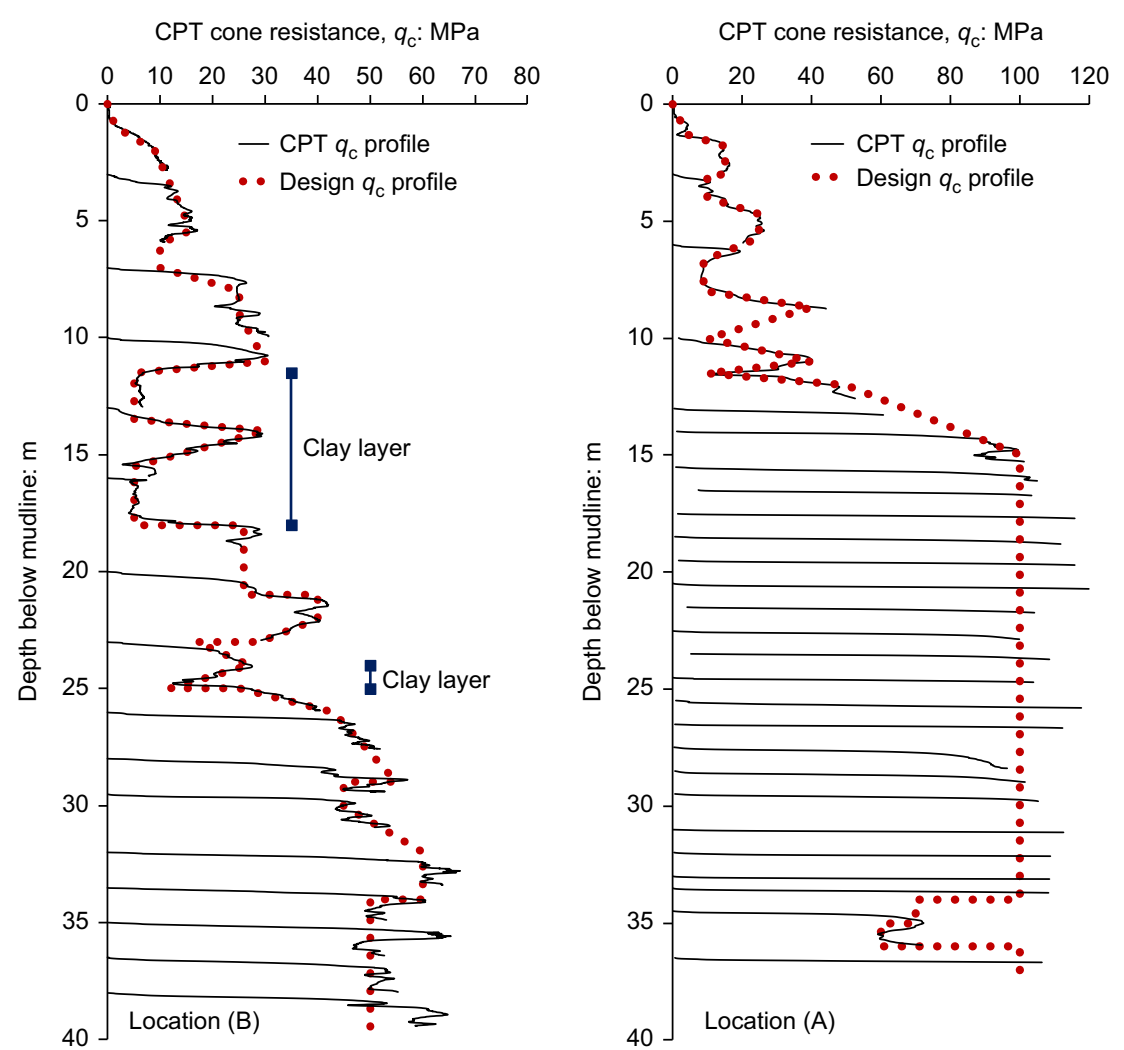

Fig. 67. Cone penetration test profiles for Borkum West II, locations A and B
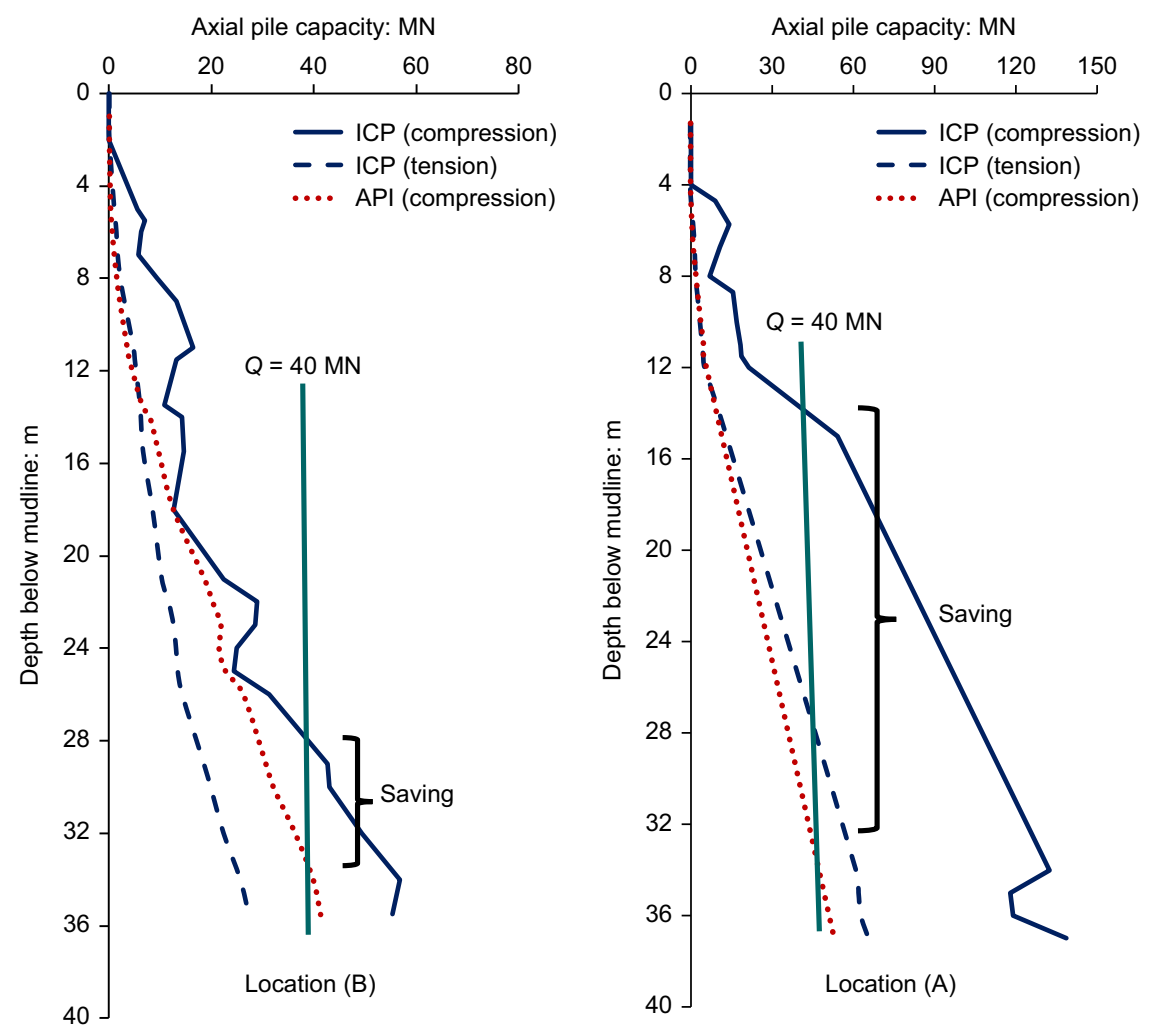

Fig. 68. Static axial capacity depth profiles by API (2014) main text and ICP-05 procedures for Borkum West II, locations A and B

site-specific pile load tests wherever possible, including checks on any beneficial set-up over time.

Pile refusals have been reported on driving through hard, high-density chalk. However, large-diameter piles installed at low-to-medium-density chalk offshore wind farm sites have penetrated (or 'run') to considerable depths under their self-weights; (Esper, 2017; Carotenuto et al., 2018). Driving is thought to de-structure the high-porosity material and 


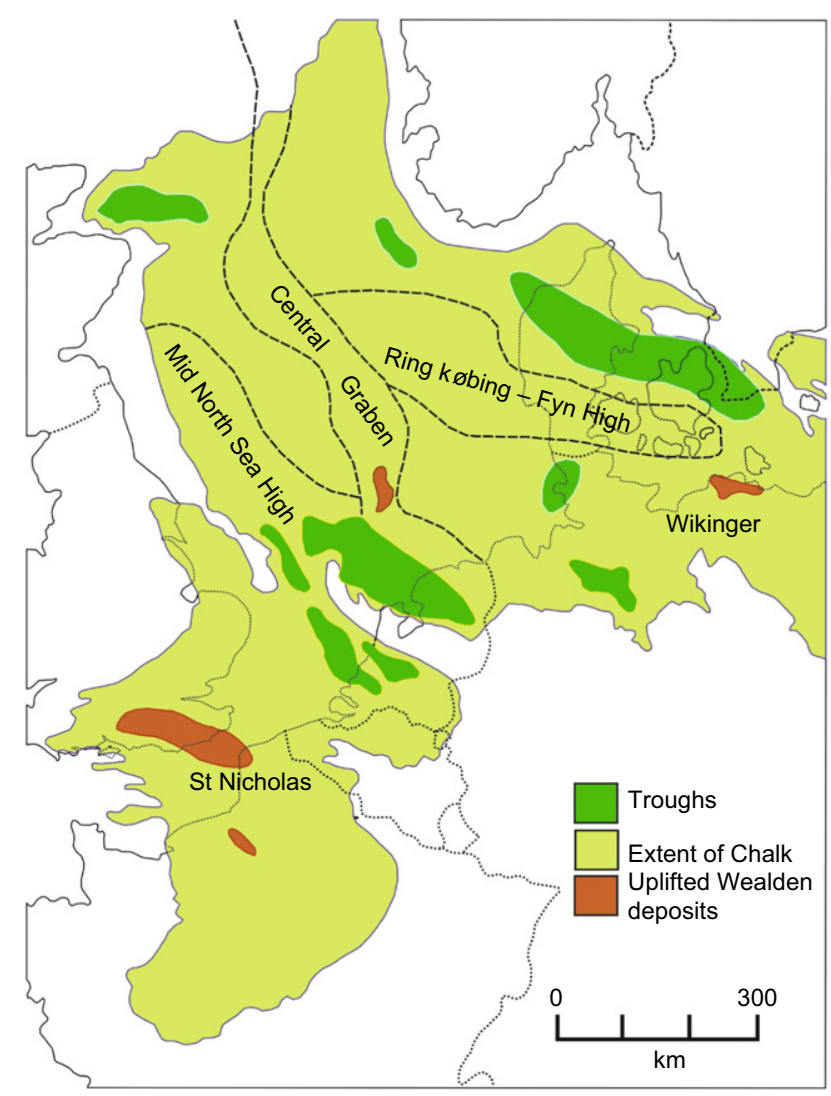

Fig. 69. Distribution of Chalk beneath NW Europe, after Mortimore (personal communication, 2016) with Wikinger and St Nicholas at Wade test site locations added

leave a low-strength 'putty' around pile shafts (Hobbs \& Atkinson, 1993) whose low shear resistances can be matched by applying high-level cyclic loading in laboratory simple shear tests (Carrington et al., 2011; Diambra et al., 2014) or by simple Proctor laboratory compaction carried out at the natural water content (Doughty et al., 2018). The reports of offshore pile 'runs' prove that very low shaft stresses can develop without cycling when the Chalk experiences very large shear strains.

Set-up has been reported for piles driven in Chalks by Vijayvergiya et al. (1977), Skov \& Denver (1988) and Lahrs \& Kallias (2013). Programmes of re-tests on research piles driven at the UK St Nicholas-at-Wade test site identified in Fig. 69 also showed marked capacity growth; Ciavaglia et al. (2017). Doughty et al. (2018) show that de-structured Chalk putty produced by dynamic compaction at natural water content can strengthen slightly over time at constant water content through thixotropy, although far more significant changes can be achieved through consolidation to higher effective stresses. Physio-chemical reactions, including corrosion of the steel pile shafts, may also progress in situ over time around pile shafts after driving.

An urgent need existed for research to refine pile driveability assessment and design for service performance in Chalk, ideally leading to effective stress based procedures, comparable to the ICP-05 methods for clay and sand sites. Gaining information on the set-up characteristics of 'virgin' piles was central to this, through research similar to that outlined for sands in Figs 11 and 12. Guidance was also needed on lateral and cyclic loading. An invitation from Scottish Power Renewables (SPR) to participate in their Wikinger wind farm project in the German Baltic (see Figs 65 and 69) offered opportunities for new

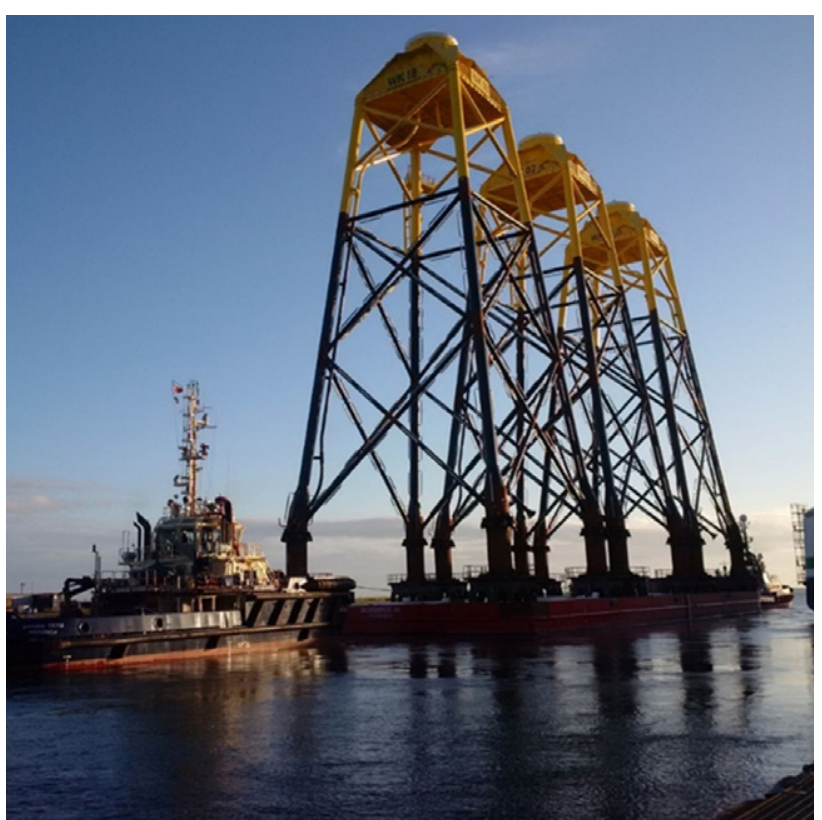

Fig. 70. Photograph of three offshore wind turbine jacket structures in transit for installation at Wikinger; courtesy of Scottish Power Renewables

collaborative research on Chalk. This included conducting the first remotely controlled, full-scale, seabed offshore pile load tests. Wikinger involves seventy $5 \mathrm{MW}$ turbines installed in 35 to $42 \mathrm{~m}$ water on four-legged jackets (see Fig. 70) founded on open-ended steel $2.7 \mathrm{~m}$ OD piles; the single offshore sub-station employs a six-legged jacket and $3.66 \mathrm{~m}$ OD piles (Barbosa et al., 2015, 2017).

The Wikinger ground conditions comprise variable profiles of glacial till over Chalk. The tills, which classified alternately as very dense sands or hard clays in different layers, dominate design at around 20 turbine locations. Chalk controls pile capacity for most of the other turbines, although harder limestones were encountered at six locations. Several fluvioglacial channel structures are present in the wind farm area that cut deep into the Chalk, which varies from Grade D (structureless low density) to Grade A1/A2 (structured low to medium density) according to the Lord et al. (2002) system. The deepest and oldest unit is the lightly overconsolidated white 'Schreibkreide' Maastrichtian (70.6 to 65.5 Ma) Chalk, which extends well below foundation depth. Uncertainties in pile behaviour were resolved through dynamic and static offshore tests conducted in advance of the final design over the 2014 to 2015 winter. Nine $1.37 \mathrm{~m} \mathrm{OD,} 40 \mathrm{~mm}$ wall thickness, piles were driven to penetrations of $16.8 \mathrm{~m}$ to $31 \mathrm{~m}$ at three representative locations. Two piles at each location were monitored continuously with strain gauges and accelerometers during driving. Parallel static tension tests and instrumented restrikes were conducted on identical pairs of 'virgin' piles at each location around 100 days after driving. The latter period was the minimum expected to apply between production pile driving and turbine installation.

Supporting research resources were allocated through the Innovate UK (project 101968) study led by Pedro Barbosa of SPR and Imperial College (R. J. Jardine, S. Kontoe and R. M. Buckley) with input from Drs Merritt and Schroeder at GCG. The team worked to optimise robust and novel field testing arrangements. They analysed dynamic measurements from both the pre-design and later production piling campaigns through the advanced signal matching code Impact (Randolph, 2008). Their analysis of the static and dynamic load tests employed the site characterisation data 
acquired by SPR, supplemented by specialist laboratory testing at Imperial College. Dynamic signal matching analysis carried out by Buckley (2018) demonstrated: $(a)$ very marked reductions in local shaft resistance with relative pile tip depth $\left(h / R^{*}\right.$, see equation (2)); (b) low end-of-driving capacities; and $(c)$ rapid set-up during any driving pauses. Buckley et al. ('Full-scale observations of dynamic and static axial responses of offshore piles driven in chalk and tills', submitted to Géotechnique) report on the static and dynamic offshore testing, demonstrating that excess pore pressure dissipation and other ageing processes led to large shaft capacity gains that were two to three times more significant in the permeable Chalk than in the variable till strata.

Additional research experiments were carried out with two highly instrumented closed-end $102 \mathrm{~mm}$ OD ICP piles and seven, $139 \mathrm{~mm}$ OD, steel pipe piles driven at the analogous St Nicholas-at-Wade low-to-medium-density Chalk test site. Buckley (2018) and Jardine et al. (2018) summarise the combined outcomes from the research and propose a new preliminary Chalk ICP-18 method for assessing driveability and long-term static capacity. The latter employs similar forms for base and shaft resistance to the ICP-05 sand approach (equations (1), (2), (5) and (6) and calls for full CPT profiling and interface shear testing as well as information on the Chalk's shear stiffness at small strains. Buckley et al. ('Full-scale observations of dynamic and static axial responses of offshore piles driven in chalk and tills', submitted to Géotechnique) provide a detailed analysis of the Wikinger field tests and show how the Chalk ICP-18 approach was able to capture the full-scale offshore load test results as well as the behaviour of smaller piles tested at St Nicholas-at-Wade and the Fleury-sur-Andelle test site in France. Jardine et al. (2018) also describe the ALPACA project, supported by the Engineering and Physical Sciences Research Council (EPSRC, grant EP/P033091/1) and ten industrial sponsors, which is now extending the research in conjunction with a team from Oxford (Professors Byrne and McAdam) to cover static, cyclic, dynamic, axial and lateral experiments on $14508 \mathrm{~mm}$ OD steel pipe piles instrumented with fibre optic strain gauges (of the type described by Doherty et al. (2015)) driven at the St Nicholas-at-Wade site, along with a larger number of smaller pipe piles. Parallel in situ and laboratory testing campaigns are also underway.

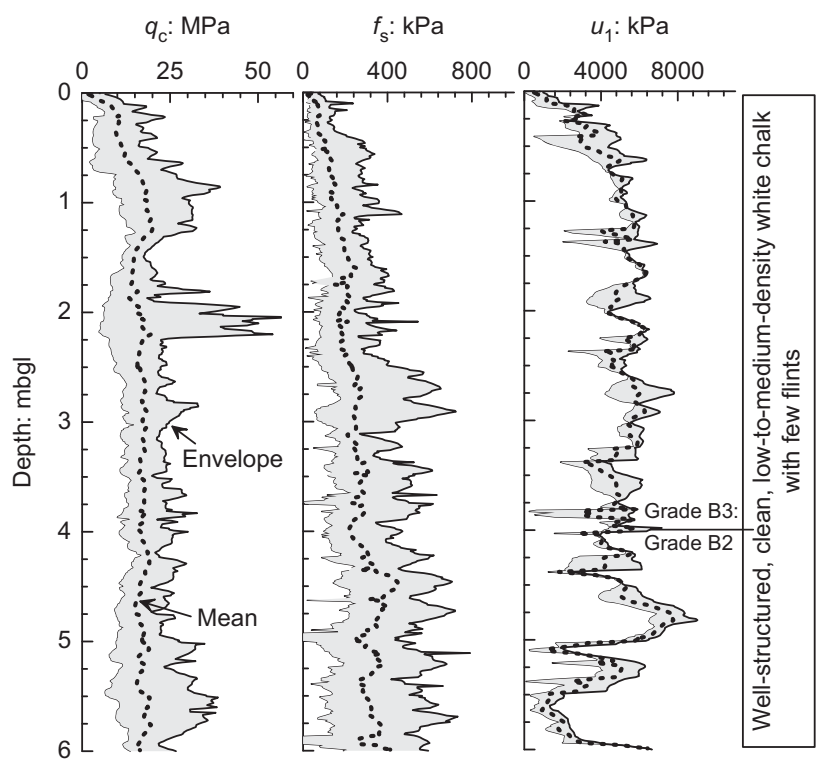

Fig. 71. Piezocone soundings for St Nicholas at Wade test site; after Buckley (2018)

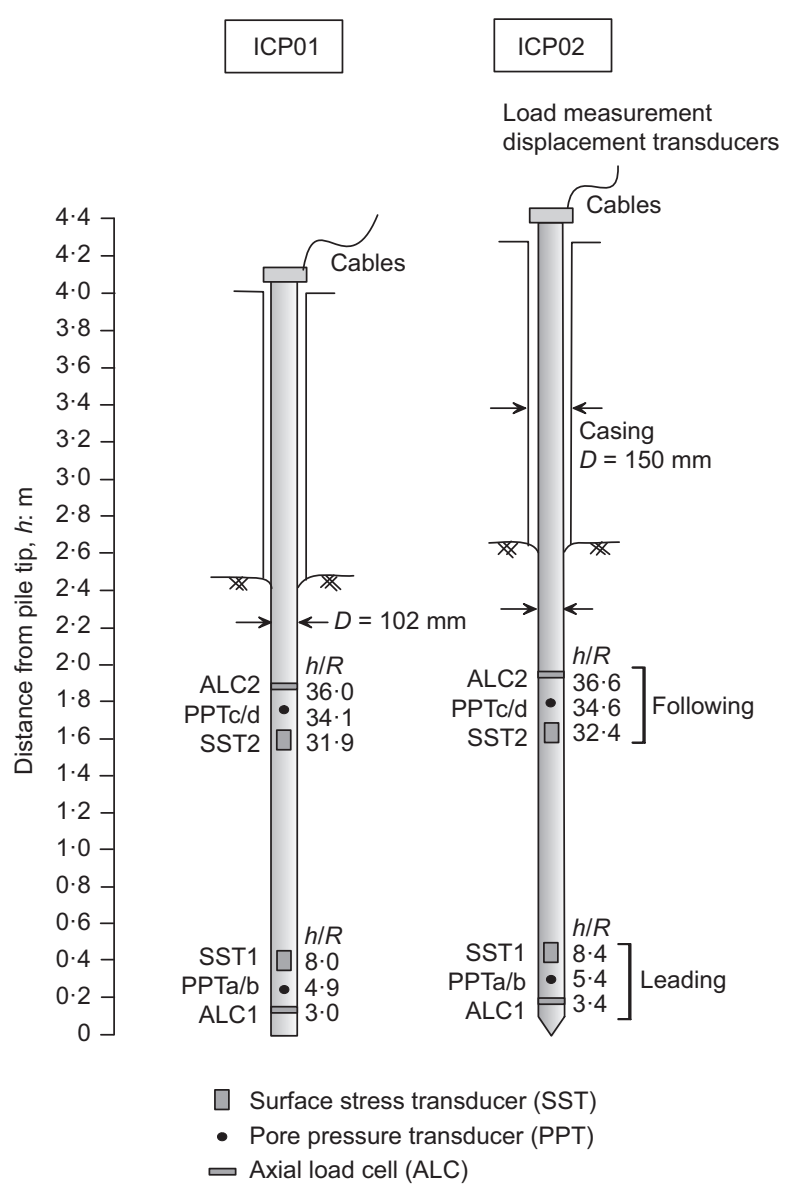

Fig. 72. Configuration of ICP piles installed at St Nicholas at Wade test site; after Buckley (2018)

Piezocone profiles established through the St Nicholasat-Wade Chalk are outlined in Fig. 71, after Buckley (2018). The Chalk, which has a natural water content close to its liquid limit, generally develops $5<q_{\mathrm{c}}<35 \mathrm{MPa}$, with higher resistances in flint bands. Very high excess pore pressures are recorded at the piezocone cone face $\left(u_{1}\right)$ position. Lower, but still considerable, pressures develop at the cone shoulder $\left(u_{2}\right)$ location. The Chalk fails and starts to de-structure under the high stresses developed beneath the cone tip, but retains sufficient shearing resistance to give sleeve resistances of up to $400 \mathrm{kPa}$ as it flows around the cone. The eventual reduction to putty takes place progressively through shearing continuing at higher points on the CPT shaft as the tip advances to greater relative depth $(h)$.

Experiments conducted by the Imperial College team at St Nicholas-at-Wade in conjunction with Professor Lehane from the University of Western Australia (UWA) with the closed-ended, cyclically jacked ICP piles shown in Fig. 72 measured how the local axial loads, pore pressures, radial shaft effective $\sigma_{\mathrm{r}}^{\prime}$ and shear stresses $\tau_{\mathrm{r} z}$ developed on the pile shafts varied during penetration. Buckley et al. (2018a) report that, as with sands: (a) the end bearing pressures $q_{\mathrm{b}}$ of the closed-ended ICP piles and their local radial shaft stresses $\sigma_{\mathrm{r}}^{\prime}$ vary systematically with local CPT $q_{\mathrm{c}}$ resistance and $(b)$ the local $\sigma_{\mathrm{r}}^{\prime}$ stresses decline with relative pile tip depth $h / R$. The ICP experiments also showed that static loading to failure leads to the local $\tau_{\mathrm{r} z}-\sigma_{\mathrm{r}}^{\prime}$ paths illustrated in Fig. 73. As in earlier ICP tests in sands, constrained interface dilation was apparent and the shaft failure was governed by a Coulomb effective stress interface slip criterion, giving in this case $\delta^{\prime} \approx 31^{\circ}$. The latter angle matches the ultimate angle found in ring shear tests that followed the ICP-05 test procedures and 


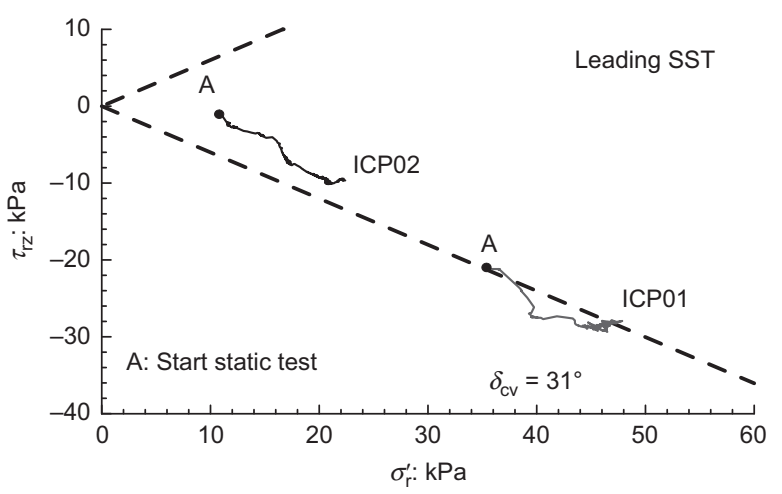

Fig. 73. Local shaft effective stress paths for leading SST positions of ICP piles during tension loading to failure at $\mathrm{St}$ Nicholas at Wade test site; after Buckley et al. (2018b)

sheared chalk from the site against interfaces that matched the pile shaft's material and surface roughness.

Different phenomena were investigated at the same site by experiments on the $139 \mathrm{~mm}$ OD open-ended piles, which were equipped with strain gauges and accelerometers during their driving to $5.5 \mathrm{~m}$ depth. As with the large piles driven at Wikinger, the small-diameter open piles drove without plugging and their internal cores of soft chalk rose to levels above the surrounding ground level at the end of driving. The analysis of the tests by Buckley et al. (2018a) led to five main conclusions.

(a) End bearing pressures $q_{\mathrm{b}}$ developed over the annular tip areas during driving were proportional to local $q_{\mathrm{c}}$ values. The fully coring piles developed very little resistance $\tau_{\mathrm{r} z}$ over their interior shaft areas.

(b) The average end-of-driving exterior shaft shear resistances $\tau_{\mathrm{r} z}$ fell close to the Lord et al. (2002) $20 \mathrm{kPa}$ static design recommendations. However, the $\tau_{\mathrm{r} z}-$ depth distributions deduced by dynamic signal-matching were markedly non-uniform. Local shear stresses declined even more steeply with increasing relative pile tip penetration $\left(h / R^{*}\right.$, as defined in equation (2)) than had been seen with sands or clays.

(c) Staged tension testing of identical 'virgin' piles at 10, 106 and 249 day ages provided the shaft capacity-time trend given in Fig. 74, with resistances increasing

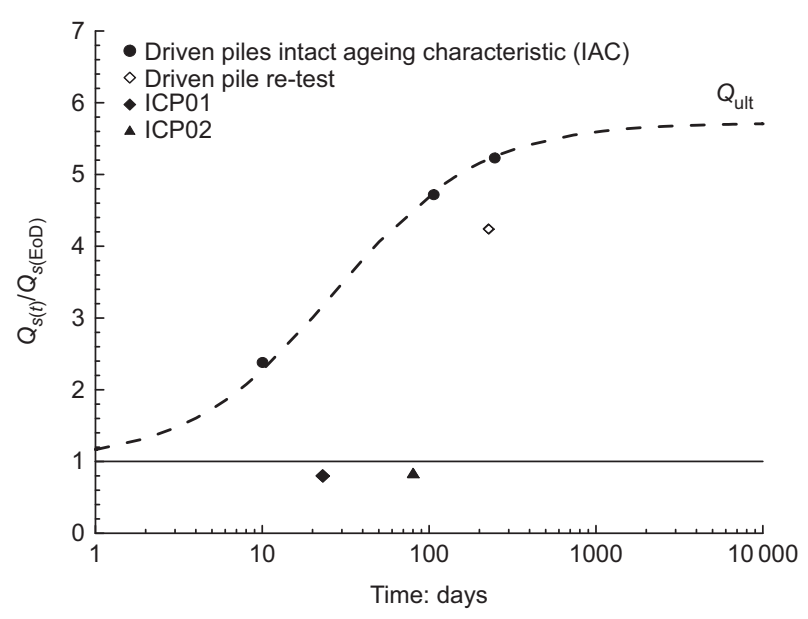

Fig. 74. Normalised shaft capacity ageing trends for driven open (139 $\mathrm{mm}$ OD) and cyclically jacked $(102 \mathrm{~mm}$ OD) closed ICP piles from tension load tests to failure at St Nicholas at Wade test site; after Buckley et al. (2018a)

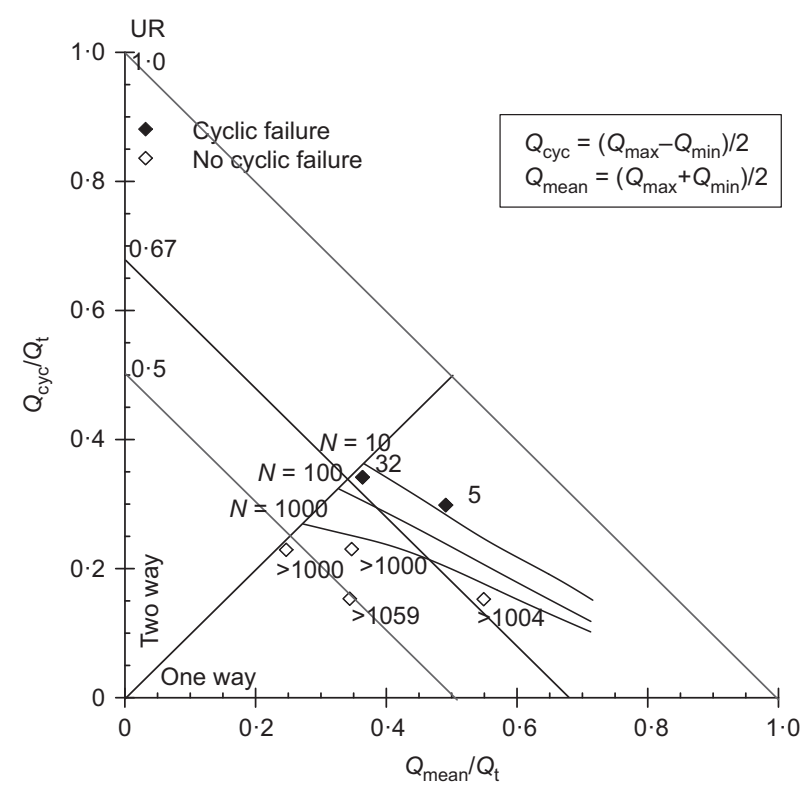

Fig. 75. Global cyclic interaction diagram for $139 \mathrm{~mm}$ OD steel tubular piles tested under axial cycling at St Nicholas at Wade test site; after Buckley et al. (2018a)

five-fold. A previously failed pile could not recover the 'virgin' piles' ageing trend on re-testing.

(d) The driven piles' final set-up factors exceed those for sands (see Fig. 12) and shaft capacity, $Q_{\mathrm{s}}$, could be fitted with a hyperbolic relationship with time suggested by Tan et al. (2004). In contrast, the cyclically jacked ICP piles did not show any such gains. Set-up appears sensitive to either pile tip conditions (closed as opposed to open-ended) or installation method (slow cyclic jacking as opposed to dynamic driving) in Chalk. The ALPACA research programme includes an investigation of how set-up varies with pile shape, shaft material and groundwater conditions.

(e) Batches of one-way axial cycling applied 250 days after driving led to responses ranging from unstable to essentially stable over 1000 cycles, depending on the combination of cyclic loading variables defined in Fig. 20. The interaction diagram presented in Fig. 75 shows contours interpreted for conditions under which failure could be expected after 10, 100 or 1000 cycles. Lines indicating the equivalent mobilised levels of utilisation ratio (UR) are also shown, where UR is defined as the peak cyclic load $Q_{\max }$ divided by the static (pre-test) tension capacity $Q_{\mathrm{t}}$.

Figure 75 shares several common features with the sand cases shown in Figs 21 and 32. The piles driven in Chalk did not appear to be particularly sensitive to one-way axial cyclic loading when applied 250 days after driving. The Alpaca research programme includes experiments that demonstrate that high-level two-way cycling impacts more severely on axial capacity. The programme also includes multiple instrumented tests that explore the driven piles' response to static and cyclic lateral loading.

\section{Full-scale offshore load tests}

As noted in Part 1, subsea static tests on full-scale piles are usually considered impractical in offshore engineering. The only prior static offshore pile tests of which the author is aware were conducted from the decks of existing 


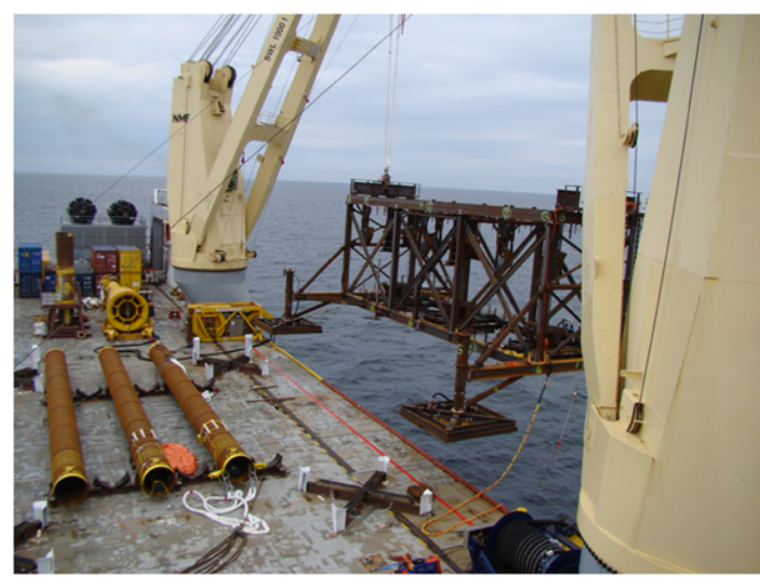

(a)

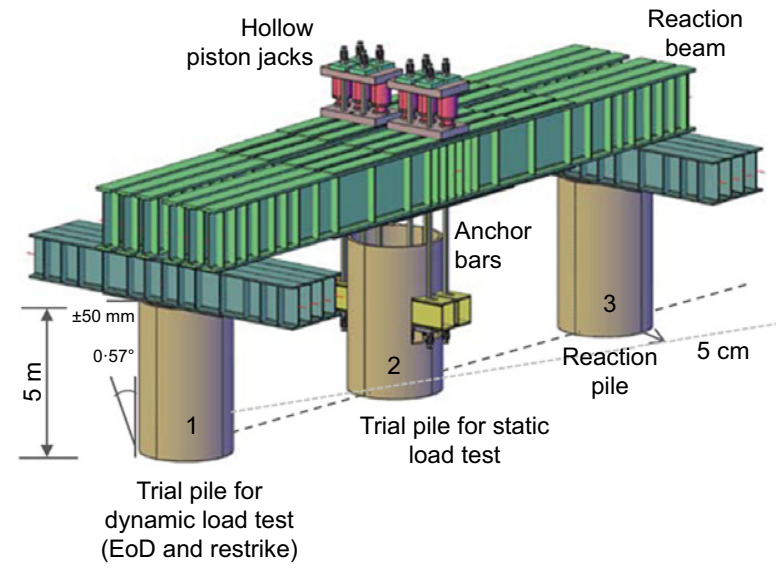

(b)

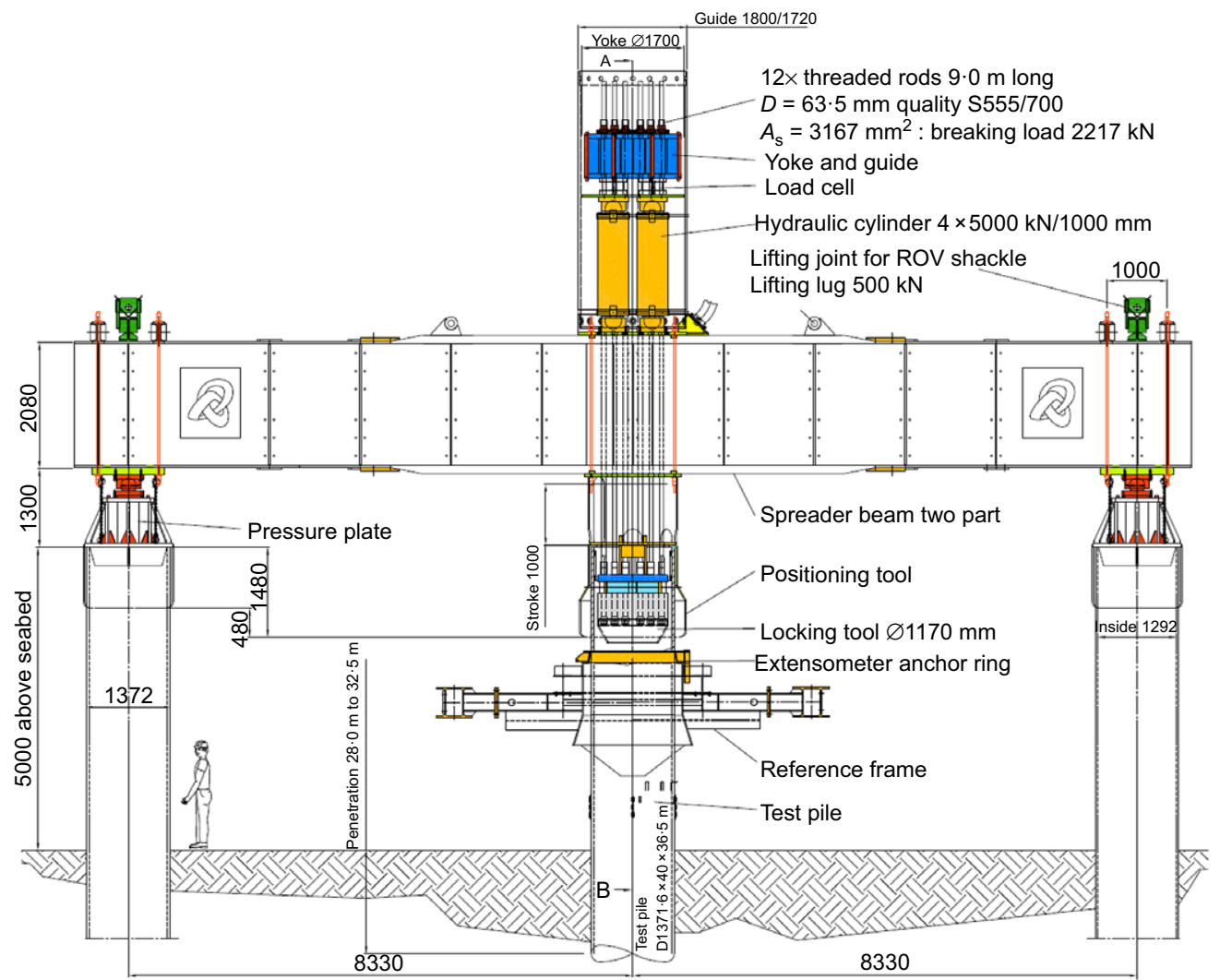

(c)

Fig. 76. (a) Photograph of piles on installation vessel deck and piling template being lifted for deployment prior to driving at Wikinger. Same template provided a reference beam during static tension testing with subsea, remotely operated system; after Barbosa $e t$ al. (2015). (b) Schematic drawing of loading frame and reaction pile arrangement for subsea, remotely operated, static load tests at Wikinger; after Barbosa et al. (2015). (c) Detailed drawing of loading frame and reaction pile arrangement for subsea, remotely operated, static load tests at Wikinger. Person shown for scale; after Barbosa et al. (2015). Dimensions in mm, unless otherwise specified

structures and involved piles with outside diameters no greater than $0.76 \mathrm{~m}$. In the same way, long-term restrikes are rarely deemed feasible. The Wikinger field tests showed how remotely operated static seabed systems can be deployed effectively, in advance of final design, to test carefully aged piles in parallel with long-term restrikes made with fully recoverable driving instrumentation. The test piles were driven through the truss structure shown in Fig. 76(a), which was located first as a temporary template on the seabed at each location. The same truss was re-deployed, up to 108 days later, as a displacement measurement reference frame for the static tests. A guide cone, moveable ring and subsea extensometer fixed to the frame allowed axial displacement measurements to be made at three points relative to the reference beam, which rested on the substantial and hydraulically adjustable mudmat footings that sat firmly on the seabed at suitable distances from the test pile. After locating the template over the central test pile, the moveable extensometer ring was positioned by lowering the reference frame until the extensometers rested on pre-installed pile brackets. The test beam shown schematically in Fig. 76(b) and in greater detail in Fig. 76(c) was then lowered to the seabed, with the guide cone ensuring a central placement over the test pile's axis. The beam was rotated until catcher plates contacted the reaction piles before being lowered into its test position. Locking plates were activated hydraulically, latching into a 
steel ring inside the test pile, monitored by fixed underwater television cameras.

Static loading was applied through multiple hydraulic jacks fed from the surface and monitored by subsea load cells. Programmable pumps maintained each load step for at least $30 \mathrm{~min}$ while creep was monitored in accordance with EA-Pfähle (2014). Each test took 13 to $18 \mathrm{~h}$ to complete. Post-failure cyclic loading stages were applied at location WK38, with two batches of up to ten cycles at different levels, the second of which applied loading up to $84 \%$ of the static capacity and led to full cyclic failure (Barbosa et al., 2017). Other novel arrangements involving storable subsea cable reels and high-quality retrievable terminations (in combination with instrument redundancy) ensured a remarkable $100 \%$ long-term survival rate for the parallel dynamic testing systems.

Recalling that tests on two relatively small $(457 \mathrm{~mm}$ OD, $9.2 \mathrm{~m}$ embedment) piles driven at Cowden (UK Humberside) comprise the only glacial till data in the international axial capacity database reported by Lehane et al. (2017), the focus here is placed on the glacial till dominated WK38 Wikinger test location. Buckley et al. (2018a, 2018b, 'Full-scale observations of dynamic and static axial responses of offshore piles driven in chalk and tills', submitted to Géotechnique) provide a detailed analysis of the Wikinger tills' properties and give details of the capacities found in the well-controlled static test shown in Fig. 77 and the compression shaft capacities interpreted from independent signal-matching analyses of $(a)$ the final blow at the end of driving $(\mathrm{EoD})$ and at $(b)$ the beginning of restrike $(\mathrm{BoR})$ in the long-term dynamic test on the adjacent WK38 test pile. Encouraging agreement is shown in Fig. 77 between the static and BoR 108 day age shaft capacities. Comparison between the long-term and EoD capacities also attests to the very significant set-up shown by the piles. The signal-matching analyses of the BoR test indicated that the till contributed $69 \%$ of the piles' overall long-term (108 day age) shaft capacity.

The Wikinger tills comprise glacial and fluvioglacial units, both of which are well graded and have very low plasticity indices $(8$ to $9 \%$ ) and natural water contents close to their plastic limits (around 13\%). The glacial unit has more significant coarse sand and gravel fractions. The till classifies as stiff to hard clay (with undrained shear strengths $S_{\mathrm{u}}$ ranging from $0 \cdot 2$ to $1 \mathrm{MPa}$ ) in some locations and depths, while appearing as a dense sand at others. Buckley et al. (2018a, 2018b, 'Full-scale observations of dynamic and static axial responses of offshore piles driven in chalk and tills', submitted to Géotechnique) show that the WK38 till profile

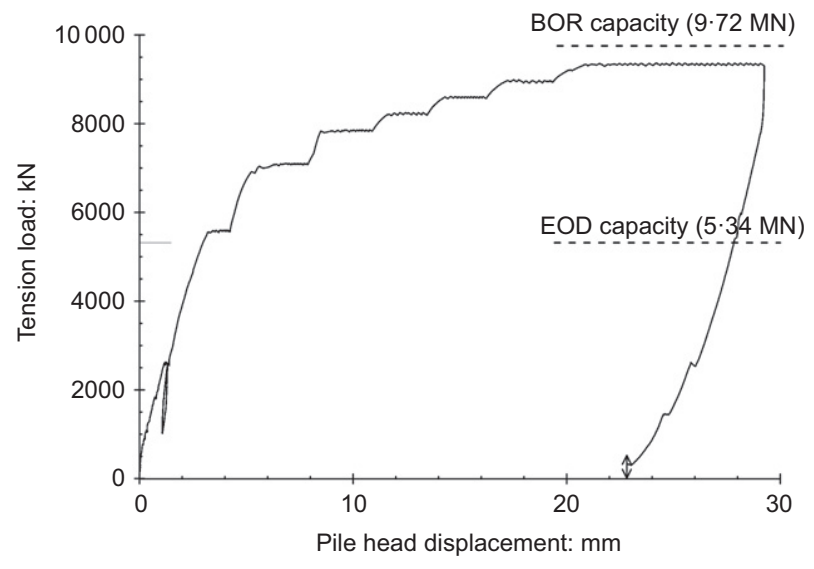

Fig. 77. Load-displacement curve from static tension test on $1 \cdot 37 \mathrm{~m}$ OD test pile at till dominated Wikinger WK38 location, conducted 108 days after driving has low clay contents and relatively high permeabilities and classifies, overall, as a sand.

Capacity predictions were made with the ICP approaches for the WK38 piles. The tests were conducted 108 days after driving. The tension capacity ageing trends reported in Figs 11 and 12 from open steel piles tested at Dunkirk, Blessington and Larvik suggest that a set-up factor of 1.9 might be expected between the 10 day and 100 day capacities within sand layers. Applying the latter factor to ICP-05 sand calculations, along with site-specific CPT data and $26.5^{\circ}<\delta^{\prime}<$ to $28^{\circ}$ interface shear angles found in ring shear tests run at Imperial College, provided a shaft capacity contribution estimate for the upper till section of the piles' embedded length, while the Chalk ICP-18 method was applied to the lower section driven into chalk. The combined calculated tension shaft capacity $\left(Q_{\mathrm{c}}=7 \cdot 7 \mathrm{MN}\right)$ falls $13 \%$ below that measured statically $\left(Q_{\mathrm{m}}\right)$ after deducting the pile and plug weights, giving $Q_{\mathrm{c}} / Q_{\mathrm{m}}=0.87$; the predicted distribution of shaft shear capacity with depth was also broadly comparable to that interpreted from stress wave analysis of the BoR test. Applying the same approach to the tests conducted at the Chalk-dominated WK43 and WK70 locations also led to moderately conservative $Q_{\mathrm{c}} / Q_{\mathrm{m}}$ ratios (of 0.77 and 0.99 , respectively) and shaft shear stress distributions that were again broadly compatible with the long-term field test trends; see Buckley et al. (2018a, 2018b, 'Full-scale observations of dynamic and static axial responses of offshore piles driven in chalk and tills', submitted to Géotechnique).

Geduhn et al. (2018) report on the initial axial capacity assessment methodology available to the Wikinger test pile designers and note that this led to $Q_{\mathrm{c}} / Q_{\mathrm{m}}$ ratios of $0 \cdot 87,0 \cdot 41$ and 0.35 when tested against the long-term WK38 to WK70 capacity measurements, as well as indicating quite different shaft shear capacity profiles to those interpreted from BoR signal matching. The initial methodology systematically underestimated capacity in chalk and overestimated that in the sandy till. Barbosa et al. (2017) show that the Wikinger field testing, while expensive, was fully cost-effective. Developing improved, site-proven, design rules eliminated critical project risks for Wikinger, helped to secure regulatory consents, led to a foundation re-design that reduced steel weights and emitted carbon dioxide (by $8000 \mathrm{t}$ and $16000 \mathrm{t}$, respectively) and cut pile installation costs. Still greater structural savings could have been achieved if more had been known at an earlier stage about driven pile behaviour in the Chalk and tills. Similar field testing systems are now being deployed at other offshore sites where greater certainty is required regarding the foundations' response to static or cyclic axial loading.

\section{TOPIC 3.2: OPTIMISING FOUNDATION DESIGN} FOR MONOPILE OFFSHORE WIND TURBINES

The paper's final topic is research into the behaviour of single, large-diameter, driven monopiles, which comprise the most common wind turbine substructure form employed worldwide. Monopiles, as shown schematically in Fig. 78, sustain turbine and tower wind loads, along with wave and current loading on the pile and transition piece, by applying principally lateral and moment loading to the foundation. Increasing rotor diameters and water depths have led to monopile diameters $(D)$ growing from $4 \mathrm{~m}$ to $8 \mathrm{~m}$ and potentially more, while their typical embedded lengthto-diameter $(L / D)$ ratios have reduced. Most installations' $L / D$ ratios fall below the minimum (10) set by API and ISO to define a (deep) pile foundation; some monopiles have $L / D$ as low as 2. Monopiles classify as caissons, which are intermediate between shallow and deep foundations. Davidson (1982), Lam \& Martin (1986), Gerolymos \& Gazetas (2006), 


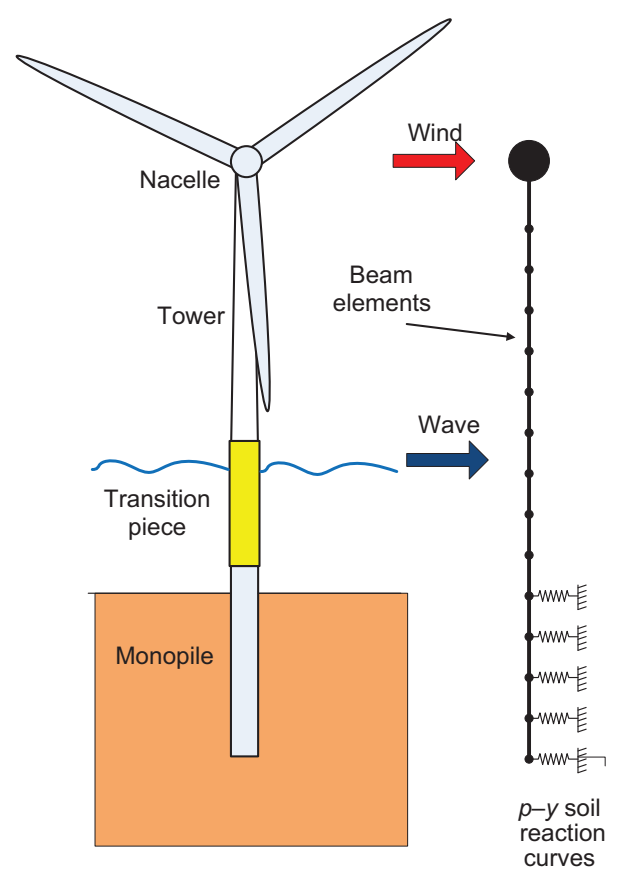

Fig. 78. Schematic representation of monopile structure and $p-y$ foundation reaction response system; after Byrne (personal communication, 2015)

Lam (2009) and Byrne et al. (2015a) have shown that their overall resistances result from four components

R1 lateral soil reactions

R2 vertical shear stresses induced on the external perimeter of the foundation

R3 base moment reaction

R4 horizontal reaction developed across the base.

Foundation stiffness and verticality are critical to monopiles and their design involves multiple iterative calculations; DNV-GL (2016). Although base springs (R4) are added by some designers in an uncodified manner, it is usual to consider only the R1 component and employ the API (2014) $p-y$ method to provide the lateral reaction curves. It is therefore instructive to outline the API method before describing the new research and summarising how it and alternative methods perform in comparison with large-scale field tests. The emphasis given to sands in Part 1 is balanced by focusing on clays in this final section.

API (2014) states that, in the absence of more definitive criteria, the local lateral capacity per unit depth in clays, expressed as $p_{\mathrm{u}} D$, increases with depth $z$ below seabed level from $3 S_{\mathrm{u}} D$ according to equation (20)

$$
p_{\mathrm{u}} D=3 S_{\mathrm{u}} D+\gamma^{\prime} z D+J S_{\mathrm{u}} z
$$

where is $p_{\mathrm{u}}$ is the equivalent lateral pressure per unit pile width (diameter $D$ ) under static loading and is limited to $9 S_{\mathrm{u}}$ for $z \geq z_{\mathrm{R}}$, where $z_{\mathrm{R}}$ is the depth at which $p_{\mathrm{u}}$ reaches the $9 S_{\mathrm{u}}$ limit; $\gamma^{\prime}$ is the submerged soil unit weight and $J$ is a dimensionless empirical constant between 0.25 and 0.5 that 'should be determined by field testing'. $J$ is usually taken as 0.5 in Gulf of Mexico clays. The API guidance implies that the stiff 'non-linear' clays on which the method was based generally behave in a brittle manner, especially under cyclic loading where the ultimate local $p_{\mathrm{u}}$ is reduced by a factor $\left(0.72 z / z_{\mathrm{R}}\right)$; the factor is capped at 0.72 when $z>z_{\mathrm{R}}$. The resistance $p$ builds up with local pile lateral deflection, $y$, according to non-dimensional functions $p / p_{\mathrm{u}}=f\left(y / y_{\mathrm{c}}\right)$ where $y_{\mathrm{c}}=2 \cdot 5 \varepsilon_{\mathrm{c}} D$, which differ between the 'shallow' $\left(z<z_{\mathrm{R}}\right)$ and 'deep' $\left(z>z_{\mathrm{R}}\right)$ cases.

The only site-specific 'stiffness' information considered is $\varepsilon_{\mathrm{c}}$, the axial strain at which deviator stresses reach half the peak value in unconsolidated, undrained (UU) triaxial tests: the relative secant stiffnesses deduced from the local $\Delta p / p_{\mathrm{u}}-\Delta y / D$ curves scale in proportion to $1 / \varepsilon_{\mathrm{c}}$. The 'stiffness' function is expressed as five non-zero tabulated $p / p_{\mathrm{u}}, y / y_{\mathrm{c}}$ points, the first of which (for both cases) is $y / y_{\mathrm{c}}=0 \cdot 1$, $p / p_{\mathrm{u}}=0.23$; linear $p-y$ behaviour is usually assumed for $y<0 \cdot 1 y_{\mathrm{c}}$. Considering piles driven in stiff, ductile glacial till, the first $y / y_{\mathrm{c}}=0 \cdot 1$ point would typically correspond to a local lateral deflection $y \approx 10 \mathrm{~mm}$ for a $2 \mathrm{~m}$ OD pile and $\approx 50 \mathrm{~mm}$ for a $10 \mathrm{~m}$ OD monopile, with $p$ amounting to almost one-third of its 'cyclic' local ultimate value. The sand method also depends principally on relative depth below the seabed and shear strength, which in this case is characterised by the peak drained angle of shearing resistance $\left(\phi^{\prime}\right)$, which usually has to be estimated, often through further empirical correlations involving the local CPT resistance, $q_{\mathrm{c}}$. A modulus of subgrade reaction is incorporated, but it is usually estimated from a tabulated correlation with peak $\phi^{\prime}$.

The classical API approaches were shown in Part 1 to under-predict markedly the axial, lateral and moment stiffnesses of large offshore piles which were driven with $L / D$ ratios of 24 to 40 at the Magnus, Hutton TLP and Shearwater stiff glacial till and dense sand North Sea sites. The same was observed in a lateral loading test conducted onshore at the LDP Tilbrook Grange site, where the upper part of the pile was in stiff, lean, Lowestoft glacial clay till; Hamilton \& Dunnavant (1993). Indications that the API $p-y$ methods often underestimate monopile stiffness at North Sea sites has emerged from the dynamic resonant frequencies recorded by accelerometers mounted in the monopile wind turbines' machine pods and from other structural monitoring.

\section{The PISA research project}

Noting that the existing API $p-y$ design tools may not be representative for North Sea geotechnical conditions, or low $L / D$ monopile geometries, the joint industry pile soil analysis (PISA) project led by Jesper Skov Gretlund of Orsted was established in 2013 to improve design methods. More than 100 individuals were involved. The JIP (joint industry project) employed funding from the Carbon Trust and 11 industrial sponsors to integrate theoretical studies, numerical analysis, in situ and laboratory site characterisation with, most crucially, comprehensive field testing. The scientific and technical direction and interpretation came from an academic work group led by Professor Byrne that involved teams from Oxford, Imperial College (including the author) and University College Dublin (UCD). Consultants and contractors made specialist contributions to the JIP, including Socotec's central role in the advanced pile testing and ICFEP analyses by GCG that assisted with the initial experimental design. Byrne et al. (2017) outline the principal findings from the JIP, which was completed in 2016. Detailed articles on specific aspects of the research are forthcoming; a second PISA 2 programme has extended the scope of the research over 2016-2018.

\section{PISA design principles}

The key aim for PISA was to develop new design approaches. It was decided that these could involve fully non-linear 3D FE numerical treatments combined with state-of-the-art site investigation and soil characterisation programmes, as in the Magnus and Hutton TLP studies cited in Part 1. However, a more computationally efficient Winkler treatment was also required that could improve the $(p-y)$ 

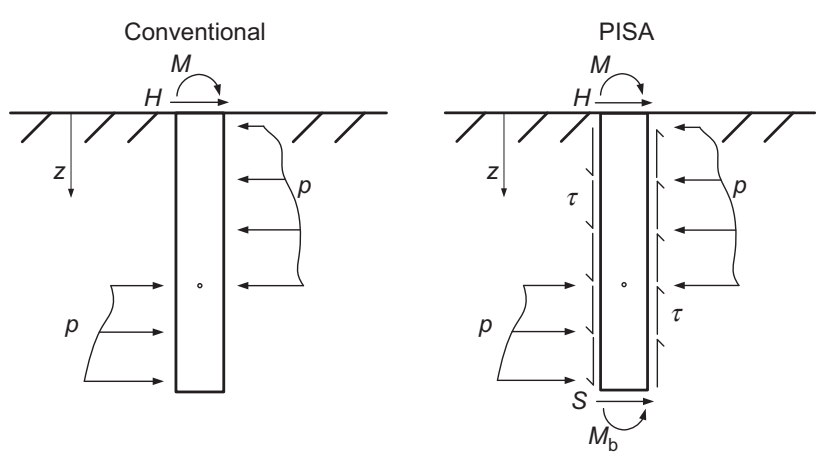

Fig. 79. Schematic representation of $p-y$ and PISA monopile foundation reaction response systems; after Byrne et al. (2015a, 2015b)

lateral $\mathrm{R} 1$ reaction component defined above and introduce non-linear 'springs' to capture components R2 to R4 as shown schematically in Fig. 79. Advanced site investigations and FE analysis may be applied to derive best-fitting R1 to R4 spring curves that meet specific structural, loading and geotechnical conditions. The Winkler models can be tuned to site-specific data or based, when appropriate, on simple 'look-up table' curves and applied in iterative calculations to reach optimal designs for each wind turbine location.

\section{PISA field testing and numerical modelling programmes}

Field verification was understood to be central to acceptance of the PISA outcomes by industry, independent verification bodies and national regulators. Naturally, geology was the first factor to consider when choosing the test sites. Stiff glacial tills and dense silica sands are commonly encountered in the North Sea, and these were agreed to be of greatest interest to PISA. The project identified first the stiff glacial Cowden till, part of the Bolders Bank formation that extends under the North Sea, as shown in Fig. 2. Lehane \& Jardine (1994a) had conducted tests with the ICP piles shown in Fig. 7 at Cowden, while Powell \& Butcher (2002) had undertaken site characterisation. The PISA team chose also the Flandrian dense sand site at Dunkirk, where earlier work had included the research described in Part 1 by Brucy et al. (1991), Chow (1997) and Jardine et al. (2006) as well as later in situ and laboratory investigations by Kuwano (1999), Aghakouchak (2015) and others. The PISA analyses have since extended to include the London and Bothkennar clays, in which ICP tests were conducted (Bond \& Jardine, 1991, 1995, Lehane \& Jardine, 1994b) at the locations shown in Fig. 8.

PISA progressed with four parallel streams: $(a)$ in situ testing with CPTu and seismic CPT techniques; led by Professor Gavin's team at UCD; $(b)$ advanced numerical analysis with ICFEP led by Professor Zdravkovic, following the approach set out by Zdravković et al. (2015); (c) advanced laboratory testing led by the present author; and $(d)$ field test design, which was led by Oxford. As described by Byrne et al. (2015b), 14 steel tubular test piles were driven at each site and subjected to combined lateral and moment loading. Piles with $L / D$ ratios of $3,5 \cdot 25,8$ and 10 were tested and Fig. 80 shows how three pile diameters and a pair of pile wall thicknesses were considered. Loading was applied $10 \mathrm{~m}$ above ground level in all cases, giving three ratios of loading eccentricity $e$ to diameter $D$. The tests applied staged loading with creep pause periods and one small load-unload loop. Programmes of cyclic lateral and moment loading tests were also undertaken that included taking the largest (2 m OD) piles to cyclic failure. The piles were instrumented with inclinometers, strain gauges of both foil and fibre-optic

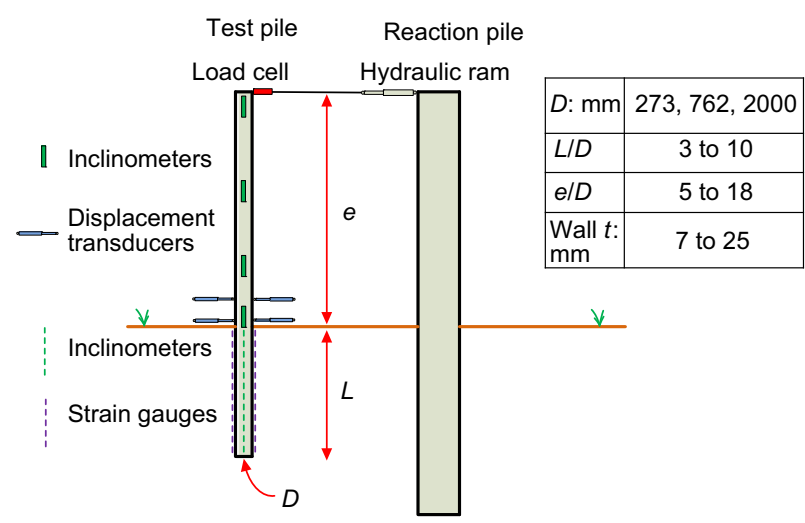

Fig. 80. Test arrangements for PISA piles as employed at Cowden till and Dunkirk sand sites; after Byrne et al. (2015b)

(Doherty et al., 2015) design and displacement transducers. The driven piles were aged in situ after driving before being tested. Vibrating wire piezometers installed at the Cowden till site demonstrated that installation-induced pore pressures had dissipated before the load testing commenced.

\section{PISA test site characterisation}

Characterisation of the two PISA test sites started with programmes of in situ tests that were interpreted in conjunction with all existing information and input into initial FE calculations that fed into the field experiments' design. Geobor-S wireline rotary and block sampling took place subsequently at Cowden, although frequent cobbles and large gravel particles (see Fig. 81) made sampling and laboratory specimen preparation difficult. Reliance was placed at Dunkirk on existing shallow pit samples and cores from an earlier rotary campaign. Extensive laboratory testing by Ushev (2018) and Liu (2018) followed. The first half of their work fed into the Class A FE predictions made for PISA by the Imperial College numerical group (D. M. Potts, D. M. G. Taborda and L. Zdravkovic) and the Oxford extended 'Winkler model' studies. The laboratory studies

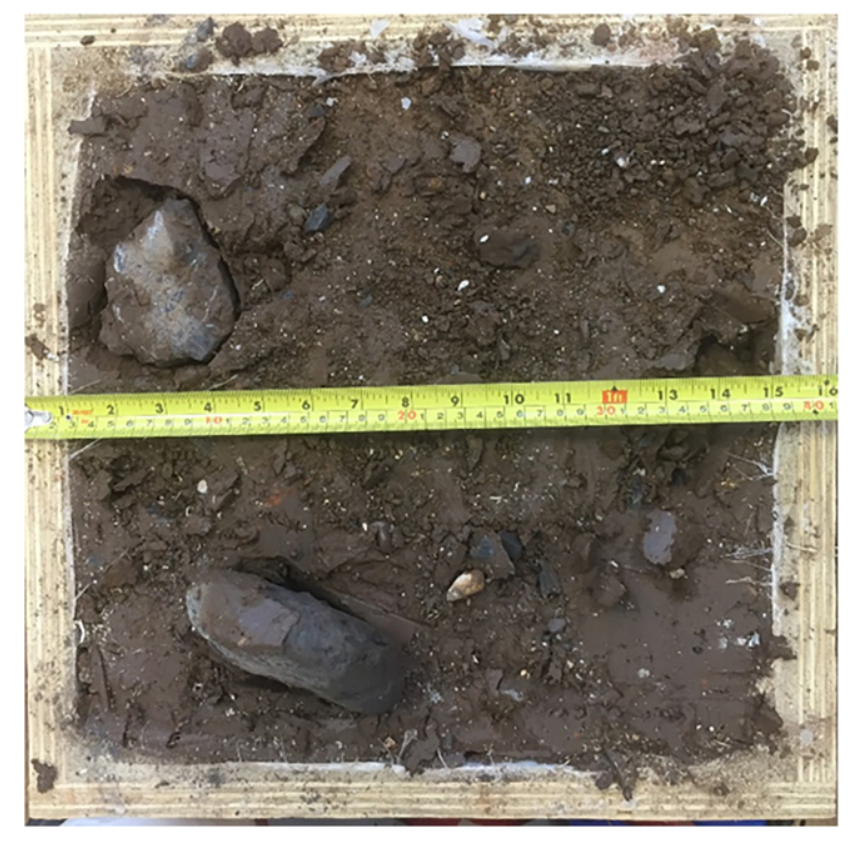

Fig. 81. Example of $350 \mathrm{~mm} \times 350 \mathrm{~mm} \times 350 \mathrm{~mm}$ block sample of Cowden till showing gravel and cobble inclusions; photograph by T. F. Liu 
progressed to consider anisotropy, behaviour under elevated effective stresses, strain rate dependency and response to cyclic loading. The extended studies by Ushev (2018) and Liu (2018) provide the basis for further analysis of the PISA tests. They also provide guidance for wind farm designers dealing with comparable soils.

\section{Laboratory triaxial and HCA equipment employed for PISA geotechnical characterisation}

The PISA laboratory testing programmes combined index, oedometer, ring and interface shear testing with stress path experiments with systems similar to those applied in earlier stiff clays studies by Gasparre et al. (2007a, 2007b) Nishimura et al. (2007), Hosseini Kamal et al. (2014) and Brosse et al. (2017). The triaxial programmes employed hydraulic stress path cells that accommodated 38 and $100 \mathrm{~mm}$ dia. specimens with $2: 1$ height to diameter ratios. The arrangements shown in Fig. 82 met the requirements for investigating pile-soil interaction problems set out by Jardine (2013). Lubricated sample ends were employed in many of the tests and all employed high-resolution linear variable differential transducer (LVDT) local strain sensors. Mid-height pore pressure probes were deployed for Cowden till and dual-axis bender element systems were installed in many cases. The $100 \mathrm{~mm}$ dia. cells employed the radial strain sensors described by Ackerley et al. (2016).

Ushev (2018) and Liu (2018) show that, as with London Clay and other stiff, high-YSR, plastic clays (see Gasparre et al., 2007a, 2007b; Brosse et al., 2017), Cowden till has higher undrained and drained elastic moduli (at very small strains) when loaded horizontally than vertically, which is significant when modelling monopile response to lateral loading. The soils' anisotropy was explored over the wider non-linear region of behaviour through tests with the combined HCA and resonant column apparatus shown schematically in Fig. 28, working with specimens that had outside and inside diameters of $72 \mathrm{~mm}$ and $38 \mathrm{~mm}$, respectively, and heights of $190 \mathrm{~mm}$.

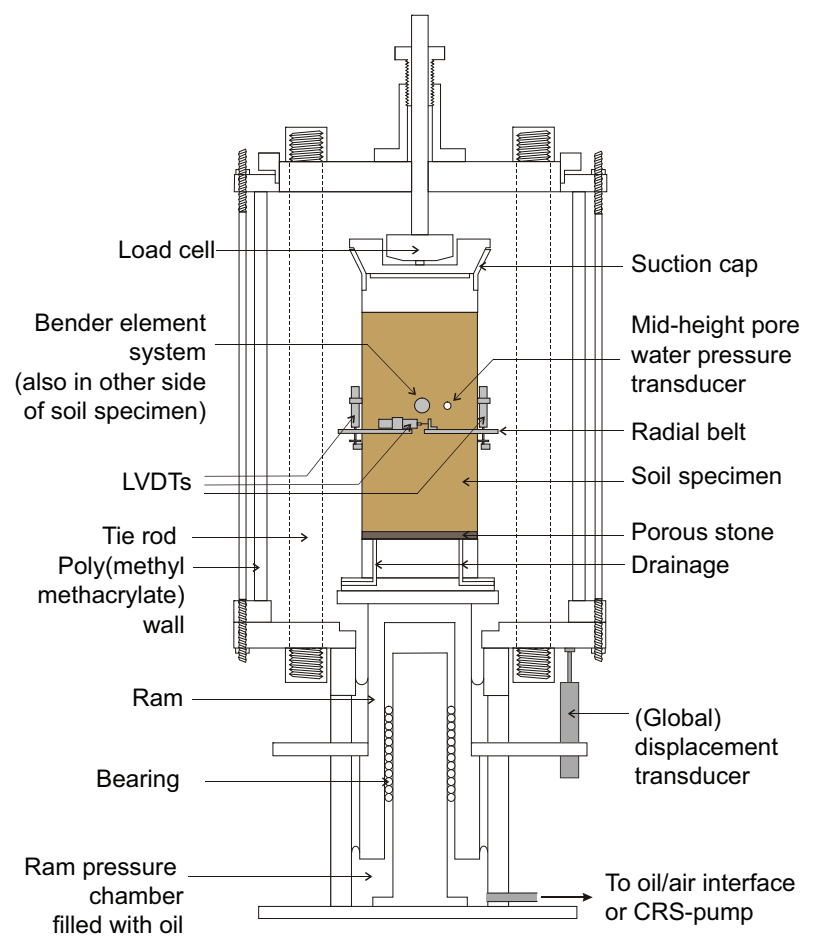

Fig. 82. Schematic diagram of Imperial College hydraulic stress path cell, as employed for testing on Cowden till and Dunkirk sands by Ushev (2018) and Liu (2018). CRS, constant rate of strain
This equipment could rotate the major principal stress axis to any desired orientation in the vertical plane and control the intermediate (in this case radial) intermediate principal stress $\sigma_{2}$ and so investigate non-linear stiffness and shear strength anisotropy. As may be appreciated from Fig. 81, it was difficult to form intact HCA specimens from the Cowden block samples. Liu (2018) cut his blocks into prisms with hardened saws, trimming these into cylinders and then forming hollow cylinder specimens through the progressive lathe and drill approach described by Nishimura et al. (2007). Despite computerised tomography scanning to help identify suitable areas of the block samples, the till's coarse gravel fraction and fissuring led to a high failure rate: great patience was required to complete the programme effectively.

\section{Contrasting triaxial and HCA test behaviours of Cowden and London stiff clays}

Before reporting how the Cowden PISA test field test measurements compare with various predictions, it is instructive to consider the wide spectrum of behaviours shown by stiff clays and how these may affect numerical predictions. Recalling that the UK's largest currently operating installation is founded in stiff, high-OCR, high-plasticity $\left(I_{\mathrm{p}} \approx 40 \%\right)$ London Clay, Figs 83 and 84 contrast its response to that seen in parallel experiments on lean $\left(I_{\mathrm{p}} \approx 18 \%\right)$ glacial Cowden (Bolders Bank) till in triaxial tests that involved the same equipment and techniques. High-quality samples of both stiff, high-YSR clay deposits from depths around $6 \mathrm{~m}$ were reconsolidated to similar (overconsolidated) effective stress conditions, applying the same $K_{0}(1 \cdot 5)$ and then subjected (after extended pause periods to eliminate creep) to undrained shearing. The deviator stress-vertical strain $\left(q-\varepsilon_{\mathrm{v}}\right)$ curves (in undrained triaxial tests $\varepsilon_{\mathrm{v}}=$ shear strain invariant, $\varepsilon_{\mathrm{s}}$ ) and effective stress paths (normalised by initial mean effective stress, $p_{0}^{\prime}$ ) are compared in Fig. 83. The Cowden till behaves as a ductile 'critical-state' soil whose effective stress path rotates to the right after undergoing 'gross yielding' and migrates towards its final state following a dilatant stress path. The deviator stress rises steadily with axial strain until its ultimate and peak strengths develop simultaneously after a vertical strain $\approx 25 \%$.

In contrast, the London Clay reaches its peak shear strength after just $4 \%$ vertical strain and then softens, leading to a notably lower ratio of peak undrained shear strength to initial mean effective stress, $S_{\mathrm{u}} / p_{0}^{\prime}$ than Cowden till. Shear bands develop in the London Clay that truncate any migration towards a uniform critical state condition. Polished shear surfaces gradually form that develop low angles of shearing resistance after large shear displacements, as were seen with the high-plasticity Sigsbee Escarpment clays. The strains $\varepsilon_{\mathrm{c}}$ at which the two samples reached their half failure deviator stress points are $\approx 0.9 \%$ and $\approx 1.8 \%$ for the London Clay and Cowden till, respectively. Recalling that the API (2014) approach expects the stiffnesses of the local $\Delta p / p_{\mathrm{u}}-\Delta y / D$ curves to scale in proportion to $1 / \varepsilon_{\mathrm{c}}$, the API approach predicts that the Cowden till will develop, for any given $\Delta p / p_{\mathrm{u}}$ value, twice as high a relative deflection, $\Delta y / D$, as the London Clay.

The two stiff clays' true stiffness behaviours are illustrated in Fig. 84 by plotting the undrained secant equivalent Young's moduli $E_{\mathrm{v}}^{\mathrm{u}}$ stiffness trends over four log cycles of vertical strain. The moduli are normalised by $S_{\mathrm{u}}$ in Fig. 84(a) and $p^{\prime}$ in Fig. 84(b). Although linear behaviour is implied by the API (2014) approach up to large strains, both clays are highly non-linear from around $0.002 \%$, three orders of magnitude lower than $\varepsilon_{\mathrm{c}}$. While the ordering of the nonlinear $E_{\mathrm{v}}^{\mathrm{u}} / p^{\prime}$ and $E_{\mathrm{v}}^{\mathrm{u}} / S_{\mathrm{u}}$ curves differ because of the clays' contrasting $S_{\mathrm{u}} / p_{0}^{\prime}$ ratios, the glacial till has higher initial 


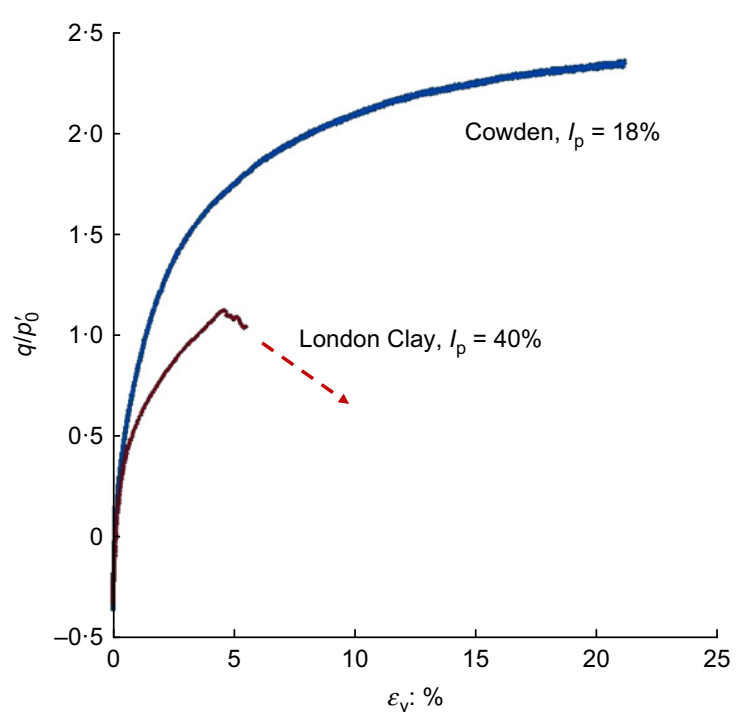

(a)

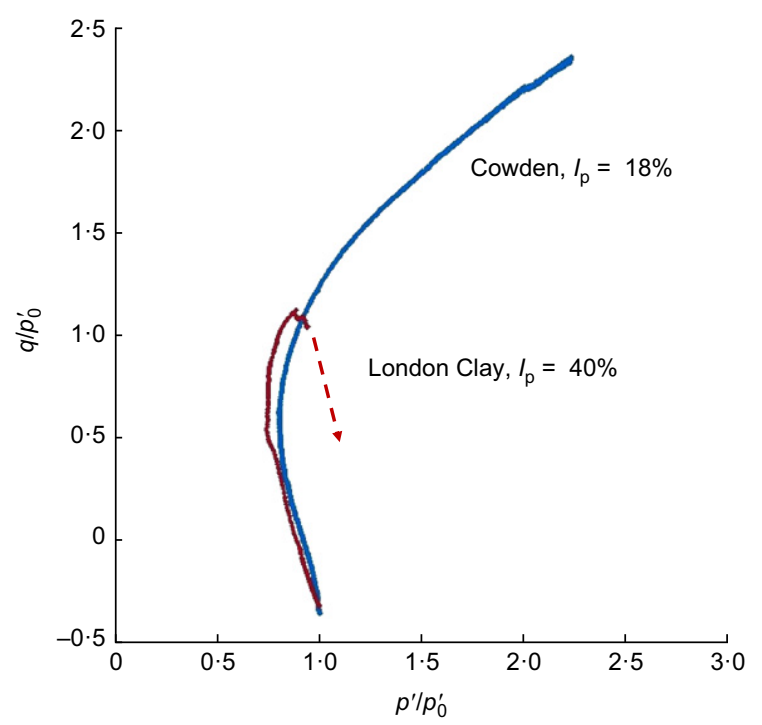

(b)

Fig. 83. Undrained triaxial compression tests on $K_{0}$ reconsolidated samples of Cowden till and London Clay from approx. $6 \mathrm{~m}$ depth: (a) normalised deviator stress-strain plots; (b) normalised effective stress paths. Tests by Gasparre (2005) and Ushev (2018)

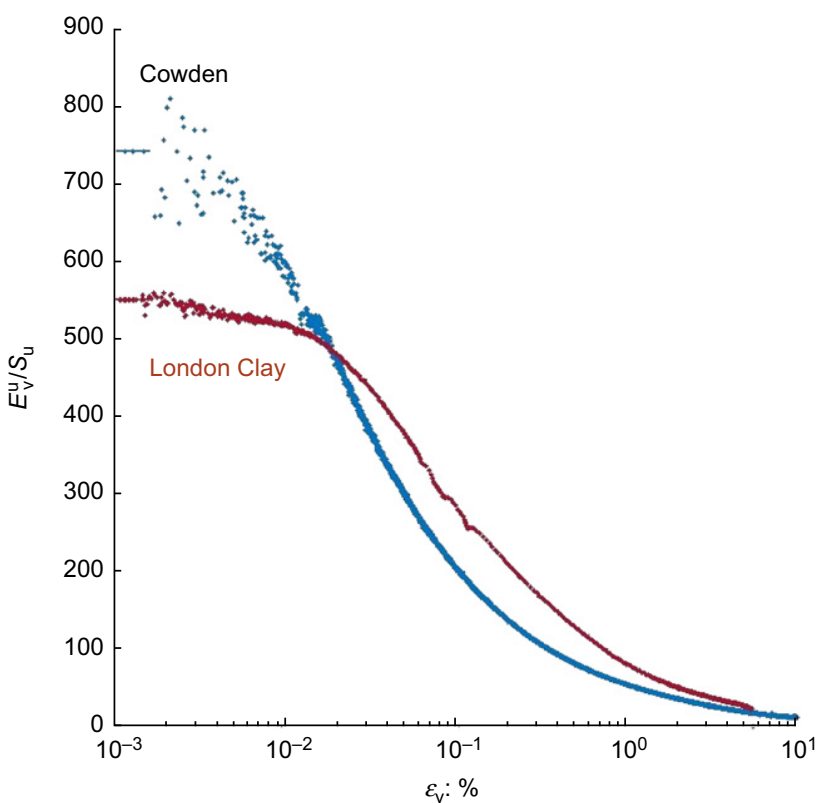

(a)

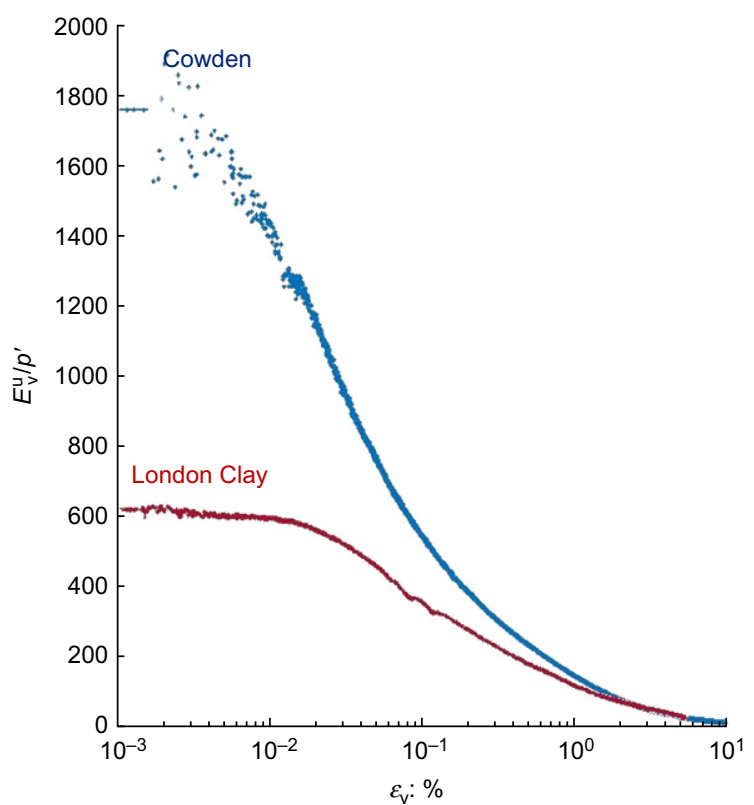

(b)

Fig. 84. Secant equivalent vertical Young's modulus-vertical strain response of undrained triaxial compression tests on $K_{0}$ reconsolidated samples of Cowden till and London Clay from approximately $6 \mathrm{~m}$ depth: (a) normalised by peak undrained shear strength, $S_{\mathrm{u}}$; (b) normalised by mean effective stress, $p^{\prime}$. Tests by Gasparre (2005) and Ushev (2018)

stiffness ratios by both measures and shows more steeply non-linear trends. The API (2014) approach assumes implicitly that the London Clay has twice the Cowden till's $E_{\mathrm{v}}^{\mathrm{u}} / S_{\mathrm{u}}$ stiffness ratio at all strains up to failure, but the stress path tests show the London Clay has a lower ratio up to $0 \cdot 01 \%$ strain and only achieves $E_{\mathrm{v}}^{\mathrm{u}} / S_{\mathrm{u}}=2$ when the strains reach the (relatively large) $\varepsilon_{\mathrm{c}}$ values.

The PISA approach aims to overcome such shortcomings by defining the geomaterials' stiffness curves and yielding behaviours representatively through high-quality site characterisation. As mentioned earlier, Jeanjean et al. (2017) also propose that the API method should be updated to incorporate a more accurate failure mechanism and stressstrain curves derived from site-specific simple shear tests.

Lateral pile loading invokes a range of stress paths that differ from triaxial compression. The laboratory programme therefore assessed the test soils' potential anisotropy in stiffness and shear strength. Fig. 85 illustrates the outcomes from parallel sets of HCA tests on samples of Cowden till and London Clay, which were consolidated in the same way as the triaxial specimens discussed above and sheared to failure at a range of values of $\alpha$, the $\sigma_{1}$ axis orientation with respect to the vertical, while keeping $\sigma_{2}^{\prime}$ close to the average $\left(\sigma_{1}^{\prime}+\sigma_{3}^{\prime}\right) / 2$ range expected for near plane-strain conditions. In this plot the Cowden till test that failed at $\alpha=48^{\circ}$ was conducted as an HCA simple shear test, applying the same principles and control systems as described earlier in relation to the HCA simple shear tests on sands conducted by Aghakouchak (2015). The peak strengths mobilised are expressed as variations in $S_{\mathrm{u}}$ (normalised by the triaxial compression value) with $\alpha$. Both high-YSR clays develop higher than triaxial compression shear strengths when loaded to failure 


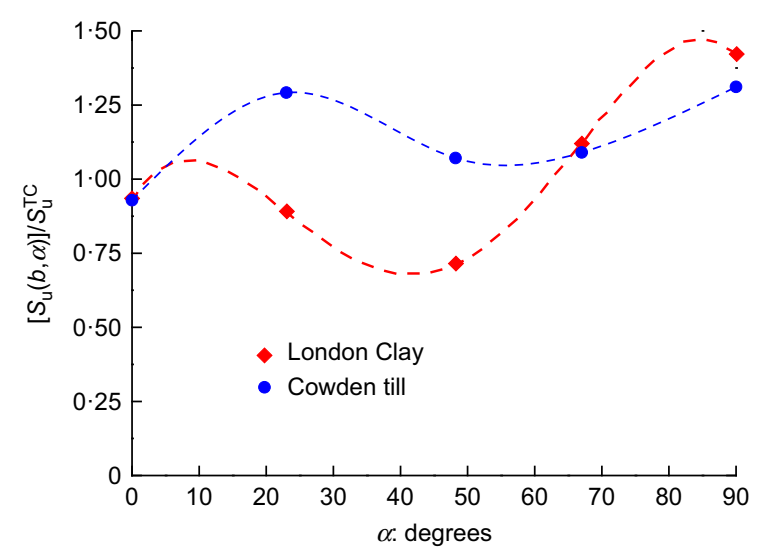

Fig. 85. Undrained shear strength anisotropy of Cowden till and London Clay samples, tested in HCA equipment after $K_{0}$ reconsolidation. Peak $S_{\mathrm{u}}$ values mobilised at four orientations $\alpha$ of $\sigma_{1}$ axis with respect to the vertical, normalised by triaxial compression peak $S_{\mathrm{u}}$. Tests by Nishimura (2006) and Liu (2018)

laterally (with $\alpha=90^{\circ}$ ) under plane-strain conditions, showing the opposite pattern to that shown of low-OCR clays (see e.g. Jardine, 2002). Parallel plane-strain simple tests conducted on London Clay in the HCA apparatus also show failure developing with $\alpha$ values exceeding $45^{\circ}$ (at $\approx 55^{\circ}$ ), as is usual when $K_{0}>1$. The glacial till shows higher shear strengths (relative to triaxial compression) under these conditions than the more plastic, brittle and older sedimentary London Clay.

The HCA and triaxial experiments confirmed still more marked anisotropy in stiffness, with both Cowden till and London Clay proving markedly stiffer under horizontal than vertical loading over the full strain range. Forthcoming papers describe the mechanical behaviour of the PISA site soils in greater detail.

\section{Measurements and Class A predictions for the $2 \mathrm{mOD}$ PISA} piles at Cowden

The PISA programme involved comprehensive testing on 28 piles driven at Dunkirk and Cowden which are reported by Byrne et al. (2017) and in forthcoming papers that also cover the ICFEP numerical modelling and four component 'Winkler' design theory. It is only possible, and appropriate, to outline one illustrative example in this paper. Fig. 86

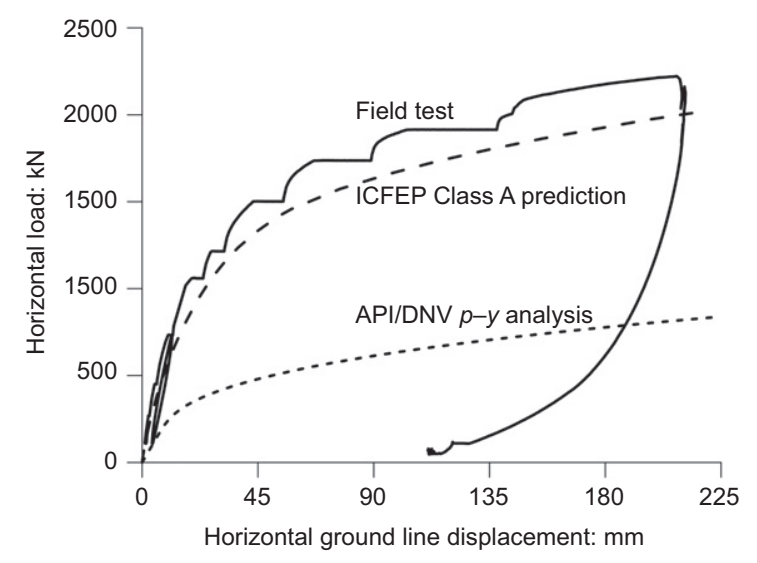

Fig. 86. Field lateral and moment loading test to failure on $10.5 \mathrm{~m}$ embedment, $2 \mathrm{~m}$ OD PISA test pile in glacial till at Cowden, Humberside. Numerical Class A predictions also shown from API (2014) approach and ICFEP numerical analysis conducted as described by Zdravković et al. (2015) presents the ground level load-displacement curve determined for the largest ( $2 \mathrm{~m}$ dia., $10 \cdot 5 \mathrm{~m}$ embedded length) monopile driven at Cowden when taken to failure under static lateral and moment loading.

Zdravković et al. (2015) outline how Class A ICFEP numerical predictions were undertaken for Cowden. As in the earlier described Magnus and Hutton TLP case histories, the clay layers were modelled with a modified Cam Clay variant, which captures the ductile and dilatant experimental behaviour illustrated above in Figs 83 and 84. An updated and extended variant was adopted to cover more realistically variations of strength and yielding on the 'dry' side (Tsiampousi et al., 2013) and included a hyperbolic description of shear stiffness non-linearity from small strains (Taborda et al., 2014). Given the horizontal and moment loading focus, fully rough interface behaviour was simulated. It was also considered that pile installation effects (which are hard to model accurately, as noted in Part 1) were less important for lateral than axial loading analyses. Account was taken of the till's potential stiffness anisotropy by upscaling the relatively soft triaxial compression shear stiffness curves based on in situ shear wave velocity measurements. Ushev (2018) and Liu (2018) show that both stiffness anisotropy and the mean effective stress level increases generated around driven pile shafts by installation (Bond \& Jardine, 1991; Pellew \& Jardine, 2008) are likely to raise the operational field stiffnesses above the values expected from triaxial compression tests conducted from 'undisturbed' in situ stress conditions.

The $2 \mathrm{~m}$ dia. PISA Cowden test pile had an $L / D=5 \cdot 25$ aspect ratio at Cowden and was loaded by horizontal actions applied $10 \mathrm{~m}$ above ground level. Ten stages were imposed and, as illustrated in Fig. 86, displacements grew over time while loads were held constant. The test data can be interpreted to provide a family of curves, each representing a single pile head displacement rate, as proposed for axially loaded piles in stiff London Clay by Pellew \& Jardine (2008). No absolute peak lateral load developed, which reflects the large strains required by Cowden till to reach its critical state conditions (see Fig. 83). Fig. 86 also presents the PISA teams' Class A predictions. Experienced designers from Orsted provided the industry-standard API/ISO/Det Norske Veritas (DnV) method predictions. As in the Magnus, Hutton TLP, Shearwater and Tilbrook Grange case histories described earlier, the conventional approach led to very significant under-predictions for field stiffness and capacity. In contrast, the ICFEP Class A predictions fell only slightly below the 'end-of-creep' points recorded for each loading stage. Their match with the field tests is generally good, from the initial stiffness slope up to the large displacement point at which the test terminated.

The PISA tests at Cowden and Dunkirk included a range of pile sizes as well as comprehensive on-pile strain gauges and other instrumentation. A range of loading parameters and styles was considered, including cyclic tests and experiments with variable displacement rates. The ICFEP predictions gave similarly encouraging results for the $762 \mathrm{~mm}$ and $273 \mathrm{~mm}$ OD piles tested at Cowden, and in the dense Dunkirk sand (Byrne et al., 2017). The PISA programme delivered new information that is now being applied by the project's sponsors, their consultants and software developers (see Plaxis, 2018) to aid monopile optimisation at new offshore wind turbine sites. One example of the benefits for new wind farm projects is the report by Foxwell (2018) on PISA being applied to design the monopiles for the 600-900 MW capacity Triton Knoll wind farm, which is to be installed off the coast of Lincolnshire, to the east of the UK. 
Geotechnical contributions to off shore renewable energy economics

Remarkable reductions are taking place in the costs of electricity from offshore wind, which can now compete with new gas developments (Carbon Brief, 2017). The case histories and research programmes outlined in Part 3 of this paper show how geotechnical research is contributing, along with work in many other engineering disciplines, to rapidly improving renewable wind energy economics. Collaborative research covering geology, experimental, numerical and theoretical geotechnics is also delivering findings that can be applied more generally in bridge, port, industrial and housing developments, as well as offshore oil and gas projects.

\section{CONCLUDING REMARKS}

This paper has reported geotechnical contributions towards resolving the global energy conundrum, presenting paired topics in each of its three main parts. These were interlinked with a narrative informed by current understanding of: the demands for and benefits of adequate energy supplies; the consequences of sustaining or increasing current fossil consumption levels; and the scope to move to more sustainable low-carbon-dioxide energy resources.

Part 1 described research directed towards maintaining safe and efficient offshore oil and gas supplies. Attention was focused on a series of studies into understanding, analysing and designing driven piles, followed by a contrasting account of how the hazards posed by large offshore landslides to deep-water developments can be understood and assessed through an integrated, first principles, approach.

Part 2 reported geotechnical research into the impact of climate change in cold permafrost regions, demonstrating the application of novel thermal regional-level analyses and reporting tools developed to help design, or retro-fit, individual high-value infrastructure components. Climate change is likely to have profound effects, and research contributions towards effective adaptation were noted for permafrost applications and described in more detail through the example of a study that aided flood dyke strengthening on difficult peat ground in the Netherlands.

Part 3 of the lecture reviewed how geotechnics can help to tackle the climate change problem at source, by improving renewable energy economics. Significant benefits were reported from applying the research outlined in Part 1 to tripod and jacket-supported wind turbine projects in Quaternary soils; new research that offers comparable contributions for difficult Chalk sites was also presented. The shortcomings of conventional current design methods for assessing the lateral and moment-carrying characteristics of monopile foundations were identified next and the benefits of improved design procedures developed through a recent joint industry programme were demonstrated.

The paper emphasises the need when considering broad areas of geotechnical engineering for a collaborative approach that integrates advanced laboratory, numerical and theoretical research. Echoing the Rankine Lecture by Skempton (1964), it was shown to be essential to start from a sound understanding of geology and to test and refine new proposals through careful field observations. A further theme that continued throughout was the creative interplay between different geotechnical engineering sectors. Examples included extending progressive failure analysis tools developed for cut highway and railway slopes to enable novel analyses for deep-water slides. Similarly, advances in offshore foundation engineering were noted to have offered better ways of treating urban soil-structure interaction analyses, as well as improving pile design for bridges and ports.

The need to keep any developments 'as simple as possible, but no simpler' was recognised at the outset. A wide spectrum of complexity was found necessary to achieve design tools that are physically representative of the problems considered and yet sufficiently attractive and tractable to encourage practical application. However, many questions remain open to further investigation. Examples of unclosed research questions are given below, offering one question in relation to each of the six main areas discussed.

(a) An outstanding question from Part 1 is how to develop accurate and representative analyses for the full stress conditions developed inside and outside open-ended steel tubular piles during driving and over service lives, which may include extended ageing periods.

(b) Closer quantitative correlation between the geophysical and geotechnical characterisation of deep sediments would be of great benefit to the offshore landslide studies discussed as the second Part 1 topic, especially at depths where geotechnical sampling is either sparse or unfeasible.

(c) The analytical geotechnical modelling of permafrost covered in Part 2 requires improvement to capture the creeping failures that are being witnessed in thermally activated landslides in cold regions.

(d) Better models are needed to capture the constitutive behaviour of the fibrous peats encountered in the flood dyke study presented as the second Part 2 topic.

(e) Turning to the offshore wind research applications covered in Part 3, quite different silts, liquefiable and non-siliceous sands, and rock ground conditions are being encountered in new offshore wind developments around the world. New field studies are required to investigate how piles behave in these unfamiliar geomaterials. These uncertain conditions also call for the wider application of effective offshore pile testing.

( $f$ ) Finally, one urgent task relating to monopiles is the development of simple and representative cyclic loading analysis tools to ensure that their design meets the wind turbines' lifetime performance requirements.

The paper has reported encouraging progress in its six main topic areas. However, it is important to acknowledge that much still remains to be achieved in each of these topics, and in many related areas.

\section{ACKNOWLEDGEMENTS}

The author is deeply grateful to Antonio Gens, David Hight, Stavroula Kontoe and Philip Smith, who provided essential guidance during the preparation of the lecture and paper, as well as to Royal Haskoning DHV for their help in redrafting figures and to David Potts and Jamie Standing who reviewed the written version as well as contributing to the research described. He is also indebted to the organisations who funded, facilitated or collaborated in the research described, including Atkins, BP, Cambridge Insitu, Chevron, Conoco Phillips, Deltares, EPSRC, Socotec, Fugro, Geotechnical Consulting Group, Université Grenoble Alpes, Health and Safety Executive, Scottish Power Renewables, Innovate UK, Lankelma UK, Offshore Wind Consultants, Orsted, OWC, Oxford University, Shell UK, UPC Barcelona, University College Dublin, University of Western Australia and Zhejiang University. The contributions of many individuals are also recognised gratefully including those of Amin Aghakouchak, Ricardo Argiolas, Pedro Barbosa, Andrew Bond, Róisín Buckley, John Burland, Byron Byrne, 
Fiona Chow, Jim Clarke, Clive Dalton, Bethan Davies, Itai Einav, Trevor Evans, Pierre Foray, Clark Fenton, Liana Gasparre, Angeliki Grammatikopolou, Joanna Haigh, Michael Hotze, Rupert Hunt, Nebojsa Kovacevic, Barry Lehane, Tingfa Liu, Christopher Martin, Ross McAdam, Andrew Merritt, Way-Way Moinet, Michael Mygind, Rory Mortimore, Alastair Muir-Wood, David Nethercot, Satoshi Nishimura, Robert Overy, Eric Parker, Mark Randolph, Michael Rattley, Siya Rimoy, Carlos Santamarina, Felix Schroeder, Matias Silva, Philip Smith, David Taborda, Ralf Toumi, Christian Le Blanc Thilstead, Cristina Tsuha, Emil Ushev, Robert Whittle, Zhongxuan Yang, Lidija Zdravkovic, Bitang Zhu, Cor Zwanenburg and many others.

Finally, special mention must be made of patient support from the author's family, Sue Feller at Imperial College and the technical team with whom the author has worked since 1981: Steve Ackerley, Alan Bolsher, Graham Keefe and Duncan Parker.

\section{NOTATION}

$A, B, C$ empirical factors applied in cyclic analyses; see equation (7)

$B \quad$ Skempton's pore pressure parameter

$B$ Einav's particle breakage parameter

$b$ measure of intermediate principal stress $=\left(\sigma_{2}^{\prime}-\sigma_{3}^{\prime}\right) /\left(\sigma_{1}^{\prime}-\sigma_{3}^{\prime}\right)$

$C_{\mathrm{C}}$ one-dimensional compressibility in $e-\log \sigma_{\mathrm{v}}^{\prime}$

$C_{\alpha e}$ coefficient of secondary compressibility

$c_{\mathrm{s}}, c_{1}, c_{\mathrm{i}}$ specific heat of soil particles, liquid water and ice

$D$ pile diameter

$d_{10} \quad$ effective particle diameter

$d_{50}$ mean particle diameter

$d_{\mathrm{r}}$ radial dilation at pile shaft on loading to failure in sand, related to pile roughness $R$

$E_{\mathrm{h}}^{\prime}, E_{\mathrm{v}}^{\prime} \quad$ drained Young's moduli for cross-anisotropic elastic soil

$E_{\mathrm{h}}^{\mathrm{u}}, E_{\mathrm{v}}^{\mathrm{u}} \quad$ undrained Young's moduli for cross-anisotropic elastic soil

$e$ void ratio

$e \quad$ eccentricity of horizontal loading for a pile

$e_{\max }$ maximum voids ratio

$e_{\min }$ minimum voids ratio

$G$ operational shear stiffness

$G_{\mathrm{hh}}$ shear modulus in horizontal plane

$G_{\mathrm{hv}}, G_{\mathrm{vh}}, G_{\mathrm{z} \theta}$ shear moduli in vertical plane

$G_{\mathrm{s}} \quad$ specific gravity

$g(\theta) \quad$ yield function in the deviatoric plane

$h$ height of point above pile tip

$I_{\mathrm{at}}, I_{\mathrm{af}}, I_{\mathrm{st}}, I_{\mathrm{sf}}$ air thawing, air freezing, surface thawing and surface freezing indices

$I_{\mathrm{D}} \quad$ sand density index

$I_{\mathrm{v}}$ clay void index, $I_{\mathrm{vy}}$ is value at yield

$J$ deviatoric stress $=\left[\left(\sigma_{1}^{\prime}-\sigma_{2}^{\prime}\right)^{2}+\left(\sigma_{2}^{\prime}-\sigma_{3}^{\prime}\right)^{2}+\left(\sigma_{3}^{\prime}-\sigma_{1}^{\prime}\right)^{2}\right]^{0.5} / \sqrt{ } 6$

$J$ empirical constant in API $p-y$ curve formulation

$K_{\mathrm{A}}$ coefficient of active earth pressure

$K_{\mathrm{C}}$ earth pressure ratio close to driven pile $=\sigma_{\mathrm{r}}^{\prime} / \sigma_{\mathrm{v} 0}^{\prime}$

$K_{0}$ coefficient of earth pressure at rest

$L$ pile length

$L_{\mathrm{i}} \quad$ loss on ignition for organic soil, in percent

$l$ specific latent heat of fusion

$N$ number of cycles in cyclic test

$N_{\text {ball }} \quad$ factor applied to deduce $S_{\mathrm{u}}$ from ball penetrometer tests, see equation (17)

$N_{\mathrm{kt}}$ factor applied to deduce $S_{\mathrm{u}}$ from cone penetration tests, see equation (16)

$n_{\mathrm{t}}, n_{\mathrm{f}} \quad$ air-ground temperature transfer factors

$P_{\text {a }} \quad$ atmospheric pressure

$P_{\mathrm{u}} \quad$ ultimate horizontal load per metre depth in API $p-y$ curve formulation

$p^{\prime} \quad$ mean effective stress

$p_{0}^{\prime} \quad$ initial mean effective stress

$p_{\mathrm{u}} \quad$ ultimate local pile lateral resistance in $p-y$ analysis $p-y \quad$ local pile lateral load-deflection relationship

$Q_{\text {c }}$ calculated pile capacity

$Q_{\text {cyclic }}$ cyclic pile load

$Q_{\mathrm{m}}$ measured pile capacity

$Q_{\text {mean }}$ mean pile load under cyclic loading

$Q_{\text {s }}$ pile shaft capacity in compression

$Q_{\mathrm{T}}$ pile capacity in tension

$Q-z \quad$ local pile tip axial load-deflection relationship

$q$ heat production/sink

$q$ deviatoric stress $=\left(\sigma_{\mathrm{a}}-\sigma_{\mathrm{r}}\right)$ under triaxial test conditions

$q_{\mathrm{b}} \quad$ pile tip resistance pressure

$q_{\text {ball }}$ ball penetrometer resistance

$q_{\mathrm{c}}$ cone penetration test tip resistance

$q_{\text {cyclic }}$ deviatoric stress amplitude under cyclic conditions

$q_{\mathrm{t}}$ corrected (for pore pressure) cone penetration test tip resistance

$R$ pile outer radius

$R^{*} \quad$ open-ended pile effective radius

$R_{\text {cla }}$ mean centre-line surface roughness

$R_{\text {inner }} \quad$ open-ended pile inner radius

$R_{\text {outer }}$ open-ended pile outer radius

$r$ radial distance from axis

$S_{1} \quad$ degree of liquid saturation in pore space

$S_{\mathrm{t}} \quad$ clay sensitivity

$S_{\mathrm{u}} \quad$ undrained strength

$T$ temperature (absolute in Kelvin)

$T_{\mathrm{a}}$ air temperature

$t$ time

$t_{\mathrm{s}} \quad$ shear band thickness

$t_{\mathrm{t}}, t_{\mathrm{f}}$ periods for which $T_{\mathrm{a}}>0$ and $T_{\mathrm{a}}<0$, respectively

$t-z$ local pile shaft shear load-deflection relationship $u$ specific internal energy

$V, V_{\mathrm{s}}, V_{\mathrm{l}}, V_{\mathrm{i}}$ volume of soil mass, soil particles, liquid water and ice

$v \quad$ specific volume $=1+e$

$x$ depth into ground

$y$ local pile lateral deflection

$y_{\mathrm{c}} \quad$ local pile lateral deflection at specified normalised stage

$z$ axial depth, $z_{\mathrm{R}}$ is depth at which $p$ reached $p_{\mathrm{u}}$ in API $p-y$ curve formulation

$\alpha$ inclination of major principal stress to sample vertical direction

$\alpha$ parameter in soil freezing function

$\beta$ parameter in soil freezing function

$\gamma$ bulk unit weight

$\gamma_{\mathrm{z} \theta}$ shear strain in vertical plane

$\gamma^{\prime} \quad$ submerged unit weight

$\Delta$ change in a parameter

$\Delta I_{\mathrm{vy}} \quad$ oedometer sensitivity parameter $=\log S_{\mathrm{t}}$

$\delta^{\prime}$ angle of interface shearing resistance

$\varepsilon_{\mathrm{a}} \quad$ axial strain, also $\varepsilon_{z}$

$\varepsilon_{\mathrm{c}}$ axial strain in undrained triaxial test at half way to peak deviator stress stage

$\varepsilon_{\mathrm{r}} \quad$ radial strain, also horizontal strain $\varepsilon_{\mathrm{h}}$

$\varepsilon_{\mathrm{v}} \quad$ vertical strain

$\varepsilon_{\theta} \quad$ circumferential strain, also horizontal strain $\varepsilon_{x}$

$\theta$ Lode's angle in the deviatoric plane

$\kappa$ gradient of isotropic swelling line in $v: \ln p^{\prime}$ plane

$\lambda$ gradient of isotropic compression line in $v: \ln p^{\prime}$ plane

$\lambda, \lambda_{\mathrm{s}}, \lambda_{1}, \lambda_{\mathrm{i}}$ thermal conductivity of soil mass, soil particles, liquid water and ice

$\mu \quad$ field vane correction factor to find operational $S_{\mathrm{u}}$, see equation (16)

$\rho_{\mathrm{s}}, \rho_{\mathrm{l}}, \rho_{\mathrm{i}}$ mass density of soil particles, liquid water and ice

$\sigma_{\mathrm{a}}^{\prime} \quad$ axial effective stress

$\sigma_{\mathrm{h}}^{\prime}$ horizontal effective stress

$\sigma_{\mathrm{r}}^{\prime}$ radial effective stress, $\sigma_{\mathrm{rf}}^{\prime}$ is value at failure

$\sigma_{\mathrm{rc}}^{\prime} \quad$ stationary (at rest) radial effective stress

$\sigma_{\mathrm{rd}}^{\prime}$ dilative radial effective stress change

$\sigma_{\mathrm{v}}^{\prime} \quad$ vertical effective stress, $\sigma_{\mathrm{v} 0}^{\prime}$ is undisturbed initial free-field value

$\sigma_{\mathrm{vy}}^{\prime} \quad$ oedometer vertical yield stress

$\sigma_{z}^{\prime} \quad$ vertical effective stress

$\sigma_{\theta}^{\prime} \quad$ circumferential effective stress 
$\tau_{\text {cyclic }} \quad$ cyclic pile shaft interface shear stress

$\tau_{\text {mean }}$ mean pile shaft interface shear stress under cyclic loading

$\tau_{\mathrm{r} z} \quad$ pile shaft interface shear stress

$\tau_{\mathrm{rzf}}$ pile shaft interface shear stress at failure

$\phi$ angle of shearing resistance in soils

$\phi_{\text {crit }}^{\prime} \quad$ critical state angle of shearing resistance

$\phi_{\text {peak }}^{\prime}$ peak angle of shearing resistance

$\phi_{\text {res }}^{\prime} \quad$ residual angle of shearing resistance

\section{REFERENCES}

Ackerley, S. K., Standing, J. R. \& Hosseini Kamal, R. (2016). A system for measuring local radial strains in triaxial apparatus. Géotechnique 66, No. 6, 515-522, https://doi.org/10.1680/jgeot. 15.T.027.

Aghakouchak, A. (2015). Advanced laboratory studies to explore the axial cyclic behaviour of driven piles. $\mathrm{PhD}$ thesis, Imperial College, London, UK.

Aghakouchak, A., Sim, W. W. \& Jardine, R. J. (2015). Stress-path laboratory tests to characterise the cyclic behaviour of piles driven in sands. Soils Found. 44, No. 5, 917-928.

Altuhafi, F. \& Jardine, R. J. (2011). Effect of particle breakage and strain path reversal on the properties of sands located near to driven piles. In Deformation characteristics of geomaterials: proceedings of 5th international symposium IS-Seoul (eds C.-K. Chung, H.-K. Kim, J.-S. Lee, Y.-H. Jung and D.-S. Kim), vol. 1, pp. 386-395. Seoul, Korea: Hanrimwon.

Altuhafi, F., Jardine, R. J., Georgiannou, V. N. \& Sim, W. (2018). Effects of particle breakage and stress reversal on the behaviour of sand around displacement piles. Géotechnique 68, No. 6, 546-555, https://doi.org/10.1680/jgeot.17.P.117.

AMAP (Arctic Monitoring and Assessment Programme) (2017). Snow, water, ice and permafrost in the Arctic (SWIPA) 2017. Oslo, Norway: Arctic Monitoring and Assessment Programme (AMAP).

Andersen, K. (2015). Cyclic soil parameters for offshore foundation design. 3rd McClelland lecture. In Frontiers in offshore geotechnics III (ed. V. Meyer), vol. 1, pp. 5-82. London, UK: Taylor \& Francis Group.

Andersland, O. B. \& Ladanyi, B. (2004). Frozen ground engineering, 2nd edn. Hoboken, NJ, USA: John Wiley \& Sons.

Anderson, D. M. \& Morgenstern, N. R. (1973). Physics, chemistry and mechanics of frozen ground: a review. North American contribution: proceedings of the 2nd international conference on permafrost (eds T. L. Pewe and J. R. Mackay), pp. 257-288. Washington, DC, USA: National Academy of Sciences.

Anh-Minh, N., Nishimura, S., Takahashi, A. \& Jardine, R. J. (2011). On the control systems and instrumentation required to investigate the anisotropy of stiff clays and mudrocks through hollow cylinder tests. In Deformation characteristics of geomaterials: proceedings of 5th international symposium IS-Seoul (eds C.-K. Chung, H.-K. Kim, J.-S. Lee, Y.-H. Jung and D.-S. Kim), vol. 1, pp. 287-294. Seoul, Korea: Hanrimwon.

API (American Petroleum Institute) (2014). ANSI/API recommended practice 2GEO. RP2GEO, 1st edn. Washington, DC, USA: API

Argiolas, R. \& Jardine, R. J. (2017). An integrated pile foundation re-assessment to support life extension and new build activities for a mature north sea oil field project. In Proceedings of the 8th international conference on offshore site investigations and geotechnics (ed. T. Powell), vol. 2, pp. 695-702. London, UK: Society for Underwater Technology (SUT).

Atkins (2000). Cyclic degradation of offshore piles. Prepared by WS Atkins Consultants Ltd for the Health and Safety Executive, Offshore Technology Report, 2000/013. London, UK: HSE.

Axelsson, G. (2000). Long term set up of driven piles in sand. $\mathrm{PhD}$ thesis, Royal Institute of Technology, Stokholm, Sweden.

Barbosa, P., Geduhn, M., Jardine, R. J., Schroeder, F. C. \& Horn, M. (2015). Full scale offshore verification of axial pile design in chalk. In Frontiers in offshore geotechnics III (ed. V. Meyer), vol. 1, pp. 515-520. London, UK: Taylor \& Francis Group.

Barbosa, P., Geduhn, M., Jardine, R. J. \& Schroeder, F. C. (2017). Large scale offshore static pile tests: practicality and benefits. In Proceedings of the 8th international conference on offshore site investigations and geotechnics (ed. T. Powell), vol. 2, pp. 644-651. London, UK: Society for Underwater Technology (SUT).

Bond, A. J. (1989). Behaviour of displacement piles in overconsolidated clays. $\mathrm{PhD}$ thesis, Imperial College London, London, UK.

Bond, A. J. \& Jardine, R. J. (1991). Effects of installing displacement piles in a high OCR clay. Géotechnique 41, No. 3, 341-363, https://doi.org/10.1680/geot.1991.41.3.341.

Bond, A. J. \& Jardine, R. J. (1995). Shaft capacity of displacement piles in a high OCR clay. Géotechnique 45, No. 1, 3-24, https://doi.org/10.1680/geot.1995.45.1.3.

Bond, A. J., Jardine, R. J. \& Dalton, C. (1991). The design and development of the Imperial College Instrumented Pile. ASTM J. Geotech. Testing 14, No. 4, 413-424.

Bowden, A. J., Spink, T. W. \& Mortimore, R. N. (2002). The engineering description of chalk: its strength, hardness and density. Q. J. Engng Geol. Hydrogeol. 35, No. 4, 355-361.

Boylan, N., Long, M. \& Mathijssen, F. A. J. M. (2011). In situ strength characterisation of peat and organic soil using full flow penetrometers. Can. Geotech. J. 48, No. 7, 1085-1099.

Brandl, H. (2006). Energy foundations and other thermo-active ground structures. Géotechnique 56, No. 2, 81-122, https://doi. org/10.1680/geot.2006.56.2.81

Briaud, J. L. \& Tucker, L. M. (1988). Measured and predicted axial response of 98 piles. ASCE J. Geotech. Engng 114, No. 9, 984-1001.

Brosse, A., Hosseini Kamal, R., Jardine, R. J. \& Coop, M. R. (2017). The shear stiffness characteristics of four Eoceneto-Jurassic UK stiff clays. Géotechnique 67, No. 3, 242-259, https://doi.org/10.1680/jgeot.15.P.236.

Brucy, F., Meunier, J. \& Nauroy, J. F. (1991). Behaviour of pile plug in sandy soils during and after driving. Proceedings of the 23rd offshore technology conference, Houston, TX, USA, paper OTC 6514, pp. 145-154.

Buckley, R. M. (2018). The axial behavior of displacement piles in chalk. $\mathrm{PhD}$ thesis, Imperial College, London, UK.

Buckley, R. M., Jardine, R. J., Kontoe, S., Parker, D. \& Schroeder, F. C. (2018a). Ageing and cyclic behaviour of axially loaded piles driven in chalk. Géotechnique 68 , No. 2, 146-162, https://doi.org/10.1680/jgeot.17.P.012.

Buckley, R. M., Jardine, R. J., Kontoe, S. \& Lehane, B. M. (2018b). Effective stress regime around a jacked steel pile during installation ageing and load testing in chalk. Can. Geotech. J. 55, No. 11, 1577-1591.

Bustamante, M. \& Gianeselli, L. (1982). Pile bearing capacity by means of static penetrometer CPT. In Proceedings of the 2nd European symposium on penetration testing (eds A. Verruijt, F. L. Beringen and E. H. de Leeuw), pp. 493-500. Rotterdam, the Netherlands: Balkema.

Byrne, T., Doherty, P., Gavin, K. \& Overy, R. (2012). Comparison of pile driveability methods in North Sea sand. In Proceedings of the 7th international conference on offshore site investigations and geotechnics (ed. P. Allan), pp. 481-488. London, UK: Society for Underwater Technology (SUT).

Byrne, B. W., McAdam, R., Burd, H. J., Houlsby, G. T., Martin, C. M., Zdravkovic, L., Taborda, D. M. G., Potts, D. M., Jardine, R. J., Sideri, M., Schroeder, F. C., Gavin, K., Doherty, P., Igoe, D., Muir Wood, A., Kellahave, D. \& Skov Gretlund, J. (2015a). New design methods for large diameter piles under lateral loading for offshore wind applications. In Frontiers in offshore geotechnics III (ed. V. Meyer), vol. 1, pp. 705-710. London, UK: Taylor \& Francis Group.

Byrne, B. W., McAdam, R., Burd, H. J., Houlsby, G. T., Martin, C. M., Gavin, K., Doherty, P., Igoe, D., Zdravković, L., Taborda, D. M. G., Potts, D. M., Jardine, R. J., Sideri, M., Schroeder, F. C., Muir Wood, A., Kallehave, D. \& Skov Gretlund, J. (2015b). Field testing of large diameter piles under lateral loading for offshore wind applications. In Geotechnical engineering for infrastructure and development: XVI European conference on soil mechanics and geotechnical engineering (ed. M. Winter), pp. 1255-1260. London, UK: ICE Publishing.

Byrne, B. W., McAdam, R. A., Burd, H. J., Houlsby, G. T., Martin, C. M., Beuckelaers, W. J. A. P., Zdravkovic, L., 
Taborda, D. M. G., Potts, D. M., Jardine, R. J., Ushev, E., Liu, T. F., Abadias, D., Gavin, K., Igoe, D., Doherty, P., Skov Gretlund, J., Pacheco Andrade, M., Muir Wood, A., Schroeder, F. C., Turner, S. \& Plummer, M. (2017). PISA: new design methods for offshore wind turbine monopiles. In Proceedings of the 8th international conference on offshore site investigations and geotechnics (ed. T. Powell), vol. 1, pp. 142-161. London, UK: Society for Underwater Technology (SUT).

Carotenuto, P., Meyer, V. M., Strøm, P. J., Cabarkapa, Z., St John, H. D. \& Jardine, R. J. (2018). Installation and axial capacity of the Sheringham shoal offshore wind farm monopiles - a case history. In Engineering in chalk (eds J. A. Lawrence, M. Preene, U. L. Lawrence and R. Buckley), pp. 117-122. London, UK: ICE Publishing.

Carrington, T. M., Li, G. \& Rattley, M. J. (2011). A new assessment of ultimate unit friction for driven piles in low to medium density chalk. In Proceedings of the 15th European conference on soil mechanics and geotechnical engineering (XVECSMGE): Geotechnics of hard soils - weak rocks (eds A. Anagnostopoulos, M. Pachakis and Ch. Tsatsanifos), pp. 825-830. Amsterdam, the Netherlands: IOS Press.

Carroll, R., Carotenuto, P., Dano, C., Salama, I., Silva, M., Gavin, K. \& Jardine, R. J. (2019). Field experiments at three sites to investigate the effects of age on steel piles driven in sand. Géotechnique, https://doi.org/10.1680/jgeot.17.P.185.

CB (Carbon Brief) (2017). See https://www.carbonbrief.org/ analysis-uk-auction-offshore-wind-cheaper-than-new-gas (accessed 01/11/2017).

Chow, F. C. (1997). Investigations into displacement pile behaviour for offshore foundations. PhD thesis, Imperial College London, London, UK.

Ciavaglia, F., Carey, J. \& Diambra, A. (2017). Time-dependent uplift capacity of driven piles in low to medium density chalk. Géotechnique Lett. 7, No. 1, 90-96, https://doi.org/10.1680/ jgele.16.00162.

Clarke, J. (ed.) (1993). Proceedings of ICE conference. Large-scale pile tests in clay. London, UK: Thomas Telford.

Clarke, J., Fenton, C., Gens, A., Jardine, R., Martin, C., Nethercot, D., Nishimura, S., Olivella, S., Reifen, C., Rutter, P., Strasser, F. \& Toumi, R. (2008). A multi-disciplinary approach to assess the impact of global climate change on infrastructure in cold regions. In Proceedings of 9th international conference on permafrost (eds D. L. Kane and K. M. Hinkel), pp. 279-284. Fairbanks, AK, USA: Institute of Northern Engineering, University of Alaska, Fairbanks.

Clausen, C. J. F., Aas, P. M. \& Karlsrud, K. (2005). Bearing capacity of driven piles in sand, the NGI approach. In Frontiers offshore geotechnics (eds S. Gourvenec and M. Cassidy), pp. 677-681. London, UK: Taylor \& Francis Group.

Coulomb, C. A. (1776). Essai sur une application des règles des maximis et minimis a quelques problèmes de statique relatifs a l'architecture. In Memoires de mathematique et de physique de l'Academie de Sciences. Par divers savants, pp. 343-382. Paris, France: L'Imprimerie Royale (in French).

Davidson, H. L. (1982). Laterally loaded drilled pier research, vol 1 . design methodology, vol. 2: research documentation, Final Report. Monroeville, PA, USA: GAI Consultants Inc., for the Electric Power Research Institute (EPRI).

Davies, B. J., Roberts, D. H., Bridgland, D. R., O’Cofaigh, C. \& Riding, J. B. (2011). Provenance and depositional environments of quaternary sediments from the western North Sea Basin. J. Quaternary Sci. 26, No. 1, 59-75.

Delisle, G. (2007). Near-surface permafrost degradation: how severe during the 21 st century? Geophys. Res. Lett. 34, No. 9, L09503.

Den Haan, E. J. \& Kruse, G. A. M. (2006). Characterisation and engineering properties of Dutch peats. In Characterisation and engineering properties of natural soils (eds T. S. Tan, K. K. Phoon, D. W. Hight and S. Leroueil), vol. 3, pp. 2101-2133. London, UK: Taylor and Francis.

Diambra, A., Ciavaglia, F., Dimelow, C., Carey, J. \& Nash, D. F. T. (2014). Performance of cyclic cone penetration tests in chalk. Géotechnique Lett. 4, No. 3, 230-237, https://doi.org/10.1680/ geolett.14.00050.

DNV-GL (Det Norske Veritas) (2016). Offshore standard DNVGL-ST-0126 design of offshore wind turbine structures. Oslo, Norway: DNV-GL AS.
Doherty, P., Igoe, D., Murphy, G., Gavin, K., Preston, J., McAvoy, C., Byrne, B. W., McAdam, R., Burd, H. J., Houlsby, G. T., Martin, C. M., Zdravkovic, L., Taborda, D. M. G., Potts, D. M., Jardine, R. J., Sideri, M., Schroeder, F. C., Muir Wood, A., Kallehave, D. \& Skov Gretlund, J. (2015). Field validation of fibre Bragg grating sensors for measuring strain on driven steel piles. Géotechnique Lett. 5, No. 2, 74-79, https://doi.org/10.1680/geolett.14.00120.

Doughty, L. J., Buckley, R. M. \& Jardine, R. J. (2018). Investigating the effect of ageing on the behaviour of chalk putty. In Engineering in chalk (eds J. A. Lawrence, M. Preene, U. L. Lawrence and R. Buckley), pp. 695-702. London, UK: ICE Publishing.

EA-Pfähle (2014). Recommendations on piling: piling committee of the German geotechnical society. Weinheim, Germany: John Wiley \& Sons.

Esper, S. (2017). Back analysis of offshore pile driving records in chalk. MSc thesis, Imperial College London, London, UK.

Evans, T. G., Finnie, I., Little, R., Jardine, R. J. \& Aldridge, T. R. (2010). BP clair Phase I - geotechnical assurance of driven piled foundations in extremely hard till. In Frontiers in offshore geotechnics II (eds S. Gourvenec and D. White), pp. 495-500. Boca Raton, FL, USA: CRC Press.

Foxwell, D. (2018). Monopiles continue to evolve as search continues for optimised foundations. Offshore Wind J. 7, No. 1, 24-26.

Ganendra, D. (1994). Finite element analysis of laterally loaded piles. $\mathrm{PhD}$ thesis, Imperial College London, London, UK.

Gasparre, A. (2005). Advanced laboratory characterisation of London Clay. PhD thesis, Imperial College, University of London, London, UK.

Gasparre, A., Nishimura, S., Coop, M. R. \& Jardine, R. J. (2007a). The influence of structure on the behaviour of London Clay. Géotechnique 57, No. 1, 19-32, https://doi.org/10.1680/geot. 2007.57.1.19.

Gasparre, A., Nishimura, S., Anh-Minh, N., Coop, M. R. \& Jardine, R. J. (2007b). The stiffness of natural London clay. Géotechnique 57, No. 1, 33-48, https://doi.org/10.1680/geot. 2007.57.1.33.

Gavin, K. G., Igoe, D. J. P. \& Kirwan, L. (2013). The effect of ageing on the axial capacity of piles in sand. Proc. Instn Civ. Engrs Geotech. Engng 166, No. 2, 122-130, https://doi.org/10.1680/ geng.12.00064.

Gavin, K., Jardine, R. J., Karlsrud, K. \& Lehane, B. M. (2015). The effects of pile ageing on the shaft capacity of offshore piles in sand. Keynote paper. In Frontiers offshore geotechnics III (ed. V. Meyer), vol. 1, pp. 129-152. London, UK: Taylor \& Francis Group.

Geduhn, M., Barbosa, P. \& Duhrkop, J. (2018). Offshore static and dynamic pile load tests in low density chalk Grade A1/A2 to optimize the foundation design of jacket piles. In Engineering in Chalk (eds J. A. Lawrence, M. Preene, U. L. Lawrence and R. Buckley), pp. 403-407. London, UK: Institution of Civil Engineers.

Gens, A. (2010). Soil-environment interactions in geotechnical engineering. Géotechnique 60, No. 1, 3-74, https://doi.org/ 10.1680/geot.9.P.109.

Georgiadis, K. (2010). Undrained bearing capacity of strip footings on slopes. J. Geotech. Geoenviron. Engng 136, No. 7, 77-685.

Gerolymos, N. \& Gazetas, G. (2006). Development of Winkler model for static and dynamic response of caisson foundations with soil and interface nonlinearities. Soil Dynamics Earthquake Engng 26, No. 5, 63-376.

Guo, W. B. (2017). Pile-soil interaction and database assessment of design methods for axial loaded piles driven in sands. $\mathrm{PhD}$ thesis, Zhejiang University, Zhejiang, China.

GWEC (Global Wind Energy Council) (2017). See http:/gwec.net/global-figures/global-offshore (accessed 10/11/ 2017).

Hamilton, J. M. \& Dunnavant, T. W. (1993). Analysis of behaviour of the Tilbrook Grange lateral test pile. In Proceedings of ICE conference: Large-scale pile tests in clay (ed. J. Clarke), pp. 448-463. London, UK: Thomas Telford.

Hampson, K., Evans, T. G., Jardine, R. J., Moran, P., Mackenzie, B. \& Rattley, M. J. (2017). Clair ridge: independent foundation assurance for the capacity of driven piles in very hard soils. 
In Proceedings of the 8th international conference on offshore site investigations and geotechnics (ed. T. Powell), vol. 2, pp. 1299-1306. London, UK: Society for Underwater Technology (SUT).

Hayashi, H., Yamazoe, N., Mitachi, T., Tanaka, H. \& Nishimoto, S. (2012). Coefficient of earth pressure at rest for normally and overconsolidated peat ground in Hokkaido area. Soils Found. 52, No. 2, 299-311.

Heerema, E. P. (1980). Predicting pile driveability: heather as an illustration of the 'friction fatigue' theory. Ground Engng April, $15-20$.

Higgins, K. G. \& Jardine, R. J. (1998). Experience of the use of non-linear pre-failure constitutive soil models. In Pre-failure behaviour of geomaterials (eds R. J. Jardine, M. C. R. Davies, D. W. Hight, A. K. C. Smith and S. E. Stallebrass), pp. 409-412. London, UK: Thomas Telford.

Ho, Y. K., Jardine, R.J. \& Anh-Minh, N. (2011). Largedisplacement interface shear between steel and granular media. Géotechnique 61, No. 3, 221-234, https://doi.org/ 10.1680/geot.8.P.086.

Hobbs, N. B. \& Atkinson, M. S. (1993). Compression and tension tests on an open-ended tube pile in chalk. Ground Engng 26, No. 3, 31-34.

Hosseini Kamal, R., Coop, M. R., Jardine, R. J. \& Brosse, A. (2014). The post-yield behaviour of four Eocene-to-Jurassic UK stiff clays. Géotechnique 64, No. 8, 620-634, https://doi.org/ 10.1680/geot.13.P.043.

Houlsby, G. T. (2016). Interactions in offshore foundation design. Géotechnique 66, No. 10, 791-825, https://doi.org/10.1680/jgeot. 15.RL.001.

Hunt, R. J. (1999). Jack-up and jacket relative motions, prediction and measurement. In Proceedings of 7 th international conference: the jack-up platform (ed. L. Boswell). Hove, UK: AST Press.

Hvorslev, M. J. (1937). Ueber die Festigkeitseigenschaften gestoerter bindiger Boeden. Ingeniavvidenskabelige Skrifter A. No. 45, 159 pp. (in German).

INDCs (Intended Nationally Determined Contributions) (2016). See http://www.avoid.uk.net/indcs (accessed 10/01/2016).

IPCC (Intergovernmental Panel for Climate Change) (2015). Near-term climate change: projections and predictability. Geneva, Switzerland: Intergovernmental Panel for Climate Change.

ISO (International Organization for Standardization) (2007). BS EN ISO 19902:2007: Petroleum and natural gas industries fixed steel offshore structures. London, UK: BSI.

Jardine, R. J. (1985). Investigations of pile - soil behaviour. $\mathrm{PhD}$ thesis, Imperial College, London, UK.

Jardine, R. J. (1991). The cyclic behaviour of large piles. In Cyclic loading of soils (eds M. P. O'Reilly and S. F. Brown), pp. 174-248. Glasgow, UK: Blackie \& Son.

Jardine, R. J. (2002). Stability and instability: soft clay embankment foundations and offshore continental slopes. Keynote paper. In Proceedings of international symposium on coastal geotechnical engineering in practice (eds A. Nakase and T. Tsuchida), vol. 2, pp. 99-118, Rotterdam, the Netherlands: Balkema.

Jardine, R. J. (2013). Advanced laboratory testing in research and practice. 2nd Bishop Lecture. In Proceedings of ICSMGE (eds P. Delage, J. Desrues, R. Frank, A. Puech and F. Schlosser), vol. 1, pp. 35-55. Paris, France: Presses des Ponts.

Jardine, R. J. \& Chow, F. C. (1996). New design methods for offshore piles, MTD Publication 96/103. London, UK: MTD.

Jardine, R. J. \& Chow, F. C. (2007). Some developments in the design of offshore piles. Keynote paper. In Proceedings of the 6th international conference on offshore site investigations and geotechnics (ed. P. Allan), pp. 303-332. London, UK: Society for Underwater Technology (SUT).

Jardine, R. J. \& Menkiti, C. O. M. (1999). The undrained anisotropy of $K_{0}$ consolidated sediments. In Geotechnical engineering for transport infrastructure: proceedings of the 12th ECSMGE (eds F. B. J. Barends, J. Lindenberg, H. J. Luger, A. Verruijt and L. de Quelerij), vol. 2, pp. 1101-1108. Rotterdam, the Netherlands: Balkema.

Jardine, R. J. \& Potts, D. M. (1988). Hutton tension leg platform foundations: an approach to the prediction of driven pile behaviour. Géotechnique 38, No. 2, 231-252, https://doi. org/10.1680/geot.1988.38.2.231.
Jardine, R. J. \& Potts, D. M. (1993). Magnus foundations: soil properties and predictions of field behaviour. In Proceedings of ICE conference: large-scale pile tests in clay (ed. J. Clarke), pp. 69-83. London, UK: Thomas Telford.

Jardine, R. J. \& Standing, J. R. (2012). Field axial cyclic loading experiments on piles driven in sand. Soils Found. 52, No. 4, 723-737.

Jardine, R. J., Symes, M. J. P. R. \& Burland, J. B. (1984). The measurement of soil stiffness in the triaxial apparatus. Géotechnique 34, No. 3, 23-340, https://doi.org/10.1680/geot. 1984.34.3.323.

Jardine, R. J., Potts, D. M., Fourie, A. B. \& Burland, J. B. (1986). Studies of the influence of non-linear stress-strain characteristics in soil-structure interaction. Géotechnique 36, No. 3, 377-396, https://doi.org/10.1680/geot.1986.36.3.377.

Jardine, R. J., Hight, D. W. \& McIntosh, W. (1988). Hutton tension leg platform foundations: measurement of pile group load displacement relations. Géotechnique 38, No. 2, 219-230, https://doi.org/10.1680/geot.1988.38.2.219.

Jardine, R. J., St. John, H. D., Hight, D. W. \& Potts, D. M. (1991). Some practical applications of a non-linear ground model. In Deformation of soils and displacements of structures: proceedings of the 10th ECSMFE, vol. 1, pp. 223-228. Rotterdam, the Netherlands: Balkema.

Jardine, R. J., Lehane, B. M., Smith, P. R. \& Gildea, P. A. (1995). Vertical loading experiments on rigid pad foundations at Bothkennar. Géotechnique 45, No. 4, 573-599, https://doi.org/ 10.1680/geot.1995.45.4.573.

Jardine, R. J., Chow, F. C., Overy, R. F. \& Standing, J. R. (2005a). ICP design methods for driven piles in sands and clays. London, UK: Thomas Telford Ltd.

Jardine, R. J., Standing, J. R. \& Kovacevic, N. (2005b). Lessons learned from full scale observations and the practical application of advanced testing and modelling, Keynote paper. In Proceedings of international symposium on deformation characteristics of geomaterials (eds H. Di Benedetto, T. Doanh, H. Geoffroy and C. Sauzeat), vol. 2, pp. 201-245. Lisse, the Netherlands: Balkema.

Jardine, R. J., Standing, J. R. \& Chow, F. C. (2006). Some observations of the effects of time on the capacity of piles driven in sand. Géotechnique 55, No. 4, 27-244, https://doi. org/10.1680/geot.2006.56.4.227.

Jardine, R. J., Zhu, B., Foray, P. \& Dalton, C. P. (2009). Experimental arrangements for the investigation of soil stresses developed around a displacement pile. Soils Found. 49, No. 5, 661-673.

Jardine, R. J., Aldridge, T. \& Evans, T. G. (2011). Offshore foundation engineering in extremely dense glacial tills west of the Shetland Islands. In Proceedings of the 15th European conference on soil mechanics and geotechnical engineering (XVECSMGE): geotechnics of hard soils - weak rocks (eds A. Anagnostopoulos, M. Pachakis and Ch. Tsatsanifos), pp. 879-884. Amsterdam, the Netherlands: IOS Press.

Jardine, R. J., Andersen, K. \& Puech, A. (2012). Cyclic loading of offshore piles: potential effects and practical design. Keynote paper. In Proceedings of the 7th international conference on offshore site investigations and geotechnics (ed. P. Allan), pp. 59-100. London, UK: Society for Underwater Technology (SUT).

Jardine, R. J., Zhu, B. T., Foray, P. \& Yang, Z. X. (2013a). Measurement of stresses around closed-ended displacement piles in sand. Géotechnique 63, No. 1, 1-17, https://doi.org/10. 1680/geot.9.P.137.

Jardine, R. J., Zhu, B. T., Foray, P. \& Yang, Z. X. (2013b). Interpretation of stress measurements made around closed-ended displacement piles in sand. Géotechnique 63, No. 8, 613-628, https://doi.org/10.1680/geot.9.P.138.

Jardine, R. J., Thomsen, N. V., Mygind, M., Liingaard, M. A. \& Thilsted, C. L. (2015a). Axial capacity design practice for North European wind-turbine projects. In Frontiers offshore geotechnics III (ed. V. Meyer), vol. 1, pp. 581-586. London, UK: Taylor \& Francis Group.

Jardine, R. J., Merritt, A. S. \& Schroeder, F. C. (2015b). The ICP design method and application to a North sea offshore wind farm. In IFCEE 2015 (eds M. Iskander, M. T. Suleiman, J. B. Anderson and D. F. Laefer), ASCE Geotechnical Special 
Publication 256, pp. 247-256. Reston, VA, USA: American Society of Civil Engineers.

Jardine, R. J., Buckley, R. M., Kontoe, S., Barbosa, P. \& Schroeder, F. C. (2018). Behaviour of piles driven in chalk. In Engineering in chalk (eds J. A. Lawrence, M. Preene, U. L. Lawrence and R. Buckley), pp. 33-52. London, UK: ICE Publishing

Jeanjean, P., Zakeri, A., Al-Khafaji, Z., Hampson, K., Clukey, E. \& Liedtke, E. (2015). Geotechnics for wells, top-hole section and conductor. In Frontiers in offshore geotechnics III (ed. V. Meyer), vol. 1, pp. 581-586. London, UK: Taylor \& Francis Group.

Jeanjean, P., Zhang, Y., Andersen, K. H., Gilberrt, R. \& Senanayake, A. I. M. J. (2017). A framework for monotonic $p-y$ curves in clays. Keynote paper. In Proceedings of the 8th international conference on offshore site investigations and geotechnics (ed. T. Powell), vol. 1, pp. 95-128. London, UK: Society for Underwater Technology (SUT).

Kane, D. L., Hinzman, L. D. \& Zarling, J. P. (1991). Thermal response of the active layer to climate warming in a permafrost environment. Cold Regions Sci. Technol. 19, No. 2, 111-122.

Karlsrud, K. \& Haugen, T. (1985). Axial static capacity of steel model piles in overconsolidated clay. In Proceedings of the 11th international conference on soil mechanics and foundation engineering, vol. 3, pp, 1401-1406. Rotterdam, the Netherlands: Balkema.

Karlsrud, K., Nowacki, F. \& Kalsnes, B. (1992). Response in soft clay and silt deposits to static and cyclic loading based on recent instrumented pile load tests. In Proceedings of the SUT international conference (eds D. A. Ardus, D. Clare, A. Hill, R. Hobbs, R. J. Jardine and J. M. Squire), pp. 549-584. Dordrecht, the Netherlands: Kluwer.

Karlsrud, K., Jensen, T. G., Wensaas Lied, E. K., Nowacki, F. \& Simonsen, A. S. (2014). Significant ageing effects for axially loaded piles in sand and clay verified by new field load tests. Proceedings of the offshore technology conference, Houston, TX, USA, paper OTC 25197, https://doi.org/10.4043/25197-MS.

Kenley, R. M. \& Sharp, D. E. (1993). Magnus foundation monitoring project instrumentation data processing and measured results. In Proceedings of ICE conference: large-scale pile tests in clay (ed. J. Clarke), pp. 28-51. London, UK: Institution of Civil Engineers.

Kolk, H. J., Baaijens, A. E. \& Sender, M. (2005a). Design criteria for pipe piles in silica sands. In Frontiers offshore geotechnics (eds S. Gourvenec and M. Cassidy), pp. 711-716. London, UK: Taylor \& Francis Group.

Kolk, H. J., Baaijens, A. E. \& Vergobi, P. (2005b). Results of axial load tests on pipe piles in very dense sands: the EURIPIDES JIP. In Frontiers offshore geotechnics (eds S. Gourvenec and M. Cassidy), pp. 661-667. London, UK: Taylor \& Francis Group.

Kovacevic, N., Jardine, R., Potts, D., Clukey, E., Brand, J. R. \& Spikula, D. (2012). A numerical simulation of progressive slope failures generated by salt diapirism combined with active sedimentation. Géotechnique 62, No. 9, 777-786, https://doi.org/ 10.1680/geot.12.OG.004.

Kuwano, R. (1999). The stiffness and yielding anisotropy of sand. $\mathrm{PhD}$ thesis, Imperial College, University of London, London, UK.

Kvalstad, T., Andresen, L., Forsberg, C., Berg, K., Bryn, P. \& Wangen, M. (2005). The Storegga slide: evaluation of triggering sources and slide mechanics. Mar. Petrol. Geol. 22, No. 2, 245-256.

Ladd, C. C. \& Foot, R. (1974). A new design procedure for stability of soft clays. J. Geotech. Engng Div., ASCE 100, No. GT7, 763-786.

Lahrs, T. \& Kallias, A. (2013). Probebelastungen von Stahlrohren in Kreide für den Offshore-Windpark Baltic 2. Proceedings of Pfahl symposium, Braunschweig, Germany, pp. 451-466 (in German).

Lam, I. P. O. (2009). Diameter effects on $p-y$ curves. In Deep marine foundations - a perspective on the design and construction of deep marine foundations (eds R. B. Bittner and R. A. Ellman), pp. 27-42. Hawthorne, NJ, USA: Deep Foundations Institute.

Lam, I. P. O. \& Martin, G. R. (1986). Seismic design of high-way bridge foundations, Report No. FHWA/RD-86/102. Washington, DC, USA: US Department of Transportation.
Lambe, T. W. (1973). Predictions in soil engineering. Géotechnique 23, No. 2, 149-202, https://doi.org/10.1680/geot. 1973.23.2.151.

Landva, A. O. (2006). Characterization of Escuminac peat and construction on peatland. In Characterisation and engineering properties of natural soils (eds T. W. Tan, K. K. Phoon, D. W. Hight and S. Leroueil), pp. 2135-2192. London, UK: Taylor \& Francis Group.

Lehane, B. M. (1992). Experimental investigations of pile behaviour using instrumented field piles. $\mathrm{PhD}$ thesis, Imperial College London, London, UK.

Lehane, B. M. \& Jardine, R. J. (1994a). Displacement pile behaviour in glacial clay. Can. Geotech. J. 31, No. 1, 79-90.

Lehane, B. M. \& Jardine, R. J. (1994b). Displacement pile behaviour in a soft marine clay. Can. Geotech. J. 31, No. 2, 181-191.

Lehane, B. M. \& Jardine, R. J. (2003). Effects of long-term pre-loading on the performance of a footing on clay. Géotechnique 53, No. 8, 689-695, https://doi.org/10.1680/ geot.2003.53.8.689.

Lehane, B. M., Jardine, R. J., Bond, A. J. \& Frank, R. (1993). Mechanisms of shaft friction in sand from instrumented pile tests. ASCE J. Geotech. Engng 119, No. 1, 19-35.

Lehane, B. M., Schneider, J. A. \& Xu, X. (2005). CPT based design of driven piles in sand for offshore structures, GEO:05345. Perth, WA, Australia: The University of Western Australia.

Lehane, B. M., Li, Y. \& Williams, J. (2013). Shaft capacity of displacement piles in clay using the cone penetration test. J. Geotech. Geoenviron. Engng 139, No. 2, 253-266.

Lehane, B. M., Lim, J. K., Carotenuto, P., Nadim, F., Lacasse, S., Jardine, R. J. \& Dijk, B. F. J. (2017). Characteristics of unified databases for driven piles. Keynote paper. In Proceedings of the 8th international conference on offshore site investigations and geotechnics (ed. T. Powell), vol. 1, pp. 162-194. London, UK: Society for Underwater Technology (SUT).

Liu, T. F. (2018). Advanced laboratory testing for offshore pile foundations under monotonic and cyclic loading. $\mathrm{PhD}$ thesis, Imperial College London, London, UK.

Liu, T. F., Aghakouchak, A., Taborda, D. M. G. \& Jardine, R. J., (2017). Advanced laboratory characterization of a fine marine sand from Dunkirk, France. In Proceedings of the 19th international conference on soil mechanics and geotechnical engineering (ICSMGE) (eds W. Lee, J. S. Lee, H. K. Kim and D. S. Kim), pp. 457-460. Seoul, Republic of Korea: Korea Geotechnical Society.

Lord, J. A., Clayton, C. R. L. \& Mortimore, R. N. (2002). Engineering in chalk, CIRIA C574. London, UK: Construction Industry Research and Information Association (CIRIA).

Lunardini, V. J. (1978). Theory of n-factors and correlation of data. In Proceedings of the $3 r$ international conference on permafrost (ed. R. Brown), vol. 1, pp. 41-46. Ottawa, Canada: Natural Resources Council of Canada.

Lyle, R. R., Brideau, M. A., Lipovsky, P. \& Hutchinson, D. J. (2014). Landslides on ice-rich slopes - a geohazard in a changing climate. Proceedings of the 4th Canadian conference on geohazards, Kingston, ON, Canada, paper 119.

Marsland, A. \& Powell, J. J. M. (1977). The behaviour of trial bank constructed to failure on soft alluvium of the river Thames. In Proceedings of the international symposium on soft clay (eds R. P. Brenner and E. W. Brand), pp. 505-526. Bangkok, Thailand: AIT Thailand.

Martin, C. J. (2008). Addressing the risk of climate change to BP projects. Appendix G2: engineering geology and geomorphology of the study region, Imperial College Report to BPImperial College London, London, UK.

Menck (2018). See http://www.menck.com/deep-to-ultradeep (accessed 10/02/2018).

Menkiti, C. O. (1995). Behaviour of clay and clayey-sand, with particular reference to principal stress rotation. $\mathrm{PhD}$ thesis, Imperial College London, London, UK.

Merritt, A., Schroeder, F., Jardine, R., Stuyts, B., Cathie, D. \& Cleverly, W. (2012). Development of pile design methodology for an offshore wind farm in the North Sea. In Proceedings of the 7th international conference on offshore site investigations and geotechnics (ed. P. Allan), pp. 439-448. London, UK: Society for Underwater Technology (SUT). 
Mesri, G. \& Ajlouni, M. (2007). Engineering properties of fibrous peats. J. Geotech. Geoenviron. Engng 133, No. 7, 850-866.

Nakicenovic, N., Alcamo, J., Davis, G., deVries, B., Fenhann, J., Gaffin, S., Gregory, K., Grubler, A., Jung, T., Kram, T., La Rovere, E., Michaelis, L., Mori, S., Morita, T., Pepper, W., Pitcher, H. M., Price, L., Riahi, K., Roehrl, A., Rogner, H., Sankovski, A., Schlesinger, M., Shukla, P., Smith, S. J., Swart, R., VanRonijen, S., Victor, N. \& Dadi, Z. (2000). Special report on emissions scenarios: a special report of working group III of the intergovernmental panel on climate change. Cambridge, UK: Cambridge University Press.

Nicholson, D. P. \& Jardine, R. J. (1981). Performance of vertical drains at Queenborough bypass. Géotechnique 31, No. 1, 76-90, https://doi.org/10.1680/geot.1981.31.1.67.

Nishimura, S. (2006). Laboratory study of the anisotropy of natural London Clay. $\mathrm{PhD}$ thesis, Imperial College London, London, UK.

Nishimura, S., Minh, N. A. \& Jardine, R. J. (2007). Shear strength anisotropy of natural London clay. Symposium in print on stiff clays. Géotechnique 57, No. 1, 49-62, https://doi.org/10.1680/ geot.2007.57.1.49.

Nishimura, S., Gens, A., Olivella, S. \& Jardine, R. J. (2009a). THM-coupled finite element analysis of frozen soil: formulation and application. Géotechnique 59, No. 3, 159-171, https://doi. org/10.1680/geot.2009.59.3.159.

Nishimura, S., Martin, C. J., Jardine, R.J. \& Fenton, C. H. (2009b). A new approach for assessing geothermal response to climate change in permafrost regions. Géotechnique 59, No. 3, 213-227, https://doi.org/10.1680/geot.2009.59.3.213.

Nowacki, F., Solhjell, E., Nadim, F., Liedke, E., Andersen, K. H. \& Andresen, L. (2003). Deterministic slope stability analyses of the Sigsbee Escarpment. Proceedings of the offshore technology conference, Houston, TX, USA, paper OTC 15160.

NRCan (Natural Resources Canada) (2017). Energy fact book 2016-2017. Ottawa, ON, Canada: NRCan. See https://www.nrcan.gc.ca/sites/www.nrcan.gc.ca/files/energy/pdf/ EnergyFactBook_2016_17_En.pdf (accessed 09/07/2019).

NWTGS (North West Territories Geological Survey) (2015). Permafrost thaw slumps. Yellowknife, NT, Canada: NWTGS. See http://www.nwtgeoscience.ca/project/summary/permafrostthaw-slumps (accessed 10/11/2015).

OET (Offshore Engergy Today) (2016). Uruguay first offshore well in years breaks world record. Offshore Energy Today, 16 April. See https://www.offshoreenergytoday.com/uruguayfirst-offshore-well-in-years-breaks-world-record (accessed 09/07/2019).

Offshore (2001). Geosciences: deepwater currents form megafurrows near US Gulf, Sigsbee Escarpment. Offshore, 1 July. See https:// www.offshore-mag.com/home/article/16758824/geosciencesdeepwater-currents-form-megafurrows-near-us-gulfs-sigsbeeescarpment (accessed 09/07/2019).

Orange, D. L., Angell, M. M., Brand, J. R., Thomson, J., Buddin, M. W., Hard, W. \& Berger, W. J. (2003). Geological and shallow tectonic setting of the Mad Dog and Atlantis fields: relationships between salt, faults and seafloor geomorphology. Proceedings of the offshore technology conference, Houston, TX, USA, paper OTC 15157.

Overy, R. (2007). The use of ICP design methods for the foundations of nine platforms installed in the UK North Sea. In Proceedings of the 6th international conference on offshore site investigations (ed. P. Allan), pp. 359-366. London, UK: Society for Underwater Technology (SUT).

Parker, E. J., Jardine, R. J., Standing, J. R. \& Xavier, J. (1999). Jet grouting to improve offshore pile capacity. Proceedings of the offshore technology conference, Houston, TX, USA, paper OTC 10828

Pasten, C. \& Santamarina, J. C. (2012). Energy and quality of life. Energy Policy 49, 468-476.

Pellew, A. \& Jardine, R. J. (2008). Aged steel displacement and bored concrete piles in London clay. In Proceedings of the 2nd international conference on foundations (eds M. J. Brown, M. F. Bransby, A. J. Brennan and J. A. Knappett), vol. 1, pp. 269-282. Bracknell, UK: IHS BRE Press.

Plaxis (2018). See https://www.plaxis.com/software/plaxis-modeto (accessed 01/03/2018).
Potts, D. M. \& Zdravkovic, L. (1999). Finite element analysis in geotechnical engineering: theory. London, UK: Thomas Telford.

Potts, D. M. \& Zdravkovic, L. (2001). Finite element analysis in geotechnical engineering: application. London, UK: Thomas Telford.

Potts, D. M., Dounais, G. T. \& Vaughan, P. R. (1990). Finite element analysis of progressive failure of Carsington embankment. Géotechnique 40, No. 1, 79-101, https://doi.org/10.1680/geot. 1990.40.1.79.

Potts, D. M., Kovacevic, N. \& Vaughan, P. R. (1997). Delayed collapse of cut slopes in stiff clay. Géotechnique 47, No. 5, 953-982, https://doi.org/10.1680/geot.1997.47.5.953.

Powell, J. J. M. \& Butcher, A. P. (2002). Characterisation of a glacial clay till at Cowden, Humberside. In Characterisation and engineering properties of natural soils (eds T. S. Tan, K. K. Phoon, D. W. Hight and S. Leroueil), pp. 983-1020. Lisse, the Netherlands: Swets \& Zeitlinger.

Power, P. (1982). The use of the electric static cone penetrometer in the determination of the engineering properties of chalk. In Penetration testing: proceedings of the second European symposium on penetration testing, ESOPT II (eds A. Verruijt, F. L. Beringen and E. H. de Leeuw), pp. 769-774. Boca Raton, FL, USA: CRC Press.

Prandtl, L. (1920). Uber die Härte plasticher Köorper. Nachrichten von der Königlichen Gesellschaft der Wissenschaften, Göttingen, Math.-phys. Klasse 1920, 74-85 (in German).

Puech, A. (2013). Advances in axial cyclic pile design: contribution to the SOLCYP project. In Proceedings of TC-209 workshop at 18th ICSMGE Paris (ed. A. Peuch), pp. 45-58. Paris, France: Presses des Ponts.

Pugh, R. S. (1978). The strength and deformation characteristics of a soft alluvial clay under full scale loading conditions. $\mathrm{PhD}$ thesis, Imperial College, University of London, London, UK.

Pugh, R. S. (1985). Field observations of embankment failures on soft clay. In Failures in earth works (eds R. T. Murray, R. Jewell, C. J. F. P. Jones, E. A. Snedker and S. Thorburn), pp. 411-413. London, UK: ICE Publishing.

Ramsey, N., Jardine, R. J., Lehane, B. M. \& Ridley, A. M. (1998). A review of soil-steel interface testing with the ring shear apparatus. In Proceedings of conference on offshore site investigations and foundation behaviour (eds D. Ardus, R. Hobbs, M. Horsnell, R. Jardine, D. Long and J. Sommerville), pp. 237-258. London, UK: Society for Underwater Technology.

Randolph, M. F. (2008). IMPACT-dynamic analysis of pile driving, program manual. Crawley, Australia: Department of Civil and Environmental Engineering, University of Western Australia.

Randolph, M. F. \& Wroth, C. P. (1981). Application of the failure state in undrained simple shear to the shaft capacity of driven piles. Géotechnique 31, No. 1, 143-157, https://doi.org/10. 1680/geot.1981.31.1.143.

Rankine, W. J. M. (1850). On the mechanical action of heat. Trans. R. Soc. Edinburgh 20, 147-204.

Rankine, W. J. M. (1857). On the stability of loose earth. Phil. Trans. R. Soc. London 147, 9-27.

Rattley, M. J., Costa, L., Jardine, R. J. \& Cleverly, W. (2017). Laboratory test predictions of the cyclic axial resistance of a pile driven in North Sea soils. In Proceedings of the 8th international conference on offshore site investigations and geotechnics (ed. T. Powell), vol. 2, pp. 636-643. London, UK: Society for Underwater Technology (SUT).

Rimoy, S. P. (2013). Ageing and axial cyclic loading studies of displacement piles in sands. $\mathrm{PhD}$ thesis, Imperial College London, London, UK.

Rimoy, S., Jardine, R. J. \& Standing, J. R. (2013). Displacement response to axial cycling of piles driven in sand. Geotech. Engng 116, No. 2, 131-146.

Rimoy, S. P., Silva, M., Jardine, R. J., Foray, P., Yang, Z. X., Zhu, B. T. \& Tsuha, C. H. C. (2015). Field and model investigations into the influence of age on axial capacity of displacement piles in silica sands. Géotechnique 67, No. 7, 576-589, https://doi.org/10.1680/geot.14.P.112.

Silva, M. (2014). Experimental study of ageing and axial cyclic loading effect on shaft friction along driven piles in sand. $\mathrm{PhD}$ thesis, University of Grenoble, Grenoble, France.

Simmons, A. J. \& Gibson, J. K. (2000). The ERA-40 project plan, ERA-40 Project Report Series No. 1. Reading, 
UK: European Centre for Medium-Range Weather Forecasts (ECMWF).

Skempton, A. W. (1964). Long-term stability of clay slopes. Géotechnique 14, No. 2, 77-102, https://doi.org/10.1680/geot. 1964.14.2.77.

Skov, R. \& Denver, H. (1988). Time-dependence of bearing capacity of piles. In Proceedings of the 3rd international conference on the application of stress-wave theory to piles, pp. 879-888. Richmond, BC, Canada: BiTech Publishers Ltd.

Slusarchuk, W. A., Clark, J. I., Nixon, J. F., Morgenstern, N. R. \& Gaskin, P. N. (1978). Field test results of a chilled pipeline buried in unfrozen ground. In Proceedings of the 3rd international conference on permafrost (ed. R. Brown), vol. 1, pp. 878-883. Ottawa, ON, Canada: Natural Resources Council of Canada.

Smith, E. A. L. (1960). Pile driving analysis by the wave equation. J. Soil Mech. Found. Div., ASCE 86, No. 4, 35-64.

Statoil (2017). See https://www.statoil.com/en/news/worlds-firstfloating-wind-farm-started-production.html (accessed 05/11/ 2017).

Taborda, D. M. G., Zdravković, L., Kontoe, S. \& Potts, D. M. (2014). Computational study on the modification of a bounding surface plasticity model for sands. Comput. Geotech. 59, 145-160.

Tan, S. L., Cuthbertson, J. \& Kimmerling, R. E. (2004). Prediction of pile set-up in noncohesive soils. In Current practices and future trends in deep foundations: contributions in honor of George G. Gobel (eds J. A. DiMaggio and M. H. Hussein), Geotechnical Special Publication 125, pp. 50-65. Reston, VA, USA: American Society of Civil Engineers.

Tang, W. H., Woodford, D. L. \& Pelletier, J. H. (1990). Performance reliability of offshore piles. Proceedings of the 22nd offshore technology conference, Houston, TX, USA, paper OTC 6379, pp. 299-308.

Terzaghi, K. (1925). Erdbaumechanik auf Bodenphysikalischer Grundlage. Liepzig, Germany and Vienna, Austria: Franz Deuticke (in German).

Tomlinson, M. J. (1996). Recent advances in driven pile design. Ground Engng 29, No. 10, 31-33.

Tsiampousi, A., Zdravkovic, L. \& Potts, D. M. (2013). A new Hvorslev surface for critical state type unsaturated and saturated constitutive models. Comput. Geotech. 48, 156-166.

Tsuha, C. H. C., Foray, P. Y., Jardine, R. J., Yang, Z. X., Silva, M. \& Rimoy, S. P. (2012). Behaviour of displacement piles in sand under cyclic axial loading. Soils Found. 52, No. 3, 393-410.

UN (United Nations) (2018). The Paris agreement. Geneva, Switzerland: UN. See http://unfccc.int/paris_agreement/items/ 9485.php (accessed 10/11/2017).

US EPA (United States Environmental Protection Agency) (2015). Climate change indicators: global greenhouse gas emissions. Washington, DC, USA: US EPA. See http://www3.epa. gov/climatechange/science/indicators/ghg/global-ghg-emissions. html (accessed 04/02/2018).

USGS (United States Geological Survey) (2017). See https://lta.cr. usgs.gov/SRTM (accessed 08/11/2017).

Ushev, E. (2018). Laboratory investigation of the mechanical properties of Cowden till under static and cyclic conditions. $\mathrm{PhD}$ thesis, Imperial College London, London, UK.

US NOAA (United States National Oceanic and Atmospheric Administration) (2017). The NOAA annual greenhouse gas index ( $A G G I)$. Silver Spring, MD, USA: US NOAA. See http://www. esrl.noaa.gov/gmd/aggi/aggi.html (accessed 09/07/2019).

Viggiani, G. M. B. \& Cassini, F. (2015). Artificial ground freezing: from applications and case studies to fundamental research. Keynote lecture. In Geotechnical engineering for infrastructure and development: XVI European conference on soil mechanics and geotechnical engineering (ed. M. Winter), vol. 1, pp. 65-92. London, UK: ICE Publishing.

Vijayvergiya, V. N., Cheng, A. P. \& Kolk, H. J. (1977). Design and installation of piles in chalk. Proceedings of the offshore technology conference, Houston, TX, USA, pp. 459-464.

World Bank (2018). Energy use ( $k g$ oil equivalent per capita). Washington, DC, USA: World Bank. See https://data. worldbank.org/indicator/EG.USE.PCAP.KG.OE (accessed 14/02/2018).

WER (World Energy Resources) (2013). World energy council 2013: peat. London, UK: World Energy Council. See https://www. worldenergy.org/wp-content/uploads/2013/10/ WER_2013_6_Peat.pdf (accessed 04/02/2018).

Williams, R. E., Chow, F. C. \& Jardine, R. J. (1997). Unexpected behaviour of large diameter tubular steel piles. In Proceedings of international conference on foundation failures (eds T. W. Hulme and Y. S. Lau), pp. 363-378. Singapore: Singapore Institution of Engineers.

Yamaguchi, H., Ohira, Y., Kogure, K. \& Mori, S. (1985). Undrained shear characteristics of normally consolidated peat under triaxial compression and extension. Soils Found. 25, No. 3, $1-18$.

Yang, Z. X., Jardine, R. J., Zhu, B. T., Foray, P. \& Tsuha, C. H. C. (2010). Sand grain crushing and interface shearing during displacement pile installation in sand. Géotechnique 60, No. 6, 469-482, https://doi.org/10.1680/geot.2010.60.6.469.

Yang, Z. X., Jardine, R. J., Guo, W. B. \& Chow, F. C. (2015). A comprehensive database of tests on axially loaded piles driven in sands. Amsterdam, the Netherlands: Elsevier.

Yang, Z. X., Guo, W. B., Jardine, R. J. \& Chow, F. C. (2017). Design method reliability assessment from an extended database of axial load tests on piles driven in sand. Can. Geotech. J. 54, No. $1,59-74$

Yershov, E. D. (1991). Geocryological map of Russia and neighbouring republics, 1:2,500,000 scale. Moscow State University, Russian Ministry of Geology. (Williams, P. J. \& Warren, M. T. (2003). The English language version of the geocryological map of Russia and neighbouring republics, 2nd edn. A project of Moscow State University, Department of Geocryology; Cambridge University, Scott Polar Research Institute; and Carleton University. Ottawa: Collaborative Map Company.).

Young, A. G., Bryant, W. R., Slowey, N. C., Brand, J. R. \& Garter, S. (2003). The dating of past slope failures of the Sigsbee escarpment within Atlantis and Mad Dog developments. Proceedings of the offshore technology conference, Houston, TX, USA, paper OTC 15204.

Zdravković, L., Taborda, D. M. G., Potts, D. M., Jardine, R. J., Sideri, M., Schroeder, F. C., Byrne, B. W., McAdam, R., Burd, H. J., Houlsby, G. T., Martin, C. M., Gavin, K., Doherty, P., Igoe, D., Muir Wood, A., Kallehave, D. \& Skov Gretlund, J. (2015). Numerical modelling of large diameter piles under lateral loading for offshore wind applications. In Frontiers in offshore geotechnics III (ed. V. Meyer), vol. 1, pp. 759-764, London, UK: Taylor \& Francis Group.

Zhang, C., Nguyen, G. D. \& Einav, I. (2013). The end-bearing capacity of piles penetrating into crushable soils. Géotechnique 63, No. 5, 341-354, https://doi.org/10.1680/geot.11.P.117.

Zhang, C., Yang, Z. X. Nguyen, G. D., Jardine, R. J. \& Einav, I. (2014). Theoretical breakage mechanics and experimental assessment of stresses surrounding piles penetrating into dense silica sand. Géotechnique Lett. 4, No. 1, 11-16, https://doi.org/10.1680/geolett.13.00075.

Zhu, B., Jardine, R. J. \& Foray, P. (2009). The use of miniature soil stress measuring cells in laboratory applications involving stress reversals. Soils Found. 49, No. 5, 675-688.

Zwanenburg, C. \& Jardine, R. J. (2015). Laboratory, in situ and full-scale load tests to assess flood embankment stability on peat. Géotechnique 65, No. 4, 309-326, https://doi.org/ 10.1680/geot.14.P.257.

Zwanenburg, C., Den Haan, E. J., Kruse, G. A. M. \& Koelewijn, A. R. (2012). Failure of a trial embankment on peat in Booneschans, the Netherlands. Géotechnique 62, No. 6, 479-490, https://doi.org/10.1680/geot.9.P.094.

\section{VOTE OF THANKS}

PROFESSOR ANTONIO GENS, Department of Geotechnical Engineering and Geo-Sciences (ETCG), Universitat Politècnica de Catalunya, Barcelona, Spain.

It is an honour and also a great pleasure to propose the vote of thanks for Professor Richard Jardine, the 56th Rankine lecturer.

We have been fortunate to witness a most comprehensive survey of critical issues for our future made from the privileged perspective of an extensive and fruitful career of 
research. The scope of the lecture has been breath-taking; geographically from the outer reaches of the North Sea, through the Gulf of Mexico all the way to the Siberian wilderness. But not only geographically, geotechnically we have been guided through sophisticated laboratory tests, high-level constitutive, numerical and physical modelling together with a large number of outstanding field tests and landmark projects, all grounded on a sound understanding of the geological background. Indeed, it can be argued that the best geotechnical research is achieved by a combination of all these aspects performed in close collaboration with many people. It is guided by the goal of providing tools to the profession; tools that are applicable and yet commensurate with the complexity of the problems. As quoted in the lecture 'as simple as possible but not simpler'. This talk has been given by a master of this approach.

In the lecture, we have travelled a long way. It began with the research on offshore pile foundations back in the 1980s. Indeed, one of my first memories of Richard is watching him wading in a pool of mercury trying to assemble the settlement gauges for the Magnus platform. Since then, progress has been uninterrupted, bringing in more and more phenomena, new challenging research questions and an enhanced requirement for close attention to detail. It is characteristic, for instance, that, since the capacity of a very large pile may well be controlled by what happens just a few millimetres away from the shaft, it is necessary to bring out the microscope and to examine the phenomenon at the very small scale. And then, he can change scale again over several orders of magnitude to deal with huge landslides, global climate change and the promising world of renewable energy sources. If proof were needed that geotechnical engineering has a central role to play in all those endeavours, today's lecture has provided plentiful evidence of the key contribution that our discipline makes today and will make in the future to many of the demanding problems associated with energy issues.

I have also to say that I have not been surprised by this impressive tour de force. Breadth of scope is a hallmark of Richard's outlook; it was what it struck me most when I came to know him when the two of us were doing our $\mathrm{PhD}$ research at Imperial College a few years ago. Our conversations ranged very widely not only over many topics of soil mechanics but also far beyond.

And with that, I would like to bring up a final point. You have noted that he started his lecture placing the technical content within a much broader context. All those who know Richard are aware that he cares deeply about the political, environmental and social issues confronting humankind in our days. I am sure that this commitment underlies much of what we have heard this evening.

Ladies and gentlemen, we have been privileged to listen to a memorable lecture that, I am sure, will be considered a landmark not only for all that it contains but also, and perhaps mainly, for being a harbinger of the future. It was not an account of a closed chapter; it contains many seeds for future developments in the field.

On behalf of the British Geotechnical Association, I thank you, Richard for an outstanding and stimulating lecture and I am sure you all wish to join me by endorsing my thanks. 